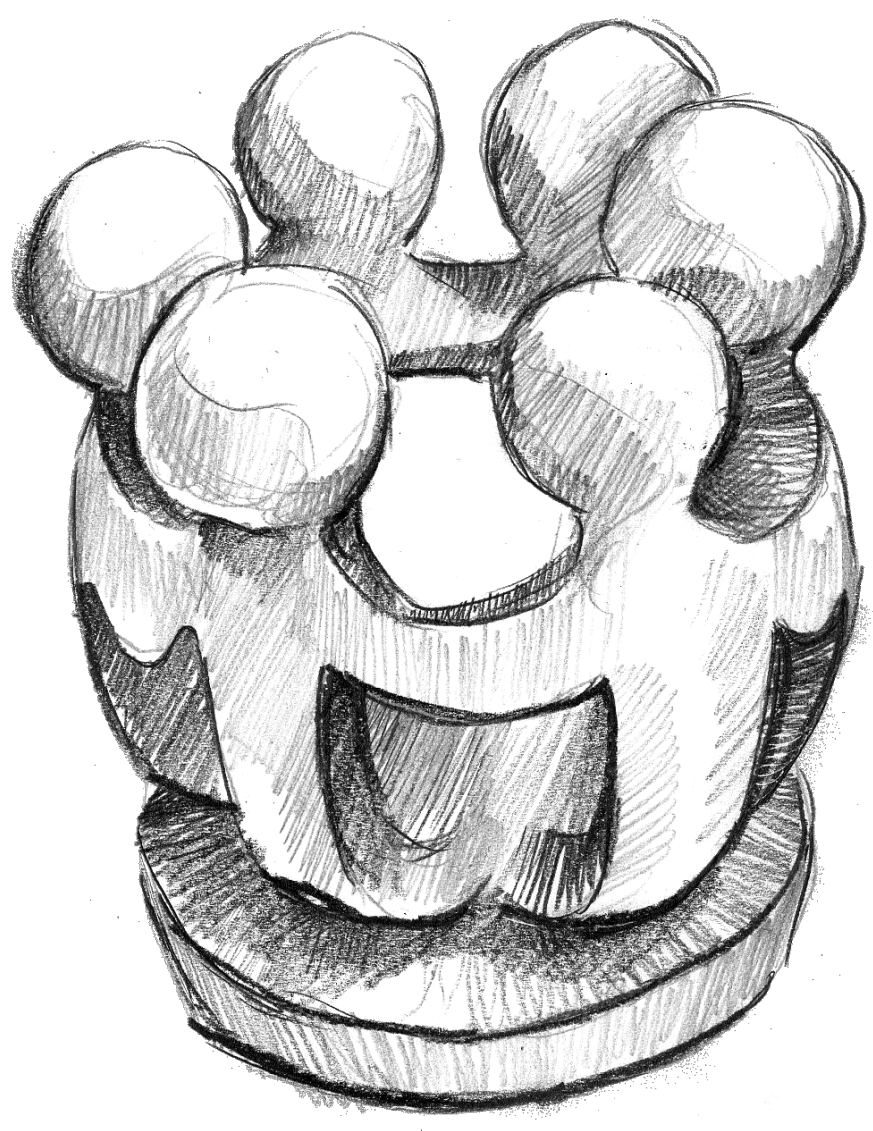




\section{Propositions}

1. Family members shape each other's preferences and constraints regarding fertility (this thesis).

2. Intergenerational correlations in fertility are weak but present (this thesis).

3. "Evolutionary demography is best viewed not as an alternative to traditional approaches but as a general theoretical framework that can inform and enhance existing research endeavors" (Kaplan and Lancaster 2003, p. 212).

4. When fertility decisions are concerned, people often do not behave as pure rational agents.

5. Fertility in the Netherlands will increase if the labour market can be reformed to better match individual preferences regarding the work-life balance, child care and care for the elderly - as long as flex-contracts are not synonymous to job-insecurity.

6. "Design depends largely on constraints" (Charles Eames, 1972).

Propositions belonging to the thesis, entitled

'Family Influences on Fertility in Europe, 1850-1920'.

P.P.P. Rotering

Wageningen, June 10, 2020 


\section{Family Influences on Fertility in Europe, 1850-1920}




\section{Thesis committee}

\section{Promotors}

Prof. Dr H.A.J. Bras

Associate Professor of Economic and Social History

University of Groningen

Prof. Dr J. Kok

Professor of Economic, Social and Demographic History

Radboud University Nijmegen

\section{Other members}

Prof. Dr E.S. van Leeuwen, Wageningen University \& Research Prof. Dr S. Edvinsson, Umeå University, Sweden Prof. Dr I. Devos, Ghent University, Belgium

Dr P. Puschmann, Radboud University Nijmegen

This research was conducted under the auspices of the Wageningen School of Social Sciences (WASS) 


\title{
Family Influences on Fertility in Europe, 1850-1920
}

\author{
Paul Pieter Philippus Rotering
}

\section{Thesis}

submitted in fulfilment of the requirements for the degree of doctor at Wageningen University by the authority of the Rector Magnificus Prof. Dr A.P.J. Mol in the presence of the Thesis Committee appointed by the Academic Board to be defended in public on 10 June 2020 at 11 a.m. in the Aula. 
P.P.P. Rotering

Family Influences on Fertility in Europe, 1850-1920

228 pages

PhD thesis, Wageningen University, Wageningen, NL (2020)

With references, with summaries in English and Dutch

ISBN 978-94-6395-342-9

DOI https://doi.org/10.18174/517335 
Voor Anneleen, je bent de liefde van mijn leven 



\section{Dankwoord}

Voor u ligt mijn proefschrift, een onderzoek naar het dalende geboortecijfer in Nederland en Zweden in de 19e eeuw. Rond het midden van de 19e eeuw daalde het geboortecijfer in West-Europa vrij plots, maar een sluitende verklaring voor de timing en ruimtelijke variatie van deze daling is tot op heden niet gevonden. Vrij recent hebben wetenschappers zich gericht op de invloed van de sociale omgeving, op het aantal kinderen dat geboren wordt en de timing van deze geboorten. Ik richt mij in dit onderzoek specifiek op de invloeden van familieleden. De hoofdvraag luidt: "In hoeverre hing het krijgen van kinderen samen met de familiale context in West-Europa tussen 1850 en 1920?". Dit onderzoek laat zien dat de famiale context bepalend was voor de timing van geboorten en gezinsgrootte. Echter, de sterkte en richting van de invloed was afhankelijk was van het type familielid en de onderzochte periode. Er is geen significant verband gevonden tussen veranderingen in het geboortecijfer en regionale 'familie systemen'.

Ik ben blij dat dit proefschrift na ruim acht jaar eindelijk is voltooid. Ik heb nooit getwijfeld òf het proefschrift afgerond zou worden, maar mij wel - net als vrienden en familie - vaak afgevraagd hoeveel tijd het nog zou kosten. Je hoort veel verhalen van collega-promovendi die de academie verlaten en daarna nooit hun proefschrift weten te voltooien. Begin 2016 dacht ik overmoedig dat mij dat nooit zou overkomen, niet wetende hoeveel toewijding dit zou vragen. Van mijzelf, maar ook van mijn familie. Nu ik dit dankwoord schrijf, besef ik goed hoeveel inspanning de afronding van dit proefschrift heeft gevraagd en welke last nu van mijn gezin valt.

Mijn avontuur begon in het Erasmusgebouw op 11 mei 2011, toen ik aan het einde van de middag op de deur van Hilde Bras klopte. Hilde was nieuw bij de afdeling Geschiedenis van de Radboud Universiteit en had een vacature opengesteld voor drie promovendi op haar VIDI project. Na een korte kennismaking was ik ervan overtuigd dat ik mijn best zou gaan doen om bij haar project betrokken te mogen zijn. Als student was zeer ik geïnteresseerd in de laat-moderne economische en sociale geschiedenis, maar ook in de statistische analyse van grootschalige 
datasets. Dit project bood het beste van twee werelden en de kans om mij verder te ontwikkelen als academicus. Mijn stille ambitie was toen om 'later' als docent/onderzoeker op de universiteit te zullen blijven werken.

De begeleiding van Hilde Bras en Jan Kok, mijn promotoren, was uitstekend. $\mathrm{Zij}$ hebben mij beide vrij gelaten om zelf te ondervinden hoe ik een goed onderzoeker zou kunnen worden, maar op cruciale momenten hebben zij mij wel steeds in de juiste richting geduwd. Ik heb veel tijd en energie gestoken in het verzamelen, prepareren en bijna eindeloos door-analyseren van de data. Maar, op een bepaald moment moet een artikel af zijn en naar een journal voor publicatie. De ondersteuning van mijn promoteren was hierbij zeer welkom. Hilde en Jan, ik wil jullie hartelijk bedanken voor al jullie hulp en geduld bij de totstandkoming van dit proefschrift.

Yuliya en Bastian, we hebben samen een hele mooie tijd gehad in Nijmegen en Wageningen. Ondanks onze verschillende karakters en nationaliteiten konden we het heel goed met elkaar vinden. Ook inhoudelijk konden we elkaar goed versterken. Ik heb vooral goede herinneringen aan onze reizen naar conferenties (de SSHA in Vancouver! Daar stonden we dan opeens!) en de Posthumus bijeenkomsten. Maar ook 'thuis' op de universiteit was het fijn dat wij zo'n prettig team waren. Ik wens jullie allebei ontzettend veel succes in jullie verdere academische carrières!

In Nijmegen dank ik de collega's van de sectie Economische, Sociale en Demografische Geschiedenis. Twee collega's in het bijzonder hebben bijgedragen aan de uitstekende sfeer in het Nijmeegse. Nynke, het was altijd gezellig met jou op de kamer en ik heb nog altijd spijt dat wij samen geen artikel hebben kunnen schrijven. Robin, waar jij gaat krijgt iedereen een lach op het gezicht! Het was een enorme eer om het Big Lebowski Bowlingtoernooi op mijn palmares bij te mogen schrijven. Ook jullie heel veel succes gewenst met jullie carrières.

$\mathrm{Na}$ twee jaar in het Erasmusgebouw verruilde ik mijn alma mater voor Wageningen Universiteit. Ons team verhuisde naar de groep Sociologie van Consumptie en Huishoudens met Hilde als leerstoelhouder. Al vlug nam ik deel aan verschillende seminars en werd ik actief lid van de promovendi-medezeggenschap. Hierdoor voelde ik mij in Wageningen snel thuis. Veel dank aan de collega's van de voormalige SCH groep, de WASS medezeggenschap, de WUR PhD Council en in het bijzonder aan Sandra Vermeulen voor jouw hulp tijdens de allerlaatste fase van dit proefschrift.

Enkele personen hebben dit onderzoek in het bijzonder ondersteund. Lotta Vikström nodigde mij uit om in oktober 2012 als gastonderzoeker te verblijven in Umeå, om zo de Demographic Database van CEDAR goed te leren kennen. Dit bleek cruciaal en ik ben haar ontzettend dankbaar. Zonder Lotta's hulp was 
het niet mogelijk geweest dit onderzoek te verrichten op basis van de Zweedse data. In januari 2012 heb ik deelgenomen aan een cursus spatiële analyse aan het Max Planck Institute for Demographic Research in Rostock. Ik wil Sebastian Klüsener bedanken voor zijn colleges en latere hulp bij het prepareren van de data die gebruikt is in hoofdstuk 5. Tot slot gaat ook bijzonder veel dank uit aan George Alter, Katherine Lynch, Ken Smith en de andere docenten van de cursus Longitudinal Analysis of Historical Demographic Data, die werd gegeven in de zomer van 2013. Die cursus was zeer - zeer - intensief, maar heeft mijn kennis van historische demografie en event history analyse erg verrijkt.

"It takes a village to raise a child", een bekend gezegde dat ook zeker opgaat voor dit proefschrift. Zonder de ondersteuning van mijn vrienden en familie was het onmogelijk geweest dit boek af te ronden. Ik wil allereerst mijn ouders bedanken voor hun nimmer aflatende steun, zij hebben mij altijd aangespoord om het werk op te blijven pakken. De combinatie van werk, de kinderen en het proefschrift vanaf april 2016 was erg zwaar en als gevolg hiervan heb ik mij vaak, tijdens avonduren, weekenden en vakanties, op het schrijven moeten richten in plaats van op mijn gezin, familie en vrienden. De afgelopen jaren waren zeer intensief en zonder de steun en het vertrouwen van Anneleen, mijn lieve vrouw, was dit nooit gelukt. Anneleen, jij hebt ongelooflijk veel last van mijn schouders gehaald door mij de rust en ruimte te geven om aan dit proefschrift te werken. Tijd nu om samen te genieten van de herwonnen vrije tijd en onze drie prachtige dochters. Ik draag dit boek met veel liefde aan jou op. 


\section{Contents}

Dankwoord (in Dutch) vii

1 Introduction: Family Influences on Fertility 1

1.1 Introduction . . . . . . . . . . . . . . . . . . 3

1.1.1 Aim of this study . . . . . . . . . . . . 6

1.1.2 Research framework . . . . . . . . . . . . . 7

1.2 The First Demographic Transition . . . . . . . . . . . . . . . . . 10

1.2.1 Demographic Transition Theory . . . . . . . . . . . . 11

1.2.2 The Princeton European Fertility Project . . . . . . . . . . 16

1.2.3 Toward a restatement of Demographic Transition Theory . 19

1.3 Social interactions and the role of family members . . . . . . . . . 22

1.3.1 Pathways of kin influence . . . . . . . . . . . . . . 23

1.3.2 Evolutionary theory . . . . . . . . . . . . . 30

1.3.3 Diffusion theory . . . . . . . . . . . . . . . . 32

1.3.4 Family systems as 'cultural moulds' . . . . . . . . . . . 35

1.4 Data sources and setting . . . . . . . . . . . . . . 36

1.4.1 Data sources ................. 36

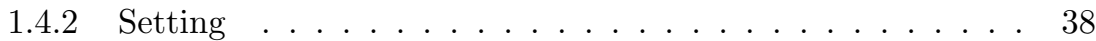

1.5 Outline of the dissertation . . . . . . . . . . . . . . 39

2 With the Help of Kin? Household Composition and Reproduction in The Netherlands, 1842-1920 43

2.1 Introduction . . . . . . . . . . . . . . . . . 45

2.2 Data, Measurements, and Methods . . . . . . . . . . . . . . 48

2.2.1 Co-Residence with kin in the Netherlands . . . . . . . . . . 48

2.2.2 Data.................... 49

2.2 .3 Outcome variable . . . . . . . . . . . . . . . 51

2.2 .4 Independent variables . . . . . . . . . . . . . . . . 52

2.2.5 Methods .................. 57 
2.3 Results. . . . . . . . . . . . . . . . . . . . . 59

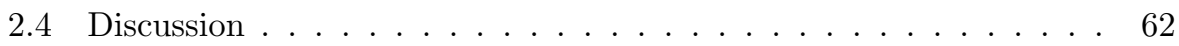

3 Intergenerational Transmission of Reproductive Behaviour in Swe$\begin{array}{ll}\text { den, } 1850-1889 & 65\end{array}$

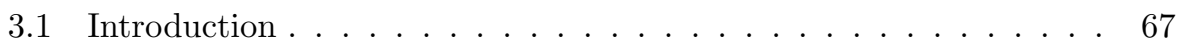

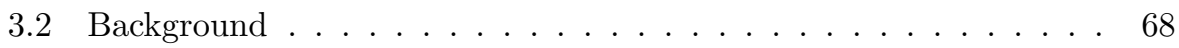

3.2.1 Parental influences on family formation . . . . . . 68

3.2 .2 Intergenerational continuities in childbearing . . . . . . 70

3.2.3 Fertility decline in nineteenth century Sweden . . . . . . . . 73

3.2.4 Hypotheses . . . . . . . . . . . . . . . . . . 74

3.3 Data, Measurements and Methods . . . . . . . . . . 75

3.3 .1 Sample construction . . . . . . . . . . . . . 75

3.3 .2 Methods .................... . 80

3.4 Results . . . . . . . . . . . . . . . . . 81

3.4 .1 Correlation coefficients . . . . . . . . . . . . . . . 82

3.4 .2 Age at marriage and parity transition . . . . . . . . 84

3.4.3 Children ever born . . . . . . . . . . . . . . . . . 90

3.5 Summary and Discussion $\ldots \ldots \ldots$. . . . . . . . . . 92

4 The Age Difference between Spouses and Reproduction in 19th $\begin{array}{ll}\text { century Sweden } & 95\end{array}$

4.1 Introduction . . . . . . . . . . . . . . . . . . . 97

4.2 Age difference between spouses . . . . . . . . . . . . . . 97

4.2.1 Age differences and female autonomy . . . . . . . . . . 97

4.2.2 Spousal age differences and fertility, evidence from previous studies . . . . . . . . . . . . . . . . . . 99

4.3 Marriage and reproduction in 19th century Sweden . . . . . . . . 100

4.4 Hypotheses . . . . . . . . . . . . . . . . . . . . . 103

4.5 Data, measures and methods . . . . . . . . . . . . . . 104

4.5 .1 Data . . . . . . . . . . . . . . . . . 104

4.5 .2 Outcome variables . . . . . . . . . . . . . 106

4.5.3 Independent variables . . . . . . . . . . . . . . 106

4.5 .4 Methods . . . . . . . . . . . . . . . . . . . 109

4.6 Results . . . . . . . . . . . . . . . . . . . . 110

4.7 Discussion . . . . . . . . . . . . . . . . . . . . . . . . . . . . . . . . . . 119

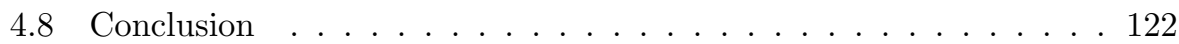


5 Family Systems and Fertility, Western Europe 1870-1960

5.1 Introduction . . . . . . . . . . . . . . . . . . 127

5.2 Family Systems and Fertility . . . . . . . . . . . . . . . 129

5.2.1 Classification of Family Systems . . . . . . . . . . . . . 129

5.2.2 Regional differences and persistence of Family Systems . . . 132

5.2.3 Family Systems and regional differences in reproductive outcomes . . . . . . . . . . . . . . . . 135

5.2.4 Hypotheses . . . . . . . . . . . . . . 137

5.3 Data, Measurements, and Methods . . . . . . . . . . . 138

5.3.1 Data and measures . . . . . . . . . . . . . . . 138

5.3 .2 Methods . . . . . . . . . . . . . . . 140

5.4 Results........................ . . 142

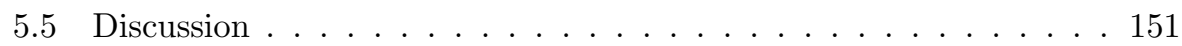

6 Conclusion and Discussion $\quad \mathbf{1 5 5}$

6.1 Conclusion ...................... 157

6.1.1 The family factor in fertility . . . . . . . . . . 157

6.1.2 Summary and contributions to the literature . . . . . . 157

6.2 Discussion ...................... 159

6.2.1 Methodological considerations . . . . . . . . . . . . 159

6.2.2 Policy and societal implications . . . . . . . . . . . . 165

$\begin{array}{lr}\text { Bibliography } & 169\end{array}$

$\begin{array}{ll}\text { Training and Supervision Plan } & 197\end{array}$

$\begin{array}{ll}\text { About the author } & 200\end{array}$

$\begin{array}{lr}\text { Summary } & 202\end{array}$

$\begin{array}{ll}\text { Samenvatting (in Dutch) } & 206\end{array}$ 


\section{List of Tables}

2.1 Mean length of birth interval in months by parity and mean total number of children, by birth cohort of the wife . . . . . . . . . 52

2.2 Descriptive statistics for variables used in the analysis, by parity . 53

2.3 Estimated coefficients for the effects of kin presence in the household on the likelihood of second or later-order marital births by parity ..................... 60

3.1 Descriptive information for index women with complete reproductive history of their parents and parents-in-law . . . . . . . . . 78

3.2 Bivariate Pearson correlation coefficients for index women and their mothers(-in-law) . . . . . . . . . . . . . . 83

3.3 Intergenerational correlation coefficients by birth cohort of index women . . . . . . . . . . . . . . . 85

3.4 Summary table of Cox proportional hazard models . . . . . . . . . 88

3.5 Estimated Poisson regression coefficients of indicators of parental fertility on the index women's number of children born (summary

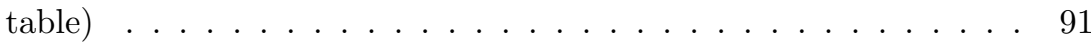

4.1 Descriptive statistics . . . . . . . . . . . . . . . 107

4.2 Timing of childbirth in the regions Sundsvall and Skellefteå (Sweden), 1840-1890 . . . . . . . . . . . . . . . 111

4.3 Hazard ratios for spousal age differences on the transition time to first and higher order births (Cox regression model) . . . . . . . . 113

4.4 Effect of spousal age differences on children ever born (Poisson model)117

5.1 Main Characteristics of Emmanuel Todd's Typology of Family Systems in Europe . . . . . . . . . . . . . . . . . 130

5.2 Summary Statistics of $I_{f}$, by Family System . . . . . . . . . . . . . 144 


\section{LIST OF TABLES}

5.3 Ordinary Least Squares Regression Coefficients of the Princeton $I_{f}$ Fertility Index . . . . . . . . . . . . . . . . . . . . 147

5.4 Spatial Lag Model of the Princeton $I_{f}$ Index (Maximum Likelihood Estimation $\ldots \ldots \ldots \ldots$. . . . . . . . . . . . . 149

5.5 Spatial Lag Model of the Princeton $I_{f}$ Index, including a TimeLagged Control Variable (Maximum Likelihood Estimation) . . . . 150 


\section{List of Figures}

1.1 World Total Fertility Rate, $2017 \ldots \ldots \ldots \ldots$

1.2 Total Fertility Rate, selected countries 1850-2006 . . . . . . . 5

1.3 Theoretical framework . . . . . . . . . . . . . 8

1.4 Illustration of the demographic transition in the Netherlands and Sweden. . . . . . . . . . . . . . . . . . 12

2.1 Average household size, the Netherlands 1899 . . . . . . . . . . 50

3.1 Schematic kinship diagram $\ldots \ldots \ldots \ldots \ldots$. . . . . . . 77

3.2 Average number of children ever born by index women (birth cohort 1850-1890) and their mothers . . . . . . . . . . 86

4.1 Average age at first and last birth in Sundsvall and Skellefteå (Sweden), 1840-1890, by spousal age difference . . . . . . . . . . . 112

4.2 Average number of children ever born in Sundsvall and Skellefteå (Sweden), 1840-1890, by spousal age difference and age at marriage 119

5.1 Family Systems in Western Europe . . . . . . . . . . . . . . 133

5.2 Values of $I_{f}, 1870-1960 \ldots \ldots \ldots \ldots \ldots \ldots \ldots \ldots \ldots$

5.3 Change in $I_{f}$ by Family System (box plots) $\ldots \ldots \ldots \ldots$

5.4 Moran's I: Spatial Autocorrelation in Fertility Levels (significant

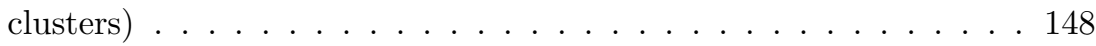


xviii 
Chapter 1

\section{Introduction: Family}

\section{Influences on Fertility}





\subsection{INTRODUCTION}

\section{$1.1 \quad$ Introduction}

Today, many countries face challenges related to high or low fertility (Casterline, 2017; UN Population Division, 2017b). ${ }^{1}$ While high fertility rates in most developing countries have been declining in recent decades (Madsen et al., 2018; Lerch, 2019; UN Population Division, 2017a), developed nations now face belowreplacement fertility levels (i.e. less than two children born per woman). Although some nations show development-reverse fertility patterns, for most developed nations low fertility rates are regarded as a key social issue of the twenty-first century, together with population ageing and growing costs of medical care (Bloom et al., 2010; Reher, 2007; Myrskalä et al., 2009). The question which factors are associated with fertility behaviour has received attention from both academics as well as policy makers who look for ways to change the demographic future of their countries (Aksoy \& Billari, 2018).

Figure 1.1: World Total Fertility Rate, 2017

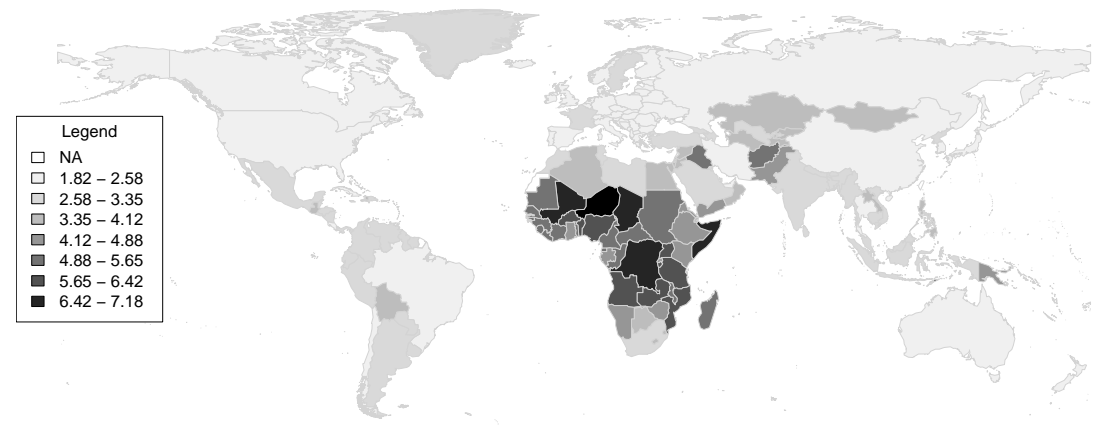

Sources:

Data: UN Population Division (ID: SP.DYN.TFRT.IN. License: CC BY-4.0)

Map: World Borders Dataset (Bjørn Sandvik. Licence: CC BY-SA 3.0)

This dissertation contributes to the academic debate on fertility, by examining in which ways and to what extent fertility outcomes are influenced by family members. This study employs aggregated and individual-level data from Sweden and the Netherlands between the mid-nineteenth century and beginning of the twentieth century. ${ }^{2}$ A greater understanding of the factors associated with the

\footnotetext{
${ }^{1}$ Demographers generally use the term 'fertility' loosely as an expression that captures behaviours and outcomes related to having children. In general, it refers to the total number of children born per woman, but it is also used to denote particular indicators of reproduction such as age at first or last birth. In this thesis, the term 'fertility' is used loosely in the same way as in most demographic studies. More specific descriptions are provided in the text when needed.

${ }^{2}$ Chapter 5 is based on an analysis of all West-European countries. The data from Sweden covers the regions of Sundsvall, Skellefteå, Linköping and the Northern Inland regions. The data from the Netherlands covers the entire country.
} 
decline of fertility during the $19^{\text {th }}$ and early $20^{\text {th }}$ century may help policy makers to devise interventions better aimed at changing fertility outcomes.

During the second half of the nineteenth century, a remarkable decline in European fertility levels in Europe took place. ${ }^{3}$ This decline in fertility, referred to as 'First Demographic Transition', was in its essence the result of a change in attitudes towards having children; a new view on the role of children in society. Family limitation, which had in the centuries before been 'unthinkable' (Alter, 1992, p. 22), somehow became the norm for most families in Western Europe over the course of the nineteenth century. ${ }^{4}$ Limited forms of contraception were available since the $1870 \mathrm{~s}$, but these were by no means working as good as contemporary methods such as the pill or condom (Van Poppel, 1974). The causes of the first demographic transition have been studied intensively and explanations range from a focus on economic or structural conditions (e.g. Demographic Transition Theory, supply-demand framework, macro-economic approaches) to cultural explanations (e.g. diffusion and adaptation approaches).

However, neither structural nor cultural explanations have been able to clarify the large regional differences in fertility levels and reproductive change that have been prevalent and remain existent. For example, while France pioneered in family limitation already in the eighteenth century, the country was still largely agrarian. Conversely, England, a forerunner of industrialization, retained high levels of fertility until far into the nineteenth century. More importantly, with the exception of innovation-diffusion approaches, most theories do not sufficiently take into account that fertility decisions are influenced by the behaviours, attitudes or statements of other individuals surrounding them (Newson et al., 2005, 2007).

The decision to have a child is not made in a social vacuum. More recent explanations of fertility transitions therefore have shifted their focus towards the role of social relations and interactions with others - in particular with family members - friends and co-workers (Bongaarts \& Watkins, 1996; Newson et al., 2005). Social interaction can be understood as "the active evaluation and transformation of new information and ideas by peers" (Bongaarts \& Watkins, 1996, p. 657). Family members can influence fertility outcomes, both negatively or positively, by providing resources, knowledge, or support (Turke, 1989; Tymicki, 2004) or by passing on preferences and attitudes towards parenthood and childbearing (Axinn et al., 1994; Bernardi, 2004).

\footnotetext{
${ }^{3}$ European fertility levels have never recovered to the levels observed in the mid-nineteenth century.

${ }^{4}$ It should be noted that between religious groups large fertility differentials are visible, even throughout the Demographic Transition (see e.g. Van Bavel \& Kok, 2010; Kok \& Van Bavel, 2006). Furthermore, there is considerable debate on the question whether or not family limitation already existed before the demographic transition - for instance in the form of spacing. See (Santow, 1995; Anderton \& Bean, 1985; Van Bavel \& Kok, 2004; Szreter \& Garrett, 2000;
} 


\subsection{INTRODUCTION}

Figure 1.2: Total Fertility Rate, selected countries 1850-2006

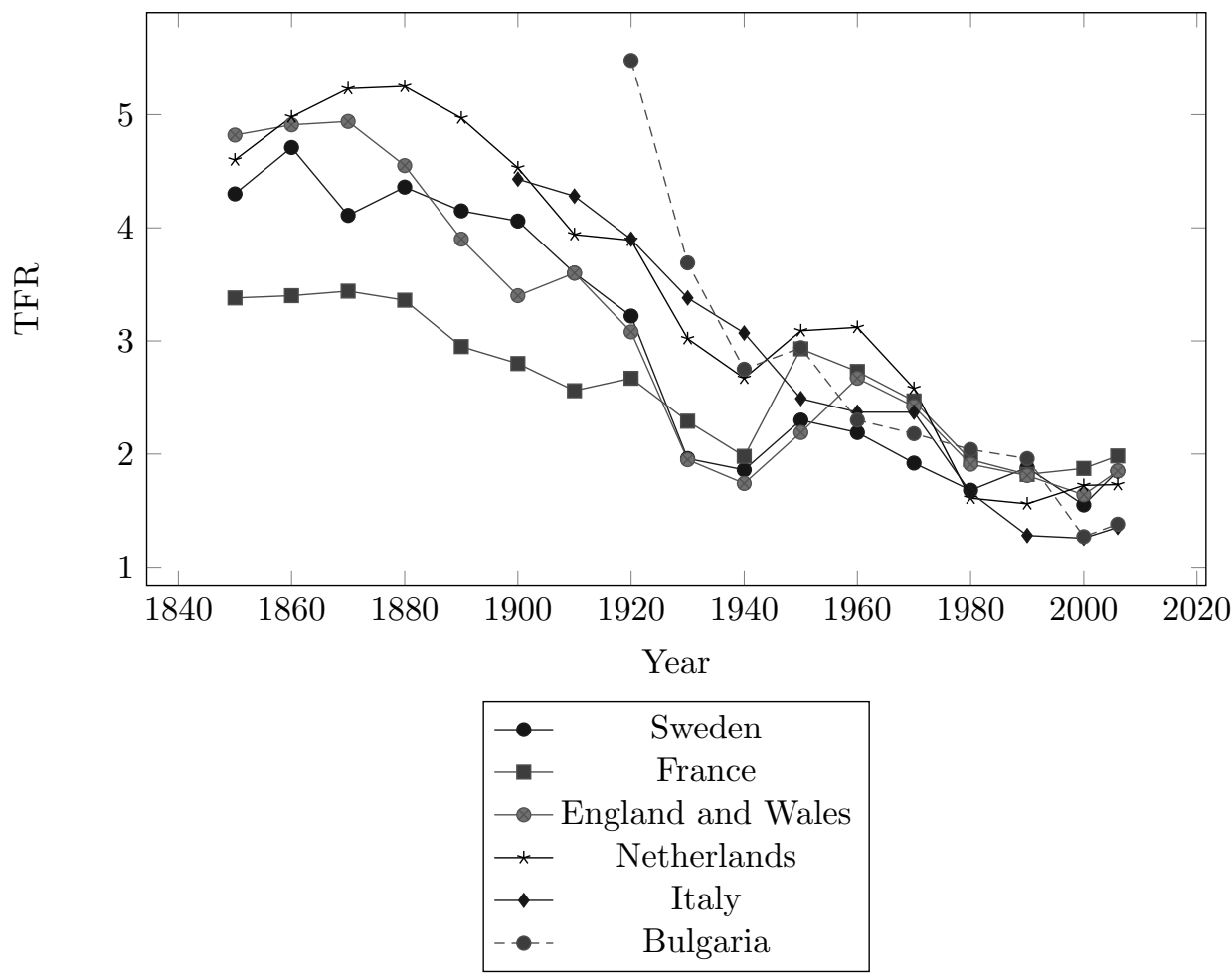

Sources: 1850-1987: Chesnais (1992); 2000-2006: UN Population Division (2017).

It is hypothesized that the influences of family members may vary between geographical regions. In this dissertation the term 'family systems' is used to denote regionally clustered norms and values towards the family and parenthood (Mason, 2001). Family systems provide different incentive structures or constraints, which mediate social influences on reproductive outcomes; in other words they provide a 'cultural mould' that is shaping behaviour (Kok, 2009). In order to better understand regional and temporal variations in fertility outcomes, it is important to recognize the complex interactions between the factors which affect the decisions made at the level of the individual, the household and the meso- or macro-level context.

Building upon and extending previous approaches, this thesis concentrates on the influences of family members on fertility outcomes, and the family or kinship context in which fertility decisions are made. It hopes to contribute to Van Bavel, 2004). 
our understanding of how fertility decisions are made, how and to what extent they are influenced by others, and the role of the social context in which decisions are made. This thesis is part of the larger research project "The Power of the Family: Family Influences on Long-Term Fertility Decline in Europe, 1850-2010", aimed at opening new vistas for understanding long-term population change. ${ }^{5}$

\subsubsection{Aim of this study}

Recent research has called for greater attention to the various ways in which fertility outcomes are shaped by micro- and meso-level influences on the fertility decision-making process (Madhavan et al., 2003; Mathews \& Sear, 2013b; Balbo et al., 2013; Jayakody et al., 2008). In particular, recent studies have highlighted the role of social relations and interactions that connect individuals to one another, focussing on the role of family, peers and other relevant others, as an important factor for understanding fertility outcomes (Bongaarts \& Watkins, 1996; Bras \& Van Tilburg, 2007; Coall \& Hertwig, 2010).

The first aim of this study is to examine in which ways and to what extent fertility outcomes are influenced by family members.

As more detailed, individual-level data became available since the mid-twentieth century, an increasing number of demographic studies have focussed on the role of micro-level factors (Coale \& Treadway, 1986). However, while the decision-making process takes place at the level of the individual or household, it is still influenced by (and interacting with) the context in which these decisions are made. The context in which fertility decisions are made consists of many different factors including, but not limited to, regional (cultural) norms surrounding what constitutes a family, the availability of contraceptive knowledge, the economic situation of the household, the social status of the family, religious attitudes, media, the presence and support of family members, and the role of others such as peers, friends or co-workers. There are many influences on fertility outcomes and it is quite impossible to examine all their effects simultaneously. Nevertheless, a growing number of studies has addressed in more detail the various ways in which these micro- and meso-level factors, alone or in tandem, are associated with fertility behaviour (e.g. Keim et al., 2009; Kok \& Van Bavel, 2006; Goldstein \& Klüsener, 2014; Dribe, 2003; Mönkediek, 2016; Hilevych, 2016).

Family systems capture interregional variations in values and norms surrounding family and parenthood. They can be defined as local sets "of beliefs and norms, common practices, and associated sanctions through which kinship and the rights and obligations of particular kin relationships are defined" (Mason, 2001, p. 160),

\footnotetext{
${ }^{5}$ Supported by a VIDI Innovational Research Grant to Hilde Bras from the Netherlands Organization for Scientific Research (NWO). Contract grant number 452-10-013.
} 


\subsection{INTRODUCTION}

or as the "cultural mould [that is] shaping behaviour" (Kok, 2009). They can also be regarded as institutions, as they represent clusters of social norms, values and practices which shape and constrain the behaviours of and interactions between people (cf. North, 1990). Family systems are important for understanding reproductive outcomes and their interregional variations since, as they embody norms and values, they form an important part of the context in which reproductive decision-making takes place. This does not mean that other contextual factors such as economic conditions, urbanization, or progress in medical care are not of importance. On the contrary, but their impact goes beyond the scope of this study. Hence, the second objective of this study is to understand how fertility outcomes are shaped by 'family systems'; regional norms and values surrounding family and parenthood.

In this study family systems are taken as given, as cultural moulds that may explain "long-term persistence in behaviour, that apparently resists socio-economic changes such as industrialization or urbanization" (Kok, 2009, p. 13). The historical origin or changes in the geographical distribution of family systems are not examined in this thesis, for these aspects warrant attention beyond the scope of this work.

\subsubsection{Research framework}

Before we expand on the theoretical connections between fertility outcomes and the presence of family members, we first make three assumptions concerning fertility decision-making. First, based on recent insights in behavioural ecology, it is assumed that human beings are no different from other species, in the way that our biology influences some parts of our behaviour - consciously or unconsciously (Hrdy, 2009; Sear, 2015). It is taken as given that there is a connection between individual biological traits and the ability of humans to reproduce, their desire to reproduce, and their willingness to provide support to others.

Second, it is assumed that individuals make some form of cost-benefit analysis when deciding whether or not to have a first, or another child (cf. Leibenstein, 1957; Becker, 1981; Caldwell, 1982; Easterlin, 1975). However, it is immediately acknowledged that this rational-choice approach in its purest form is insufficient in this field. Rational behaviour cannot always be assumed when it comes to the decision to have a child. Furthermore, for most couples today and in the past, a complete cost-benefit analysis of having another child is difficult to perform because of the many unknown variables. However, as a thought framework a rational-choice approach helps to explain in part why fertility outcomes are influenced by family members, since their presence and behaviours affect the couple's perceived costs and benefits surrounding parenthood. 
Figure 1.3: Theoretical framework

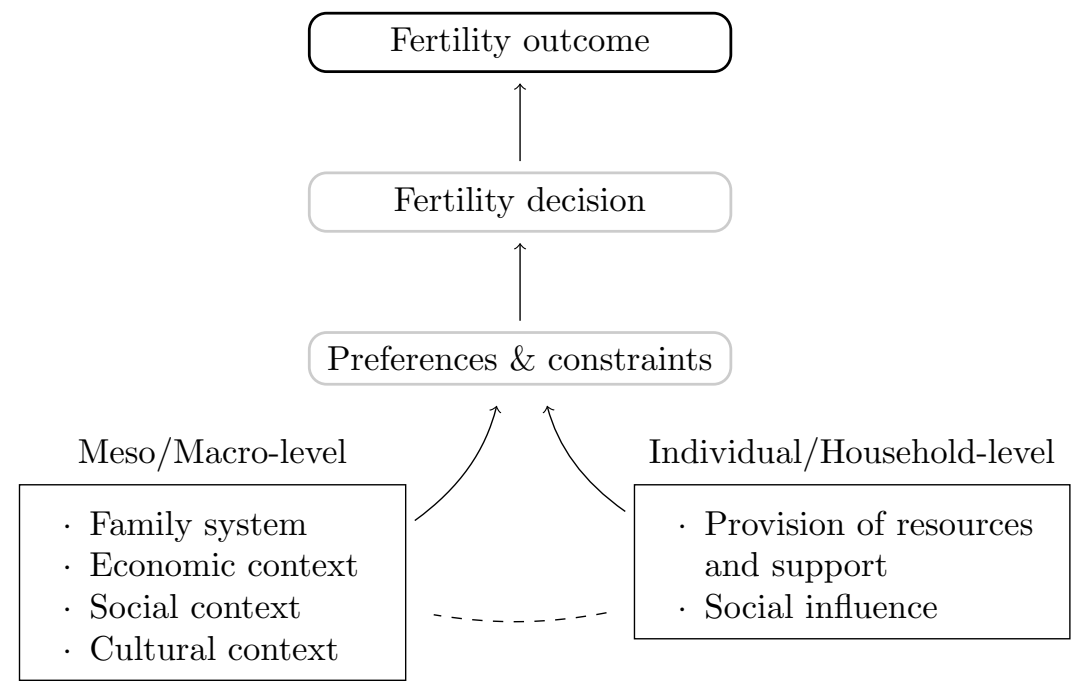

Third, and continuing on the previous assumption, it is assumed that fertility decisions do not to take place in a social vacuum. ${ }^{6}$ The people making decisions are instead influenced by other people surrounding them. A growing body of recent empirical studies has shown that the (fertility) behaviour of couples is associated with fertility outcomes of others, in particular family members (Pollet et al., 2007; Voland \& Beise, 2002; Hawkes et al., 1997, 1998; Tymicki, 2004; Crognier et al., 2001; Kramer, 2005; Draper \& Hames, 2000; Feng et al., 2010; Hill \& Hurtado, 2009; Sear et al., 2003; Sear \& Mace, 2008; Kana'iaupuni et al., 2005). The research framework of this dissertation builds upon these insights.

In summary, human fertility outcomes are thus viewed here as the product of an incomplete cost-benefit analysis, influenced by the biological traits of individuals - including their ability to have children or their inclination to provide support to others - and the presence and actions of others surrounding each individual. Given these assumptions, we can now focus on the factors involved when making fertility decisions.

Figure 1.3 illustrates the decision-making process regarding parenthood. This framework provides a highly stylized representation of the micro- and macro-level factors which may affect fertility outcomes and the key role of individual preferences and constraints regarding parenthood. The decision to have a child comes before an actual fertility outcome. Fertility decisions are shaped by an individ-

\footnotetext{
${ }^{6}$ Rational-choice approaches would discount the context in which fertility decisions are made into the cost-benefit equation.
} 


\subsection{INTRODUCTION}

ual's preferences (perceived benefits) in relation to their constraints (perceived costs). Both preferences and constraints are shaped by a plethora of contextual factors. Contextual factors work on the one hand at the meso- and macro-level, and on the other hand on individual or micro-level influences.

At the meso- and macro-level, preferences and constraints regarding parenthood are shaped by economic conditions (including household level socio-economic status), industrialisation and urbanisation, available knowledge of birth control methods, media, religious attitudes, local culture and local clusters of norms and values regarding parenthood (i.e. the family system) and others. At the individual level, relevant others such as family members, friends, peers, co-workers, or role models shape fertility preferences and constraints through the provision of resources and support (Turke, 1989; Tymicki, 2004), and through the exertion of social influences (Newson et al., 2005; Mathews \& Sear, 2013b; Rotkirch, 2007; Bernardi \& Klärner, 2014; Bernardi et al., 2015). Section 1.3.1 describes the ways in which social interactions are associated with fertility outcomes in more detail. ${ }^{7}$

Using the above framework, we can identify the specific connections between fertility outcomes and the presence and behaviours of family members. Depending on the influencing actors and the different contexts in which the decision-making process takes place, it is possible to question the ways in which family influences fertility outcomes. For example; what is the dominant family system in a region, and how is this affecting fertility outcomes by shaping a couple's preferences and constraints regarding parenthood? Or, who is providing resources or support to the couple who is considering having a child? And do siblings or parents act as role models, by setting an example regarding the optimal timing of childbearing?

The couple itself deserves special attention, since the nature of their relationship may be associated with particular fertility outcomes. Given that childbearing comes with physical costs for the wife, she may be inclined not to have children too soon after each other, in contrast to the husband who bears no direct physical costs of childbirth. The question is how such different preferences regarding fertility are shaped by the nature of the spousal relationship. How can we specify the nature of the relationship, and does fertility depend on the degree of female autonomy within marriage?

The influence of family members can be distinguished by their generation. Siblings and cousins form same-age peers, while parents(-in-law) provide intergenerational influences on fertility outcomes. The decision-making process takes place in a multitude of contexts. The household is one of such settings, but so are

\footnotetext{
${ }^{7}$ It is possible that the influences of family members on fertility outcomes are by themselves mediated by the context in which decision-making takes place. Furthermore, following Giddens' theory of structuration, the context (or structure) is also shaped by and in interaction with the behaviour of individuals (Giddens, 1984).
} 
the local community, the social network of the couple, and the regional context in particular the dominant family system and the fertility regimes in surrounding regions.

Each chapter in this dissertation examines in more detail the theoretical connections between fertility outcomes and the particular family context regarding:

- the composition of the household (chapter 2),

- the fertility outcomes of parents (chapter 3),

- the relationship between the spouses (chapter 4),

- the family system and the fertility outcomes in surrounding regions (chapter 5).

The data used in this study (further described in section 1.4) covers the First Demographic Transition in West-European societies during the end of the nineteenth century. The outcomes of this study therefore show how family influences are associated with fertility behaviour during a pre-transitional or transitional phase - before the introduction of modern birth control methods and generally low fertility rates in the developed world. The research framework helps understanding the connections between fertility and the presence of family members, but is less suited for explaining the decline itself - although it has been argued in other literature that the decline in kin presence in couples' social networks, as a result of modernization, is the most important factor behind the decline in fertility outcomes (Newson et al., 2005, 2007). In line with Mason (2001), the demographic transition is regarded in this dissertation as a "path-dependent social [process] responsive to a variety of initiation conditions, rather than as [a] mechanistic [response] to a single set of conditions" (Mason, 2001, p. 161). From this point of view, kin influences and family systems are therefore not regarded as the sole 'master determinant' of fertility outcomes, but instead both, together with other factors, provide conditions in which particular fertility behaviour is supported or discouraged (Lesthaeghe, 1998; Mason, 2001).

\subsection{Early explanations for the First Demographic Transition}

The influence of family members on fertility outcomes is the central theme of this study, but it is worth to briefly pay attention to earlier theories of demographic change. They provide context to the body of this thesis, introduce important 


\subsection{THE FIRST DEMOGRAPHIC TRANSITION}

themes in the debate on fertility behaviour, and show the changing motivations behind academic interest in fertility. The following paragraphs provide a concise description of demographic thinking since the beginning of the twentieth century, thereby passing over preceding but nevertheless prominent scholars such as Malthus, Marx and Engels, Dumont, and Mill. We will focus on Demographic Transition Theory, the Princeton European Fertility Project, and subsequent restatements of Demographic Transition Theory, before examining current debates on family influences on fertility behaviour in section 1.3.

\subsubsection{Demographic Transition Theory}

In the years following the First World War, it became clear that a historic change in West-European childbearing patterns had occurred during the previous half century. $^{8}$ Since the mid-nineteenth century, birth rates were decreasing in all West-European nations. Even in the years following the First World War, during which a recovery of birth rates may have been expected, on average fewer children were born than before the war, with the exception of France and the Netherlands (Thompson, 1929). The average number of children born per woman decreased from around 4.7 children in 1860 to around 3 children per woman in $1930 .{ }^{9}$ For married women, the number of children born decreased from around 8.4 children in 1860 to around 5.3 in 1930 (Coale \& Watkins, 1986). ${ }^{10}$ The radical transition from high to low birth- and death rates, and the resulting increase in population size, was truly a revolutionary change, now referred to as the First Demographic Transition (Thompson, 1929; Landry, 1934).

The changes in the size of families did not escape the attention of contemporary scholars, such as Warren Thompson. ${ }^{11}$. Based on fertility and mortality rates from a large number of populations all over the world, Thompson argued that countries

\footnotetext{
${ }^{8}$ North America, Latin America, China, Japan and other parts of Asia also experienced considerable increases in population during the same period, but the discussion in this dissertation is limited to Western Europe.

${ }^{9}$ The mean " $I_{f}$ " index for all European regions ranged from 0.37 in 1860 to 0.24 in 1930 . Multiplied by 12.4, the maximum childbearing rate observed in the American and Canadian Hutterite communities between 1921 and 1930, results in around 3 and 4.7 children per woman. See Coale \& Treadway (1986, p. 33-34).

${ }^{10}$ Based on the " $I_{g}$ " index. $I_{g}$ values decreasing from 0.68 to 0.43 .

${ }^{11}$ As a demographer, Thompson was particularly concerned with the consequences of population growth on matters such as the supply of food or housing, or possible readjustments in land holdings (Thompson, 1929). He regarded the decline of fertility as only one part of the larger transformation of the world population. Population growth, he argued, could invoke relocations of massive groups of people - from rural areas to cities, and from Asia to Europe. The foremost question was whether or not this redistribution of people would be effected peacefully or achieved by war (Thompson, 1929, p. 975). In the decades after the publication of Thompson's Population not all demographers shared Thompson's concern about overpopulation. Kingsley Davis for example wrote in the conclusion of his study on the demographic transition; "a rapid growth of the world's population need hold no terrors" (Davis, 1945, p. 11).
} 
Figure 1.4: Illustration of the demographic transition in the Netherlands and Sweden.

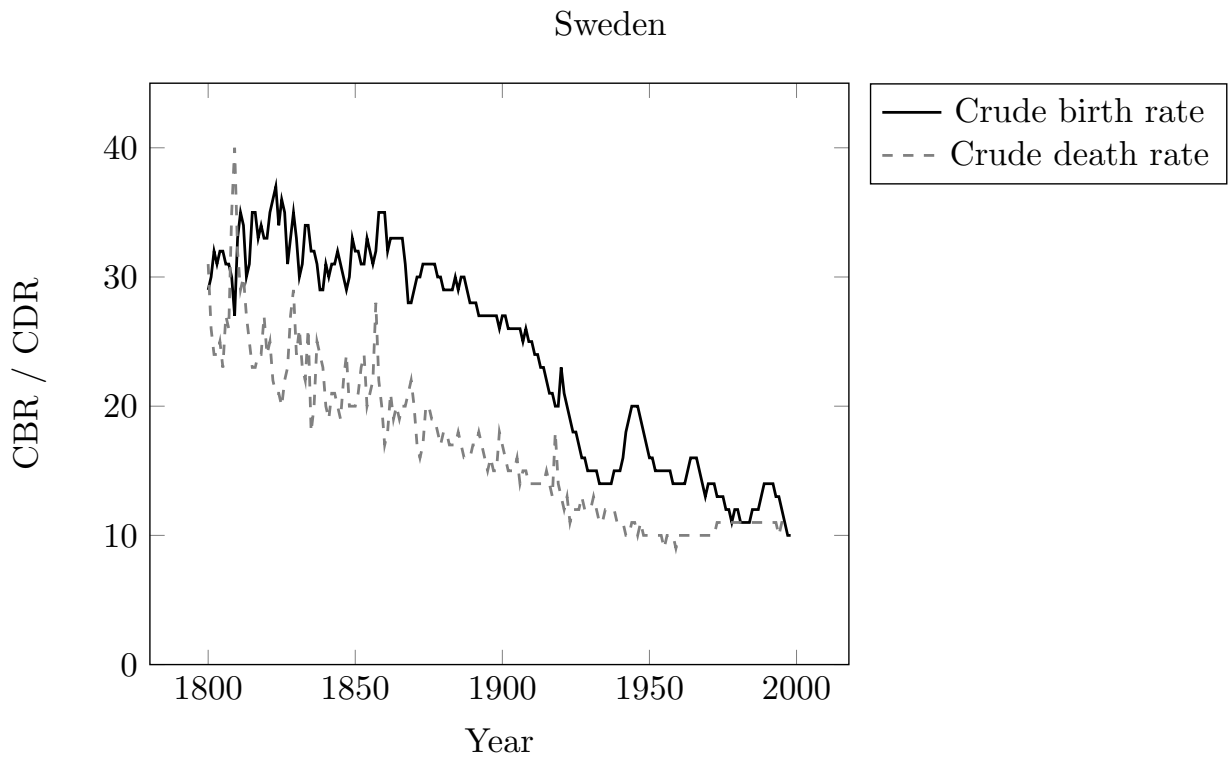

The Netherlands

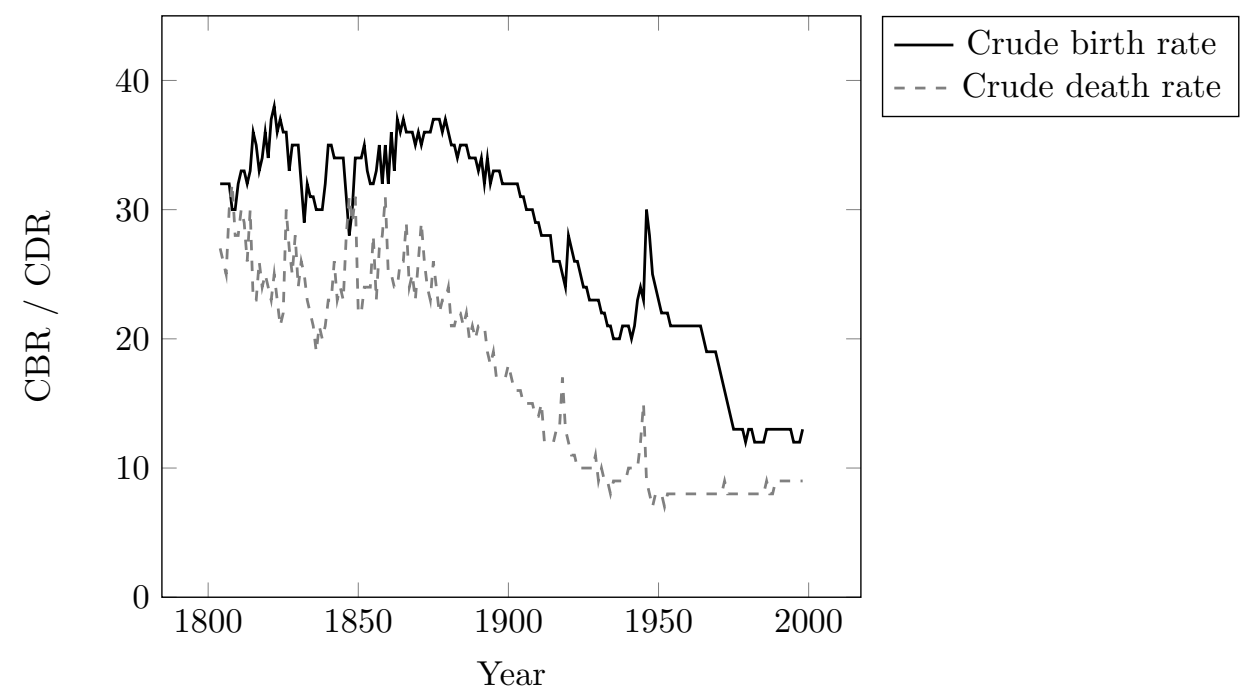

Crude birth and death rates, Sweden and the Netherlands 1800-1990.

Sources: Statistics Sweden (SCB) Population and Population Changes; Statistics Netherlands (CBS) 200 Jaar Statistiek in Tijdreeksen. 


\subsection{THE FIRST DEMOGRAPHIC TRANSITION}

could be grouped into three demographic clusters (Thompson, 1929). ${ }^{12}$

- Group A: Declining birth and death rates, with the birth rate declining more rapidly than the death rate, therefore positive but declining population growth (mainly Northern and Western Europe and United States).

- Group B: Declining birth and death rates, with the death rate declining more rapidly than the birth rate, therefore positive and no diminishing population growth (mainly Central and Southern Europe).

- Group C: Little to no voluntary control on birth and death rates, with the growth of the population being determined mainly by positive checks (Russia, Japan, India). ${ }^{13}$

Using this stylized classification scheme, Thompson drew inferences about the consequences of worldwide population growth during the twentieth century. Thompson argued that most of the landholdings were in the possession of countries belonging to group A. These countries were relatively rich and did not have increasing populations which would require additional land to settle on. Since groups $\mathrm{B}$ and $\mathrm{C}$ would likely show the largest increase in population in the coming decades, Thompson expressed deep concerns about how landholdings would be distributed among all three groups.

Although Thompson was particularly concerned with the long-term consequences of population growth on population movements, today his 1929 work Population receives most attention for laying the foundations of Demographic Transition Theory (DTT) - even though Thompson does not explicitly use the phrase 'demographic transition'. ${ }^{14}$ DTT describes the process by which countries transition from high mortality and fertility rates to low mortality and fertility rates. Thompson observed that in West-European countries a fall in death rates preceded the decline in birth rates. In the period between, when the death rate was low and the birth rate was still high, the population was expanding until the moment that the birth rate started to decrease.

\footnotetext{
${ }^{12}$ Thompson's analysis was based on data gathered from Northern and Western Europe (Austria, Belgium, England and Wales, France, Germany, the Netherlands, Sweden, and Switzerland), the United States, Italy, Spain, Central European countries (Hungary, Bulgaria, Czechoslovakia, Poland, and Romania), Russia, Japan, India, New Zealand and Canada for the period 1908-1927.

${ }^{13}$ The term 'positive checks' originates from Malthus' work on population growth. Malthus makes two basic assumptions concerning population growth; people will reproduce exponentially, food production will increase arithmetically (in a linear fashion). The positive check is mortality; the preventive checks are customs which prevent people in general from having too many children, such as postponing marriage or celibacy.

${ }^{14}$ Demographic Transision Theory is in fact not a causal theory - since it does not explain fertility decline nor does it help to predict fertility change - but instead a descriptive account of the changes in West-European fertility and mortality at the end of the nineteenth century accompanied by a changes in economic development.
} 


\section{Modernization as a driver of fertility decline}

Thompson also provided an explanation for the observed pattern of declining death and subsequently birth rates. According to him, 'industrialization' - in particular improvements in agriculture and urbanization - was the prime factor causing first mortality and later fertility levels to decline. Thompson argued that in rural populations, such as Hungary and Poland, people would be far less inclined to reduce fertility rates using birth-control methods compared to urban populations. For a modernized country such as Japan, he notes that the country "through modernization of its industry and some improvement in its agriculture has brought about some release of the positive checks" (Thompson, 1929, p. 972). In addition, the average birth rate in cities, housing more than half of the Japanese population, was considerably lower compared to the birth rate in rural areas. Hence, without industrialization - improved agriculture and urbanization - countries would not move from Group C to B, or from B to A. Fertility rates would remain high in regions where industrialization did not occur and the size of the population could therefore only be balanced by positive checks. ${ }^{15}$

Demographic Transition Theory gained popularity among demographers in the decades after the publication of Thompson's Population. In particular the works of Adolphe Landry (1934), Frank Notestein (1945; 1953), and Kingsley Davis (1945) strongly influenced demographic thinking during the mid-twentieth century. Although upon close reading there are important differences between publications describing a demographic transition theory, the general picture arising from these works is similar to Thompson's original depiction; modernization brings down mortality rates, followed by a decline in fertility rates.

Modernization, the proposed root cause of mortality and fertility decline, can be understood as an encompassing concept including industrialization, agricultural improvements, urbanization, improvements in medical care, rising standards of living and economic growth. Davis (1945) for example stated that; "behind the specific factors causing the unprecedented decline in mortality there was the general and all-inclusive change through which European society was passing - a change from illiterate agriculturalism to literate industrialism." (Davis, 1945, p. 5). Modernization was also argued to affect fertility rates, albeit indirectly and with a time-lagged effect. The increase in the standard of living, connected to urbanization and industrialization, provided parents with ample alternative opportunities to spend their time and money. For parents, modernization brought

\footnotetext{
${ }^{15}$ Interestingly, Thompson also identified knowledge-diffusion as a driver of declining birth rates, but he does not follow up on this line of reasoning. He suggests that fertility decline in the Group B countries would occur at a faster rate than what was observed for the Group A countries, since "the greater ease of communication makes the spread of contraceptive knowledge easier than it has been in the past" (p. 969).
} 


\subsection{THE FIRST DEMOGRAPHIC TRANSITION}

an alternative for the "family-oriented life-style of previous generations" (Alter, 1992, p. 18). The processes by which modernization brought down fertility rates have been nicely described by William Peterson in 1969:

"Industrialization loosens the social structure of an agrarian society: the sharp increase in both geographical and social mobility means that more and more persons are removed from the influence and control of the extended kin group to the relatively anonymous life of the large city. The normative system of the agrarian society (religious values, family sentiments, etc.) may also be weakened by this loss of its institutional bias, which is challenged as well by the higher valuation of rationality in an industrial urban setting. Fertility, in brief, tends to be associated with social structure, technological standards, and specific prescriptions or taboos; all three of these determinants have been markedly changed by industrialization."

(Quotation from Alter, 1992, p. 194)

\section{Critique on an influential narrative}

Demographic Transition Theory provided a convincing and influential narrative for patterns of fertility decline observed in nineteenth and early twentieth century Europe. In most European regions, fertility rates were indeed observed to be less responsive to changes related to modernization than mortality rates. Most populations that underwent a decline in fertility rates, also showed higher population growth in the years before the onset of fertility decline (Notestein, 1945). The majority of these populations could also be described as 'modern', in the sense that urbanization, improvements in agriculture or medical care, or industrialization were actual, visible developments preceding or operating in tandem with the fall in fertility levels.

However, DTT became criticized for a number of different reasons. As a theory, it was never really specific about the components of modernization that are the actual drivers of changes in mortality and fertility rates. Although societal changes are an important explanatory element, it is unclear whether these changes are predominantly technological, economic, or even cultural in nature. DTT has also received criticism for being 'Eurocentric', by assuming that patterns observed in Western Europe would be applicable to other parts of the world as well (Weeks, 2011). The most substantial critique on DTT was that it theorizes mainly at the aggregate level, overlooking the fact that people take their fertility decisions at the level of the individual and household level. Already during the 1950s and 1960s, researchers acknowledged the problems with DTT's explanations of fertility 
decline. One of the most prominent projects to cast doubt on the assumptions of DTT - and look for look for alternative explanations - was the Princeton European Fertility Project (see section 1.2.2) which showed that newly gathered empirical data did not fit the narrative outlined by DTT.

The lack of specificity has been both a strength and weakness of Demographic Transition Theory. It gained considerable popularity because it provided a good fit for most early empirical observations. With its emphasis on urbanization, industrialization and improvements in medical care as the key drivers of mortality and fertility change, it provided a convincing narrative for the decline of fertility in 19th century Europe. Because of the popularity of Demographic Transition Theory, policy makers in the 1960s and 1970s were operating on the assumption that "economic development is the best birth control pill" for developing countries (Alter, 1992).

\subsubsection{The Princeton European Fertility Project}

In 1963, Ansley Coale, who was associated with the Office of Population Research at Princeton University, started a research project that aimed to "determine the social and economic conditions that prevailed when the modern reduction in the rate of childbearing began" (Coale \& Watkins, 1986, p. 32). The researchers of the Princeton European Fertility Project gathered detailed, quantitative records of fertility from 24 European countries for the period 1860 until 1960. Indexes were calculated for total fertility, marital and non-marital fertility, and the share of married women for each European region (using the self-constructed measures $I_{f}, I_{g}, I_{h}$, and $\left.I_{m}\right) .{ }^{16}$ These indexes are "measures of the rate of childbearing in a given population (or defined segment [...]) relative to the maximum fertility the population in question might achieve". The fertility schedule of the Hutterites, an Anabaptist Protestant religious sect, was considered to be the maximum fertility schedule (Coale \& Watkins, 1986, p. 153). ${ }^{17}$ The academic output of the Princeton Project was impressive; a summary of the main findings is presented in Coale \& Watkins (1986). ${ }^{18}$ Today, the Princeton Project is best-known for

\footnotetext{
${ }^{16}$ The fertility indexes can be used as comparative measures to identify trends in marriage, overall fertility, marital fertility and non-marital fertility. The indexes were calculated using local census data, but with corrections for differences in under-registration of births and the quality of the census between regions. They were developed to allow for differences in age structure and nuptiality between European regions.

${ }^{17}$ The maximum fertility schedule was based on data from 1921-1930. The Hutterites religious sect was founded in the sixteenth century. They moved from West-Europe to Russia in the eighteenth century and later to the United States and Canada. The fertility of the Hutterites is traditionally high because the use of contraception or abortion was strictly forbidden. In addition, infants were nursed for only a few months by their mother, allowing for a new conception.

${ }^{18}$ The researchers of the Princeton Project published a considerable number of books and articles, and also a publicly available database. Chapter 5 uses the Princeton Project's dataset
} 


\subsection{THE FIRST DEMOGRAPHIC TRANSITION}

showing that many of the assumptions of DTT were not supported by the newly gathered empirical data.

Two examples of early studies conducted within the Princeton Project provided empirical evidence which was incompatible with DTT. In 1962, William Leasure $^{19}$ observed that the linguistic regions of Spain showed marked differences in the patterns of fertility decline (Leasure, 1963). The idea that linguistic borders could act as demarcation lines between different fertility regimes was later asserted by Ron Lesthaege in his study on fertility decline in Belgium (1977). In contrast with predictions based on DTT, in parts of Belgium fertility began to decline before infant mortality declined. Regional disparities in the decline of fertility were most prominently observed along the linguistic boundary that separates the regions of Wallonia and Flanders. Lesthaeghe compared villages on both sides of this boundary and found that, although they were geographically close to each other, fertility rates began to decline much earlier in the French-speaking Walloon villages than in the Dutch-speaking Flemish villages. The degree to which these villages were industrialized, or economically developed, had a much smaller impact on fertility outcomes than their language had. ${ }^{20}$.

In another study, Paul Demeny (1968) showed that the beginning of fertility decline in the Hungarian provinces (vármegye) of Austria-Hungary occurred around the same time as the fertility decline in England. Interestingly, while England at the end of the nineteenth century was industrialized and urbanized, the Hungarian provinces were still predominantly rural. Also, within AustriaHungary there were marked regional differences in the timing of fertility decline and its underlying causes. As Demeny states, "in the Austrian lands [of AustriaHungary], fertility decline does seem to fit the conventional picture of demographic transition as a process associated with urbanization, industrialization, and their various correlates. [... In contrast,] it can be positively shown that the decline of fertility [in the Hungarian provinces] originated and developed in and among the peasantry" (Demeny, 1968, p. 518-519). ${ }^{21}$

\footnotetext{
to investigate the association between family systems and fertility outcomes.

${ }^{19}$ William Leasure was at that time conducting his dissertation research under supervision of Ansley Coale.

${ }^{20}$ In later work, Lesthaeghe (1983) emphasizes the increasing centrality of the individual in contrast to the larger kinship group and the community. He argues that "a fertility decline is in essence part of a broader emancipation process. More specifically, the demographic regulatory mechanisms, upheld by the accompanying communal or family authority and exchange patterns, give way to the principle of individual freedom of choice, thereby allowing an extension of the domain of economic rationality to the phenomenon of reproduction." (Lesthaege, 1983, p. 411, emphasis added)

${ }^{21}$ Another interesting argument made by Demeny in this study is that the decline of fertility can be understood as a process of geographical diffusion of a preference for raising only one child, rather than an increased awareness of methods of birth control. Fertility decline originated within particular cultural homogeneous groups, which could be considered the nucleus of change, and from these groups fertility decline would spread outward. Interestingly, the prefer-
} 
Based on the data gathered by the participants of the Princeton Project, it was thus clear that considerable differences in fertility patterns could be observed within countries. However, contrary to hypotheses based on DTT, socio-economic indicators were found to be only weak predictors of fertility decline. Modernization, usually approximated by literacy rates or the shares of the population involved in agriculture, industry and the service sector, only weakly correlated with marital fertility. Furthermore, mortality decline also was not in all cases a precondition for a decline in fertility. Populations, in particular geographically adjacent populations, could display similar patterns in mortality or fertility decline even while the level of industrial development differed markedly (Watkins, 1986). It seemed that when fertility decline reached a certain threshold, around 10 percent decline, further fertility decline was very likely to occur in the next few decades.

The findings of the Princeton Project were unexpected and warranted a revised explanation for fertility decline. The authors of the Princeton Project pointed at the role of culture, or 'pre-existing regional conventions' since neighbouring regions often showed similar levels of fertility and nuptiality - in particular when the same language was spoken (Coale \& Watkins, 1986, p. 448). Local similarities in fertility levels were a "common solution to the problem of societal reproduction in the context of a particular environment" (Coale \& Watkins, 1986, p. 443). Cultural rules within a particular territory would mediate the effects of modernization, causing differences in the time between the onset of modernization and actual fertility decline. The conclusions of the Princeton Project can be summarized by the following quote:

[The] cultural setting influenced the onset and spread of fertility decline independently of socio-economic conditions. Proximate areas with similar socio-economic conditions but dissimilar cultures entered the transition period at different times, whereas areas differing in the level of socio-economic development but with similar cultures entered the transition at similar times.

(Knodel \& Van de Walle, 1986, p. 412)

\footnotetext{
ence for smaller family sizes did not originate from one particular culturally homogeneous group. Instead, early fertility decline in the Hungarian provinces was observed as much in the Protestant (Calvinist) community, as in the Roman Catholic community and in the Greek Orthodox community. Thus, neither urbanization and industrialization, nor any particular religion proved to be sufficient for explaining the observed patterns of fertility decline. Literacy and infant mortality however, which can also be seen as aspects of modernization, did play a role in explaining within-country differences in fertility decline in Austria-Hungary according to Demeny. Provinces that showed lower infant mortality rates and higher literacy rates, also showed lower fertility rates. However, these factors were not strongly associated with the timing of fertility decline and Demeny therefore argued that literacy and infant mortality were only facilitating, but not conclusive factors.
} 


\subsection{THE FIRST DEMOGRAPHIC TRANSITION}

However, critics of the Princeton Project argued that the fertility indices used were not suitable for rejecting hypotheses on the correlation between fertility and socio-economic indicators. Since the indices were aggregated to the level of provinces, correlations between fertility and socio-economic conditions may still have existed at the level of the individual or household (Kertzer et al., 1989). ${ }^{22}$ Also, while culture played an important role in the Princeton Project's theoretical framework, a full understanding of its exact role was never developed within the project. For most regions the data did not include extensive indicators of culture. Recognizing this issue, some authors such as Lesthaeghe (1977) attempted to capture particular regional aspects of culture. Lesthaeghe, for example, included an analysis on secular voting behaviour as an approximation of belief systems associated with fertility. In a later study, he provides a detailed framework for understanding changes in fertility as 'manifestations of a cultural dimension' (Lesthaege, 1983). But what are cultural regions? According to which dimensions do they differ from each other? How can they develop over time? Or how do these matters affect changes in fertility or nuptiality? The Princeton Project's impact on historical demography is not at all lessened by the fact that it could not provide a novel, comprehensive explanation for fertility decline, but the credit given to 'culture' in explaining fertility decline is perhaps not too enlightening.

\subsubsection{Toward a restatement of Demographic Transition Theory}

In 1976, a paper was published by John Caldwell, entitled 'Toward a Restatement of Demographic Transition Theory'. Caldwell recognized that while DTT was a popular theory which guided the work of international organizations and government programs, it had not been adapted to more recently uncovered empirical data and insights regarding the demographic transition gained from the Princeton Project and other research. Caldwell's approach emphasized the role of decision-making at the level of the individual or household. His work can therefore be regarded in particular as a reaction to the macro-level perspectives upheld by DTT and the Princeton Project.

Caldwell (1976) argued that there are only two possible fertility regimes; one in which there is no economic gain from restricting fertility, and one in which there is (possibly long-run) economic gain from restricting fertility. Between these two fertility regimes, a population can be in a state of transition. The chosen regime

\footnotetext{
${ }^{22}$ The fertility indexes were developed to allow for differences in nuptiality between European regions, but at the same time to be calculated from the simplest information available. Thus, with the total number of births, number of births per married woman and the number of married women as given, more detailed information such as birth order, age of the parents at first birth, age of parents at marriage, etc. cannot be derived.
} 
depends on the implicit cost-benefit trade-off between unrestricted and restricted fertility behaviour made by each individual. The key to understanding fertility transitions lies in the magnitude and direction of "intergenerational wealth flows"; wealth transfers from parents to children and vice versa. Fertility outcomes are high when wealth is flowing from children to their parents. In contrast, when wealth starts flowing reversely from parents to their children, fertility rates will decrease. Caldwell brings out that both high and low fertility are rational modes, determined by the flow of wealth between the generations. If the direction in which wealth flows is altered, fertility outcomes will change as a rational response.

Economic approaches to fertility - such as Caldwell's - were not new in the 1970s, with earlier works provided by Leibenstein (1957), Gary S. Becker (1960) and Easterlin (1975), amongst others. ${ }^{23}$ However, Caldwell extended the definition of wealth to include non-economic or intangible motivations, both in the present and anticipated over the life course (Caldwell, 1976, 1978). Hence, the reversal of wealth flows itself can also be explained as a rational response to ideational changes such as the amount of education children should receive. ${ }^{24}$ Caldwell suggests that the growth of capitalist modes of production during the nineteenth century brought with it important ideational changes regarding the role of children in society. Children's education rather than child labour became the norm and since schooling required funding, the costs of raising children increased. In addition, home production gave way to industrial production causing an increased demand for labour. As a result, women's employment in factories increased and wages rose. Within the household, women now provided relatively more income to the household and children required more consumption due to schooling. As a result, the wealth flow was reversed from parents to their children and couples responded by limiting their fertility (Caldwell, 1976, 1978).

Caldwell's Wealth Flow Theory is an important approach, because it demonstrates how both low and high fertility can be regarded as rational responses to changes in intergenerational wealth transfers. Furthermore, it emphasizes rational individual-level decision-making, rather than macro-level phenomena. Caldwell's

\footnotetext{
${ }^{23}$ The essence of economic models of fertility behaviour is that a fertility outcome is the result of each individual balancing the marginal benefits of the $n^{\text {th }}$ child to its marginal costs (Leibenstein, 1957; Becker, 1960).

${ }^{24}$ For example, Caldwell argues that West-European families in the beginning of the nineteenth century were characterized by a sharply gendered division of labour, with the husband working outside the home for wages and the wife and children providing domestic work. When the wife or children did work outside the home, they would generally receive a lower wage than the husband. Given that children required relatively little consumption and that both could provide services to the household, high fertility levels were a rational response. In other words, there was a net transfer of wealth from children to parents. Note that Caldwell $(1976 ; 1978)$ suggests that ideational change is a response to changes in production modes. However, in later work on demographic change in contemporary Nigeria, he states that ideational change can also occur independently from changes in production modes, for example via mass media and education.
} 


\subsection{THE FIRST DEMOGRAPHIC TRANSITION}

central assumption, that fertility decisions are made based upon the marginal utility of an additional child, provided important extensions to the demographic debate. $^{25}$ There are many examples of (recent) studies that take such an 'economic' approach to reproductive decision-making (see e.g. Ashraf et al., 2014).

Following Caldwell's framework, it would be unlikely to see large fertility differentials within culturally and economically homogeneous groups. Yet, later empirical studies show that this deduction does not withstand empirical testing. Van Poppel for example observed in his study on fertility patterns in The Netherlands during the first half of the twentieth century that the moral acceptance of fertility limitation is an important determinant of fertility outcomes; "where we compared groups with the same socio-economic background within a given region, great differences in fertility were found, due mainly to high fertility of Catholics" (Van Poppel, 1985). ${ }^{26}$

While the work of Leibenstein, Becker, Caldwell and others has brought attention to processes operating at the level of the individual, rather than macro-level phenomena, economic approaches to reproductive behaviour are less clear about how individuals carry out their cost-benefit analysis. In practice it may be impossible to determine the relative costs and benefits perceived by each individual. How does one for example determine the costs of an additional child? And what about estimating the costs or benefits of not having a child? Also, factors which alleviate the costs of raising children, such as the support of others, are challenging to determine beforehand (Robinson, 1997). In addition, economic approaches assume that fertility behaviours are rational responses to conditions given by the cost-benefit analysis. However, in the real world people my behave irrationally or not in full support of their long-term interests. ${ }^{27}$ Furthermore, only limited

\footnotetext{
${ }^{25}$ Fertility decisions are according to Caldwell the result of implicit cost-benefit analyses at the level of the individual. By extending wealth to include intangible motivations, perceived benefits or costs today or in the future, it is possible to introduce - or discount - all (future) external factors into the cost-benefit equation, including irrational behaviour or the influences of other people. However, it could be questioned whether individuals are capable of incorporating each of these factors in the decision; the relative cost or benefit of each external factor has to be specified. In addition, this approach assumes completely rational actors. Within a cost-benefit equation irrationality is no factor, but in the real world people do display behaviours which do not necessarily support their own (long-term) interests.

${ }^{26}$ On the other hand, by stretching the definition of wealth to include intangible, non-economic motivations it can be argued that individuals take the moral acceptability of their actions into account when analysing the direction of wealth flows. The problem with this approach however is that the relative costs or benefits perceived by an individual can differ and are also very difficult to measure. The concept of intergenerational wealth transfers is also employed by Ron Lesthaeghe and Chris Wilson, who were participants of the Princeton Project. They examined the role of the dominant mode of production, extent of child labour and secularisation and argued that wealth transfers from children to parents will be associated with higher levels of fertility (Lesthaege \& Wilson, 1986). However, a reversal in wealth transfers alone will not be sufficient to trigger a decline in fertility; they argue that fertility limitation should also be morally acceptable.

${ }^{27}$ Studies in evolutionary biology similarly argue that individuals strive to maximize the rep-
} 
attention is paid to the role of social interactions with other people, or the social context in which fertility decisions are made. The activities of relevant others are reduced to elements of the cost-benefit equation. The economic approach is helpful as a framework, or paradigm, to help understand parts of the fertility decision-making process, but not in its entirety. A more holistic approach was and perhaps still is - needed.

\subsection{Social interactions and the role of family members}

As has been described in the previous sections, academic approaches to understanding reproductive behaviour shifted from a focus on macro-level oriented phenomena, such as culture or modernization, towards decision-making at the level of the individual and couple (Jayakody et al., 2008; Madhavan et al., 2003; Mathews \& Sear, 2013b,a; Balbo et al., 2013). Recent studies in demography have furthermore highlighted the role of social relations and interactions that connect individuals to one another, focussing on the role of family, peers and other relevant others (Bongaarts \& Watkins, 1996; Bras \& Van Tilburg, 2007; Coall \& Hertwig, 2010). A large number of - both older and more recent - empirical studies have demonstrated for example that parents and children show correlations in terms of children ever born (Pearson et al., 1899; Duncan et al., 1965; Murphy \& Wang, 2003; Murphy \& Knudsen, 2002; Johnson \& Stokes, 1976; Zimmer \& Fulton, 1980; Anderton et al., 1987) or in age at first birth (Steenhof \& Liefbroer, 2008; Barber, 2001). Since fertility decisions are not made in a social vacuum, recent studies also take the context, including social networks, in which fertility decisions are made into account (Kok, 2009; Bras et al., 2013; Bras, 2014; Mönkediek, 2016; Hilevych, 2016; Hilevych \& Rotering, 2013). Fertility outcomes may be responsive to macro-level socio-economic or cultural conditions, but are also guided by other aspects such as knowledge about how to control family size, the availability of support of relevant others, social acceptance and the organisation of kinship.

In this section, we first discuss how social interactions can bring about changes in reproductive behaviours. We consider in some detail the different pathways though which family members may affect each other's fertility outcomes. Since the focus of this dissertation is on family influences, the influences of friends, peers, co-workers etc. are not covered - even though these people too exercise their influences. Next, we examine why family members are motivated to provide support in the form of resources, aid, or assistance. This question is approached from the actions should not outweigh their benefits (Hamilton, 1964a,b; Hrdy, 2007; Mace, 2014). 


\subsection{SOCIAL INTERACTIONS AND THE ROLE OF FAMILY MEMBERS}

perspective of evolutionary biology. Briefly put, evolutionary approaches suggest that through natural selection people are more likely to assist blood-related kin than non-kin because such actions maximize their own genetic representation in future generations (Hamilton, 1964a,b; Grafen, 1984; Sear, 2015). ${ }^{28}$

After examining how and why kin may influence fertility outcomes, we examine the role of the context in which fertility decisions are made. Previous approaches such as DTT, the Princeton Project and Wealth Flow theory have approached the role of context by focussing in particular on socio-economic conditions (e.g. modernization), culture, and the influences of media. While these factors are relevant, they are by themselves not sufficient to trigger a decline in fertility (Lesthaege \& Wilson, 1986). Another perspective on the interaction between fertility decisions and the context in which decision-making takes place, is given by diffusion theory. Diffusion theory regards fertility behaviour as a learned behaviour that is responsive to the introduction of new information, such as knowledge of birth control methods. In addition, diffusion theory emphasises that the more direct effects of new information are mediated by the context in which the information is transmitted and received.

Recognizing that fertility decisions are influenced by the context in which they are made, we examine what is meant by context in the last section. We use the concept of family systems, to describe local sets "of beliefs and norms, common practices, and associated sanctions through which kinship and the rights and obligations of particular kin relationships are defined" (Mason, 2001, p. 160). During the past decades, many typologies of family systems have been developed. This thesis uses the classification of family systems developed by Emmanuel Todd, a description of his classification of family systems is provided in chapter 5 (Todd, 1985).

\subsubsection{Pathways of kin influence}

\section{Preferences and constraints}

Today as well as in the past, couples considering childbearing are inevitably confronted with attitudes, behaviours, and comments of other people around them, including family members, people at work, role models, friends, and even strangers or media. In addition, other people may provide support or resources, including information about birth control methods. ${ }^{29}$ The provision of such information or resources in itself may also be a means of communicating a message. While there

\footnotetext{
${ }^{28}$ Help of kin may include physical assistance, knowledge transfers or resource provision, but also the exertion of social pressure to increase offspring size. See section 1.3.1.

${ }^{29}$ The pill and properly functioning condoms became widely available since the mid-twentieth century.
} 
are many relevant others who are influential for a couple's fertility decisions, the discussion below concentrates exclusively on the influence of family members.

It is assumed that people's fertility decisions are based on their preferences, taking into account constraints such as their biological ability to reproduce and the physical, emotional, and monetary costs of raising children (Easterlin, 1975; Pollak \& Watkins, 1993; Becker \& Barro, 1988; Kodzi et al., 2010; Kaplan \& Lancaster, 2003; Kaplan, 1996; Caldwell, 1976). ${ }^{30}$ By shaping an individual's preferences, or by adjusting the constraints which the individual faces, family members can affect fertility.

Family members can affect preferences and constraints via two mechanisms; relieving constraints by providing resources and practical support (Tymicki, 2004; Turke, 1989) and shaping preferences by exerting social influence ${ }^{31}$ (Newson et al., 2005, 2007; Bernardi, 2004; Bernardi \& White, 2010; Axinn et al., 1994; Kohler, 2001; Mathews \& Sear, 2013a). These two mechanisms of kin influence ultimately affect fertility outcomes through the age at starting or stopping, the transition time between subsequent childbirths, the total number of children born, and the chances of offspring survival (Van Bavel \& Kok, 2005; Kemkes-Grottenthaler, 2005). Since childbirth requires a mother and a father, it is important to recognize that each partner has individual preferences and that the outcome of their fertility decision process is affected by the bargaining power of each partner. In addition, both partners have family members who may affect the couples' preferences and constraints (Thomson \& Hoem, 1998). ${ }^{32}$

\section{Resources and support}

By providing resources and support, family members can affect fertility outcomes by relieving perceived or actual constraints of couples with a demand for children (Hill \& Hurtado, 2009; Hawkes et al., 1997; Kramer, 2005; Coall \& Hertwig, 2010). According to Turke (1989), kinship networks in traditional societies functioned "to disperse the costs of child-rearing among an array of relatives" (Turke, 1989, p. 64). ${ }^{33}$ Having children offers serious challenges to young couples regarding the

\footnotetext{
${ }^{30}$ See the research framework, described in section 1.1.2.

${ }^{31}$ In the literature, this is also referred to as emotional support, or kin priming.

${ }^{32}$ The discussion below is focussed on the West-European context. This means that complex household formation patterns, such as three-generation households observed in China but also in Eastern Europe during the period of this study, are not taken into account. It is assumed implicitly that the couple is also head of the household. An important limitation is that the extended household economy (support and resources from others outside of the household) has not been taken into account due to a lack of data.

${ }^{33}$ Turke (1989) argues that fertility decline occurred when kinship networks broke down and the costs of raising children increased. In addition, other life-styles or opportunities shaped preferences of young adults. The breakdown of kinship networks caused control over household resources to be transferred from the elderly to the young adults themselves. Turke argues that these processes led to a reduction in the demand for children over time in modern societies.
} 


\subsection{SOCIAL INTERACTIONS AND THE ROLE OF FAMILY MEMBERS}

direct and opportunity costs of raising offspring. Resource provision and practical support by kin can help to relieve this burden. ${ }^{34}$ In a study on first childbirth in modern-day Germany, Hank and Kreyenfeld (2003) observed that a couple's likelihood of first childbirth was higher when one of their parents was living in the same town. The possible explanation for this is that the parents could provide childcare services to the couple (Hank \& Kreyenfeld, 2003).

Recent empirical studies, many of which cover observations from contemporary and historical pre-transition societies, find that reproductive outcomes are indeed associated with the availability of kin assistance (Pollet et al., 2007; Voland \& Beise, 2002). Research suggests that among the most important caregivers are the couple's parents (Hawkes et al., 1997; Tymicki, 2004; Hawkes, 2003), their children, referred to as 'helpers-at-the-nest' (Crognier et al., 2001; Kramer, 2005), and the siblings of the couple (i.e., aunts and uncles of the newborn child) (Draper \& Hames, 2000; Feng et al., 2010; Hill \& Hurtado, 2009; Sear et al., 2003; Sear \& Mace, 2008). For example, Kana'iaupuni et al. (2005) find that in modern-day Mexico mothers with young children whose kin network is larger, are offered more practical support and had healthier children than those with smaller kin networks.

Interestingly, the positive association between resource provision and higher fertility outcomes is not always observed in empirical studies. In a study in the UK using data from the Millenium Cohort Study, Shaffnitt and Sear (2017) observed that the likelihood of parity transition from first to second birth is reduced when mothers receive practical support, with the exception of women with the lowest socio-economic position. In contrast, for greater emotional support (see next section) a shorter birth interval is observed for all groups, the authors conclude that feeling supported may be more important than the actual provision of support (Schaffnit \& Sear, 2017). Likewise, Tanskanen and Rotkirch (2014) observe mixed effects for the association between fertility intentions and practical support in their comparative study of women in four modern-day European countries.

In conclusion, while many empirical studies show a positive association between kin support and fertility outcomes, support of family members does not necessarily mean that people will maximize their reproductive success. The net costs of raising children do not only depend on the resources and support provided by family members, but also on less visible opportunity costs (such as the perceived returns of possible alternative life styles) and the social context in which decision-making takes place. The role of family members in fertility decisions thus goes beyond the provision of resources and support.

\footnotetext{
${ }^{34}$ For example, when the couple is provided with necessary materials or support required to nurture a new-born, or expect that these factors are provided when the child is born, it is likely to expect that the age at first birth will be lower compared to couples who are in a similar socio-economic position but do not receive this support (Davis, 1955; Hrdy, 2007; Kaptijn et al., 2010).
} 


\section{Social influences}

In addition to providing resources or practical support, family members can also influence fertility outcomes through communications which encourage or discourage reproduction, thereby shaping the preferences or perceived constraints of the couple (Newson et al., 2005). Social influences do not affect fertility outcomes directly, but rather through an increased exposure to pro-natal sentiments. This process is also referred to as emotional support, or kin priming, and it can occur consciously or completely unconscious (Mathews \& Sear, 2013b; Rotkirch, 2007; Bernardi et al., 2015). As noted above, the provision of resources or practical support by itself may exert subtle pro- or anti-natal notions as a by-product of the exchange.

Several empirical studies have examined the association between fertility outcomes and the degree of kin presence in the social network of individuals (Hilevych, 2016; Mönkediek, 2016; Madhavan et al., 2003; Bernardi et al., 2007; Keim et al., 2009; Mace \& Colleran, 2008; Borgerhoff Mulder, 2007; Mathews \& Sear, 2013a; Bras, 2014). A larger degree of kin presence in social networks is in general hypothesized to be associated with higher fertility (Newson et al., 2007). Some authors argue that during the First Demographic Transition processes of modernization have led to a disintegration of kin-based networks, causing a transition from high to low fertility (Turke, 1989; Newson et al., 2005; Ruggles, 1994). The positive association between higher fertility outcomes and a larger kin-presence in social networks is described as the 'kin influence hypothesis' (Newson et al., 2005, 2007). This hypothesis holds that "communications between kin are more likely than communications between non-kin to encourage behaviour consistent with achieving reproductive success" (Newson et al., 2007, p. 199). Pro-natal cultural norms are more strongly present in social networks surrounding an individual which is relatively dense with kin. In contrast, a larger share of non-kin in an individual's social network, or more precisely, fewer interactions with kin relative to non-kin, gives way to the evolution of cultural norms which "allow behaviour to become increasingly less consistent with the efficient conversion of resources to offspring" (Newson et al., 2007, p. 199). The positive association between higher fertility outcomes and a greater share of family members in an individual's social network has been confirmed in recent empirical studies (e.g. Sear \& Coall, 2011; Mönkediek, 2016).

The pathways of social influence through which individual attitudes, values, and behaviours regarding reproductive behaviour are shaped through interaction with others, have been described extensively by Laura Bernardi (Bernardi, 2004; Bernardi \& Klärner, 2014; Keim et al., 2009). ${ }^{35}$ Her classification is presented

\footnotetext{
${ }^{35}$ There are many other valuable classifications of the various ways in which people influence
} 


\subsection{SOCIAL INTERACTIONS AND THE ROLE OF FAMILY MEMBERS}

here in some detail since it is rather extensive, complementary to other literature, and based on a large number of qualitative empirical studies. Bernardi (2004) distinguishes four pathways of social influence: social learning, social pressure, subjective obligation, and social contagion. ${ }^{36}$

These pathways provide a stylized abstraction of the ways in which fertility behaviour is affected through social influence. The pathways provide a framework, although in practice it is rather difficult to see clear-cut differences in their effects (see e.g. Hilevych, 2016, for a qualitative study of the pathways of social influence on fertility behaviour). The following paragraphs are based on Bernardi (2004) and Bernadi and Klärner (2014), and describe these four pathways in more detail. ${ }^{37}$

Social learning: Social learning is the process of information exchange through which people are presented with new information that shapes the perceived costs and benefits of their decision-making process. ${ }^{38}$ Social learning can present people with new information, a perspective that was previously 'unthinkable'. With regard to diffusion models of fertility change (see section 1.3.3 below), social learning is thus a key process in order to understand how information is transferred between geographical areas or persons.

Bernardi (2004) argues that the nature of the relationship between individuals affects the transmission of information. Parents and siblings are perceived as an influential source of social learning because they are close to the individual, although dissimilarities between siblings and the generational gap between parents and children are factors which decrease their influence (Thornton, 1980; Anderton

each other's fertility behaviours (e.g. Newson et al., 2005; Montgomery \& Casterline, 1996)

${ }^{36}$ In a recent overview of social influence on reproductive behaviour, Bernardi and Klärner (2014) have slightly re-framed Bernardi's original classification. The pathways of subjective obligation and social contagion were grouped together, and a new dimension is added; social support. Social support refers to the exchange of tangible or intangible resources, including physical materials, emotional support and a helping hand. Individuals in a social network may for example share children's clothes, or a grandmother may assist her daughter when she has given birth.

${ }^{37}$ For her 2004 study, Bernardi conducted 54 interviews with women between 30 and 39 years old, living in Lombardy, Northern Italy. The conducted interviews had an open, unstructured format allowing the interviewees to express their thoughts on subjects previously touched upon. She found that most women, when asked direct questions, such as "do you feel you have been influenced by anybody in your decision [to have children]", were reluctant to confirm the influence of others (Bernardi, 2004, p. 530). However, Bernardi observed that during the interview most women did provide rich descriptions of occasions, settings and actors. Many of the interviewees would recollect conversations, even casual, which had significantly affected the way they thought about having children. Thus, although women were in general disinclined to confirm that their fertility decisions could have been influenced by their social network, Bernardi observed that the social background of individuals did shape their decision-making process.

${ }^{38}$ Rational-actor models of decision-making assume that each behaviour has costs and benefits that can be identified and balanced. Present, but also past or expected, messages and behaviours of others modify the perceived costs and benefits of any decision, thereby rewarding or sanctioning particular behaviours. 
et al., 1987; Montgomery \& Casterline, 1996). ${ }^{39}$ Although the social distance between individuals is an important mediator of the effect of social learning, this does not mean that family members who are not closely bonded to one another cannot have a meaningful impact. Even occasional contacts with others can provide information that ends up being crucial to the reproductive decisionmaking process.

Social pressure: Other people may express their expectations about future life outcomes. When these expectations are expressed, they provide a normative framework that shapes the perceived costs and benefits of reproductive decisionmaking, and possibly future behaviours. Bernardi describes the mechanism of social pressure as fertility behaviour which conforms to the expectations of others. Social pressure can for example reduce age at first birth when parents speak out their wishes for having grandchildren. Vice versa, when parents express expectations such as 'do not have children before you get your degree', social pressure can postpone childbirth.

Subjective obligation: The behaviour of others, or the information they provide, may be perceived as a social cost or as a social benefit when it is anticipated that sanctions or rewards from the other will follow. Perceived prospective sanctions and rewards produces a third mechanism, subjective obligation. Such subjective beliefs, the perception of how others may respond, are by themselves sufficient to trigger changes in fertility behaviour. There is no need for others to articulate or enforce their rewards or sanctions, since individuals behave in the anticipation of such. The impulse to behave in accordance with the perceived expectation of others can have both positive and negative effects on fertility outcomes. Individuals who are most likely to prompt subjective obligations are those who are likely to retain bonds with the individual in the future, such as the spouse, parents, and siblings.

Social contagion: Bernardi argues that others can have an unconscious influence on each other's decision-making process through a mechanism she calls social contagion. In close-knit groups of friends, it is often observed that people have the same age of entry into parenthood (Bernardi, 2004, p. 540). For her study on fertility outcomes in Ukraine, Yuliya Hilevych conducted several interviews with Ukrainian couples, born in the 1930s-40s. Her study gives rich examples of couples whose fertility outcomes, such as the timing of the first child, were influenced by the behaviour of their peers. As one participant in her study remembered the timing of her first pregnancy; "My friends also gave birth and we had many

\footnotetext{
${ }^{39}$ Although they are not part of this study, peers are another important source of social learning. Co-workers, friends, neighbours are suggested to be highly influential in shaping decision-making through social learning because they face similar contingencies. In others words, they are more similar to the individual and the choices they make can be perceived against a similar social background.
} 


\subsection{SOCIAL INTERACTIONS AND THE ROLE OF FAMILY MEMBERS}

common interests, like children" (Hilevych, 2016, p. 71). Bernardi argues that the underlying cause of social contagion is that people are motivated to comply with the behaviours and opinions of other people with whom they have a close emotional bond. Although social contagion is a difficult measure to quantify, it is, with social learning, a particularly important mechanism for understanding diffusion processes of fertility change.

These four pathways of social influence provide stylized descriptions of the ways in which preferences and constraints regarding fertility are influenced by others. It is important to note that Bernardi (2004) does not make a distinction between the influences of kin versus non-kin. These pathways can help to understand particular associations between family members and fertility outcomes, but this requires additional theorization about the particular influences of kin and non-kin. For example, the aforementioned 'kin influence hypothesis' proposes that when the share of family members in social networks declines, fertility is also likely to decrease. The pathway of social learning suggests in this example that when individuals are exposed to non-kin more than to kin, previously unthinkable views may be introduced regarding alternative life courses. Or, using the pathway of social pressure, the kin influence hypothesis suggests that kin and non-kin differ in the way they express expectations regarding future life outcomes. In summary, the pathways described by Bernardi do not distinguish between the influences of kin and non-kin, while some hypothesis - such as the kin influence hypothesis do.

\section{Complex interactions}

While the effects of social influences and the provision of resources and support on fertility outcomes make an interesting and important research topic, the precise mechanisms are not easily identified, nor is the direction of the effect always clear. Genetic heritability, individual preferences, biological heterogeneity in individual fertility, and other confounding factors further add to the complexity of understanding reproductive behaviour at the level of the individual. In addition, the influences of kin on fertility outcomes may also be mediated by, or interact with, the context in which fertility decisions are made.

For example, growing up in a large family may lead to a preference for a larger offspring in later life (Murphy \& Wang, 2001; Murphy \& Knudsen, 2002; Axinn et al., 1994). It is however difficult to disentangle whether social learning or contagion is the most dominant mechanism shaping fertility preferences. Also, growing up in a large family may even not necessarily entail a preference for larger offspring. Easterlin (1980) for instance hypothesized that fertility correlations between generations can be negative; people with a small family background 
may be more likely to have many children themselves. Ceteris paribus, such people had less competition over resources with their siblings and therefore were economically advantaged compared to their peers. As a result, they were more likely to marry and produce a larger family. Evidence for this hypothesis is however rather limited for pre-transitional populations, as most studies show a small, but positive correlation between fertility outcomes of parents and children, see also chapter 3 in this thesis (Murphy \& Wang, 2001).

Apart from family size, individual experiences with the parental family in one's youth can also have other effects on preferences regarding reproduction later in life. Duncan (1965) suggested that the relationship between sibling size and offspring is mediated by an individual's 'satisfaction' with the family of origin (see also Hendershot, 1969; Johnson \& Stokes, 1976). Exposure to constant quarrels or a lack of resources in the parental home may also reduce preferences for a larger family (Salmon \& Hehman, 2015). In addition, the divorce of parents may alter one's perspective on marriage and possibly reduce preferences for a larger family size (Axinn \& Thornton, 1996). Instead of providing resources and support, coresident kin, or family members who live nearby may also require care themselves (see chapter 2). Furthermore, the very act of resource provision may entail hidden notions concerning preferences of the benefactor, as has been noted above. This makes it difficult to distinguish between the effects of practical support and social pressure.

Kin influences are also competing with the influences of non-kin in an individual's social network (Newson et al., 2005, 2007; Udry, 1996). When people are exposed to a wider variety in life courses, biological factors tend to explain a larger portion of variation in fertility behaviour and intergenerational fertility correlations become stronger. This association is supported by later studies on genetic components of fertility behaviour, see chapter 3 (Kohler et al., 1999; Bras et al., 2013).

These are important considerations and researchers should be aware of the multitude of factors affecting reproductive outcomes. Statistical models only provide an abstract approximation of reality, and give up much of the complexity of real-life outcomes. It is important to be aware of the many ways in which fertility outcomes can be influenced, since with better knowledge, policy makers striving to alter fertility outcomes will be able to derive better instruments to help them reach their goals.

\subsubsection{Evolutionary theory}

The above description of the various pathways through which kin may influence fertility behaviour leaves open the question what influence family members are 


\subsection{SOCIAL INTERACTIONS AND THE ROLE OF FAMILY MEMBERS}

likely to have. Are family members more likely to express pro-natal views? Why would kin even bother to provide support? Recently, a growing number of studies in demography have employed the perspective of evolutionary biology in order to answer these questions (Mathews \& Sear, 2013a; Sear, 2015; Sear et al., 2016). This approach suggests that people are more likely to assist in raising offspring of family members than non-relatives, because such behaviour yields an indirect 'inclusive fitness' benefit (Hamilton, 1964a,b).

Inclusive fitness theory assumes that all species, including humans, allocate their resources, support, knowledge and time, in such a way that they maximize the presence of their own genes in future generations - provided that the costs of such actions do not outweigh their benefits (weighted by the genetic distance) (Hamilton, 1964a,b; Hrdy, 1999; Mace, 2014). As long as the marginal genetic benefit of providing support is higher than its marginal cost, care-giving is likely to increase the number and survival chances of offspring of relatives (Grafen, 1984). Recent studies have shown that couples who can rely on the support of close kin, are indeed more likely to raise more and/or better-quality children than couples who are not helped by kin (Kaptijn et al., 2010; Kramer, 2010; Salmon \& Shackelford, 2008; Schaffnit \& Sear, 2014; Mace \& Sear, 2005; Sear \& Coall, 2011; Rotering \& Bras, 2015). ${ }^{40}$

It is however too simple to assume that there are no limits to the pro-natal support of family members, and that such support will always increase the number of offspring. When people do not space their births sufficiently, maternal depletion may cause suboptimal investment of the mother in her children. While women on average have the physical potential of bearing at least 15 children, in most cases they raise far fewer. This illustrates that childbearing involves costs, including physical costs for the mother, and also that women are not evolved to maximize their reproductive success (Turke, 1989). ${ }^{41}$ In addition, the provision of support by family members also entails costs for the giver. Thus, when the relative costs per child increase, family members may not be willing to increase their support to match the increased costs. ${ }^{42}$

\footnotetext{
${ }^{40}$ Because of the relatively short interval between successive births and the long period during which newborns are dependent on others for their nutrition, Hrdy argues that people behave as 'cooperative breeders' (Hrdy, 2007, 2009). This means that parents rely on other people alloparents - who provide assistance in the form of care or resources, thereby helping to raise offspring and enabling parents to increase their reproductive outcomes (Kramer, 2010).

41 'Reproductive success' can be defined as the number of offspring, and the number of children surviving until sexual maturity (Crognier et al., 2001) while the 'optimal number of children' depends on the marginal costs and benefits of each additional child (Becker \& Barro, 1988; Caldwell, 1976).

${ }^{42}$ Costs as in 'opportunity costs', including elements such as the costs of giving up an alternative lifestyle. The evolutionary perspective may also help to explain why the female lifespan is longer than their reproductive years. The 'grandmother hypothesis' suggests that even though post-menopausal women can no longer reproduce, they can still contribute to their inclusive fitness by providing resources or care to their children and grandchildren, thereby enabling them to
} 


\subsubsection{Diffusion theory}

Academic interest in the diffusion of fertility has grown since the results of the Princeton Project showed that structural effects were not sufficient in explaining the first demographic transition. Diffusion models emphasize the significance of social interactions and social networks for understanding changes in fertility behaviour (Boyd \& Richerson, 1985; Cleland \& Wilson, 1987; Montgomery \& Casterline, 1996; Bocquet-Appel \& Jakobi, 1998; Bongaarts \& Watkins, 1996; Kohler, 2001). Diffusion can be defined broadly as "the process in which an innovation is communicated through certain channels over time among the members of a social system" (Rogers, 1962, p. 5).

The principal characteristic of diffusion theory, as applied in demography, is that it explains regional persistences in attitudes towards family life and childbearing as a result of the diffusion of 'new information' (Aries, 1980; Caldwell, 1982; Lesthaege, 1983; Knodel, 1977; Knodel \& Van de Walle, 1986). Fertility behaviour is thus regarded as a learned behaviour, as opposed to behaviour that is completely guided by biological incentives or structural conditions, adaptive to the information that is available. New information can be introduced through direct interaction with other individuals via social learning and social pressure, or through institutions such as for example mass media or the church (Rogers, 1962; Brown, 1981; Montgomery \& Casterline, 1993; Bongaarts \& Watkins, 1996; Rosero-Bixby \& Casterline, 1993). ${ }^{43}$

The information that is transmitted between geographical areas does not only reflect knowledge of birth control methods, but also values, preferences or attitudes towards parenthood which were before unknown or not strongly present. Diffusion models have been applied in many scientific areas since the mid-twentieth century, such as agriculture, medicine and public health, political science, technological innovations in general and demography (Ryan \& Gross, 1943; Green, 2009; Geroski, 2000; Casterline, 2001; Cleland \& Wilson, 1987). Diffusion models help to extend existing theories of demographic behaviour, while some go as far as to argue that diffusion theory can provide a full substitute for economic or social explanations of behavioural change (e.g. Cleland \& Wilson,

increase their children's fertility or child survival rates (Hawkes, 2003; Hawkes et al., 1998). The grandmother hypothesis has received strong empirical support (Sear \& Coall, 2011), although the pro-natal effects of the couple's parents may differ between paternal and maternal parents (cf. Euler \& Weitzel, 1996; Pollet et al., 2007; Sear et al., 2003; Strassmann \& Garrard, 2011; Voland \& Beise, 2002) or are conditional on the family's social class (Johow \& Voland, 2012). The influence of co-resident mothers on their daughters fertility outcomes in the Netherlands is examined in chapter 2 of this thesis.

${ }^{43}$ Caldwell (1976) also emphasizes mass media as a pathway for the spread of new information. He suggests that the exposure to new information provided by mass media results in new behaviour because the perception of children's role in the family is altered by the information being spread. 


\subsection{SOCIAL INTERACTIONS AND THE ROLE OF FAMILY MEMBERS}

1987).

\section{Regional- and individual-level effects}

Diffusion processes have a spatio-temporal dimension when fertility decline in one particular geographical area is 'transmitted' to adjacent areas. ${ }^{44}$ Diffusion theory suggests that when fertility decline occurs in one geographical area, neighbouring regions are likely to also display declining fertility after some time. The decline in fertility can best be viewed as a behavioural innovation which gradually disperses to other, mainly adjacent, areas. Differences in the speed and direction in which such a contagion process occurs may be indicative of accelerating or obstructing factors at the regional level, such as local cultures, language barriers or attitudes towards parenthood. ${ }^{45}$ Local clusters of norms and attitudes regarding parenthood, also referred to as family systems, are further examined below and in chapter 5 .

At the level of the individual, diffusion occurs when people come in contact with innovative behaviour or views through institutions or through interactions with other people. ${ }^{46}$ The significance of the exchange of information, makes that diffusion theory is related to communication theory. The receiving individual will evaluate the information before any real change in fertility outcomes is visible. This evaluation process is an interplay between the individual receiving the information, the sender, and the context in which the exchange occurs. Individuals receiving information may for example consider the position of the sender and how this person may perceive their behaviour, before adjusting their behaviour or preferences (Preston, 1986; Bongaarts \& Watkins, 1996).

Applying this perspective to the family, siblings form a particularly relevant source of new information because they are in most cases of relatively similar age and their role is sustained over the life course (Axinn et al., 1994; Lyngstad \&

\footnotetext{
${ }^{44}$ Diffusion can also occur between social strata, meaning that one social group can act as a forerunner in fertility decline. This phenomenon is not part of this thesis, but a good example of such a 'trickle-down' approach using data on marital fertility in Alghero, Sardinia (1866-1935) is given by Marco Breschi et al. (2014).

${ }^{45} \mathrm{Cf}$. the Princeton Project.

${ }^{46}$ The church and mass media, or friends, family members and co-workers may express preferences or attitudes towards parenthood and childbearing, or provide new information concerning birth control methods (Axinn et al., 1994; Bernardi, 2004). Through social learning, new information or new perspectives on parenthood can be transmitted from one person to another (Bernardi, 2004, p. 535). For example, the frequent observation that the elite were forerunners in the decline of fertility may not only be caused by the particular ways in which people with a higher socio-economic status are adapted to changes in structural conditions, but also because they had access to channels of communication which other social groups had not (Bras, 2014, p. 152). New information however does not only come in the form of useful knowledge, it also originates from changes in the perspectives of other people, e.g. social pressure (see section 1.3.1 on page 28 ).
} 
Prskawetz, 2010). ${ }^{47}$ It is also worth noting that communication between family members is not a one directional process. Furthermore, Gidden's theory of structuration suggests that individual behaviour is shaped by, and interact with social context (Giddens, 1984). This makes individuals at the same time producers and consumers of their social institutions. A person can thus be sending and receiving information at the same time, thereby also affecting the context in which fertility decisions are made.

While diffusion theory provides a useful narrative, its explanatory power has been disputed (Mason, 1992; Burch, 1996; Bongaarts \& Watkins, 1996). In practice it can be very difficult to define or identify 'new information', or to determine whether this new information was truly responsible for triggering a decline in fertility. Granovetter's work on the strength of 'weak ties' suggests that information that is to be diffused may reach a larger number of people through weak ties than strong (Granovetter, 1973). The role of weak ties (dyadic interactions characterized by low emotional intensity, time allocation or minimal reciprocal services) is particularly relevant when people are less motivated to spread information that can be perceived as sensitive, such as ways to reduce the possibility of childbirth. Weak ties are more likely to transmit this kind of knowledge than strong dyadic ties, which may act as 'bridges' and prevent information from reaching the other person. Family members in this regard may not necessarily be the most important drivers of fertility decline through diffusion processes. Perhaps most importantly, diffusion theory addresses the role of information and its evaluation, but overlooks other ways in which people's reproductive behaviours are influenced through social interactions. For example, family members may provide physical or mental support, or be in need of support, and changes in the capability or opportunity costs of support provision may be relevant too for understanding changes in fertility outcomes. This criticism is relevant and must be overcome by a careful consideration of other factors which may be responsible for changes in reproductive behaviour. Nevertheless, diffusion theory can help to better understand fertility processes, by highlighting the role of information and views which are transmitted from one area or person to another, and the context in which interactions between individuals take place.

\footnotetext{
${ }^{47}$ Perceived social approval is another example of a factor which may delay a transition from high to low fertility. Even when new information regarding birth control methods is introduced, or when limiting the number of children born is in the best interest of individuals (consider for example a reversal of Caldwell's wealth flows), social disapproval may still keep fertility rates at higher levels (Bongaarts \& Watkins, 1996, p. 660). An illustration is given by the relatively high fertility levels of early twentieth century Dutch Catholics. While Protestants showed declining fertility rates (indicating that methods to control the number of births were known), the Catholic Church advocated large families, thereby providing a context in which limiting fertility outcomes was not socially accepted among Dutch Catholics (Van Poppel, 1985).
} 


\subsection{SOCIAL INTERACTIONS AND THE ROLE OF FAMILY MEMBERS}

\subsubsection{Family systems as 'cultural moulds'}

As has been described above, kin may influence fertility outcomes through various pathways of interaction. An evolutionary perspective helps to understand the motivations of kin members providing support to each other. From a diffusion perspective, changes in fertility behaviour can be transmitted from one person to another or from one area to the other area. However, the role of the context in which communications take place between individuals and fertility decisions are made has not yet been described carefully enough. The context can mediate the pathways of influence between kin, or the diffusion of fertility between regions.

There is a large variation in how families in Europe are organized (Mönkediek, 2016; Caldwell, 1982; Das Gupta, 1999; Davis, 1955; Hajnal, 1982; Mason, 2001; Skinner, 1997; Therborn, 2004; Todd, 1990, 1985, 2011; Reher, 1998; Kok, 2009). The organization of families results from local norms, values, and practices that lay out expectations and behavioural patterns surrounding kin support and interactions (Opp, 2001). In general, close relationships between kin are observed in Southern Europe, while more loosely knit networks of kin are found in Northern Europe (see Grandits, 2010, and the other volumes in the Kinship and Social Security research project). The organization of families concerns among other things the frequency of contact between kin, the way in which resources are shared among family members, the nature of the relationship between parents and children, household formation rules (e.g. when to marry, where to live when married, who to marry) or arrangements concerning elderly care (e.g. where to live after retirement, retirement contracts between parents and children, and rules of inheritance, see Gaunt, 1983, 1987; Reher, 1998). At the individual level, no two families are similar, but from a wider point of view important differences in the organization of family life can be discerned between geographical regions.

This thesis uses 'family systems' to understand differences in the organization of the family context between European regions. Family systems can be regarded as institutions, or constructions of social norms and values which shape and constrain interactions between people (cf. North, 1990). Family systems are defined as local sets "of beliefs and norms, common practices, and associated sanctions through which kinship and the rights and obligations of particular kin relationships are defined" (Mason, 2001, p. 160). Others simply describe a family system as the "cultural mould [that is] shaping behaviour" (Kok, 2009). ${ }^{48}$ Fam-

\footnotetext{
${ }^{48}$ Another widely used definition of family systems is given by William Skinner; "[A] family system refers to the customary, normative manner in which family processes unfold - that is, the usual, preferred pattern of family practices and household dynamics. It incorporates marriage form(s) and preferences, succession, the transmission of property, the normal sequence of coresidential arrangements, the normative roles associated with family statues and relationships, and the customary bias by gender and relative age that informs the system as a whole." (Skinner, 1997, p. 54).
} 
ily systems are considered here as a cultural setting in which decision-making takes place, going beyond the concept of household formation rules (e.g. Hajnal, 1982). ${ }^{49}$ Family systems are also used in studies on extramarital fertility (Kok, 2009), female agency (Kok, 2017), disparities in social and economic indicators (Duranton et al., 2009), economic performance (Alesina \& Giuliano, 2007; Greif, 2006; Kick et al., 2000), alternative indicators of well-being (Brulé \& Veenhoven, 2014), migration (Kok, 2010), gender systems (Bertocchi \& Bozzano, 2014; Mason, 2001), and the origins of political divergence (Mamadouh, 1999; Todd, 1985, 1990).

Several authors have developed typologies of family systems. Emmanuel Todd $(1985 ; 1990)$ has organised his classification based on the degree of parental authority and sibling equality. David Reher (1998) distinguishes between regions with 'weak' and 'strong' ties between family members, with a particular focus on how societies take care of their elderly citizens. Göran Therborn (2004) has defined world-wide family systems that are geographically anchored to the major continents. This thesis makes use of Emmanuel Todd's typology of family systems, in particular because it is well-developed for Western Europe, displaying considerable regional variation. There are also theoretical connections between reproductive outcomes and the organising principles of this classification, although other works on the institution of the family have expanded on this subject even further (e.g. Therborn, 2004). Todd's family systems are described in chapter 5.

\subsection{Data sources and setting}

\subsubsection{Data sources}

In order to examine the main research questions, this dissertation uses data from a number of different sources. The maps and datasets used are:

Individual level information, the Netherlands:

Data from civil certificates and municipal population registers from the Netherlands for the second half of the nineteenth century is obtained from the Historical Sample of the Netherlands (HSN), Release 2007 (Mandemakers, 2002, 2004). This dataset contains life courses of individuals who have been 'followed' after migration from one municipality to another within the Netherlands. For more information on the data obtained from the HSN, see chapter 2.

\footnotetext{
${ }^{49}$ Although these two concepts are related, household formation rules are more associated with the question who is living together in what stage of their life course, while family systems embody the broader questions of what is meant by family, the nature of their relationships, and the consequences for behaviours - including reproduction.
} 


\subsection{DATA SOURCES AND SETTING}

Individual level information, Sweden:

Parish registers from Sweden are obtained from the Demographic DataBase, Centre for Demographic and Ageing Research (CEDAR), Umeå University. ${ }^{50}$ The longitudinal databases used are POPLINK and POPUM version 4.4.2. ${ }^{51}$ This database contains digitized church records such as registers of birth and baptism, banns and marriage, migration, and death for particular regions (Sundsvall, Skellefteå, Linköping and the Northern Inland). The datasets are linked, allowing to follow people when they migrate to a parish included in the sample. ${ }^{52}$ For more information on the data obtained from the Demographic DataBase, see chapters 3 and 4.

\section{Aggregated fertility data and cartography of Western Europe:}

The Princeton Project fertility indexes are obtained from the Max Planck Institute for Demographic Research (MPIDR) in Rostock and the Chair for Geodesy and Geoinformatics, University of Rostock. ${ }^{53}$ The maps have been enriched by the MPIDR with the Princeton fertility indexes for each historical province in Europe, for the years 1870, 1900, 1930 and 1960. For more information on the Princeton Project's data, see chapter 5 .

Aggregated family systems data and cartography of Western Europe:

A machine-readable map of the distribution of Todd's family systems in Europe, used in chapter 5, is kindly provided by Gilles Duranton et al. (2009). Duranton made two small corrections to Todd's original 1985 map, in accordance with Todd's L'invention de l'Europe (Todd, 1990). The Languedoc region (France) and the Andalucía regions (Spain) are labelled as undetermined on Todd's original map, whereas in his text Todd describes the Languedoc region as incomplete stem family and Andalucía as egalitarian nuclear (Duranton et al., 2009).

Census data, the Netherlands:

Historical census data from the Netherlands in 1899 is provided by CBS StatLine.

\footnotetext{
${ }^{50}$ Data has been made available in the Intermediate Data Structure format (Alter \& Mandemakers, 2014).

${ }^{51}$ Project number U12024. Time period for Skellefteå region: from 1820 to approx. 1950 (POPLINK) and for Linköping, Sundsvall and Northern Inland regions: from 1820 to approx. 1900 (POPUM)

${ }^{52}$ The full list of parishes available is: Linköping region: Björsäter, Grebo, Kaga, Kärna, Landeryd, Rappestad, Rystad, Slaka, St Lars, Vikingstad, Vårdsberg, Värna. Sundsvall region: Alnö, Attmar, Galtström, Hässjö, Indal, Lagfors bruk, Ljustorp, Lögdö, Njurunda, Selånger, Skön/Skönsmon, Sundsvalls stad, Svartvik, Sättna, Timrå, Tuna, Tynderö. Skellefteå region: Bureå, Byske, Jörn, Norsjö, Skellefteå landsförsamling, Skellefteå stadsförsamling, Ytterstfors. Northern Inland region: Föllinge lappförsamling, Föllinge, Frostvikens lappförsamling, Frostviken, Gällivare, Hede lappförsamling, Hotagen, Hotagen lappförsamling, Jokkmokk, Jukkasjärvi, Karesuando, Undersåker, Undersåkers lappförsamling, Vilhelmina.

${ }^{53}$ CGG \& MPIDR Population History GIS Collection, administrative boundaries partly based on EuroGeographics (C).
} 
Cartography of the Netherlands:

A map of administrative boundaries in the Netherlands ca 1899 is obtained from the Netherlands Geographic Information System (NLGIS) shapefiles by Onno Boonstra (2007).

\subsubsection{Setting}

\section{Sweden}

According to the Swedish economic-historian Eli Heckscher, Sweden underwent a 'Great Transformation' between 1815 and 1914 (Heckscher, 1954, p. 209). ${ }^{54}$ The economic development of Sweden began relatively late compared to other countries in Central and Western Europe. Throughout the nineteenth century, iron (manufactures) and timber (and wood products) were the main industrial sectors. The growth of the Swedish industrial sector during the second half of the nineteenth century caused a considerable growth in GDP and the import of foreign capital. Rail roads were also built relatively late, with the first (horse powered) rail road built in Värmland in 1849. However, at the end of nineteenth century steam operated rail roads already reached Northern Sweden, allowing for more swift transportation of goods and people.

Since the population did not grow as fast as the economy, an overall increase in the standard of living took place. Compared to Central- and West-European countries, the population density in Sweden was low. The Swedish population grew from around 3 million in 1840 to almost 6 million in 1920, with the average life expectancy at birth of women increasing from 46 to 63 years during the same period. ${ }^{55}$ The percentage of the population involved in agriculture decreased from $72,4 \%$ in 1870 to $48,8 \%$ in 1910 and 36,2\% in 1936 (Heckscher, 1954, p. 214). ${ }^{56}$

The Sundsvall region (located near the Gulf of Bothnia around 400 kilometres north of Stockholm) and Skellefteå region (around 350 kilometres north of Sundsvall) both grew significantly during the second half of the nineteenth century. The main industries in these regions were iron, timber and farming, with smaller industries such as fishing and glass works near the coast. Sundsvall had around 36.000 inhabitants in 1865 and Skellefteå around 12.200. Linköping and the Northern Inland region were less affected by industrialization. The population in the Northern Inland region at the beginning of the nineteenth century were

\footnotetext{
${ }^{54}$ Heckscher received fame among economists for the Heckscher-Ohlin model of international trade

${ }^{55}$ Source: Statistics Sweden. http://www.scb.se/en/finding-statistics/statistics-bysubject-area/population/population-composition/population-statistics/pong/tablesand-graphs/yearly-statistics-the-whole-country/life-expectancy - last retrieved October 5th, 2018.

${ }^{56}$ Private property of landholdings was common since 1823.
} 


\subsection{OUTLINE OF THE DISSERTATION}

mainly Sámi, but before the mid-twentieth century they became a minority as the population of Sweden began to grow. The stem family, with a relatively high degree of parental authority, was the dominant family system in the coastal area of Northern Sweden during the nineteenth century (Egerbladh, 1989). The diversity of family forms in the inland regions of Northern Sweden was however wider, Todd (1985) refers to the family system in Northern Sweden as 'indeterminate'.

\section{The Netherlands}

Similar to Sweden, the industrial sector in the Netherlands was rather small in size compared to other West-European countries in the first half of the nineteenth century. At that time there were however important regional centres of industry, such as the sugar-refining industry in Amsterdam and the cotton textile industry in Twente. The Industrial Revolution began in the second half of the nineteenth century, causing a slow increase in the standard of living as time went by (Van Zanden, 2009). In 1849 around $43 \%$ of the workforce was involved in agriculture, a share that declined to $23.6 \%$ in 1920 (Wintle, 2000, p. 77). At the end of the nineteenth century, the industry had grown to a level comparable with surrounding countries. The Dutch population grew from almost 3 million in 1840 to around 6.7 million inhabitants in 1920. Life expectancy of women at birth increased from 38 years in 1860 to 63 years in 1920 (Source: CBS StatLine). The absolute nuclear family system is observed in the Northern and Western provinces, and in the Southern and Eastern provinces the stem family is the most dominant.

Dutch fertility rates were among the highest in Western Europe, until fertility rates began to decline around 1880. The pace of fertility decline was however rather moderate. Particular religious groups, mainly the Orthodox Protestant and Catholic churches, upheld pro-family doctrines which rejected methods of birth control (Kok \& Van Bavel, 2006). ${ }^{57}$ Fertility rates showed marked regional differences. Around 1850 the highest fertility rates are observed in the provinces of Zuid-Holland, Zeeland, and Utrecht. Around 1910 however, the highest fertility rates are found in the southern provinces of Noord-Brabant and Limburg.

\subsection{Outline of the dissertation}

Academic approaches to understanding fertility have shifted from descriptive narratives in which modernization processes were found to be key drivers of fertility decline, towards a multidisciplinary body of research ranging from a focus on

\footnotetext{
${ }^{57}$ Kok and Van Bavel (2006) find differences in the impact of religion on fertility between villages and cities. They argue that the controlling effect of religion - i.e. enforcing compliance with Church norms resulting in high fertility rates - was stronger in rural areas than cities because social control was stronger among the members of rural communities.
} 
macro-level factors such as family systems, to evolutionary biology, and to the (social) context in which fertility decisions are made. In this dissertation, hypotheses are derived from three theoretical constructs; evolutionary demography, family systems and diffusion theory. Together, they provide new insights in WestEuropean fertility outcomes at the end of the nineteenth century.

The first aim of this study is to examine in which ways and to what extent fertility outcomes are influenced by family members. The second objective of this study is to understand how family influences on fertility outcomes are shaped by 'family systems'; local norms and values surrounding family and parenthood. In order to answer the main research questions, this thesis includes four thematic chapters on the following topics:

- Kin composition of households and their association with birth intervals

- Intergenerational transmission in fertility outcomes

- Spousal age differences and fertility outcomes

- Family systems and the geographical diffusion of fertility decline

Chapter 2 examines changes and differences in the composition of Dutch households from the second half of the nineteenth century until the beginning of the twentieth century. The aim of this study is to examine the effect of co-resident (non-)kin on the length of birth intervals over the reproductive life course. The study employs data from the Historical Sample of the Netherlands (HSN, Release 2007), a representative, nationwide random sample of about 78,000 individuals born in the Netherlands between 1812 and 1922 (Mandemakers, 2002, 2004). As discussed above, the influence of kin is not necessarily conducive to higher fertility outcomes. By using kin-presence as a proxy for their influence, this chapter shows that couples living with a widowed father of either the husband or the wife were likely to have longer birth intervals compared to couples living with no relatives. In contrast, living together with a brother(-in-law) was associated with shorter birth intervals. These findings indicate that brothers(-in-law) acted as providers of support or resources, while widowed fathers(-in-law) were likely to be in need of support themselves. Interestingly, we found no evidence for the influence of sisters or a grandmother effect (Hawkes et al., 1997, 1998; Hawkes, 2003; Sear \& Coall, 2011).

Chapter 3 focusses on the intergenerational transmission of fertility of women born mostly in Northern Sweden between 1850 and 1889. While previous studies have focussed on either pre-transitional historical or contemporary developing populations, or on post-transitional populations, only few empirical studies have examined evidence of intergenerational fertility transmission during a transition 


\subsection{OUTLINE OF THE DISSERTATION}

phase (e.g. Jennings et al., 2012; Reher et al., 2008). This study uses individuallevel parish records from the POPUM and POPLINK databases of the Demographic Database (CEDAR). The transmission of different fertility outcomes (e.g. age at first birth, total fertility, birth spacing) is examined using a variety of statistical methods (e.g. bivariate correlations, event history analysis). The findings of the study are in line with the rest of the literature and show evidence of positive correlations between fertility outcomes of successive generations.

Chapter 4 examines the complex interplay between age differences, female autonomy, and reproductive outcomes for women born in Central and Northern Sweden between 1840 and 1889. The spouse is regarded as a special type of family; the partners have to go through a fertility decision-making process together and both partners take their own preferences into this decision. The study focusses on the association between age differences between spouses, used as a proxy for their power distance (Bras \& Schumacher, 2019), and timing of first and higher order births, and the total number of children born. This study provides support for the hypothesis that fertility outcomes are influenced by the power distance between husband and wife, although the age of the wife at entry into marriage also plays an important role.

Finally, chapter 5 takes a broad view at the decline of fertility in Western Europe between 1870 and 1960. The main aim of this study is to examine whether family systems are associated with the spatial diffusion of fertility decline in Western Europe between 1870 and 1960. This study uses regionally aggregated fertility measures that have been made available by the Princeton Project (Coale \& Watkins, 1986). In this chapter a diffusion approach is used to test the spatial diffusion of fertility decline, and the mediating role of family systems. It plots the marked variations in fertility decline and draws several theoretical connections between family systems and the speed of fertility change. The findings however do not show a strong connection with family systems, but show instead that fertility outcomes are strongly associated with earlier fertility rates or fertility rates in adjacent regions.

The concluding chapter provides a summary of the findings of this thesis, as well as a discussion of its limitations, suggestions for further research, and policy recommendations. 



\section{Chapter 2}

\section{With the Help of Kin?}

\section{Household Composition and}

Reproduction in The

Netherlands, 1842-1920

This chapter is based on: Rotering, P., \& Bras, H. (2015). With the help of kin? Household composition and reproduction in the Netherlands, 1842 - 1920. Human Nature, 26(1) 



\subsection{INTRODUCTION}

\subsection{Introduction}

Co-resident kin and non-kin may play an important role in human reproduction (Johow \& Voland, 2012; Sear \& Coall, 2011; Tymicki, 2004). Because of the relatively short interval between successive births and the long period during which newborns are dependent on others for their nutrition, parents behave as 'cooperative breeders' (Hrdy, 2007). This means that parents rely on other people alloparents - who provide assistance in the form of care or resources, thereby helping to raise offspring and enabling parents to increase their reproductive outcomes (Hrdy, 1999, 2009; Kramer, 2005, 2010). According to Hamilton's rule, kin assist in producing and raising offspring because of the indirect fitness benefit that this cooperative behaviour yields (Hamilton, 1964a,b). Recent empirical studies, many of which cover observations from contemporary and historical pretransition societies, find that reproductive outcomes are indeed associated with the availability of kin assistance (Pollet et al., 2007; Voland \& Beise, 2002). Research suggests that among the most important caregivers are the couple's parents (Hawkes et al., 1997, 1998; Tymicki, 2004); their children, referred to as 'helpersat-the-nest' (Crognier et al., 2001; Kramer, 2005); and the siblings of the couple (i.e., aunts and uncles of the newborn child) (Draper \& Hames, 2000; Feng et al., 2010; Hill \& Hurtado, 2009; Sear et al., 2003; Sear \& Mace, 2008).

However, empirical results vary because different categories of kin do not always influence fertility in the same manner (Sear \& Coall, 2011). These differential outcomes suggest that the effects of kin help on fertility may be contingent on specific local conditions and economic factors (Hames \& Draper, 2004) or that the effects of kin may vary over the life course of women as they progress from one birth to the next. Yet, few studies have systematically investigated the differential effects of kin on reproductive outcomes over the reproductive life course. Moreover, thus far only some studies have taken account of the influence of a wider group of kin and non-relatives (Bereczkei, 1998; Lyngstad \& Prskawetz, 2010). The large amount of attention that has been given to parental influence has left the role of co-resident siblings, cousins, and non-kin under-explored (Nath et al., 2000; Snopkowski \& Sear, 2013; Voland \& Beise, 2002). One of the main reasons for the omission of the wider group of kin and other co-residents in many studies is the scarcity of sources that encompass detailed information on both the reproductive behaviour of the couple and changes in the presence of kin and non-kin within the household over longer periods of time.

In this study, we exploit data on changes and differences in the composition of Dutch households from the second half of the nineteenth century until the beginning of the twentieth century in order to examine the effect of co-resident 


\section{CHAPTER 2. HOUSEHOLD COMPOSITION}

(non-)kin on the length of birth intervals over the reproductive life course. Focusing on sequential fertility outcomes over the life courses of the women in our sample allows for a more accurate investigation of kin effects than examining kin influences on total fertility or starting and stopping behaviour. We use a rich data source, the Historical Sample of the Netherlands, which enables us to uncover the direction, magnitude, and significance of the effects of co-resident kin and non-kin on the reproductive careers of Dutch women born between 1842 and 1920. We develop our hypotheses on kin effects on fertility using insights from inclusive fitness theory.

Inclusive fitness theory is derived from evolutionary biology and concerns the natural selection of traits, such as altruism, which increase the genetic success of an organism (Hamilton, 1964a,b; Hrdy, 2007; Mace, 2014). The main assumption of inclusive fitness theory is that humans - as do all species - strive to allocate their resources, including support, knowledge, and time, in such a way that they maximize their inclusive fitness, expressed as the number of kin weighted by the relative presence of one's genes, or alleles (Hamilton, 1964a,b; Hrdy, 2007). In general, inclusive fitness theory thus suggests that people are driven to increase the fertility of their lineal and collateral kin in order to ensure the persistence of their genes in future generations. As long as the marginal benefits and costs of such assistance are in equilibrium, alloparental care giving is likely to positively affect the number and survival chances of a person's relatives and thus confers an indirect fitness benefit (Grafen, 1984). It follows that if couples can rely on close kin members for support, they are more likely to raise more and/or betterquality children than couples who are not helped by kin (Kaptijn et al., 2010; Kramer, 2010; Salmon \& Shackelford, 2008; Schaffnit \& Sear, 2014). Inclusive fitness theory has thus been invoked to help understand the relatively long postgenerative life span of women. The 'grandmother hypothesis' suggests that even though post-menopausal mothers no longer reproduce, they can still contribute to their inclusive fitness by providing resources or care to their children and grandchildren, thereby enabling them to increase their fertility or child survival rates (Hawkes, 2003; Hawkes et al., 1997, 1998). The grandmother hypothesis has received strong empirical support (Sear \& Coall, 2011), although the pro-natal effects of the couple's parents may differ between paternal and maternal parents (cf. Euler \& Weitzel, 1996; Pollet et al., 2007; Sear et al., 2003; Strassmann \& Garrard, 2011; Voland \& Beise, 2002) or are conditional on the family's social class (Johow \& Voland, 2012).

We extend our analysis of kin influence beyond the couple's parents by also taking into account the effects of the presence of the couple's siblings, other relatives, and household members who have no genetic relationship to the couple. 


\subsection{INTRODUCTION}

Based on inclusive fitness theory, we depart from the broad hypothesis that all close kin will behave cooperatively and exert a positive influence on reproduction. We posit that the higher the degree of genetic relatedness, the more stimuli people have to increase their relatives' fertility. Genetically close relatives (e.g., the couple's parents or siblings) are expected to behave more cooperatively - leading to shorter birth intervals - than genetically more distant relatives (e.g., the couple's aunts and uncles). In addition, uncertainty about the degree or non-existence of genetic relatedness lowers the likelihood of cooperative behaviour. The 'confidence of paternity hypothesis' predicts that investments in grandchildren are lower if they are related through sons than through daughters (Strassmann \& Garrard, 2011). Moreover, the incurred fitness benefit of cooperative behaviour toward kin is possibly lower for fathers of the wife or husband, as there may be a component of uncertainty regarding the genetic bond with their offspring. For this reason, we hypothesize that mothers of the couple - in particular, maternal mothers - have a more pronounced positive effect on a woman's fertility than fathers of the couple have (Sear \& Mace, 2008). Accordingly, living with both parents or having a widowed mother will be associated with shorter birth intervals compared with living with a widowed father. The couple's siblings are hypothesized to have a positive effect on reproductive outcomes because of their genetic relation to the couple (Bereczkei, 1998; Feng et al., 2010). Finally, household members with no genetic relation to the couple are, from an evolutionary perspective, less likely to affect reproductive outcomes because their fitness is not affected by this behaviour.

Although the presence of kin is hypothesized to be associated with shorter birth intervals in general, the effects of kin on fertility may vary over the reproductive life span of the women in our sample. Kin effects are hypothesized to be stronger for the early parities than for later parities for three reasons. First, drawing on Lyngstad and Prskawetz (2010), the first, formative years of the family mark a unique transition in the life course of the young couple. Alloparental support in the early years could be important in compensating for inexperience among new parents, learning about the nutritional needs of newborns, or supplying the extra resources needed to feed an additional mouth. Second, local cultural norms concerning kinship and fertility may affect the likelihood of living together with kin before the couple is able to establish their own household. Skinner refers to this particular process as a 'launching-pad family system' in which living with parents is common in the first few years after the couple is married, and the newly formed couple establishes their own independent household only after this initial co-resident phase (Skinner, 1997). When the couple lives with the parents for longer periods of time, economic conditions or health concerns of the elderly parents, who are likely less able to provide support, may be the main motivation 


\section{CHAPTER 2. HOUSEHOLD COMPOSITION}

for kin co-residence (Pebley \& Stupp, 1987). Lastly, women who do not constrain their reproduction are not likely to be affected by the presence of others who are in a position to provide pro-natal support. The intrinsic motivation or biologically heritable specific fecundity of these women is by itself enough to ensure short birth intervals while the presence of kin likely does not affect their fertility at all.

In the next section, we discuss our sample, measurements, and methods. Subsequently, we present the results of our event history analysis showing to what extent the presence of particular kin and non-kin in the household was related to the timing of subsequent births. In the final section, we discuss our findings in light of the recent literature, our hypotheses, and the data and methods used.

\subsection{Data, Measurements, and Methods}

\subsubsection{Co-Residence with kin in the Netherlands}

The composition and size of nineteenth-century Dutch households varied considerably across regions and over time (Bras et al., 2010a; Kok \& Mandemakers, 2009; Kok et al., 2011). Kin co-residence in the Netherlands during the period of our analysis was primarily driven by altruistic motives to help kin, in particular those who were in need of help, and by rational motives, in particular in the eastern regions where co-residence was associated with inheritance practices (Kok \& Mandemakers, 2010). In her study on the dynamics of family structure in the textile town of Tilburg, Janssens (1993) concluded that poverty was not the sole reason for kin co-residence during the formative years of the family life cycle. In many cases, co-residence with immediate family occurred because it was the most practical option, for example, following a failed migration, the death of a parent, or because of the contributions kin could make to the household budget. The 1899 census indicates that 5.1 million Dutch individuals lived in about one million households, with household sizes ranging from 4.6 to 4.9 persons in the north-western coastal provinces to 5.1 to 5.5 persons in the eastern provinces of Limburg, Gelderland, Overijssel, and Drenthe (Central Bureau of Statistics). In the north-western provinces, the nuclear family, or neolocal household formation, was the norm and most couples did not live together with their parents (Van der Woude, 1977). Only in urban centres such as Amsterdam, Rotterdam, and Haarlem were households larger on average. The prevalence of co-resident kin was highest in the eastern provinces, and households in those regions were also much more likely to include persons who were not genetically related to the couple, such as boarders, servants, or lodgers (Kok \& Mandemakers, 2010). In terms of household size, the other provinces ranged somewhere in between (Fig. 2.1). Over 


\subsection{DATA, MEASUREMENTS, AND METHODS}

time, co-residence with kin became less common in the Netherlands, in particular in the cities from the early twentieth century onward (Bras et al., 2010a).

\subsubsection{Data}

The data used in the analysis were obtained from the Historical Sample of the Netherlands (HSN, Release 2007). The HSN is a representative, nationwide random sample of about 78,000 individuals (called 'research persons') born in the Netherlands between 1812 and 1922 (Mandemakers, 2002, 2004). The main sources of the HSN are civil certificates and municipal population registers, which were established by royal decree on December 22, 1849. As of January 1, 1850, all municipalities began to keep population registers, based on the census of 1849 , on a dynamic, continuous basis. Since 1861, all Dutch citizens are obligated to report events for recording in the population registers. Professional civil service workers were hired to maintain the registers. The main advantage of the HSN for our study is that people are followed from the cradle to the grave; individual life histories are not censored when individuals moved to another place in the Netherlands because their migration is recorded in the population registers. In addition, the date and place of birth or death, marital status, sex, religion, occupation, and relation to the head of the household are recorded for all members of the household. The exact date when a household member entered or left, due to birth, death, or migration, is known, including a reference to the place of origin or destination. From these registers, life courses have been reconstituted until 1939 when the registers were replaced by a system of personal cards. While the quality of the HSN is high and the observations in principle cover the entire country, there are some limitations to its use (Bras, 2014; Knotter \& Meijer, 1995; Van Poppel et al., 2012; Vulsma, 1988).

First, maintenance of the population registers required all municipalities to continuously update the records, and when a person moved from one place to another, information had to be copied from other registers. This was not always done accurately (Knotter \& Meijer, 1995; Vulsma, 1988). Second, since the nationwide registration of vital events started on January 1, 1850, the HSN does not include many complete life histories of women born before this date. Consequently, data from the 1860s and 1870s will mostly cover women born in the $1850 \mathrm{~s}$ who had their first child at a relatively young age, causing a downward bias in the age at first birth for the earliest cohort. However, for the purpose of our analysis, this bias does not alter our conclusions on the effects of kin on the length of the interval between births. Third, the HSN is in continuous development, and data before 1883 has only been digitized for three provinces (Zeeland, Utrecht, and Friesland) and one city (Rotterdam). From 1883 on, the HSN has national cov- 
Figure 2.1: Average household size, the Netherlands 1899

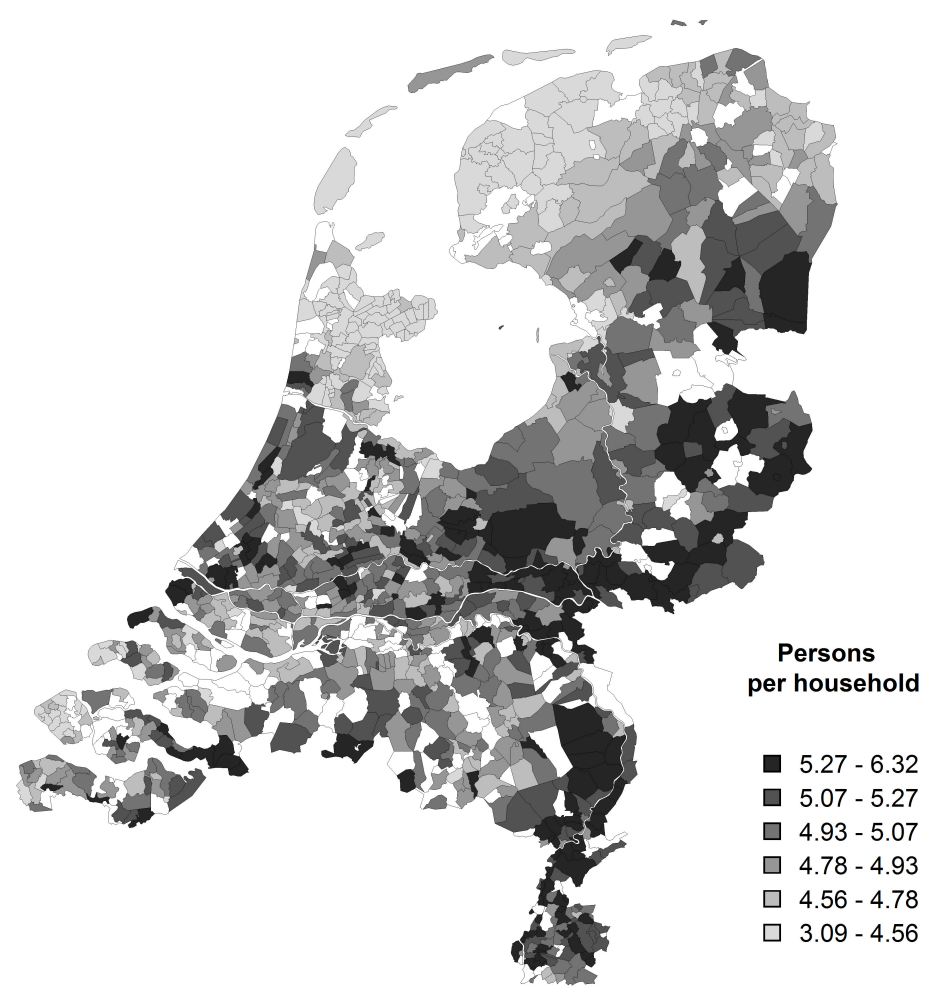

Number of persons per municipality, divided by the number of households per municipality. Data: Census 1899 (Central Bureau of Statistics). Cartography: NLGIS map of the Netherlands 1899 (Boonstra, 2007).

erage, and information is available for all 11 provinces. This gives the analytical sample we extracted from the HSN an urban bias and explains why the percentage of farmers and farmworkers $(21.6 \%$ ) is relatively small (Bras, 2014; Van Poppel et al., 2012). Fourth, owing to the nature of the registers, our observations of kin are limited to those residing with the couple and exclude relatives living outside of, but in close vicinity to the couple's house. This implies that the frequency of contact with others might have been higher in reality than is observed based on the presence of kin and non-kin in the household. Nevertheless, we assume that the presence of co-resident kin allows for frequent contact and is therefore a good and reliable measure of the availability of kin (Feng et al., 2010; Morgan \& Rindfuss, 1984; Schaffnit \& Sear, 2014; Snopkowski \& Sear, 2013; Tsay \& Chu, 2005).

For our analytical sample, we have selected couples $(N=2,628)$ who entered 


\subsection{DATA, MEASUREMENTS, AND METHODS}

a first marriage and for whom complete information is available about (1) the couple's reproductive career until the woman is 50 years old and the husband is still alive and (2) the presence of kin and non-kin in the household. We focus only on the waiting time from the first until the second marital birth and on subsequent birth intervals but exclude the interval between marriage and first birth. The interval between marriage and first birth was often relatively short and in many cases not affected by kin presence, but instead by cultural norms which prescribed that the conception of the first child should follow not too long after marriage (Liefbroer \& Jong Gierveld, 1995). Focusing on the interval between first and second or subsequent births reduces the possible influences of such cultural norms. Our analytical sample includes 2331 couples who had at least two children and 8052 closed birth intervals connecting to childbirths that took place between 1869 and 1939.

\subsubsection{Outcome variable}

Our outcome variable is the duration of the interval between first and subsequent live, marital births - i.e., parity two and up - measured in months. The birth interval is a useful indicator of fertility and is widely used in the literature on reproduction (e.g. Nath et al., 2000; Van Bavel \& Kok, 2004, 2010; Van Poppel et al., 2012; Van Bavel, 2004). As in most nineteenth- and early-twentieth-century Northwest-European societies, fertility within marriage was generally regulated by prolonged breastfeeding, periodical or complete abstinence, coitus interruptus, and, to a lesser extent, abortion (Santow, 1995). Birth spacing was part of the set of means to regulate fertility and was usually motivated by a desire to control family size. Life-cycle models of reproductive behaviour indicate that variations in household income or expenditures resulting from the birth of children may produce an imbalanced ratio between 'consumers' and 'producers' in terms of household income or labor, resulting in economic stress and thereby necessitating fertility regulation (see e.g. Alter, 1988; Heckman \& Walker, 1990; Hotz et al., 1997). Underlying our hypotheses is the assumption that, from an evolutionary perspective, shorter birth intervals and an increase in child survival rates increase the fitness of women and the inclusive fitness of kin (Morgan \& King, 2001). However, reproduction is energetically costly to women and could jeopardize their health as well as that of their offspring, leading to a trade-off between quantity and quality of children (Borgerhoff Mulder, 2000; Conde-Agudelo et al., 2006, 2007; Palloni \& Millman, 1986). Therefore, optimal birth intervals may be of intermediate length to ensure a sufficient number of offspring without exposing women and their offspring to excessive risk.

Table 2.1 reports the mean length of closed birth intervals by parity and for 
Table 2.1: Mean length of birth interval in months by parity and mean total number of children, by birth cohort of the wife

\begin{tabular}{lllllllr}
\hline $\begin{array}{l}\text { Birth cohort } \\
\text { wife }\end{array}$ & \multicolumn{6}{l}{$\begin{array}{l}\text { Length of birth interval by parity } \\
\text { (in months) }\end{array}$} & $\begin{array}{r}\text { Total number } \\
\text { of children }\end{array}$ \\
& 2 & 3 & 4 & 5 & 6 and up & Mean $^{\mathrm{a}}$ & \\
All & 27.8 & 28.9 & 28.5 & 27.5 & 25.7 & 27.6 & $4.56(2.78)$ \\
$<1860$ & 25.1 & 26.1 & 27.6 & 25.8 & 27.2 & 26.4 & $5.71(2.66)$ \\
$1861-1870$ & 24.9 & 26.7 & 26.9 & 26.4 & 26.0 & 26.1 & $5.14(2.73)$ \\
$1871-1880$ & 23.8 & 26.9 & 27.2 & 27.0 & 24.0 & 25.5 & $5.34(2.70)$ \\
$1881-1890$ & 26.4 & 29.0 & 27.6 & 27.8 & 26.0 & 27.1 & $5.31(3.23)$ \\
$1891-1900$ & 29.8 & 30.4 & 31.2 & 29.7 & 26.3 & 29.4 & $4.20(2.60)$ \\
$>1900$ & 29.7 & 30.3 & 28.7 & 26.0 & 21.6 & 28.8 & $2.93(1.32)$ \\
\hline
\end{tabular}

(a) Excluding the interval between marriage and first birth.

(b) Number of living children observed at last birth (standard deviation in parentheses).

Source: Historical Sample of the Netherlands, release 2007.

all births, as well as the total number of living children by birth cohort. Our sample covers the early period of fertility decline, between 1890 and 1920; the Dutch fertility transition was completed between 1920 and 1940 or even later in some regions (see Bras, 2014). The average number of living children per woman declined over time, most strikingly since the 1881-1890 birth cohort. In line with Van Poppel et al. (2012), the mean length of birth intervals in our sample increased most significantly after the last quarter of the nineteenth century, from 26.4 months for women born before 1860 to 28.8 months for women born in 1901 or later. As Table 2.1 shows, this was in particular due to an increase in the length of the early parities, suggesting that spacing was increasingly used as a strategy to control childbirth, although stopping altogether (rather than delaying) was the main cause of Dutch fertility decline (Van Poppel et al., 2012). When we compare birth intervals over the life course, we observe that earlier cohorts (e.g., before 1860) experienced birth intervals that were increasing in length over the reproductive life span. In contrast, women born after 1900 had increasingly shorter birth intervals over their life courses and stopped having children sooner.

\subsubsection{Independent variables}

We include the presence of one or more of the following kin and non-kin types as independent variables (all are relative to the couple): (1) parents; (2) siblings; (3) other relatives, such as cousins, aunts, and uncles; and (4) non-kin (servants, 


\subsection{DATA, MEASUREMENTS, AND METHODS}

boarders, and lodgers). Since couples may live only part of their reproductive lives together with others, all kin and non-kin are coded as time-varying dummy variables with value 0 (not present) or 1 (at least one person of that particular kin type is present in the household of the couple). Table 2.2 provides descriptive information about the different variables used in the models, by parity. Coresidence with kin occurred frequently in the Netherlands, but during the life course of the couples in our sample, many relatives left the household. There were hardly any differences in the proportion of couples living with relatives of the husband or with relatives of the wife. Around a quarter of all couples lived with both parents of either the husband or the wife during the second parity (the interval between first and second birth). Over the life course, the share of couples living with both parents or with widowed parents of either spouse decreased to less than $10 \%$ and less than $5 \%$, respectively. Co-residence with siblings was as common as living with parents. Here too, we observe no difference between relatives of the husband and relatives of the wife in terms of the share of households where these kin types lived, although co-residence with siblings of the wife occurred slightly more frequently in the highest parities (from the birth of the fifth child on). Co-residence with other types of kin (e.g., aunts or uncles of the couple) was less common and occurred in less than $5 \%$ of all cases for the first parity and decreased to around $1 \%$ for the highest parities. In our sample, co-residence with non-kin, such as servants or boarders, did not occur frequently. Servants were present in around $1 \%$ of all households and boarders were present in only a handful of cases. The share of households with non-kin did not vary significantly over the life course of the women in our sample.

Table 2.2: Descriptive statistics for variables used in the analysis, by parity

\begin{tabular}{|c|c|c|c|c|c|c|}
\hline \multirow[t]{2}{*}{ Variable } & \multicolumn{5}{|c|}{ Parity (Percentages) ${ }^{\mathrm{a}}$} & \multirow[t]{2}{*}{$F$ test $^{\mathrm{b}}$} \\
\hline & 2 & 3 & 4 & 5 & $>5$ & \\
\hline
\end{tabular}

Household characteristics

Kin present

$\begin{array}{lrrrrrl}\text { Wife, both parents } & 25.2 & 19.5 & 15.4 & 12.6 & 9.8 & * * * \\ \text { Wife, only father } & 9.8 & 9.4 & 7.1 & 6.8 & 4.1 & * * * \\ \text { Wife, only mother } & 6.5 & 6.8 & 6.1 & 5.8 & 4.5 & * \\ \text { Husband, both parents } & 24.5 & 20.1 & 16.6 & 13.1 & 8.5 & * * * \\ \text { Husband, only father } & 10.0 & 9.2 & 8.3 & 7.3 & 4.7 & * * * \\ \text { Husband, only mother } & 5.4 & 5.9 & 4.3 & 4.2 & 2.5 & * * *\end{array}$


CHAPTER 2. HOUSEHOLD COMPOSITION

Table-2.2: Continued from previous page

\begin{tabular}{|c|c|c|c|c|c|c|}
\hline \multirow[t]{2}{*}{ Variable } & \multicolumn{5}{|c|}{ Parity (Percentages) ${ }^{\mathrm{a}}$} & \multirow[t]{2}{*}{$F$ test $^{\mathrm{b}}$} \\
\hline & 2 & 3 & 4 & 5 & $>5$ & \\
\hline Wife's sister(s) & 26.1 & 20.4 & 17.6 & 15.1 & 10.5 & $* * *$ \\
\hline Husband's sister(s) & 27.4 & 22.0 & 18.1 & 13.6 & 7.9 & $* * *$ \\
\hline Wife's brother(s) & 27.1 & 22.5 & 18.0 & 16.0 & 11.9 & $* * *$ \\
\hline Husband's brother(s) & 27.3 & 21.9 & 18.9 & 15.6 & 8.4 & $* * *$ \\
\hline Other female kin & 4.3 & 3.4 & 3.2 & 2.7 & 1.2 & $* * *$ \\
\hline Other male kin & 4.2 & 3.8 & 3.3 & 2.7 & 1.7 & $* * *$ \\
\hline Servant(s) & 1.0 & 1.0 & 1.0 & 1.2 & 1.1 & \\
\hline Boarder(s) & 0.4 & 0.3 & 0.3 & 0.3 & - & \\
\hline \multicolumn{7}{|l|}{ Community characteristics } \\
\hline Nuclear & 60.4 & 59.0 & 57.4 & 57.0 & 53.4 & \\
\hline Stem & 15.4 & 15.9 & 16.4 & 17.1 & 18.7 & \\
\hline Intermediate & 24.2 & 25.1 & 26.2 & 26.0 & 27.9 & \\
\hline Urban & 67.6 & 65.6 & 64.0 & 63.1 & 62.0 & \\
\hline \multicolumn{7}{|l|}{ Religion } \\
\hline Both Roman Catholic & 25.4 & 28.4 & 30.0 & 32.3 & 35.6 & \\
\hline Both Liberal Protestant & 15.4 & 14.8 & 15.2 & 14.4 & 12.9 & \\
\hline Both Orthodox Protestant & 31.3 & 31.1 & 30.6 & 29.4 & 28.0 & \\
\hline Mixed Catholic and Protestant & 7.3 & 7.5 & 6.6 & 7.6 & 8.8 & \\
\hline Mixed Protestant & 12.7 & 11.9 & 12.0 & 11.1 & 9.9 & \\
\hline Other or unknown religion & 7.9 & 6.3 & 5.6 & 5.2 & 4.7 & \\
\hline \multicolumn{7}{|l|}{ Occupation of husband } \\
\hline Higher manager & 2.2 & 1.4 & 1.5 & 1.2 & 1.1 & \\
\hline Lower manager ${ }^{c}$ & 17.8 & 16.0 & 15.4 & 14.2 & 12.7 & \\
\hline Foremen or skilled worker & 19.6 & 20.0 & 19.6 & 19.3 & 19.7 & \\
\hline Farmer or fisher & 9.1 & 9.8 & 10.5 & 10.8 & 11.9 & \\
\hline Lower skilled worker & 17.3 & 16.4 & 15.8 & 15.9 & 13.9 & \\
\hline Unskilled worker & 15.1 & 16.5 & 16.4 & 16.4 & 15.4 & \\
\hline Lower or unskilled farmworker & 12.5 & 13.5 & 14.6 & 15.1 & 17.4 & \\
\hline Unknown occupation & 6.4 & 6.3 & 6.1 & 7.2 & 7.9 & \\
\hline
\end{tabular}

Individual characteristics

Birth cohort wife

\begin{tabular}{lccccc}
$<1860$ & 6.4 & 8.7 & 10.6 & 11.4 & 10.2 \\
$1861-1870$ & 8.2 & 9.4 & 10.6 & 12.5 & 11.8 \\
\hline & \multicolumn{5}{c}{ Table-2.2: Continued on next page }
\end{tabular}


Table-2.2: Continued from previous page

\begin{tabular}{|c|c|c|c|c|c|}
\hline \multirow[t]{2}{*}{ Variable } & \multicolumn{4}{|c|}{ Parity (Percentages) ${ }^{a}$} & \multirow[t]{2}{*}{$F$ test $^{\mathrm{b}}$} \\
\hline & 2 & 3 & 4 & 5 & \\
\hline $1871-1880$ & 10.2 & 12.3 & 14.4 & 15.1 & 15.3 \\
\hline $1881-1890$ & 20.7 & 22.2 & 25.0 & 26.5 & 33.6 \\
\hline 1891-1900 & 26.7 & 25.3 & 24.0 & 23.2 & 23.1 \\
\hline$>1900$ & 27.8 & 22.0 & 15.4 & 11.3 & 6.0 \\
\hline \multicolumn{6}{|l|}{ Age distribution wife } \\
\hline$<25$ & 42.7 & 27.4 & 14.4 & 5.9 & 0.5 \\
\hline $25-29$ & 39.2 & 43.0 & 42.9 & 36.7 & 14.4 \\
\hline $30-34$ & 15.0 & 23.6 & 32.0 & 38.9 & 36.8 \\
\hline $35-39$ & 2.3 & 4.9 & 8.7 & 15.1 & 31.5 \\
\hline$>39$ & 0.4 & 0.6 & 1.3 & 1.8 & 10.9 \\
\hline \multicolumn{6}{|l|}{ Previous infant died } \\
\hline Within 8 months & 4.4 & 4.2 & 4.7 & 4.7 & 4.5 \\
\hline After 8 months & 0.8 & 1.6 & 1.7 & 2.0 & 2.4 \\
\hline \multicolumn{6}{|l|}{ Age gap spouses } \\
\hline Wife older & 21.5 & 21.3 & 21.4 & 19.1 & 15.5 \\
\hline Husband $<6$ years older & 63.8 & 64.3 & 63.2 & 65.5 & 69.2 \\
\hline Husband $>6$ years older & 14.6 & 14.5 & 15.4 & 15.3 & 15.2 \\
\hline Mean age wife (years) & 26.1 & 27.8 & 29.5 & 31.1 & 34.6 \\
\hline Mean duration of marriage (years) & 2.1 & 4.0 & 5.9 & 7.8 & 12.0 \\
\hline Births $(\mathrm{N})$ & 2,331 & 1,727 & 1,204 & 867 & 1,923 \\
\hline
\end{tabular}

(a) Percentages rounded to the nearest tenth, unless otherwise stated.

(b) Anova $F$ test for difference between parity, kin presence only. Significance thresholds: $\dagger \mathrm{p}<0.1, * \mathrm{p}<0.05, * * \mathrm{p}<0.01, * * * \mathrm{p}<0.001$

(c) Lower manager, cleric or sales person.

Source: Historical Sample of The Netherlands, release 2007

We control for several community-level characteristics. Based on population size and the percentage of the population working in agriculture, we indicate whether the household was located in a rural or urban setting. Owing to the over-representation of urban areas in the HSN, in particular for the earlier cohorts, more than half of all households are categorized as urban. Regional differences in social norms and attitudes toward kinship are captured by a categorical variable indicating the family system in the region of the household. Family systems are connected to the composition of households, the strength of kin ties, the inheritance of property, and norms and values regarding family relations and life 


\section{CHAPTER 2. HOUSEHOLD COMPOSITION}

course events (Bras et al., 2010a; Hilevych \& Rotering, 2013; Kok et al., 2011; Todd, 1985). The north-western coastal provinces, where partible inheritance was practised and kin ties were relatively weak compared with other regions, are coded as nuclear family systems. The south-eastern provinces are coded as stem family systems because of the occurrence of impartible inheritance, or Anerbenrecht, and the specific customs with regard to co-residence in which young couples 'married in' and became part of the parental household. The remaining provinces are coded as intermediate family systems (Bras \& Van Tilburg, 2007).

At the individual level, we include the birth cohort of the wife to account for the general trend of fertility decline and increasing lengths of birth intervals over time, as discussed above. A woman's age is one of the main determinants of fecundity and coital frequency, and thus connected to the duration of parity progression (Van Bavel \& Kok, 2004). In order to control for age effects, we include the age of the wife and the duration of marriage at childbirth. Both are expected to be associated with increasing birth intervals. Larger power differences between husband and wife have been linked to increased reproductive success (Bereczkei \& Csanaky, 1996; Voland \& Engel, 1990), and therefore we include categories for the age difference between husband and wife, coded as 0 (husband 0 to 5 years older), 1 (husband more than 5 years older), and 2 (wife older), as a crude proxy for power distance between spouses. We control in all models for the total number of children born, including deceased children. The premature death of the previous child may induce a replacement effect and thus may shorten the time to conception of the next child (Derosas, 2006; Knodel, 1982; Van Bavel \& Kok, 2004, 2010). In addition, since breastfeeding delays the return to ovulation, a child's survival somewhat decreases a woman's chance of becoming pregnant (Santow, 1987). To control for these effects, we control for the death of the previous child within 8 months after birth or after 8 months since birth.

The HSN includes information on the religion of both husband and wife, which allows for coding all combinations of religious denominations as categorical dummy variables. The following categories are discerned, following Van Bavel and Kok (2004; 2005): liberal Protestants, orthodox Protestants, Catholics, 'mixed', and 'other'. The first category, liberal Protestants, includes the majority of moderate and liberal schools in the Dutch Reformed Church and the liberal Protestant churches, such as Mennonites, Lutherans, and Remonstrants. When both spouses fall under this category, the couple is classified as liberal Protestant. The second category, orthodox Protestants, contains couples in which one or both spouses were members of the Calvinist church or belonged to the orthodox denomination in the Reformed Church. The third category, Catholic, is composed of couples in which both spouses were members of any Catholic denomination, such as Roman 


\subsection{DATA, MEASUREMENTS, AND METHODS}

Catholics, Old Catholics, and Free Catholics. The fourth category, 'mixed', comprises couples where one spouse was Catholic and the other liberal or orthodox Protestant. The last category, 'other', contains couples who were Jewish, who belonged to a liberal secessionist denomination, for whom no religious affiliation was specified, or who had no religion (Bras et al., 2010b; Bras, 2014). Because orthodox Protestant and Catholic denominations were more stringent in following doctrine and were generally more likely to reject modern forms of birth control, we presume birth intervals for these groups to have been shorter compared with more liberal or moderate denominations (Van Bavel \& Kok, 2005).

The social class of the household is based on the occupation of the husband as registered in the marriage certificate. If the occupation was missing, it was taken from the population registers. These occupations are coded using the HISCO classification system, a catalogue of historical occupations that corresponds to the International Standard Classification of Occupations. The HISCO codes are then categorized according to the HISCLASS scheme, following Van Leeuwen et al. (2004), into the following categories: (1) higher managers and professionals, (2) lower managers and professionals, including clerks and salesman, (3) foremen and skilled labourers, (4) farmers and fisherman, (5) semi-skilled labourers, (6) unskilled labourers and farm labourers, and (7) unknown occupation. Previous research has shown that the middle and upper classes were the first to postpone childbirths, whereas birth intervals among farmers decreased between 1890 and 1920. Over time, however, the length of birth intervals converged among all social classes (Bras, 2014).

\subsubsection{Methods}

We use an event history approach to examine whether the lengths of women's closed birth intervals were associated with the presence of kin and non-kin in their households (Cleves et al., 2010). Event history analysis, also known as survival or duration analysis, models the effects of covariates on the time until the occurrence of a particular event. The chance of the event occurring in the next period is expressed as a coefficient that is dependent on the shape and height of the baseline hazard function. Since the composition of the household continuously changes as people move in and out, our kin covariates are timevarying. The ability of survival analysis to accommodate this type of data makes it a very useful technique. We focus on the effects of kin on the length of birth intervals and model the effects of kin on the transition from the first living child to the next birth, from the second living child to the next birth, and so on. We fit Cox proportional hazard models to examine the effect of the presence of different types of household members on parity progression risk. The Cox proportional 


\section{CHAPTER 2. HOUSEHOLD COMPOSITION}

hazard models take the following form

$$
h\left(t \mid x_{j}\right)=h_{0}(t) \cdot \exp \left(\beta_{x} X_{j}\right)
$$

where $h\left(t \mid x_{j}\right)$ denotes the hazard rate, or the chance of having a next birth, in period $\mathrm{t}$ for the specified vector of time-varying covariates, $h_{0}(t)$ is a non-negative and unspecified baseline hazard function that varies arbitrarily over time and is not dependent on the covariates $X_{j}$, and $\beta_{x}$ is a vector of unknown regression coefficients to be estimated from the data using maximum likelihood (Cleves et al., 2010). Given that we consider the effect of kin on time until next birth using a sample of closed birth intervals, the cumulative hazard rate increases over time until it is equal to one and all women have given birth. The Cox proportional hazards model allows for estimating the relative hazard rate of women in different groups - for example, living with or without particular types of kin. Both groups have the same baseline hazard at time $t$, but the magnitude of the hazard is multiplied by the exponentiated regression coefficient of each group. Time is measured in months, and a coefficient larger than zero denotes a higher chance of giving birth in period $t$, or in other words, a shorter birth interval.

The Cox model assumes that the estimated hazard ratios are proportional to each other. The assumption of proportionality was tested by examining the Schoenfeld residuals and the proportionality of the log-log plot of the survival rate against the log of time for each variable. These pre-analysis tests indicated that the baseline hazard should be allowed to vary between religions for all models, which ensures that we can still provide reliable estimates for the effects of kin on the hazard rate of childbirth in the period $t$, although the effect of religion is left unspecified. For parity six and up, we estimate one model for all births after the fifth birth and control for net parity, which is the total number of living children at time $t$. In order to ensure proportionality of hazards in this model, we included additional time-varying effects for marriage duration and the death of the previous infant if they survived until they were at least 8 months of age.

Another important assumption of the Cox model is that the risk of parity progression in the sample is randomly distributed across observations. However, since birth intervals are by their nature clustered on the level of the couple, it is likely that parity progression risks are not completely random and the hazard ratio may thus be conditional on the individual frailty of each couple (Cleves et al., 2010). When specifying multiple parities or when a couple has experienced the loss of a previous child, and thus would be observed two or more times in the analysis of a particular parity progression rate, this may be a cause for concern. Testing for the significance of the estimated frailty variance revealed that it was not necessary to include an individual frailty component for each couple. Nevertheless, 


\subsection{RESULTS}

a robust estimation of variance is recommended given the clustered nature of our observations (Lin \& Wei, 1989). Goodness of fit was evaluated by examining the Cox-Snell residuals against the Nelson-Aalen cumulative hazard function (Cleves et al., 2010; Cox \& Snell, 1968). Our analysis is robust for variations in sample size across both geographical areas and time.

\subsection{Results}

Table 2.3 provides parameter estimates for the multivariate Cox proportional hazards model by parity. Column 1 contains the results for the time until the birth of a next child, since the birth of the previous child, for all couples who had one living child. Column 2 provides estimates for the length of the birth interval for all couples who had two living children, and so on. The births of children after the fifth living child (parity six and up) are grouped in one Cox proportional hazards model in which the number of living children is controlled for. All models include control variables for unreported household and community-level characteristics.

Our results indicate that for later-order births, from parity six and up, coresidence with kin was not significantly associated with longer or shorter birth intervals. For lower parities, living with both parents of either the husband or the wife did not affect the time until next birth, although living with the husband's parents had a small delaying effect on the birth of the fourth child. In contrast, living with a widowed father of either spouse significantly reduced parity transition rates. The birth intervals of women living with a widowed father were about twice as long as birth intervals of women who did not live with a widowed father. Conversely, living with a widowed mother in the household did not significantly affect time until next birth, with the exception of the fourth parity in the case of a husband's widowed mother.

The length of time between births was at least $20 \%$ shorter for women who lived with at least one brother or brother-in-law, compared with women who did not live with a brother or brother-in-law in the same household. The positive effect of the presence of the husband's brother was particularly high for women experiencing the transition from the third to the fourth child, for whom the parity transition rate was almost twice as large as for other parities. Strikingly, in contrast to living with brothers, living with sisters of either of the spouses did not significantly affect parity transition rates. 


\section{CHAPTER 2. HOUSEHOLD COMPOSITION}

Table 2.3: Estimated coefficients for the effects of kin presence in the household on the likelihood of second or later-order marital births by parity

\begin{tabular}{lccccc}
\hline Variables & Parity & & & & \\
& 2 & 3 & 4 & 5 & 6 and up \\
\hline
\end{tabular}

Household characteristics

Kin variables ${ }^{\mathrm{a}}$

Wife, both parents

$\begin{array}{lllll}-0.077 & -0.089 & -0.082 & 0.153 & 0.140\end{array}$

Wife, only father

Wife, only mother

$-0.765^{* * *}-0.784^{* * *}-0.475^{* *}-0.949 * * *-0.292$

Husband, both parents

$-0.141$

$-0.123$

$-0.012$

$-0.271$

$-0.025$

Husband, only father

$-0.034$

0.093

$-0.262^{*}$

0.068

0.172

Husband, only mother

$-0.680^{* * *}-0.697^{* * *}-0.893^{* * *}-0.452 \dagger \quad-0.203$

Wife's sister(s)

$-0.165$

$-0.022$

$-0.511^{* *}-0.273 \dagger$

0.106

Husband's sister(s)

$-0.061$

$0.153 \dagger$

$-0.029$

0.115

$-0.047$

Wife's brother(s)

0.011

$-0.120$

$0.204 \dagger$

$-0.118$

0.136

$0.182^{*}$

$0.242^{* *} \quad 0.239 *$

0.087

$-0.028$

Husband's brother(s)

$0.115 \dagger$

$0.298^{* * *} \quad 0.549 * * *$

$0.270^{*}$

$-0.137$

Other female kin present

$-0.023$

0.192

$-0.236 \dagger$

0.050

0.083

Other male kin

0.014

$-0.039$

0.008

$-0.008$

$-0.009$

Servant(s)

0.099

$0.482 * * \quad-0.045$

$0.526 \dagger$

$0.761^{* * *}$

Boarder(s)

$-0.399$

$-0.429^{*}$

$0.939^{* * *} \quad 1.945^{* *}$

\section{Individual characteristics}

Previous infant died

$<8$ months
$>8$ months
$>8$ months $*$ time $^{\mathrm{b}}$

$$
\begin{array}{r}
0.329^{*} \\
-0.396^{*}
\end{array}
$$

$$
0.630^{* * *} \quad 0.243
$$

$0.303^{*}$

$$
\begin{array}{rrr}
0.630^{* * *} & 0.243 & 0.027 \\
-0.475^{* * *} & -0.820^{* * *} & -0.146
\end{array}
$$

$-1.737 * * *$

Birth cohort wife ${ }^{\mathrm{c}}$

\begin{tabular}{llllll}
$<1860$ & -0.125 & 0.010 & 0.075 & 0.183 & $-0.208^{*}$ \\
$1861-1870$ & -0.108 & 0.031 & 0.050 & 0.040 & $-0.235^{*}$ \\
$1881-1890$ & $-0.262^{* *}$ & -0.132 & -0.021 & -0.086 & $-0.365^{* * *}$ \\
$1891-1900$ & $-0.423^{* * *}$ & $-0.239^{* *}$ & $-0.238^{*}$ & $-0.243 \dagger$ & $-0.429^{* * *}$ \\
$>1900$ & $-0.627^{* * *}$ & $-0.487^{* * *}$ & $-0.466^{* * *}$ & $-0.421^{* *}$ & $-0.487^{* * *}$ \\
Marriage duration (in years) & $-0.058^{* * *}$ & $-0.092^{* * *}$ & $-0.119^{* * *}$ & $-0.084^{* * *}$ & $-0.069^{* * *}$ \\
Marriage duration $>18$ years ${ }^{\mathrm{d}}$ & & & & & $0.354^{* *}$ \\
\hline
\end{tabular}

Table-2.3: Continued on next page 


\subsection{RESULTS}

Table-2.3: Continued from previous page

\begin{tabular}{lccccc}
\hline Variables & Parity & & & & \\
& 2 & 3 & 4 & 5 & 6 and up \\
\hline $\begin{array}{l}\text { Crude parity } \\
\text { Net parity }\end{array}$ & 0.021 & $0.239^{* * *}$ & $0.246^{* * *}$ & $0.241^{* * *}$ & $0.091^{* *}$ \\
& & & & & 0.038 \\
Births (N) & 2,331 & 1,727 & 1,204 & 867 & 1,923 \\
Couples (N) & 2,331 & 1,727 & 1,204 & 867 & 629 \\
Observation periods (N) & 4,048 & 2,918 & 1,904 & 1,286 & 3,414 \\
\hline
\end{tabular}

Cox proportional hazards models, coefficients reported. Cluster robust standard errors, adjusted for dependence among births of the same couple, stratified on religion, Breslow approximation for tied survival times. A positive sign indicates a shorter birth interval for the associated covariate. All models control for occupation, religion, urbanization, community characteristics, age, and spousal age gap.

$\dagger \mathrm{p}<0.1, * \mathrm{p}<0.05, * * \mathrm{p}<0.01, * * * \mathrm{p}<0.001,-$ not present

(a) Reference: none present.

(b) Reference: none present.

(c) Reference: 1871-1880.

(d) Square root of marriage-duration after 18 years of marriage.

Source: Historical Sample of The Netherlands, release 2007.

Other types of co-resident kin, such as aunts or uncles, had no systematic effect on the duration of the transition to the next birth. The presence of non-kin did affect birth intervals, but their effect was not stable over the reproductive life course. The presence of servants affected only the waiting time until the birth of the third child and the birth intervals of fifth and later-order children. Co-resident boarders and lodgers had a significant delaying effect on the birth interval for the third parity, but shortened the birth interval for the fourth and fifth parity. Keeping in mind the low number of observations of non-kin in our sample, these findings should be interpreted with care.

The time until next birth was longer for couples who were married for a longer period of time, as was expected. However, for women who had at least six children, we observe that parity transition rates increased after 18 years of marriage compared with women who were married for less than 18 years. Crude parity indicates the total number of children that have been born to a woman. As would be expected, women who had experienced a larger number of pregnancies had shorter intervals between births. Similar to findings by Van Bavel and Kok (2004; 2010), parity transition rates of women whose last child died before it was 8 months old were significantly higher than those of women whose last child survived. The death of the previous infant at 8 months of age or later delayed the 


\section{CHAPTER 2. HOUSEHOLD COMPOSITION}

birth of a next child, although after 24 months the chance of having a next birth was significantly higher. In line with the observations presented in table 2.1, birth intervals were longer for women born in later cohorts compared with those born in the reference period 1871-1880.

\subsection{Discussion}

In human behaviour, as in the behaviour of other animals, the provision of support to genetically related kin is expected to confer an indirect advantage in terms of inclusive fitness (Hamilton, 1964a,b; Hrdy, 2007, 2009; Gurven et al., 2001). It follows that couples who can rely on close kin members for support are more likely to raise more or better-quality children than couples who are not surrounded by close kin (Kramer, 2010; Salmon \& Shackelford, 2008). In this study we have investigated whether the presence of co-resident kin and non-kin affected the length of birth intervals for 2,628 Dutch women born between 1842 and 1920. Our point of departure was the broad hypothesis that, on the basis of inclusive fitness theory, all close kin members would exert a positive influence on reproductive outcomes by enabling the women in our sample to have shorter intervals between births. The effects of kin on fertility were expected to be positively associated with the strength of the genetic bond between kin, whereas genetically more distant kin would have a minor effect on reproduction. Furthermore, kin influences were hypothesized to be stronger during the first, formative years of the family when alloparental support could compensate for the inexperience among new parents learning about the nutritional needs of newborns or for the extra work needed to feed an additional mouth.

Using continuous-time data on household composition as a proxy for cooperative behaviour, we find that co-resident kin had different effects on fertility at different stages of the reproductive life span of women. The effects of kin were not significant for higher parities. This finding may provide a partial explanation for the variations in kin effects on fertility that have been observed in the literature in which only measures of complete fertility outcomes are taken into account (see Sear \& Coall, 2011, for an extensive overview of the literature). However, without knowledge of the distribution of resources and care among household members over time, it is difficult to infer from our data why the effects of kin were only significant in the early parities. As Lyngstad and Prskawetz (2010) argue in their study of Swedish sibling pairs born in the mid-twentieth century, the decrease of kin influences might be attributable to uncertainties around the process of entering parenthood, but possibly also to changes in both the different roles of kin within the household and their ability to provide the couple with any 


\subsection{DISCUSSION}

form of support.

Our findings suggest that co-resident kin did not affect reproductive outcomes of Dutch women in a uniform way. In contrast to other empirical findings, we find that parity progression rates were not significantly affected by the presence of widowed mothers or both parents of either spouse (Hawkes et al., 1998; Hawkes, 2003; Pollet et al., 2007; Voland \& Beise, 2002). The absence of a positive 'grandmother effect' regarding the length of birth intervals is also observed in other studies (e.g. Hill \& Hurtado, 2009). However, Dutch women who lived with their widowed father or the widowed father of their husband experienced significantly longer birth intervals than women living without a widowed father. Whereas some studies have shown no effect of fathers on fitness outcomes (Borgerhoff Mulder, 2007; Sear \& Coall, 2011), in others a negative effect of fathers on their daughters' reproductive behaviour has been observed, in particular in relation to offspring survival chances (Kemkes-Grottenthaler, 2005). Our findings concerning the delaying effect of co-resident widowed fathers on parity progression provide support for the confidence of paternity hypothesis, which suggests that uncertainty over genetic relatedness will lower the extent of cooperative behaviour to offspring (Strassmann \& Garrard, 2011). However, on its own this hypothesis has received little empirical support in explaining differences in the influence of parents on demographic outcomes (Euler \& Weitzel, 1996; Pashos \& McBurney, 2008). The delaying effect of widowed fathers might also be attributable to the notion that fathers consumed a relatively large share of the couples' resources, especially care, for themselves while providing the couple with little support or few pro-natal incentives (see also Kemkes-Grottenthaler, 2005). Recent empirical studies show that kin effects are indeed modified by conflicts over resources (Borgerhoff Mulder, 2007; Schaffnit \& Sear, 2014). ${ }^{1}$ With regard to siblings, our findings indicate that the presence of brothers, but not the presence of sisters, was positively associated with parity progression. This observation suggests that the additional resources that brothers brought into the household had enabling effects on couples' reproductive outcomes (Becker, 1981; Becker \& Barro, 1988; Feng et al., 2010).

Our study contributes to the growing literature on empirical approaches to evolutionary theories of demographic behaviour. The findings presented here raise further questions concerning the role and position of kin members within the household as well as the extent of their cooperative behaviour, such as provisioning of care or contributions to household income, which is difficult to infer from kin

\footnotetext{
${ }^{1}$ The evolutionary approach provides a narrow perspective on the multitude of factors which affect the individual's perceived constraints and preferences regarding fertility outcomes, such as the availability and distribution of resources, power and cultural expectations regarding the provision of reciprocal support.
} 
presence alone (see e.g. Schaffnit \& Sear, 2014). In addition, owing to the nature of the HSN data, our observations are limited to household members, but kin living outside the household may also have affected the women's reproductive careers (Johow \& Voland, 2012). These issues further complicate the connection between the assumptions on which our hypotheses are based and our findings. Although people may receive fitness benefits from higher reproductive outcomes of their kin, shorter birth intervals are not by definition in the woman's interest and in fact may lower the quality of offspring (Borgerhoff Mulder, 2000; CondeAgudelo et al., 2006, 2007; Palloni \& Millman, 1986). Nonetheless, our findings do clearly indicate that the presence of widowed fathers and brothers affected parity progression rates, leading to the conclusion that reproductive outcomes were subject to the distribution of resources and care within the household.

Inclusive fitness theory enables us to understand the motives underlying the behaviour of household members toward genetically related others, but actual demographic outcomes are determined by the specific historical, social, economic, and spatial conditions of the household, as well as maternal health and the extent of cooperative behaviour of kin that enables women to give birth. Future research on the interaction between wealth and kin influence, or differences in cultural norms concerning kinship and reproduction, which lie beyond the scope of this study, may further illuminate variations in the influence of kin on reproductive outcomes. 


\section{Chapter 3}

\section{Intergenerational \\ Transmission of}

Reproductive Behaviour in Sweden, 1850-1889

This chapter is based on: Rotering, P. (2017). Intergenerational Transmission of Reproductive Behavior in Sweden, 1850-1889. Historical Life Course Studies, 4 , 181-202 



\subsection{INTRODUCTION}

\subsection{Introduction}

The intergenerational transmission of reproductive behaviour has received considerable attention from demographers in recent decades (Axinn et al., 1994; Bernardi \& White, 2010; Bittles et al., 2008; Bras et al., 2013; Dahlberg, 2013; Fasang \& Raab, 2014; Jennings et al., 2012; Kolk, 2014a; Murphy, 1999, 2013b,a; Murphy \& Knudsen, 2002; Murphy \& Wang, 2001; Van Bavel \& Kok, 2009). Many studies on family formation emphasize the effects of kin members and experiences in early life on later life reproductive behaviour (Bras et al., 2013; Sear et al., 2003). Parents undeniably play an important role in shaping the behaviours and views of their children concerning matters of childbearing. Correlations, though weak, between fertility levels of parents and children have been observed in a wide range of contemporary, post-transitional populations. In contrast, in pretransitional populations with relatively high fertility and mortality rates, there is little evidence for the transmission of reproductive behaviour from parents to children (Desjardins et al., 1991; Gagnon \& Heyer, 2001; Murphy, 1999).

While most studies focus on pre-transitional historical or contemporary developing populations, or on contemporary post-transitional populations, the aim of this study is to examine the occurrence of intergenerational transmission of fertility during a period of demographic transition, similar to Jennings et al. (2012) and Reher et al. (2008). Using parish register data, life courses are reconstructed for women born in Sweden between 1850 and $1889(N=8,172)$. During the period of this study, Sweden underwent a fertility transition, as birth rates fell from around 33 births per 1,000 individuals in 1860 to around 13 per 1,000 in 1930 . This study provides further insight into the extent of intergenerational fertility transmission in the context of Sweden during this demographic transition in the second half of the nineteenth century, by examining several different indicators of reproductive outcomes, such as age at first birth, the number of children ever born and birth spacing. The effects of parental fertility outcomes on these indicators are compared to other studies on fertility transmission.

The following section provides a summary of the mechanisms used to explain childbearing continuities over generations, followed by an overview of the recent literature on the intergenerational transmission of fertility behaviour. In the subsequent section, hypotheses are formulated on the basis of the literature. The sections thereafter introduce the data, methods and measures before presenting the results. Finally, the outcomes of this study are discussed in light of the recent literature. 


\subsection{Background}

\subsubsection{Parental influences on family formation}

Parents are likely to play an important role in shaping the views of their children on matters concerning parenthood. Previous research has indeed consistently observed correlations between reproductive outcomes of parents and children, although there is little correlation observed in historical, pre-transitional populations (Murphy, 1999). Before further describing the findings of recent literature in greater detail, we first briefly consider three mechanisms behind the transmission of reproductive behaviour which are addressed in the literature: shared genetic dispositions (Bras et al., 2013; Fisher, 1930; Rodgers et al., 2001), shared environmental factors such as the transmission of socio-economic status (Barber, 2001; Jennings \& Leslie, 2013) and childhood socialization (Anderton et al., 1987; Axinn et al., 1994; Bernardi, 2004, 2013).

In both of the earliest studies (Fisher, 1930; Pearson et al., 1899), as well as more recent studies (Bras et al., 2013; Kohler et al., 1999), genetic dispositions are used to explain intergenerational childbearing continuities. Accordingly, intergenerational transmission is either a consequence of physical conformation caused by biological advantages or limitations to producing offspring, or resulting from genetic predispositions towards larger or smaller family sizes (Kohler et al., 1999; Miller et al., 1992; Rodgers et al., 2001). These genetic predispositions include psychological traits, such as childbearing motivations, causing similarities in fertility behaviour between parents and children (Miller et al., 1992). Studies have shown that the degree to which genetic effects are expressed, depends on the interplay between social norms and economic constraints. In other words, reproductive outcomes depend on how genes interact with the environment (Low, 2015; Udry, 1996). Kohler et al. (1999) for instance observe strong intergenerational fertility transmission for Danish women born during the nineteenth-century demographic transition, as well as the late 1950s and early 1960s. They argue that the heritability of fertility was expressed more during these decades in particular because individual choice was less constrained and deliberate fertility decisions could be made more freely. In contrast, they found weak transmission for female cohorts born at the turn of the twentieth century. During this period, economic crises and the First World War formed shared environmental effects which were more relevant for fertility outcomes than heritable factors operating through individual choice. Fertility outcomes were not transmitted from parents to children when individual choice was constrained. Similar effects have been observed by Bras et al. (2013) in their study on nineteenth-century Dutch siblings. 


\subsection{BACKGROUND}

Fertility transmission is also explained in the literature by the transmission of social status (Bengtson, 1975; Anderton et al., 1987; Jennings \& Leslie, 2013). Status transmission may cause the life courses of parents and children to be shaped by similar constraints and opportunities, causing their beliefs, values and behaviours to be alike. The effect of social status transmission on reproductive behaviours, such as age at marriage and the timing of first childbirth, is shown to vary between social classes, religious denominations, genders and regions (Murphy, 1999, 2013a,b; Van Bavel \& Kok, 2009; Van Poppel et al., 2008). However, as these studies also show, intergenerational continuities in reproductive outcomes are not completely explained by socio-economic control variables (Murphy \& Knudsen, 2002; Murphy \& Wang, 2001, 2003).

The third explanation, social influences of parents on the reproductive behaviour of their children, has received broad attention from the work of Duncan et al. (1965) and more recently Bernardi (2004; 2013). Duncan et al. (1965, p. 508 ) observed "that family size has a tendency to run in families". They suggested that the childbearing behaviour of parents influences the reproductive preferences of their children through childhood socialization. In other words, people who had many siblings were more likely to prefer having more children themselves because such behaviour was observed from their parents. Later work by Thornton (1980) showed that not only the behaviour but also the values of parents regarding childbearing, represented by their statements about the ideal size of a typical family, had a positive effect on their children's expectations regarding the size of their own family (cf. e.g. Axinn et al., 1994; Axinn \& Thornton, 1996). Using a qualitative, socio-demographic perspective, Bernardi $(2004 ; 2013)$ describes the socialization mechanisms through which children adopt parental values and norms regarding family and fertility. Both direct and indirect socialization mechanisms can be distinguished. Direct, or primary, mechanisms are the use of rewards and punishments to make children adopt what parents see as appropriate behaviour. Direct mechanisms are forms of explicit support or control (Smith, 1988). In contrast, through indirect, or implicit, socialization children reproduce the behaviour and roles set by their parents when they formulate their own views on what constitutes parenthood (Duncan et al., 1965; Thornton, 1980). Bernardi and Klärner (2014) use the term 'social learning' to describe the idea that children learn from the actions and behaviours of other people, as well as the consequences of these actions. Early life experiences of growing up in a large family can produce awareness of the consequences of having a large family for physical and mental resources. Such awareness, stemming from early life experiences, may affect fertility decisions in later life. 


\subsubsection{Intergenerational continuities in childbearing}

The above section describes three commonly mentioned mechanisms explaining intergenerational childbearing continuities. While genetic dispositions, status transmission and childhood socialization explain part of the observed fertility transmission, the explained variation is often low and the association between reproductive outcomes and explanatory variables is weak, leaving a large role for other factors to determine the fertility of the children's generation (Kolk, 2014a,b). In an extensive survey of the literature, Murphy (1999) points out three main characteristics of childbearing continuities observed in empirical studies. First, the association between reproductive outcomes of parents and children appears to be almost null for historical, pre-transitional or contemporary developing populations. The association however increased over time, and for post-transitional populations the correlation is significant and positive (cf. Murphy, 2012). Furthermore, although the relationship may seem fairly weak (Pearson correlation coefficients observed in the literature range from 0.06 to 0.2 ), the impact is as large as that of employment status or education levels (Murphy, 1999; Murphy \& Wang, 2001). Second, some studies suggest that the birth order of children affects to what extent their reproductive behaviour is correlated to their parent's reproductive behaviour. Third and last, the observed correlations are in most cases somewhat higher for the family of the wife compared to the husband's family of origin (Murphy, 1999).

Recent demographic studies focusing on the intergenerational transmission of reproductive behaviour generally confirm Murphy's (1999) observations. Studies employing data from pre-transitional populations, either historical or contemporary developing populations, show no or weak correlations between reproductive outcomes of parents and children. An exception is Pluzhnikov et al. (2007) who find a positive Pearson correlation coefficient of 0.31 for the total number of children born for men and their parents, and a positive correlation of 0.23 for women and their parents. Their study is based on data from the traditional Hutterite population, known for its high natural fertility rates. In a study using data from the Dutch Caribbean in the 19th and 20th century, Jennings and Leslie also find that women and men from larger families were more likely to have more children themselves. However, other indicators of childbearing continuities, for instance age at first or last birth, provide less consistent results. Furthermore, the extent of transmission differed along gender and race, suggesting that individuals who had a broader range of choices available regarding reproduction were more likely to display a higher correlation with fertility outcomes of their parents (Jennings \& Leslie, 2013). Using family reconstitution data from English parishes between the sixteenth and nineteenth century, Langford and Wilson (1985) find no correlation between fertility of daughters and their mothers, except for one parish. Gagnon 


\subsection{BACKGROUND}

and Heyer (2001) also find that the intergenerational correlation of completed family size is almost zero for French-Canadian settlers in the seventeenth and eighteenth century. These studies show that there is mixed evidence for intergenerational transmission of reproductive behaviour in pre-transitional populations where birth and death rates are high.

A key condition for the transmission of reproductive behaviour seems to be a fertility transition, marked by the occurrence of a persistent fall in birth rates. Several studies focus on the transmission of reproductive behaviour during a fertility transition. For example, Vogl (2016) uses micro data from 48 contemporary developing countries and observes that the transmission of reproductive outcomes increased only as country-level birth rates declined. Similar patterns are observed in studies using data from historical populations. Using data on descendants of Utah pioneers of the mid-nineteenth century, Jennings, Sullivan and Hacker (2012) observe an increase in the correlation for indicators of reproductive behaviour between generations. During the period of their study, marital fertility rates declined from 11.0 in the pre-1850 birth cohort to 7.2 in 1890-1899 birth cohort (Jennings et al., 2012). Similarly, Bras, Van Bavel and Mandemakers (2013) find evidence for an increase in intergenerational transmission of fertility over the course of the Dutch fertility transition in the nineteenth century. Reher, Ortega and Sanz Gimeno (2008) also find that the transmission of fertility behaviour increased over the course of the demographic transition in 19th century Spain. However, the increased correlation in their study is evident only for indicators of completed family size, but not for the timing of reproductive events.

Studies on post-transitional populations generally show a positive correlation between reproductive behaviour of two, or in some cases three generations (Barber, 2001; Booth \& Kee, 2009; Kim, 2014; Kotte \& Ludwig, 2012; Lyngstad \& Prskawetz, 2010; Rijken \& Liefbroer, 2009; Tropf et al., 2015). There is some evidence for regional variations in the degree of transmission, which is partly explained by the strength of social relationships between family members (Bernardi, 2004, 2013; Mönkediek et al., 2017). The increased availability of data since the twentieth century also allows for the use of innovative methods for studying the intergenerational transmission of fertility. Fasang and Raab (2014) for example use sequence analysis to examine family formation and childbearing patterns over the life course of twentieth-century Americans. They observe that the strength of the emotional bond between parents and children, as well as educational upward mobility, explains intergenerational patterns of reproduction. In another study, using twentieth-century Finnish register data, Raab et al. (2014) show that reproductive outcomes also exhibit similarities among sibling dyads. Other recent studies make use of data on twins to examine the exogenous effects of ad- 


\section{CHAPTER 3. INTERGENERATIONAL TRANSMISSION}

ditional childbirths or to differentiate between genetic and shared environment effects (Bras et al., 2013; Kohler et al., 1999; Kolk, 2015; Tropf et al., 2015).

With regard to Sweden, a considerable number of studies makes use of twentiethcentury Swedish population register data to study the intergenerational transmission of fertility. Most of these studies observe significant positive correlations between reproductive outcomes of parents and children. For example, Stanfors and Scott (2013) find that Swedish women born between 1970 and 1989 were more likely to start childbearing at young age if their mothers had their first child at a relatively young age, also when controlling for education and employment. Dahlberg (2013) finds a positive correlation between the number of children born for mid-twentieth century Swedish index persons and their parents, although a higher correlation is observed between index persons and their siblings. Kolk (2014a) also finds that completed fertility outcomes are positively, though weakly, correlated between individuals and their parents. Additionally, he observes that reproductive outcomes of index persons are also associated with those of their grandparents, aunts and uncles. In another study, Kolk observes that the transmission, measured as the association between parental family size and the timing of first and later births, can partly be explained by intergenerational continuities in education and socio-economic status, although other factors - including the transmission of values and preferences regarding family size - are more important (2014b). The causal effect of having another sibling on fertility outcomes is further examined in Kolk (2015). He finds that the birth of younger twin siblings as an exogenous source of additional siblings is not strongly related to completed fertility. While people from larger families do tend to have more children themselves, Kolk (2015) argues that the observed fertility correlations in post-transitional countries are more connected to preferences shared by parents and their children regarding fertility behaviour, such as the timing of having children or preferences regarding family size. The studies on twentieth-century Sweden thus show that fertility outcomes are explained by family of origin, and that the transmission may work to through different channels. The above overview of the literature confirms Murphy's (1999) observation that there is little evidence for intergenerational transmission of reproductive behaviour in historical or contemporary pre-transitional populations. Although there are exceptions, e.g. Pluzhnikov et al. (2007), positive correlations between fertility outcomes of parents and children are more likely to be observed in transitional or post-transitional populations (Murphy, 1999). 


\subsection{BACKGROUND}

\subsubsection{Fertility decline in nineteenth century Sweden}

The Swedish demographic transition took place in the second half of the nineteenth century. The crude death rate began to decline in 1810 from a high, pre-transitional level of about 30 deaths per 1,000 individuals, with considerable yearly fluctuations, to around 11 deaths per 1,000 in 1940. The crude birth rate started to decline around 1860 and reached a post-transitional level by around 1930, marking the completion of the demographic transition. The Swedish population grew from around 2.3 million in 1800 to 3.5 million individuals in 1850 and 5.1 million in 1900 (Statistics Sweden).

Studies on family formation in Sweden during the nineteenth century show that marriages were characterized by considerable equality between men and women. The Marriage Act of 1734 banned forced marriages and equal inheritance rights for men and women were formalized by the Civil Code of 1845 (Lundh, 2003). However, parents did remain influential in the choice of a suitable partner. For members of the farming community, the motivation behind the parents' influence is particularly clear. Equal inheritance rights could risk the continuation of the family farm if the lands were split after marriage (Dribe \& Lundh, 2005). By marrying a partner of equal wealth, families could make financial arrangements in order to ensure that landholdings remained intact. Moreover, parents would rely on their children for their retirement, so it was important that the farm could support them as well at older ages. These influences of the parents on the choice of a suitable partner are also visible in legislation. The father acted as a guardian for his unmarried daughters, and parents had the right to disinherited their children, daughters as well as sons, if they married against their parents' will (Lundh 2003).

Within marriage, reproductive health concerns motivated birth control during the second half of the nineteenth century (Kling, 2010). The average number of children born remained relatively high, but evidence suggests that couples used birth spacing as a strategy for family planning. Bengtsson and Dribe (2006) and Kolk (2011) show that Swedish couples did not necessarily limit fertility in order to achieve a desired family size, but spaced their births in reaction to socioeconomic conditions. Birth control within marriage became more common during the nineteenth century as the intervals from marriage to first birth, and first to higher order births became longer over time (Junkka \& Edvinsson, 2015).

Agriculture was the main source of income in Sweden until the middle of the nineteenth century. In some areas, such as Tuna parish, iron mining industries provided employment to a large part of the population (Low, 1991; Low \& Clarke, 1991). After around 1850, industrialization occurred rapidly and the expansion of foreign trade brought about growth in the small, open economy of Sweden 
(O'Rourke \& Williamson, 1995; Edvinsson \& Nilsson, 2000). With the exception of the capital of Stockholm, Swedish towns were small compared to other WesternEuropean countries (Alm-Stenflo, 1994; Schön, 1997). The percentage of people living in cities of more than 5,000 inhabitants increased from around 6.8 percent in 1850 to 19.3 percent in 1900 in Sweden, while the average percentage in Europe increased from 16.4 percent to 30.4 percent in the same period (Bairoch \& Goertz, 1986).

\subsubsection{Hypotheses}

According to the literature, there is little evidence for positive fertility transmission in historical, pre-transitional populations. In contrast, post-transitional populations show positive, although weak, correlations between fertility outcomes of parents and children. Most studies explain the observed correlation in posttransitional or contemporary populations by the wider range of choices available to young couples in shaping their reproductive career (e.g. Jennings \& Leslie, 2013) (e.g. Jennings \& Leslie 2013). Given that this study is based on a sample from a population undergoing a transition from high to low fertility levels, it is hypothesized that fertility outcomes are positively associated with the family of origin (H1).

The assumption is that a period of fertility transition is marked by a change in behaviours and attitudes towards reproductive choices. Nonetheless, since most studies find only weak positive effects, with Pearson correlations ranging from 0.06 to 0.2 , the observed correlations are likely to be similarly small. Murphy (1999) observes a greater influence of the mother's family of origin than of the father, although he acknowledges that this finding may be based on a highly selected population (Murphy, 1999, p. 142). Given the nature of Swedish marital relationships at the end of the nineteenth century, characterized by equality between partners, it is hypothesized that there are no or little differences in childbearing continuities between the husband's and wife's family of origin (H2). Finally, although highlighted by Murphy (1999), this paper does not focus on birth order effects.

Previous studies on fertility transmission have focused on different indicators of reproductive behaviour, such as completed fertility (e.g. the number of children ever born), the timing of first birth, the length of birth intervals between subsequent childbirths and age at last birth (cf. e.g. Jennings et al., 2012; Kolk, 2014a; Reher et al., 2008). To facilitate discussion and comparison with other studies, this study includes multiple measures of fertility outcomes, and information on the families of origin of both the wife and the husband. 


\subsection{Data, Measurements and Methods}

\subsubsection{Sample construction}

This study uses data from the POPUM and POPLINK databases from the Demographic Database (DDB, CEDAR). The Demographic Database data is based on church registers which contain information from household registers, birth and baptism records, banns and marriage records, death and burial books and information on migrations (Alm-Stenflo, 1994; Jeub, 1993; Westberg et al., 2015). The data includes information on the relationships between individuals (e.g. parentchild or husband-wife), which facilitates the linking of people over generations. The DDB sample used for this study contains basic demographic information for Swedish individuals born between 1820 and 1920 in a selected number of parishes, mostly in the Northern regions of Sundsvall and Skellefteå. Not all parishes in these regions are included in the DDB sample that was available for this study.

From the DDB sample, a selection is made of first-married women born between 1850 and 1889 who have given birth to at least one child. These individuals form the basis of the analytical sample and are referred to as 'index persons'. First, all index persons are linked to their spouses using the relationship indicators available in the sample. The links given in the data between index persons and their spouses are evaluated using the date of marriage and date of first childbirth. For instance, if the date of first childbirth of her spouse was not registered on the same day, it is likely that the spouse had children from a previous marriage or that the spouse was not correctly linked. In such rare cases, the woman is excluded from the analytical sample. Index persons who migrated into a parish that is included in the DDB sample after their eighteenth birthday, meaning they were not observed in the data before their eighteenth birthday, are also excluded from the analytical sample.

Individual life histories are constructed for each individual index woman starting from her birth until the end of the observation period. The life events recorded for each individual are: her birth date, birth date of her spouse, date of first marriage, all childbirths including stillborn children and the end of the observation period. The end of the observation period is defined by her own death, the death of her spouse, marriage dissolution, or migration into a parish not registered in the sample for a period longer than three years. Since the DDB data covers multiple parishes, it is sometimes possible to follow individuals after migration as long as the destination parish is included in the sample. The time span from the date of birth of each individual to the end of the observation period is referred to as the time during which a person is followed, or under observation. The period 
during which index persons are followed thus depends on the date of the end of observation and some people are followed only for a few years after marriage.

Next, each individual woman, or index person (G2), is linked to both her own parents and to her parents-in-law (G1). Life histories are reconstructed for the parents and parents-in-law in a similar way. For each index person, mother and mother-in-law in the analytical sample, the following indicators of reproductive behaviour are created:

- Age at each childbirth

- Age at first marriage

- Second marriages are excluded

- Number of children ever born

- Only for women who are followed until age 45 or who died before age 45

- Number of children born at age 25, 30 and 35

○ Only for women who are followed until the age of 25,30 or 35 years

- Number of children surviving to age 8

- The total number of children born minus the number of children passing away before reaching 8 years old. Only for women who are followed until age 45 or who died before age 45 .

For each variable, the deviation from the individual's birth cohort mean is calculated (10-year cohorts). This procedure reduces the effects of changes in the level of fertility over time and allows us to focus on childbearing continuities. Additionally, the birth cohort and region (län) of birth are entered for each index person. For the number of children ever born, two measures are constructed: one where the mother is observed until the age of 45 , and one until the age of 30 years. There are two reasons for this. First, not all index persons are observed until the age of 45, due to migration, marriage dissolution, or death. The average life expectancy for women born in 1860 was around 46 years, increasing to 53 years in 1890 (Statistics Sweden). Second, the observation window for the parents of index persons could also be too short to observe these individuals until the age of 45, for the same reason. A simplified overview of the relationships between individuals in the analytical sample, including the terms used to refer to the different generations: parents, index persons and children, is shown in figure 3.1.

Figure 3.1 shows the crucial role of the availability of information on both the index person as well as her parents or parents-in-law for estimating the presence of fertility transmission. For example, in case an index person (G2) or parent (G1) migrated into a region that is not available in the sample before this person 


\subsection{DATA, MEASUREMENTS AND METHODS}

Figure 3.1: Schematic kinship diagram

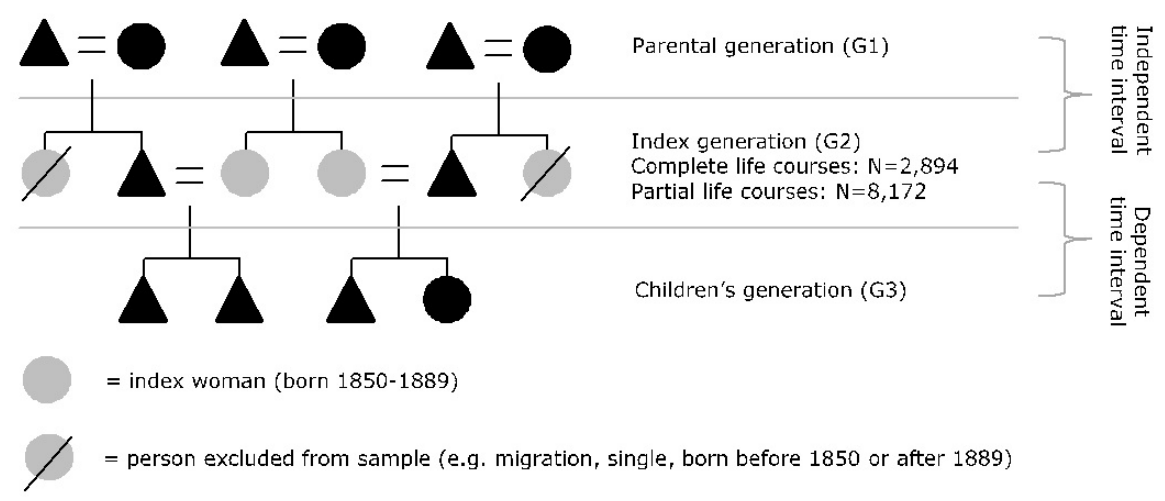

reached 45 years, it is not possible to estimate the effects for the transmission of family size for this person. However, with such partial life histories, it may still be possible to examine other transmission effects such as age at marriage or the timing of childbirths.

In order to examine fertility transmission, several different models are estimated. The sample size of each model depends on whether the variable of interest required the use of complete or partial life histories. When only index women for whom the complete reproductive history of herself and that of both her own parents and parents-in-law are considered, the sample includes 3,109 index women. For these 3,109 women, there is information on their spouses, all childbirths and all childbirths of both her mother and her mother-in-law. The sample is larger if the age at first birth is examined of index women who are linked to their own mothers, since it is not necessary to include only complete life histories to examine age at first birth $(N=8,172)$.

Since previous studies have shown that the intergenerational transmission of reproductive behaviour varied between social classes (Murphy, 1999; Van Bavel \& Kok, 2009; Van Poppel et al., 2008), control variables are included for the occupation of the husband around the time of marriage. The DDB data includes information on occupation in the form of HISCO codes, which are converted into HISCLASS codes (Van Leeuwen \& Maas, 2011; Van Leeuwen et al., 2004). The HISCLASS codes reflect a crude hierarchy between broad occupational groups. Since group sizes were small, the HISCLASS groups are combined into the following four social classes: foremen to higher managers, farmers, medium and lower skilled workers and unskilled workers. Given the strict selection criteria, necessary for the construction of individual life histories, the analytical-sample is 
largely composed of index persons who were not likely to migrate themselves and whose parents were not likely to migrate. Although in some cases it is possible to follow individuals after migration, most often such persons are lost from the analysis causing an early end to their observation window. This may explain the large share of people working in agriculture $(67.5 \%$ to $71.8 \%)$ throughout the period covered in the analytical sample, even though the industrial revolution took off in the mid-nineteenth century. Another limitation of the sample selection procedure is that childless couples are excluded from the analysis.

Table 3.1 provides descriptive information for all index women, as well as their mothers and mothers-in-law. The selection of index women in table 3.1 is limited to women for whom information is available on the complete reproductive history of both her own parents (mothers) as well as her husband's parents (mothers-inlaw).

Table 3.1: Descriptive information for index women with complete reproductive history of their parents and parents-in-law

\section{Indicator}

Index woman's birth cohort

$1850-9 \quad 1860-9 \quad 1870-9 \quad 1880-9$

$\mathrm{N}$

Index woman ${ }^{\mathrm{a}}$

Age at first birth (in years)

Age at marriage (in years)

$\begin{array}{lllll}26.2 & 25.0 & 25.0 & 25.5 & 4,310\end{array}$

Number of children ever born ${ }^{\mathrm{b}}$

25.7

24.6

$24.4 \quad 25.0 \quad 4,310$

Number of children born at age 30

5.8

6.1

6.0

$5.8 \quad 3,109$

Number of children surviving to age $8^{\mathrm{b}}$

2.2

2.5

2.3

$2.4 \quad 4,310$

4.8

5.1

5.2

$5.3 \quad 3,109$

\section{Mother}

Age at first birth

$\begin{array}{lllll}24.4 & 24.9 & 24.9 & 24.7 & 4,310\end{array}$

Age at marriage

$23.5 \quad 24.0$

$24.2 \quad 24.0 \quad 4,310$

Number of children ever born

Number of children born at age 30

$6.5 \quad 6.6$

7.1

$7.6 \quad 4,310$

Number of children surviving to age 8

2.6

2.5

2.7

$2.9 \quad 4,310$

5.3

5.3

5.9

$6.5 \quad 4,310$

Mother-in-law

Age at first birth

\begin{tabular}{rrrrr}
24.9 & 25.3 & 25.4 & 25.2 & 4,310 \\
24.2 & 24.7 & 24.8 & 24.7 & 4,310 \\
6.6 & 6.7 & 7.1 & 7.4 & 4,310 \\
2.8 & 2.6 & 2.6 & 2.8 & 4,310 \\
\hline
\end{tabular}

Age at marriage

Table-3.1: Continued on next page 
Table-3.1: Continued from previous page

Indicator

Index woman's birth cohort

\begin{tabular}{lrrrrr} 
& $1850-9$ & $1860-9$ & $1870-9$ & $1880-9$ & N \\
\hline Number of children surviving to age 8 & 5.3 & 5.4 & 5.8 & 6.3 & 4,310
\end{tabular}

Husband's occupation

Foremen to higher

Farmers

$6.1 \% \quad 5.6 \% \quad 5.5 \% \quad 9.1 \%$

Medium and lower skilled

$\begin{array}{lllll}67.5 \% & 69.5 \% & 71.8 \% & 69.9 \%\end{array}$

Unskilled

$22.2 \% \quad 21.3 \% \quad 18.0 \% \quad 17.9 \%$

$4.2 \% \quad 3.7 \% \quad 4.8 \% \quad 3.0 \%$

Index woman's birth county

Jämtlands län

Norrbottens län

Västerbottens län

Västernorrlands län

Östergötlands län

Other

(a) Selection limited to women for whom information is available for both mother and motherin-law. All variables are mean values, except when stated otherwise.

(b) Sample further restricted to women and mothers followed age 18-45 or death before their $45^{\text {th }}$ birthday.

Source: CEDAR: Demographic DataBase. POPLINK and POPUM version 4.4.2.

As table 3.1 indicates, the number of children born for women who are observed until the age of 45 or their death was on average about 5.8 to 6.1 children, with the majority of children surviving to at least eight years old. The number of children born did not change much during the period of observation. For the whole of Sweden, crude birth rates started to decline from the 1860s until the 1930s (Statistics Sweden). Given that this sample is largely composed of families who were not likely to migrate, and because the share of people involved in agriculture is fairly high (around 70 percent), relatively high and stable birth rates can be expected.

When comparing the number of children born for index women to the number of children born for their mothers or mothers-in-law (around 6.5 to 7.4), a small decline in family size over the generations is visible. A bias in the sample can be observed towards larger family sizes for mothers and mothers-in-law. Mothers and mothers-in-law of index women born in 1880-1889 had more children on average than the parents of index women born in 1850-1859, even though index women 
born in 1850-1859 could be the mothers of the index women born in 1880-1889. The likely cause of this bias is the selection of index women who are followed from age 18 to 45. Mothers and mothers-in-law may have been followed for a longer period of time after their 45th birthday than index women, causing more childbirths to be registered for the mothers compared to the index women. For the number of children born at age 30, the difference is much smaller. Finally, age at first birth is slightly lower for the parental generation than for the index women's generation.

\subsubsection{Methods}

In order to facilitate comparisons with other studies on the intergenerational transmission of reproductive behaviour, bivariate correlations between the reproductive variables of interest for both generations are examined first. Pearson correlation coefficients are calculated separately for index women and their families of origin, and for index women and their husband's families of origin. Additionally, the results are shown by birth cohort to determine if the association between fertility of parents and their children (the index women) has changed during the period of observation.

After examining the bivariate correlations, we proceed to a series of event history analyses of the length of birth intervals for the first four parities. While bivariate correlation coefficients are widely used in the literature and useful to assess correlation, the drawback is that other variables are not controlled for. By using event history analysis it is possible to control for other factors such as cohort effects. In addition, it is possible to model the transition from one life stage to the next. Separate event history models are estimated for the age at first marriage and the timing of the first four childbirths. For each of these dependent variables, the following reproductive characteristics of the parental generation are examined in separate models: Age at first birth (or age at marriage in case age at marriage is the dependent variable); children ever born; children ever born at age 30 and the number of children surviving to the age of eight years old. The effects for the index person's parents and parents-in-law are estimated simultaneously. For each reproductive variable of interest, the following Cox proportional hazard model is specified:

$$
h_{i}(t)=h_{0, C, R}(t) \cdot \exp \left(\beta_{1} X_{i, \text { mother }}+\beta_{2} X_{i, \text { mother-in-law }}+\beta_{3} S_{i}\right)
$$

In this model $h_{i}(t)$ denotes the hazard ratio, or the chance of marrying or having a (next) birth in period $t$ based on the covariates that are specified. The dependent variable of interest is thus either the age at marriage, age at first birth, 


\subsection{RESULTS}

or the length of the time interval between births. The variable $h_{0, C, R}(t)$ is the unspecified, non-negative baseline hazard which varies arbitrarily over time and is not dependent on the covariates in the model. This can be interpreted as the constant chance of having a child between period $t$ and $t+1$. This baseline hazard is the same for all index women, but is allowed to differ between birth cohort $C$ and birth region $R$ (a stratified model is specified). The Cox model assumes that the hazard ratios are proportional, meaning that the effects of the covariates do not vary over time. An analysis of the Schoenfeld residuals for each model showed that the effects of birth cohort and region were not constant over time. To resolve this, each model is stratified by birth cohort and region in order to ensure proportional hazards (Cleves et al., 2010). The effects of the index-person's family of origin and her husband's family of origin are determined simultaneously. The hazard for index person $i$ at moment $t$ is dependent on the indicator of reproductive behaviour $X$ of both the mother and mother-in-law, as described above. Additionally, all models include fixed-effects control dummies, denoted by $S_{i}$. The additional fixed effect control variables are: the husband's occupation, age of the index woman at previous birth, the death of a previous child within eight months after birth, the death of a previous child surviving to eight months but before the birth of the current child and a dummy variable for last birth. The $\beta$ parameters are unknown regression coefficients that are to be estimated using maximum likelihood.

Finally, continuities in completed family size are examined using Poisson models. This class of regression models is suitable for estimating the effects of covariates on count data, such as the number of children born. As with the event history analyses, the effects of both the mother and mother-in-law of each index person is examined simultaneously. Separate models are estimated for the indicators of reproductive behaviour of the parental generation, and all models include fixed effect control variables of the wife's birth cohort, birth region and the occupation of her husband.

\subsection{Results}

The bivariate correlations between indicators of reproductive behaviour are examined first. The results are presented separately for the index women's mother and mother-in-law in table 3.2. Next, the correlation coefficients are shown by birth cohort in table 3.3, to determine whether the degree of the intergenerational transmission of reproductive behaviour varied over time. Then, a summary of the results of the event history analyses of birth events is presented in table 3.4 and finally the results of the Poisson models for completed family size are given in 
table 3.5 .

\subsubsection{Correlation coefficients}

Table 3.2 provides correlation coefficients for the indicators of reproductive behaviour between index women and their mothers and mothers-in-law, respectively. For example, the estimated Pearson correlation coefficient between age at first birth of an index woman and her mother is $\rho=0.0281$. The correlation between age at first birth of index women and their mothers-in-law is $\rho=0.0627$. The influences of other risk factors, such as cohort effects or differences in social status, are not controlled for with the estimation of correlation coefficients. Nevertheless, the estimates allow for a simple comparison with other studies and have become widely used in the literature on intergenerational transmission (Murphy, 1999). The correlations presented in table 3.2 are given for subsamples of the data for which sufficient information is available for the index women and her mother or mother-in-law for each examined variable.

All indicators of reproductive behaviour in table 3.2 show a significant, positive correlation between the index women and their mothers or mothers-in-law, but the correlation observed is, however, fairly weak. The correlation between age at first childbirth of index women and their mothers-in-law is stronger than between index women and mothers. In contrast, measures of completed fertility show a stronger correlation between index women and mothers compared to mothers-inlaw. The correlation coefficients for completed fertility $(\rho=0.0849, N=5,008)$ between index women and their mothers are low compared to contemporary lowfertility societies in which correlations of $\rho>0.15$ are not uncommon (e.g. Murphy \& Wang, 2001). The observed correlation is also slightly lower than observed in other regions that underwent a phase of fertility transition. Reher et al. (2008) for example observed a higher correlation coefficient $(\rho=0.115, N=409)$ in their sample of women born in Spain whose first birth took place between around 1890 and 1950. Nevertheless, the observed correlation in completed family size is similar to other studies that use data from historical, transitional societies. Jennings et al. (2012) report the same correlation ( $\rho=0.085, N=19,938$ ) in their study on the intergenerational transmission of reproductive behaviour of women born in nineteenth-century Utah. When comparing the correlation between the number of children ever born to the cohort-relative number of children ever born, little differences emerge. The correlation between index women and their mothers-in-law increases slightly, but remains lower than between index women and mothers. The same is visible for the number of children surviving to the age of 8 years, here the correlation between index women and their mothers is higher than between index women and their mothers-in-law. 


\subsection{RESULTS}

Table 3.2: Bivariate Pearson correlation coefficients for index women and their mothers(-in-law)

\begin{tabular}{|c|c|c|c|c|}
\hline \multirow[b]{2}{*}{ Index women's indicator } & \multicolumn{2}{|c|}{ Mothers } & \multicolumn{2}{|c|}{ Mothers-in-law } \\
\hline & Coefficient & $\mathbf{N}$ & Coefficient & $\mathbf{N}$ \\
\hline \multicolumn{5}{|l|}{ Fundamental fertility links } \\
\hline Age at first childbirth & $0.0281^{*}$ & 7673 & $0.0627^{* * *}$ & 7031 \\
\hline Relative age at first childbirth ${ }^{\mathrm{a}}$ & $0.0382^{* * *}$ & 7673 & $0.0665^{* * *}$ & 7031 \\
\hline Number of children ever born & $0.0849^{* * *}$ & 5008 & $0.0456^{* * *}$ & 4670 \\
\hline $\begin{array}{l}\text { Relative number of children ever } \\
\text { born }^{a}\end{array}$ & $0.0853^{* * *}$ & 5008 & $0.0546^{* * *}$ & 4670 \\
\hline Number of surviving children ${ }^{\mathrm{b}}$ & $0.0903^{* * *}$ & 5032 & $0.0568 * * *$ & 4673 \\
\hline $\begin{array}{l}\text { Relative number of surviving } \\
\text { children }^{\text {a }}\end{array}$ & $0.0799^{* * *}$ & 5032 & $0.0611^{* * *}$ & 4673 \\
\hline \multicolumn{5}{|l|}{ Other indicators } \\
\hline Age at marriage & $0.0391^{* * *}$ & 8172 & $0.0651^{* * *}$ & 7264 \\
\hline \multicolumn{5}{|l|}{ Number of children ever born } \\
\hline at 25 years & $0.0682^{* * *}$ & 8172 & $0.0558^{* * *}$ & 7264 \\
\hline at 30 years & $0.0767 * * *$ & 8172 & $0.0690 * * *$ & 7264 \\
\hline at 35 years & $0.0948^{* * *}$ & 8172 & $0.0778^{* * *}$ & 7264 \\
\hline \multicolumn{5}{|l|}{$\begin{array}{l}\text { Relative number of children ever } \\
\text { born }^{\text {a }}\end{array}$} \\
\hline at 25 years & $0.0701^{* * *}$ & 8172 & $0.0768^{* * *}$ & 7264 \\
\hline at 30 years & $0.0787^{* * *}$ & 8172 & $0.0889^{* * *}$ & 7264 \\
\hline at 35 years & $0.0948^{* * *}$ & 8172 & $0.0941^{* * *}$ & 7264 \\
\hline
\end{tabular}

Notes: Bivariate Pearson correlation coefficients

Significance: $\dagger \mathrm{p}<0.1,{ }^{*} \mathrm{p}<0.05,{ }^{* *} \mathrm{p}<0.01,{ }^{* * *} \mathrm{p}<0.001,-$ not present

The number of observations is higher than in table 1 where only women for whom information of both the mother and mother-in-law is available are included.

(a) Relative to birth cohort of index person and parent

(b) Surviving to 8 years

Age at marriage is also positively correlated between generations. As with age at first birth, the correlation coefficient for age at marriage between index women and their mothers-in-law $(\rho=0.0651)$ is slightly higher than between index women and their mothers $(\rho=0.0391)$. Perhaps this is an indication of the role of the husband's family in affecting the timing of marriage in the Swedish 
context. Given that the birth of the first child usually followed within a limited time span after marriage, it can be argued that the husband's family of origin had a somewhat stronger influence than the wife's family on the timing of marriage and first childbirth. The observed correlation between age at marriage of index women and their mothers or mothers-in-law is however lower than what is found in other studies. Jennings et al. (2012) observe a correlation between index women and mothers of $\rho=0.121$ in the Utah context, while Van Poppel et al. (2008) observe a correlation of $\rho=0.167$ using nineteenth-century marriage certificates from the Netherlands. Lastly, the number of births at various ages shows a relatively high correlation between index women and their mothers or mothers-in-law, with values ranging from $\rho=0.0558$ at the age of 25 to $\rho=0.0948$ at the age of 35 .

Bivariate Pearson correlation coefficients over birth cohorts of index women are given in table 3.3. In line with what is observed in other literature, the correlation between the age at first birth of index women and their mothers increased over time (Murphy, 1999, 2013b). In contrast, other indicators of reproductive behaviour show no sign of an increase in the correlation between generations over birth cohorts. The correlation for the number of children born is significant between index women and their mothers for all birth cohorts, but the size of the correlation coefficient decreases from $\rho=0.112$ in $1850-1859$ to $\rho=0.0549$ in 1880-1889. The change in the correlation of the number of children ever born is further illustrated by figure 3.2 .

The vertical axis of figure 3.2 shows the number of children born to mothers of index women in three groups (less than 6 children, 6 to 9 children, and 10 or more children). Each group is further divided into the birth cohort of the index woman. The vertical axis shows the average number of children ever born to index women. The graphs show that index women whose mother had more children, on average had more children themselves. However, for index women whose mother had more than 10 children, the number of children ever born shows a decrease over time. Thus, while the mean number of children ever born remained constant over time with around 5.8 to 6.1 children born per women (see table 3.1), the number of index women having a relatively large offspring compared to their birth cohort declined over time. This decline in the share of large families in later birth cohorts may explain for a part why the correlation in the number of children born is not consistent over time.

\subsubsection{Age at marriage and parity transition}

Next, event history analysis is used to examine the association between indicators of reproductive behaviour of the parental generation and the index women at various stages of the life course. These models include controls variables for 


\subsection{RESULTS}

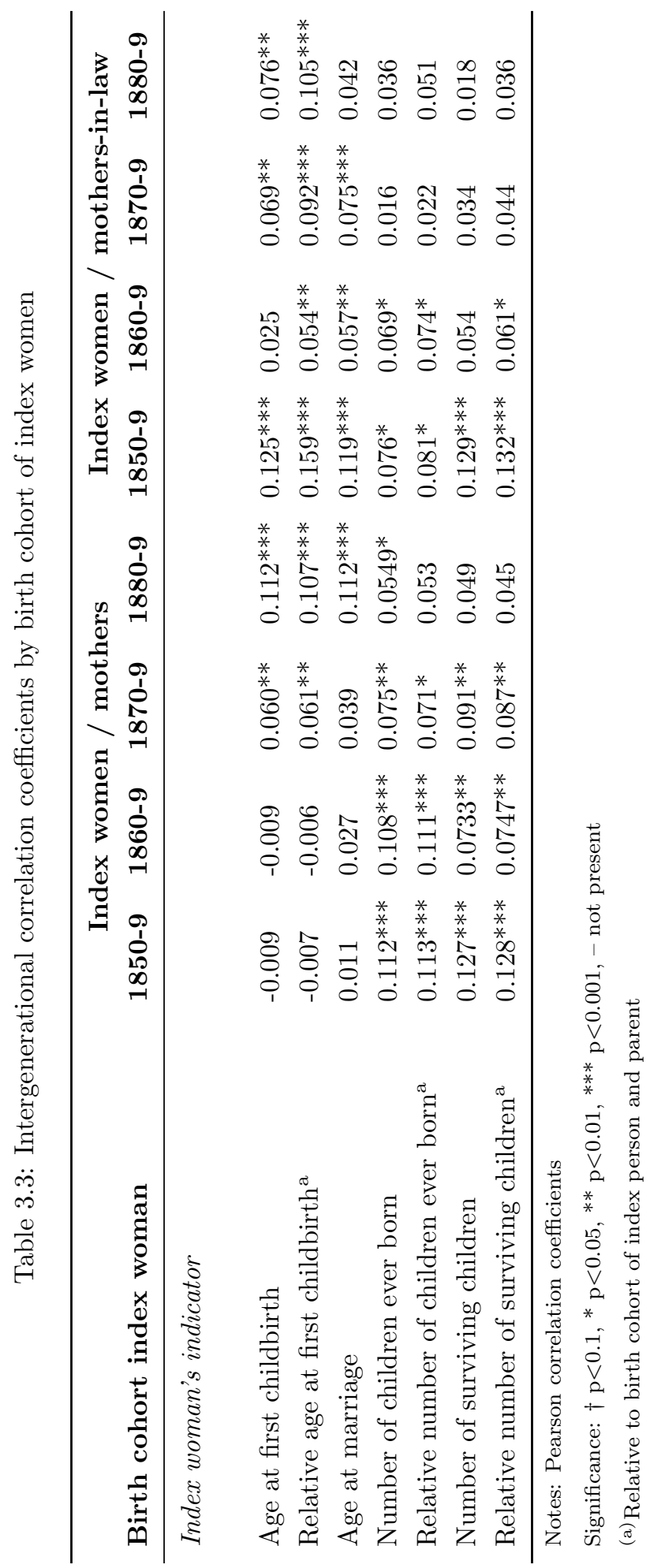


Figure 3.2: Average number of children ever born by index women (birth cohort 1850-1890) and their mothers

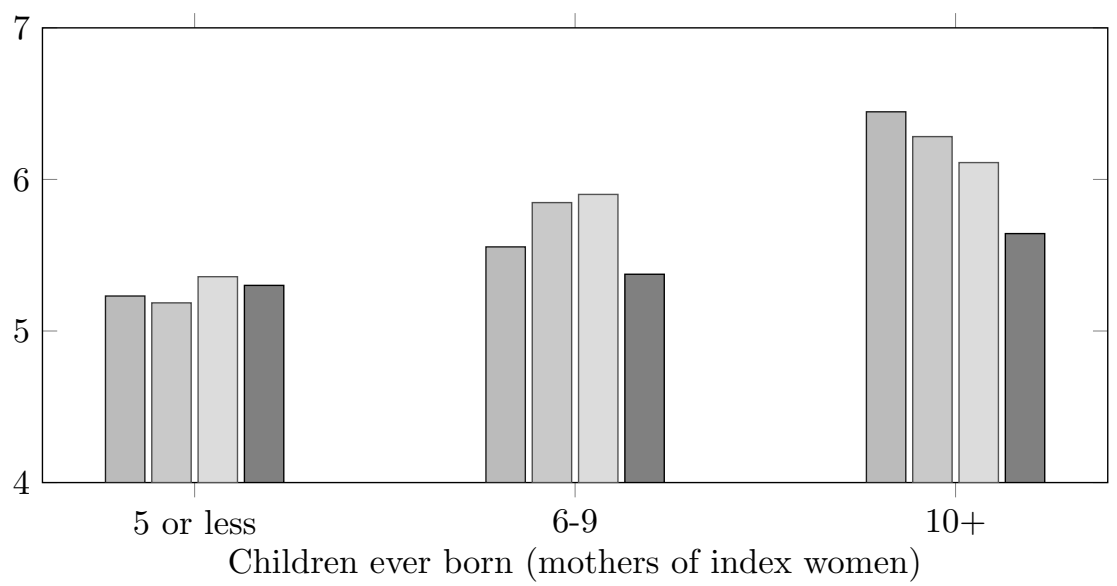

\begin{tabular}{|c|c|}
\hline पि1850 & प्1860 \\
\hline
\end{tabular}

birth cohort and birth region of the wife, socio-economic status of the husband, and previous reproductive outcomes (depending on the model, see the Methods section). In total 20 models are estimated, and summary outcomes for each event history model are presented in table 3.4. Each row presents the hazard ratios for a single model in which the characteristics of the wife's parents and husband's parents are simultaneously taken into account. Hazard ratios are exponentiated coefficients. If the hazard rate is greater than 1, an increase in the corresponding covariate will increase the hazard of the dependent variable. A hazard rate smaller than 1 denotes a smaller hazard of the dependent variable occurring, if the covariate increases. Since the dependent variable is a time interval, for example the time between births, a hazard rate greater than 1 for any covariate indicates that a one-point increase of the covariate is associated with a smaller time interval between births, since the hazard of the next birth occurring in the next time period has increased. The hazard ratios reported are proportional and must be interpreted as the chance of the event occurring relative to the unspecified baseline hazard which is constant for all index women, but stratified by birth region and birth cohort of the wife. In order to ensure proportional hazard ratios, all models are stratified by these variables. By specifying a stratified model, the direct effects of birth cohort and birth region are controlled for in the model, but their effects are not visible because they are included in the unspecified baseline hazard function. 


\subsection{RESULTS}

The left-most column in table 3.4 describes the dependent variables of interest for the index women. These are the age at marriage, age at first birth and the transition time from first to second birth, second to third, and third to fourth birth. The second column describes the independent covariates, limited to the indicators of reproductive behaviour of the parental generation. The independent variables of the index women's parents are the age at marriage or first birth, the number of children ever born, the number of children ever born at the age of 30 years and the total number of children surviving to the age of 8 years. All variables, both the dependent and the independent, are included as cohort relative measures to the birth cohort of the index women and their mothers(-inlaw) respectively. This means that a higher hazard is associated with a higher risk of the event occurring, relative to the birth cohort of the index women. The number of observations for these models are slightly lower than those given in table 3.1. This is due to the fact that for some index women, the occupation of her husband around the time of marriage could not be determined. In such cases, these index women are excluded from the event history analysis.

The first row in table 3.4 shows that index women were likely to marry at a higher age compared to other women in their birth cohort, in case their mother or mother-in-law married at a higher age (compared to their birth cohort). Controlled for the effects of the wife's birth cohort, birth region and her husband's occupation, the hazard ratios for age at marriage of the index woman's mother and mother-in-law are smaller than one (0.977 and 0.980). This means that the chance that the index woman will be married in the next year is around 2.3 percent lower if her mother was one year older than her cohort peers when she married. This finding is in line wither earlier observations by Van Poppel et al. (2008). The positive hazard ratio of 1.018 in the second row in table 3.4 shows that the index women's age at marriage is inversely associated with the relative number of children born to her mother-in-law. This means that if the index woman's mother-in-law had more children relative to her birth cohort, the index woman was likely to marry at a younger age compared to her cohort-peers. Additionally, the hazard of marrying younger is higher for women whose mother or mother-in-law had more children at the age of 30 relative to their birth cohorts.

Age at first birth, relative to the index women's birth cohort, is likely to be slightly higher for index women of whom the mothers or mothers-in-law had their first child at a higher age relative to their birth cohorts, since the hazard ratio has a value of $<1$. This positive association is expected, given the positive correlation for age at first birth observed in table 3.2.

The size of the husband's family is inversely associated with age at first birth. A hazard ratio for age at first birth depending on children ever born with a value 
CHAPTER 3. INTERGENERATIONAL TRANSMISSION

Table 3.4: Summary table of Cox proportional hazard models

\begin{tabular}{|c|c|c|c|}
\hline \multirow[t]{2}{*}{ Variables $^{\mathbf{a}}$} & \multicolumn{2}{|c|}{ Hazard ratios } & \multirow[t]{2}{*}{$\mathbf{N}^{\mathbf{b}}$} \\
\hline & Mother & Mother-in-law & \\
\hline \multicolumn{4}{|l|}{ Dependent variable: } \\
\hline \multicolumn{4}{|l|}{ Index woman's age at marriage ${ }^{c}$} \\
\hline \multicolumn{4}{|c|}{ Independent variables (Indicator of mother / mother-in-law): } \\
\hline Age at marriage & $0.977^{* *}$ & $0.980^{* * *}$ & 4039 \\
\hline Children ever born & 0.994 & $1.018^{* *}$ & 3973 \\
\hline Children ever born at age 30 & $1.031^{* *}$ & $1.045^{* * *}$ & 4041 \\
\hline Number of surviving children ${ }^{\mathrm{e}}$ & 0.990 & 1.010 & 4000 \\
\hline
\end{tabular}

Dependent variable:

Index woman's age at first birth ${ }^{c}$

Independent variables (Indicator of mother / mother-in-law):

\begin{tabular}{llll} 
Age at first birth & $0.982^{* *}$ & $0.982^{* * *}$ & 4001 \\
Children ever born & 0.996 & $1.020^{* *}$ & 3812 \\
Children ever born at age 30 & $1.031^{* *}$ & $1.044^{* * *}$ & 3879 \\
Number of surviving children & 0.991 & $1.012 \dagger$ & 3839 \\
\hline
\end{tabular}

Dependent variable:

Index woman's age at $2^{\text {nd }}$ childbirth $^{\mathrm{d}}$

Independent variables (Indicator of mother / mother-in-law):

Age at first birth $0.995 \quad 0.999 \quad 3356$

Children ever born

$1.018^{* *} \quad 1007 \quad 3329$

Children ever born at age 30

$1.025^{*} \quad 1006$

3383

Number of surviving children ${ }^{\mathrm{e}}$

$1.015^{*} \quad 1011$

3353

Dependent variable:

Index woman's age at $3^{\text {rd }}$ childbirth $^{\mathrm{d}}$

Independent variables (Indicator of mother / mother-in-law):

Age at first birth

$\begin{array}{lll}0.993 & 0.992 & 2768 \\ 1.021^{* *} & 1.019^{* *} & 2746 \\ 1002 & 1.028^{*} & 2791 \\ 1.022^{* *} & 1.028^{* * *} & 2766\end{array}$

Children ever born

Table-3.4: Continued on next page 


\subsection{RESULTS}

Table-3.4: Continued from previous page

\begin{tabular}{lcc}
\hline Variables (cohort relative) & Hazard ratios & $\mathbf{N}$ \\
& Mother $\quad$ Mother-in-law & \\
\hline
\end{tabular}

Dependent variable:

Index woman's age at $4^{\text {th }}$ childbirth $^{\text {d }}$

Independent variables (Indicator of mother / mother-in-law):

$\begin{array}{llll}\text { Age at first birth } & 0.982^{*} & 1.016^{* *} & 2243 \\ \text { Children ever born } & 1.017^{*} & 1008 & 2226 \\ \text { Children ever born at age } 30 & 1013 & 0.985 & 2259 \\ \text { Number of surviving children }^{\text {e }} & 1013 & 1.017 \dagger & 2239\end{array}$

Notes: Each row reports hazard ratios for indicators of parental fertility (independent variables) on the reproduction parameters of index women (dependent variables). The coefficients for the transition models are given as exponentiated coefficients (hazard ratios) relative to the baseline hazard.

Significance: $\dagger \mathrm{p}<0.1,{ }^{*} \mathrm{p}<0.05,{ }^{* *} \mathrm{p}<0.01,{ }^{* * *} \mathrm{p}<0.001,-$ not present

(a) Relative to the birth cohort of the index woman, her mother or mother-in-law.

(b) Failures.

(c) Relative to the index woman's birth cohort. The models include additional fixed effect control variables for the husband's occupation (not shown) and are stratified by birth cohort and region.

(d) Relative to the index woman's birth cohort. The models include additional fixed effect control variables for the husband's occupation, age of the index woman at previous birth, the death of a previous child within eight months after birth, the death of a previous child surviving to eight months but before the birth of the current child and a dummy variable for last birth (not reported). All models are stratified by birth cohort and region.

(e) Surviving to 8 years.

of 1.020 indicates that women whose mother-in-law had relatively many children would be more likely to have their first child at a younger age, compared to other women in her birth cohort. This association is however not observed for the family size of the wife herself. Nevertheless, the number of children born to either the mother or mother-in-law at the age of 30 is significantly associated with age at first birth. The more children mothers or mothers-in-law of the wife had at the age of 30 years, the younger index women were likely to enter parenthood relative to the average age at first childbirth for their birth cohort. The number of surviving children of the husband's family is only weakly associated with age at first birth.

Looking at the transition to higher order parities, the association between reproductive outcomes of index women and their mothers or mothers-in-law be- 
comes less clear. The age at first birth of the mother and mother-in-law is only significantly associated with the waiting time between the third to the fourth birth, but not for other parity transitions. Interestingly, a higher age at first birth of the index woman's mother is significantly associated with a longer birth interval for index women. In contrast, the higher age at first birth of the motherin-law is associated with having a shorter birth interval from the third to the fourth child. Both the number of children born and the number of surviving children of the wife's mother are inversely associated with the transition to the second and third birth for index women, meaning that the interval between the second and third birth is shortened if the mother of mother-in-law had more (surviving) children. For the transition to the third birth, this association is also significant for the husband's family of origin. The finding that shorter birth intervals occur among women whose parents had more children is also observed in other studies, although other studies observe more consistent parental influences on the timing of births at higher parities (e.g. Jennings et al., 2012; Kolk, 2014a).

\subsubsection{Children ever born}

Finally, the associations between the number of children born and indicators of reproductive behaviour of the parental generation are examined in four Poisson regression models. Table 3.5 reports a summary of the coefficients. As in table 3.4, each row represents a single model. Each model includes the fertility characteristics of both the wife's and the husband's parents, as well as fixed effect control variables for the wife's birth cohort, region of origin and the husband's occupation. In order to explain the number of children ever born to index women, the following measures of parental fertility are used for the wife's and husband's mother: the age at first birth, the number of children born, the number of children born at the age of 30 and the number of children surviving to age 8 .

The findings from table 3.5 confirm the picture that emerged from the results of the event history analyses and what is observed in other literature (e.g. Jennings et al., 2012; Kolk, 2014a; Murphy, 1999). The number of children born is significantly and inversely associated with the timing of entry into parenthood of the parents. The later a woman's mother or mother-in-law had her first child, the fewer children the index women is expected to have. Furthermore, if the parents or parents-in-law had more children, or had more children when they were 30 years old, the index women is also likely to have more children ever born. The only insignificant result is for the association between the number of children born and the number of surviving siblings of index women. The association with the number of siblings of the index woman's spouse is however significant and positive. 


\subsection{RESULTS}

Table 3.5: Estimated Poisson regression coefficients of indicators of parental fertility on the index women's number of children born (summary table)

\begin{tabular}{|c|c|c|c|}
\hline Indicator of parental fertility & $\begin{array}{l}\text { Wife's } \\
\text { mother }\end{array}$ & $\begin{array}{l}\text { Husband's } \\
\text { mother }\end{array}$ & $\mathbf{N}$ \\
\hline Age at first birth & $0.987^{* * *}$ & $0.995^{* *}$ & 2,914 \\
\hline Children ever born & $1.006^{*}$ & $1.009^{* *}$ & 2,894 \\
\hline Children ever born at age 30 & $1.014^{* *}$ & $1.019^{* * *}$ & 2,930 \\
\hline Number of surviving children ${ }^{\mathrm{a}}$ & 1.004 & $1.013^{* * *}$ & 2,907 \\
\hline
\end{tabular}

Notes: Pearson correlation coefficients, reported as incidence-rate ratios. Each row reports the coefficients of indicators of parental fertility (cohort relative) on the index women's number of children born (absolute values). All four models include fixed effect control variables for the birth cohort and birth region of the index woman, and for the husband's occupation (not reported).

Significance: $\dagger \mathrm{p}<0.1, * \mathrm{p}<0.05, * * \mathrm{p}<0.01, * * * \mathrm{p}<0.001,-$ not present

(a) Surviving to 8 years old.

The findings displayed in tables 3.2 to 3.5 confirm the first hypothesis. Fertility outcomes are positively associated with reproductive outcomes of the parents. For the second hypothesis, the results are less consistent, as there are differences between the effects of the husband's and wife's family of origin. For some measures, the reproductive behaviour of index persons seems to be more strongly associated with the husband's family of origin than that of the wife, but this result is not consistent as in some cases fertility outcomes were more strongly associated with the wife's family of origin. The differences between the effects of the husband's and wife's family of origin are most visible in the examination of bivariate correlations over the birth cohorts of index women (table 3.3). These show a significant correlation between the age at first birth and age at marriage of index women and their mother's-in-law in the earlier cohorts, but not for the wife's mother. In contrast, the waiting time until the second birth seems to be associated with fertility outcomes of the wife's family of origin, but not with the husband's family of origin (table 3.4). While Murphy's (1999) overview shows that most studies show a stronger association with the wife's family of origin, the stronger influence of the husband's family of origin is also observed in other studies. For example, in a study on Norwegians born in the 1960s, Cools and Hart (2016) find that men having more siblings were more likely to have three instead of two children themselves. In contrast, women with additional siblings were not more likely to have more children themselves (Cools \& Kaldager Hart, 2016). 


\subsection{Summary and Discussion}

Previous studies have consistently observed small, but significant intergenerational continuities in childbearing for contemporary, post-transitional populations, but not for historical pre-transitional populations (Dahlberg, 2013; Kolk, 2014a,b; Murphy, 1999; Stanfors \& Scott, 2013). The main aim of this study has been to examine whether reproductive outcomes are transmitted from parents to children during a period of fertility transition. For this, data was collected for women born in Sweden in the second half of the nineteenth century. While fertility decline took off in Sweden since the 1860s until the 1930s, reproductive outcomes observed in this study remained relatively constant throughout this period, signifying that the population in this sample was only in an early phase of the fertility transition. The findings show evidence of weak, but positive correlations in reproductive outcomes between parents and children during a period of fertility transition.

In order to facilitate comparisons with existing literature, bivariate correlations were examined for a large number of indicators of reproductive behaviour. These show consistent correlations between the reproductive behaviour of parents and children. The observed correlations are however slightly lower than what is observed in other European regions undergoing a period of fertility transition (cf. Reher et al., 2008). Over time, the correlations between the age at first birth of parents and their children increased, as is observed in other studies (cf. Jennings et al., 2012; Murphy, 1999). In contrast, the transmission of the number of children born decreased over time (table 3.3). A likely explanation for the decreased association over time is that for the children's generation fewer large families are observed in later birth cohorts, even for those individuals whose parents had many children (figure 3.2). Over time, family sizes remained fairly constant on average, but the number of exceptionally large families (more than 9 children) became smaller.

A series of event history analyses shows that the timing of marriage and entry into parenthood are also associated with reproductive outcomes of the parents after controlling for birth cohort, region and socio-economic status. Although it is not possible to directly compare the hazard ratios with Pearson correlations, the hazard ratios for entry into parenthood seem low in comparison to the bivariate correlations reported in Table 3.2. The control variables included in the event history models may be important drivers of reproductive outcomes themselves, thereby taking away some of the explanatory power of the parental influences. For higher order parities, less consistent effects of parents on the fertility of their children are observed. Finally, Poisson models for the relationship between the number of children born and fertility outcomes of parents show positive correla- 


\subsection{SUMMARY AND DISCUSSION}

tions, consistent with the literature (Jennings et al., 2012; Kolk, 2014a,b; Murphy, 1999).

The results of this study are inconclusive as to whether the wife's or the husband's family of origin had a stronger influence on reproductive outcomes. For some measures, e.g. the number of children ever born, the reproductive outcomes of the husband's parents were more strongly associated with fertility outcomes of the index couple, but for other measures it was the other way around. For most measures of reproductive outcomes, however, the reproductive outcomes of the family of origin of both the wife and husband were associated with fertility of the index couple. Large differences between the effects of husband's and wife's family of origin were not to be expected, given the context of the study and the nature of Swedish relationships in the nineteenth century. Around 70 percent of the index couples sampled in this study were farmers and due to the data selection procedure, the sample was mostly comprised of non-migrating couples. Dribe and Lundh (2005) argue that in central and northern Sweden, social differences between groups were smaller than in southern Sweden. Moreover, because children inherited an equal share, farmers sought partners who were evenly wealthy to compensate for the splitting of lands through inheritance. This also suggests that the transmission of social status may have been the most important mechanism behind the transmission of reproductive outcomes in nineteenth-century central and northern Sweden. The social status of index couples did not differ much from that of their parents, as individuals were likely to marry to members of the same social group. This was reinforced by the influence of the parents on finding a suitable partner for their children.

In reality, the reproductive behaviours of individual couples are only partly explained by the reproductive behaviours of their parents. The influence of other kin members on fertility behaviour is recognized in both historical and contemporary developing countries (Bernardi \& White, 2010; Rotering \& Bras, 2015; Sear et al., 2003; Tymicki, 2004). Furthermore, biological limitations as well as economic or social constraints and opportunities also play a role (Bengtsson \& Dribe, 2006). Kolk (2011) for example shows that couples spaced their births in reaction to socio-economic or family circumstances. Historical events, such as the devastating fires that destroyed most of the cities of Umeå and Sundsvall in 1888 , likely affected fertility planning to a greater extent than parental influences. Nevertheless, intergenerational childbearing continuities are persistent in contemporary developed countries, highlighting the topic's importance for scientific study in the context of modern low-fertility populations as well as developing nations (Murphy, 2013a). 



\section{Chapter 4}

\section{The age difference between spouses and reproduction in 19th century Sweden}

This chapter is based on: Rotering, P., \& Bras, H. (2019). The age difference between spouses and reproduction in 19th century Sweden. Demographic Research, 41(37), 1059-1090 



\subsection{INTRODUCTION}

\subsection{Introduction}

The question of whether female autonomy within marriage is related to fertility outcomes is addressed in a growing body of empirical research, most of which focusing on contemporary high fertility populations, such as sub-Saharan African or Asian societies (see Upadhyay et al., 2014, for a recent overview) or contemporary low fertility populations (e.g. Osiewalska, 2018). In contrast, the number of studies addressing spousal power differences in historical populations is relatively small (e.g. Feng et al., 2010). Insight into the association between female autonomy and reproductive outcomes can contribute to our understanding of regional variations in the decline of fertility (Casterline et al., 1986).

In this study, historical parish registration data from central and northern Sweden between 1840 and 1889 is used to examine the associations between female autonomy and reproductive outcomes in a historical population. The ability of women to influence reproductive decision-making may depend on her position within the marriage. Spousal age differences are here used as a proxy for female autonomy, reflecting a woman's bargaining power regarding reproductive decisionmaking (Abadian, 1996; Casterline et al., 1986; Skinner, 1993; Bras \& Schumacher, 2019). The aim of this study is to examine whether age differences between spouses can explain the timing of first and higher order births, as well as the total number of children born.

The structure of this chapter is as follows. The following section provides a brief overview of the literature on the associations between spousal age differences, female autonomy and reproductive outcomes. Then follows an account of the nature of Swedish marriages and reproduction during the nineteenth century. The hypotheses, data and methods are presented in the sections thereafter, followed by a discussion of the empirical results and the main conclusions.

\subsection{Age difference between spouses}

\subsubsection{Age differences and female autonomy}

The age difference between spouses is frequently used as a proxy for female autonomy in studies of reproductive outcomes, referring to the degree to which women can influence reproductive decision-making (Abadian, 1996; Skinner, 1993). In general, a smaller age difference between spouses suggests a higher degree of equality between them. One body of research suggests that industrialization in Western Europe has led to a reduction in patriarchal inequalities within the family, thereby increasing the bargaining power of women (Janssens, 2007; Watkins, 


\section{CHAPTER 4. SPOUSAL AGE DIFFERENCES}

1993). In a second body of research, fertility transitions are seen as the manifestation of a cultural shift towards egalitarian partnerships. According to Mason (1993), couples who are more socially equal and emotionally intimate face lower costs of family planning, since there is a greater agreement between them on the factors on which the discussion should be based and because there is a greater ability to discuss matters of reproduction. The same line of reasoning is observed in Van de Putte et al. (2009), who argue that the experiences of people belonging to the same birth cohort contribute to a sense of commonality. Shared life experiences, values about marriage and family life reinforce the mutual confirmation of each other's behaviour (Van de Putte et al., 2009, p. 1236). Van de Putte et al. (2009) observe that the age difference between spouses declined over the course of the nineteenth century in Western European societies. They argue that the increase in age homogamy brought with it a more egalitarian view on marriage and partner selection. However, as Pyke and Adams (2010) argue, the husband's older age does not need to mean that all discussions between the spouses are dominated by the husband. Nevertheless, in a comparative perspective, high proportions of marriages in which the husband is older can be seen as indicative of patriarchal family systems in which women's decision making power on matters concerning reproduction is constrained (Barbieri et al., 2005; Cain, 1993).

Previous empirical studies on the association between female autonomy and fertility outcomes have shown mixed results. A recent overview of the literature on the relationship between women's empowerment and fertility is given in Upadhyay et al. (2014). The majority of the 60 studies they examined were conducted in contemporary South Asian societies. A total of 38 studies focussed on the number of children born and only 10 of these studies found a significant negative association between the number of children born and measures of women's empowerment. Five studies examined the effects of women's empowerment on the length of birth intervals and only two of these studies found that female conjugal power was associated with longer birth intervals. One study observed mixed effects - depending on the woman's age at first birth and whether or not she had a paid occupation (Upadhyay \& Hindin, 2005), another study observed shorter birth intervals for Nepalese couples with greater female autonomy (Fricke \& Teachman, 1993) and one study found no significant association (Feldman et al., 2009). In another overview of the literature Mason (1993) also observed mixed evidence regarding a connection between the position of women and fertility outcomes. These findings illustrate that the effects of women's empowerment on fertility depend to a large degree on the regional context as well as the way female empowerment is measured. 


\subsection{AGE DIFFERENCE BETWEEN SPOUSES}

\subsubsection{Spousal age differences and fertility, evidence from previous studies}

In their study on age differences between spouses in developing regions, Casterline et al. (1986) identify three mechanisms through which spousal age differences can affect fertility. First, an increase in the age of either spouse is inversely associated with fecundability. A higher age difference will therefore negatively affect reproductive outcomes (Mineau \& Trussell, 1982). Second, higher age differences are associated with a higher risk of marital dissolution due to widowhood or severe sickness of either the husband or the wife. Finally, less palpable but perhaps more substantial effects of large age differences on reproduction can be observed through its effect on variables affecting coital frequency, such as marital stability and satisfaction, preferences concerning family size and the use of contraception (Barbieri et al., 2005; Casterline et al., 1986; Knodel, 1988; McDonald, 2000). Together, these elements reflect both direct effects of a higher age of either the wife or the husband on fertility (the ability to have children), as well as the way how reproductive decisions are made depending on the degree of equality between the husband and the wife (the nature of the relationship).

The literature provides mixed evidence for the relationship between spousal age differences and fertility. Skinner (1993) has developed an index of conjugal power which is identified by a combination of the wife's age at marriage and the age difference between husband and wife. His analysis suggests that conjugal power is connected to specific reproductive decisions, such as infanticide, abortion and early stopping of childbearing in the case of Tokugawa Japan. While Skinner demonstrates the role of spousal age differences, he also acknowledges that the absolute age of the wife accounts for a large part of the observed fertility outcomes (Skinner, 1993, p.263). In a comparative study using historical individual and household level data from three European regions and two Asian regions, Feng et al. (2010) observe that the age difference between spouses significantly reduces the likelihood of a next birth if the husband is at least six years older than the wife. This association is observed in both Western and Eastern societies. For wife-older marriages however, the likelihood of a next birth is only significantly higher in North-Eastern China. They argue that the lower probability of parity progression in husband-older marriages may indicate a negative physiological effect of the husband's older age or the wife's younger age, or it may be the result of a lower desired fertility compared to couples where the spouses are more age-homogamous. A different result is found by Abadian (1996) who examined the impact of female autonomy, operationalized by the mean spousal age difference, the mean age at marriage and the percentage of female enrolment in secondary education, on total fertility rates in a comparative study of 54 countries in the 1990s. Abadian (1996) 
finds that, between countries, fertility rates are inversely correlated with the age at marriage and female education but not with the spousal age difference. Barbieri et al. (2005) examine the effects of spousal age differences, used as a proxy for the degree of equality between spouses, on contraceptive use in eighteen SubSaharan African countries during the 1990s. They find that couples with small age differences are more likely to use contraceptives than husband-older couples.

An important question is whether women with greater autonomy with respect to their husband would use their conjugal power to either enhance or restrict reproductive outcomes, or whether there would be any effect at all on fertility outcomes. The empirical literature does not provide a definitive answer to this question. Given that the physical burden of childbearing is higher for women than men, it is arguably in the interest of the wife to postpone the birth of subsequent children or to have fewer children. Women with more authority in the decision-making process regarding having children may therefore be more likely to postpone childbirth. However, evolutionary biology suggests that all individuals face a trade-off between the costs of reproduction and the benefits of having children in terms of inclusive fitness (Conde-Agudelo et al., 2006, 2007; Hamilton, 1964a,b; Hrdy, 2009; Mace, 2014). This would suggest that women with greater conjugal power can be more successful in increasing their fertility compared to women with less conjugal power. An important assumption for the association between conjugal power and fertility outcomes is that fertility preferences between husbands and wives are different. If fertility preferences between men and women are similar, it follows that there is no association between conjugal power and fertility outcomes. As described above, the empirical evidence from the literature is mixed; some studies find shorter birth intervals for wife-older marriages in some regions (Feng et al., 2010), while others find that husband-older marriages are indicative of shorter birth intervals (Upadhyay et al., 2014).

\subsection{Marriage and reproduction in 19th century Sweden}

The demographic transition in Sweden started around 1810 when infant mortality began to decline steadily, followed by a permanent decline in birth rates after the 1870s (Brändström \& Sundin, 1981; Hofsten \& Lundström, 1976). Swedish marriages in the nineteenth century were not only an arrangement between two families, but also a social construction in which social norms carried by the law, the Church and the local community played an important role. The Civil Code of 1734 gave both spouses an even share of the property that was held in common and all children born within wedlock became legal inheritors to their parents. The law 


\subsection{MARRIAGE AND REPRODUCTION IN 19TH CENTURY SWEDEN}

also stipulated that no person could be forced into marriage (Giftermålsbalken, ch. 1:5). ${ }^{1}$ While parental influences on the choice of the marriage partner were visible through the parents' involvement in marriage negotiations and their right to disinherit children who married against the parents' will, Swedish legislation made it possible for marriages to be formed on the basis of romantic love (Aagren, 2009; Dribe \& Lundh, 2014; Lundh, 2003; Van de Putte et al., 2009).

Deeply rooted in the old Germanic tradition was the custom of betrothal, or engagement. The introduction of Christianity in the early 13th century did not dismiss the ritual but instead made its role more prominent. The betrothal signified the commitment of both partners, as well as their families, to the marriage. The 1734 Marriage Code required that all Christian weddings, the only legal form of marriage, were announced by the publishing of the marriage banns and the betrothal was to precede the wedding. This gave the betrothal legal effects and children of betrothed couples had the same rights of inheritance as if they were born in wedlock. If the fiancé refused to marry after being betrothed, the woman held her right to her share of the property in the man's household (Lundh, 2003).

Although betrothal affirmed the status of women, an unmarried woman had no authority over herself and was placed under a male person, usually her father, who acted as a guardian (giftoman) on her behalf (Giftermålsbalken ch. 1 par 1.2). Since unmarried children were considered to belong to the parental household, parents had the right to disinherit children if they married against the will of the parents, even in case of remarriage after widowhood (Giftermålsbalken ch. 6). The influence of the parents is also visible in the help parents offered in selecting a suitable partner, although the paternal influence was stronger for women than for men who could more easily refuse the involvement of their parents (Dribe \& Lundh, 2014). Contemporary narrators describe how farmers in particular had a strong influence on their daughter's partner selection, striving to retain the size of the parental homestead. Also, marrying 'beneath' one's social position was strongly resisted and could leave a couple 'standing outside the village'; to fall out of favor from the community (Dribe \& Lundh, 2014, p. 230). Parents generally sought for wealthy partners from within the same social group.

The suitor traditionally provided the woman's guardian with a gift (vängåva) at their engagement. The value of this gift was dictated by law, though before the nineteenth century it had become customary to hand the gift directly to the bride herself. In case the betrothal agreement was violated, the party not upholding the promise was forced to return the betrothal gifts and to pay an additional fine to the other family. At marriage, the bride's parents would provide her with a dowry (medgift), traditionally consisting of a bed, money or various household utilities.

\footnotetext{
${ }^{1}$ The 1734 Giftermålsbalken, Swedish marriage laws, are available online at https://sv.wikisource.org/wiki/Giftermålsbalken.
} 


\section{CHAPTER 4. SPOUSAL AGE DIFFERENCES}

The dowry remained private property of the bride, though administered by the husband, and was to be reverted to the bride's family in case the marriage ended. Apart from her dowry, the wife received a gift from her husband on the day after the wedding (morgongåva), which became the woman's private property and was intended to provide her with support in case of widowhood (Aagren, 2009; Dribe \& Lundh, 2014).

Besides the law and the parents, the Church also had a strong influence on premarital relationships in Sweden. Given the relatively small geographical size of the marriage market, the Sunday service in the parish church provided a place for youngsters to meet in person just as the local market did. The Christian moral towards prenuptial sexual relations was strongly negative. The Church strongly opposed premarital conceptions and required the payment of a fine which corresponded to about one month's pay for a farm hand (Kälvemark, 1980, p. 330). However, the fact that legislation was in place to protect betrothed women and their children in case the husband violated the wedding agreement, was a clear sign that in practice premarital sexual relations were widespread. Farmers in particular appear to have had a pragmatic attitude to premarital intimate relationships - for example in case the harvest or costly wedding preparations would delay marriage - as long as the couple would marry later (Dribe \& Lundh, 2014). In spite of the moral against premarital conception, Kälvemark (1980) observes that illegitimate births were indeed numerous in southern Sweden as around 8 to 14.9 percent of all married women had given birth out of wedlock and premarital conceptions were found to occur to around a third of all married couples.

Similar to other West-European countries, married couples in nineteenth century Sweden were expected to set up an independent household (Hajnal, 1982; Laslett \& Wall, 1972). The man was to have an occupation that could support a family and was expected to have saved enough money to set up the household. Consequently, entry into marriage was fairly restricted causing a considerable proportion of the population to remain unmarried and resulting in a relatively high age at first marriage. Several arrangements facilitated the acquisition of household goods, a home and money for the wedding. Access to land or a home could be provided through inheritance from the parents of both partners given in advance as a wedding gift. Inheritance rights were by law equal since 1845, although in practice one heir could still be favoured by setting a low price on the property, giving him or her the advantage to buy out the other siblings on favourable terms (Aagren, 2009; Lundh, 2003). Relatives, friends and other attendants of the wedding also helped to set up the household as it was customary to bring household utilities as gifts for the newly-wed couple. Relatives who lived further away, and 


\subsection{HYPOTHESES}

could not attend the wedding, usually sent money. Lundh (2003) argues that the institution of wedding gifts in central and northern Sweden had a prominent role in affirming social relations as the names of the givers and the value of the gift were announced in public during the wedding. Reciprocity was another important aspect of the wedding gifts; those who received support were obliged to return the favour if needed (Lundh, 2003). This gave a strong sense of communal cooperation to the wedding. Guests were also expected to contribute to the wedding feast by bringing food and drinks. The combination of these arrangements made the financial burden of the wedding easier to carry for the betrothed couple.

During the nineteenth century, the legal minimum age at marriage in Sweden was increased from 15 to 17 years for women and from 20 to 21 years for men (Lundh, 2003, p. 41). The actual average age at marriage was around 25 years for women and 27.5 years for men in the regions of Sundsvall and Skellefteå over the entire course of this study. Although the Swedish people married relatively late, these ages are in accordance with other countries in north-western Europe (Hajnal, 1982).

Taken together, Swedish marriages in the nineteenth century were characterized by considerable equality between the spouses. The homogamous nature of the marriage is reflected in various elements of the marital union. A betrothed woman and her illegitimate children were protected in case the man did not comply with the betrothal agreement. By law, the husband could be married to only one wife at the same time. Furthermore, the wife had a right to a half share of the property held in common in the rare case a divorce occurred. Since the Civil Code of 1734 up until 1915, the legally recognized causes for divorce were abandonment and adultery, although it was opposed by the Church and socially not well accepted (Lundh, 2003, p. 11-12). The homogamous nature is also reflected in the selection of partners. Although parents could influence the choice of a partner, youngsters in the nineteenth century became increasingly able to express their own preferences due to the rise of wage labour and the increase of the landless population. The relatively small age difference between the spouses may provide a clear indication of the equal nature of nineteenth century Swedish relationships compared to other societies (Cain, 1993).

\subsection{Hypotheses}

Following Casterline et al. (1986), the spousal age difference can be considered as an indication of the nature of the relationship and the ability to have children. These two aspects facilitate the development of the hypotheses, which are formulated below. It is important to recognize that fertility outcomes depend 
on a multitude of factors, including socio-economic conditions, customs or other cultural aspects and of course the age of both the husband and the wife. These factors are all assumed to be constant in the formulation of the hypotheses.

Ability to have a child The existence of a spousal age gap by default entails that one of the spouses is older and therefore has a higher risk of mortality or infecundity. The wife's age is the most important influencing factor in her ability to have a child (Bongaarts \& Potter, 1983; Wilson et al., 1988), although the chance of having a child also decreases when her husband reaches a higher age and is more likely to become ill or pass away. Furthermore, other non-physiological factors such as marital satisfaction and sexuality may be inversely correlated with age (Casterline et al., 1986). From this point of view, a larger age gap between husband and wife reduces - ceteris paribus - their ability to have children. Therefore: For a given age, women in age-homogamous marriages are more likely to enter parenthood, to have shorter birth intervals and to have a larger number of children ever born, compared to women (of similar age) in husband-older relationships (H1).

Nature of the relationship Age differences can lead to fertility outcomes that are more beneficial to the older partner if he or she is better able to influence decisions regarding reproduction. The assumptions here are that age differences reflect the older partner's autonomy, that fertility preferences differ between partners, and that a woman wife with greater conjugal power strives to increase her fertility. Controlling for the wife's age and other characteristics it is hypothesized that: For women of similar age, birth intervals will be shorter for wife-older couples and longer for husband-older couples, compared to same-age couples. Furthermore, wife-older couples are likely to have more children and husband-older couples are likely to have fewer children compared to same-aged couples (H2a).

Alternatively, assuming women with greater conjugal power strive to reduce fertility in order to reduce the biological costs of pregnancy: For women of similar age, women in wife-older couples will have a later entry into parenthood, longer birth intervals, and fewer children compared to same-aged and husband-older couples (H2b).

\subsection{Data, measures and methods}

\subsubsection{Data}

The data used in the analysis are obtained from the POPUM and POPLINK databases of the Demographic Data Base (DDB). The DDB is a large, histori- 


\subsection{DATA, MEASURES AND METHODS}

cal population database containing linked individual-level records from Swedish parish registers. The parish records contain event registrations such as births, baptisms, banns, marriages, deaths and migration (Alm-Stenflo, 1994; Jeub, 1993). Parish registration was regulated by canon law since 1686 , but variations occurred in the way events were registered. The establishment of the Statistical Commission (Tabellverket) in 1749 and the introduction of printed forms in the 1780s led to uniform methods of population registration. The DDB has digitized the registers of a select number of parishes, allowing for the construction of individual life histories of people living within these parishes.

An important advantage of the DDB for this study is that it is possible to follow individuals over the life course, for as long as they remained present within a parish registered in the DDB. Event registrations such as date and place of birth, marital status, sex and occupation are available for each individual, as well as their relationship to other family members. The DDB data furthermore includes information on the exact period during which a person is observed. While the quality of the DDB is high and the number of registered people in the database is large, there are some limitations to its use. First, the digitization of parish registration is not complete. This means that information on people moving to neighbouring parishes can be lost when this parish is not available within the database. This means that not everybody can be followed throughout their entire life. However, information up to the moment of out-migration can be used. Second, the records were maintained by the parish clergy, whose task was to continuously update the birth and baptismal registers, registers of banns and marriages, registers of deaths and burials, migration lists and catechetical lists (including details about church attendance and knowledge of the scriptures). In fast-growing parishes, or municipalities where servants, soldiers or lodgers frequently moved in and out of the parish, it was difficult for the parson to record the required information. In addition, depending on the quality of the registration done by hand, the treatment of the books and the occurrence of accidents, there are gaps as not all material could be preserved and digitized (Jeub, 1993).

This study is based on the life histories of 8,258 women born between 1840 and 1890 in the regions of Sundsvall and Skellefteå in central and northern Sweden. The following criteria are set for the inclusion of each individual woman in the analysis; she was born in the area of Sundsvall or Skellefteå, or entered a parish in this region at the age of 18 years or younger; she was married at least once; and the parish registration includes information on the occupation of her husband. The sample size for the analysis of completed fertility is smaller than for parity transition, due to migration to an unknown parish, marriage dissolution, the death of either the wife or the husband, or due to clerical errors. Complete 


\section{CHAPTER 4. SPOUSAL AGE DIFFERENCES}

information is available for 6,235 women. This means that they did not migrate to an unknown parish until the age of 45 years, and that both the wife and the husband survived until age 45. The construction of the sample emphasizes the observation of complete birth histories of women. This gives the sample a bias towards people who did not migrate, other than to other parishes registered in the DDB. Given the institution of domestic service, life histories of many people are truncated. As can be seen in the description of the data below, a large share of the population in this sample belonged to the farmer's class while the Swedish society as a whole witnessed industrialization and an increase of the landless labouring class during the second half of the nineteenth century.

\subsubsection{Outcome variables}

The analysis focusses on the effects of spousal age differences on the waiting time to first and subsequent births, as well as on the total number of children ever born. The locus of the analysis is the wife. For each woman, a life history is constructed which contains details on the date of her birth and that of her first husband, her date of first marriage, the birth dates of her children and the end of her observation window. The observation window ends with either her own death, the death of her partner, the dissolution of her first marriage or migration to a parish not registered in the DDB. For the purpose of counting the number of children ever born, the sample is further restricted to women who are observed in the DDB until the age of 45 years. Stillbirths, diseased deceased children and multiple births are included in the counting of the number of children ever born. In order to simplify the analysis, second or later marriages of both wife and husband are excluded. The outcome variables are the woman's age at first birth, the duration of the interval between subsequent births, and the total number of children born. The birth interval is a useful indicator of fertility and is frequently used in the literature on reproduction (see e.g. Feng et al., 2010; Van Bavel \& Kok, 2004, 2010; Van Poppel et al., 2012).

\subsubsection{Independent variables}

The age difference between spouses is the main independent variable in this analysis. The age difference is included here using dummy variables, where the reference category is an age difference between spouses of at most two years. An age difference of more than two years is coded separately for wife-older marriages and husband-older marriages. The definition of same-age marriages as marriages where the age difference between spouses is at most two years is also used in Van de Putte et al. (2009). In contrast, Feng et al. (2010) consider marriages where 


\subsection{DATA, MEASURES AND METHODS}

the husband is zero to five years older as age homogamous. For the present study, the use of other ranges did not influence the outcomes of the analysis to a great extent.

Table 4.1 provides descriptive information for the different variables used in the models. The husband is older than the wife in around half of all couples. Wife-older marriages are least frequently observed and their share decreased over time from around 22 percent to around 14 percent of all marriages. In contrast to Van de Putte et al. (2009), the data in this sample does not indicate an increase in age homogamy over time. This is presumably due to the selection of couples, as discussed above, with a majority belonging to the farmer's class and displaying regional immobility.

Table 4.1: Descriptive statistics

\begin{tabular}{|c|c|c|c|c|}
\hline Variable & Wife older & Same age & $\begin{array}{r}\text { Husband } \\
\text { older }\end{array}$ & Total \\
\hline Observations $^{\mathrm{a}}$ & $1413(17.1 \%)$ & $2467(29.9 \%)$ & $4378(53.0 \%)$ & 8258 \\
\hline \multicolumn{5}{|l|}{ Birth cohort $(\mathrm{N})$} \\
\hline $1840-1849$ & $396(22.2 \%)$ & $562(31.5 \%)$ & $827(46.3 \%)$ & 1785 \\
\hline $1850-1859$ & $433(19.5 \%)$ & $694(31.2 \%)$ & $1095(49.3 \%)$ & 2222 \\
\hline $1860-1869$ & $279(13.1 \%)$ & $615(29.0 \%)$ & $1230(57.9 \%)$ & 2124 \\
\hline $1870-1879$ & $172(14.2 \%)$ & $315(25.9 \%)$ & $728(59.9 \%)$ & 1215 \\
\hline $1880-1889$ & $133(14.6 \%)$ & $281(30.8 \%)$ & $498(54.6 \%)$ & 912 \\
\hline \multicolumn{5}{|l|}{ Region $(\mathrm{N})$} \\
\hline Sundsvall & $514(15.4 \%)$ & $1004(30.1 \%)$ & $1823(54.6 \%)$ & 3341 \\
\hline Skellefteå & $899(18.3 \%)$ & $1463(29.8 \%)$ & $2555(52.0 \%)$ & 4917 \\
\hline \multicolumn{5}{|l|}{ Social class $(\mathrm{N})$} \\
\hline Foremen to higher & $144(18.5 \%)$ & $218(27.9 \%)$ & $418(53.6 \%)$ & 780 \\
\hline Farmer & $675(15.0 \%)$ & $1298(28.8 \%)$ & $2533(56.2 \%)$ & 4506 \\
\hline Medium and lower skilled & $530(21.4 \%)$ & $824(33.3 \%)$ & $1124(45.4 \%)$ & 2478 \\
\hline $\begin{array}{l}\text { Lower manual and unskilled } \\
\text { farm worker }\end{array}$ & $64(13.0 \%)$ & $127(25.7 \%)$ & $303(61.3 \%)$ & 494 \\
\hline \multicolumn{5}{|l|}{ Age of wife $\mathrm{e}^{\mathrm{e}}$} \\
\hline Age at first marriage & $29.4(3.8)$ & $25.4(3.3)$ & $23.2(3.7)$ & $24.9(4.3)$ \\
\hline Age at first birth & $29.8(4.1)$ & $26.0(3.6)$ & $23.9(3.8)$ & $25.5(4.4)$ \\
\hline Age at last birth ${ }^{\mathrm{b}}$ & $39.0(5.0)$ & $38.1(5.6)$ & $36.6(6.2)$ & $37.4(5.9)$ \\
\hline \multicolumn{5}{|l|}{ Age of husband ${ }^{\mathrm{e}}$} \\
\hline Age at first marriage & $24.6(3.1)$ & $25.6(3.3)$ & $29.5(4.8)$ & $27.5(4.6)$ \\
\hline Age at first birth & $25.0(3.6)$ & $26.2(3.5)$ & $30.1(4.9)$ & $28.1(4.9)$ \\
\hline Age at last birth ${ }^{\mathrm{b}}$ & $34.2(5.2)$ & $38.3(5.6)$ & $43.1(6.8)$ & $40.2(7.1)$ \\
\hline
\end{tabular}


Table-4.1: Continued from previous page

\begin{tabular}{|c|c|c|c|c|}
\hline Variable & Wife older & Same age & $\begin{array}{r}\text { Husband } \\
\text { older }\end{array}$ & Total \\
\hline \multicolumn{5}{|l|}{ Children ever born ${ }^{\mathrm{e}}$} \\
\hline Overall mean & $4.9(2.6)$ & $6.0(3.0)$ & $6.1(3.2)$ & $5.9(3.1)$ \\
\hline Mean Sundsvall & $4.0(2.3)$ & $4.8(2.9)$ & $4.9(3.1)$ & $4.8(3.0)$ \\
\hline Mean Skellefteå & $5.2(2.6)$ & $6.3(3.0)$ & $6.5(3.2)$ & $6.2(3.1)$ \\
\hline \multicolumn{5}{|l|}{ Previous child ${ }^{\mathrm{c}}$} \\
\hline Twins & $1.36 \%$ & $1.22 \%$ & $1.36 \%$ & $1.32 \%$ \\
\hline Died within eight months ${ }^{\mathrm{d}}$ & $7.36 \%$ & $7.94 \%$ & $8.08 \%$ & $7.93 \%$ \\
\hline Died after eight months ${ }^{\mathrm{d}}$ & $2.87 \%$ & $3.15 \%$ & $3.20 \%$ & $3.14 \%$ \\
\hline
\end{tabular}

Independent variables are: Wife two or more years older; Same age (-2 up to 2 years); Husband two or more years older.

Source: DDB, see text. (CEDAR). POPLINK and POPUM version 4.4.2

(a) Number of observations. Based on sample of all women in the sample (row percentages between parentheses, $\mathrm{N}=8,258$ ).

(b) Based on a sample of women with complete life-course information $(\mathrm{N}=6,235)$.

(c) Proportion of all observed childbirths.

(d) Indicator for death of child before birth of next child.

(e) Standard deviation in parentheses.

Significance: $\dagger \mathrm{p}<0.1, * \mathrm{p}<0.05, * * \mathrm{p}<0.01, * * * \mathrm{p}<0.001,-$ not present

In order to control for changes in socio-economic or cultural conditions and fertility over time, dummy variables are included for the birth cohort of the wife. Community-level characteristics are controlled for using a dummy variable for the region where the wife is born. Two regions are selected based on the quality and availability of data; Sundsvall, near the Gulf of Bothnia around 400 kilometres north of Stockholm, and Skellefteå, which is located along the same coast around 350 kilometres north of Sundsvall. Forestry was the main economic sector in the first half of the nineteenth century in both Skellefteå and Sundsvall, while in Sundsvall agriculture also played an important role. The cities were small and population density was low compared to other European cities. From the 1850s, industrialization and international trade spurred economic growth, particularly in the Sundsvall region, and encouraged the development of shipyards and iron foundries (Alm-Stenflo, 1994; Schön, 1997).

The husband's occupation around marriage is used as a proxy variable to control for individual-level differences in social status. The DDB contains information on occupations in the form of HISCO codes which are converted to the HISCLASS classification scheme. The HISCLASS scheme allows for a systematic comparison of social positions, based on occupational titles (Van Leeuwen \& Maas, 2011; Van Leeuwen et al., 2004). The combination of smaller groups pro- 


\subsection{DATA, MEASURES AND METHODS}

duces four broad social classes, which are included as dummy control variables and are coded as follows: (1) foremen to higher occupations (non-manual labor), (2) farmers, (3) medium and lower skilled workers, and (4) lower manual or unskilled (farm) workers. As Table 4.1 shows, most couples in the sample belonged to the farmers' class $(N=4,506$, or $54.6 \%)$, followed by medium and lower skilled workers.

Individual level differences in past reproductive outcomes are controlled for by the inclusion of dummy variables for the occurrence of multiple births and the death of the previous child. Previous multiple births may serve as an exogenous factor influencing the time to conception of the next child given the extra care required to nurture two or more children compared to one. A twin birth increases the birth order of the following child by two, instead of one, so if a woman had twins at first childbirth, the subsequent childbirth is registered as the third parity. The death of a child before and after eight months, both before the birth of the next child, are coded separately using time-varying dummy variables. The death of a previous child may induce a replacement effect and may thus shorten the time to conception of the next child (Derosas, 2006; Knodel, 1982; Van Bavel \& Kok, 2004, 2010). Because breastfeeding can delay the return to ovulation, the child's survival decreases to a certain degree a woman's chance of becoming pregnant again (Gray et al., 1990; Santow, 1987).

Finally, the age of the wife at marriage or previous birth is included to account for the effects of age on fecundity (Van Bavel \& Kok, 2004). Table 4.1 shows that women in wife-older marriages had the highest age at marriage and highest age at first birth, followed by women in same-age marriages and husband-older marriages. The mean age at first marriage is comparable to what is observed elsewhere in Sweden (Kurosu \& Lundh, 2014).

\subsubsection{Methods}

The analysis of the effects of spousal age differences on reproductive outcomes is split up into two parts. First, Cox proportional hazard models are fitted to examine whether women's age at first birth and the likelihood of parity transition were associated with the spousal age gap. The chance of a birth occurring, given a particular age difference between the spouses, is expressed as a coefficient that denotes the hazard of having a child over time relative to an unspecified baseline hazard (Cleves et al., 2010). The assumption of proportionality is examined using Schoenfeld residuals and all models are stratified on the birth cohort of the wife. Each parity transition is estimated separately and control variables are included for the effects of the wife's age, social status, regional differences and the occurrence of multiple births or child deaths since last birth. Each parity transition 


\section{CHAPTER 4. SPOUSAL AGE DIFFERENCES}

sample includes women who do not have a next childbirth. Birth intervals of more than seven years were excluded from the analysis of each parity transition $(N=280)$. Analysis time is defined in years, with the woman's birth date as the onset of risk of first birth, and the date of previous birth for each subsequent birth. The death of previous children is included as a time-varying covariate, changing the value of the dummy and creating a new episode when the previous child died.

Second, the association between the total number of childbirths and the spousal age gap is examined using Poisson regression. The baseline model includes controls for social status, regional differences and temporal variations. The effects of the wife's age at marriage on the total number of children born are examined in a separate model.

\subsection{Results}

Descriptive statistics for the outcome variable are provided in Table 4.2 and figure 4.1. Table 4.2 reports the mean length of closed birth intervals by parity and birth cohort of the wife. Figure 4.1 shows the mean age at first and last birth over time, in relation to the age difference between husband and wife. The average age at first birth and the average number of children born remained fairly constant over time. Looking at the timing of subsequent births in table 4.2, the length of the birth interval increased over the life course of individuals, but slightly decreased over time. The relatively small number of children born to the 1880 cohort is due to the fact that for this cohort only a small number of complete life courses is available. The proportions of first born children distributed by their relation to the timing of marriage, are similar to observations for southern Sweden by Dribe and Lundh (2014) and Kälvemark (1980). A considerable proportion of births occurred before or within nine months after marriage, but around half of all births occurred after nine months of marriage. As discussed above, the general attitude towards premarital sexual behaviour was contradictory - the Christian moral opposed such relations while legislation strengthened the position of pregnant women during betrothal.

Figure 4.1 indicates that for women, who are followed from age 18 to 45, age at first and last birth were relatively constant over time. Between marriage types, there seem to be little difference in the age at last birth, but the age at first birth is highest for women who are married to a younger husband. In contrast, women with an older husband had their first child at a relatively young age. Note that figure 4.1 represents the absolute age at childbirth and does not control for differences in other characteristics such as age at marriage. 
4.6. RESULTS

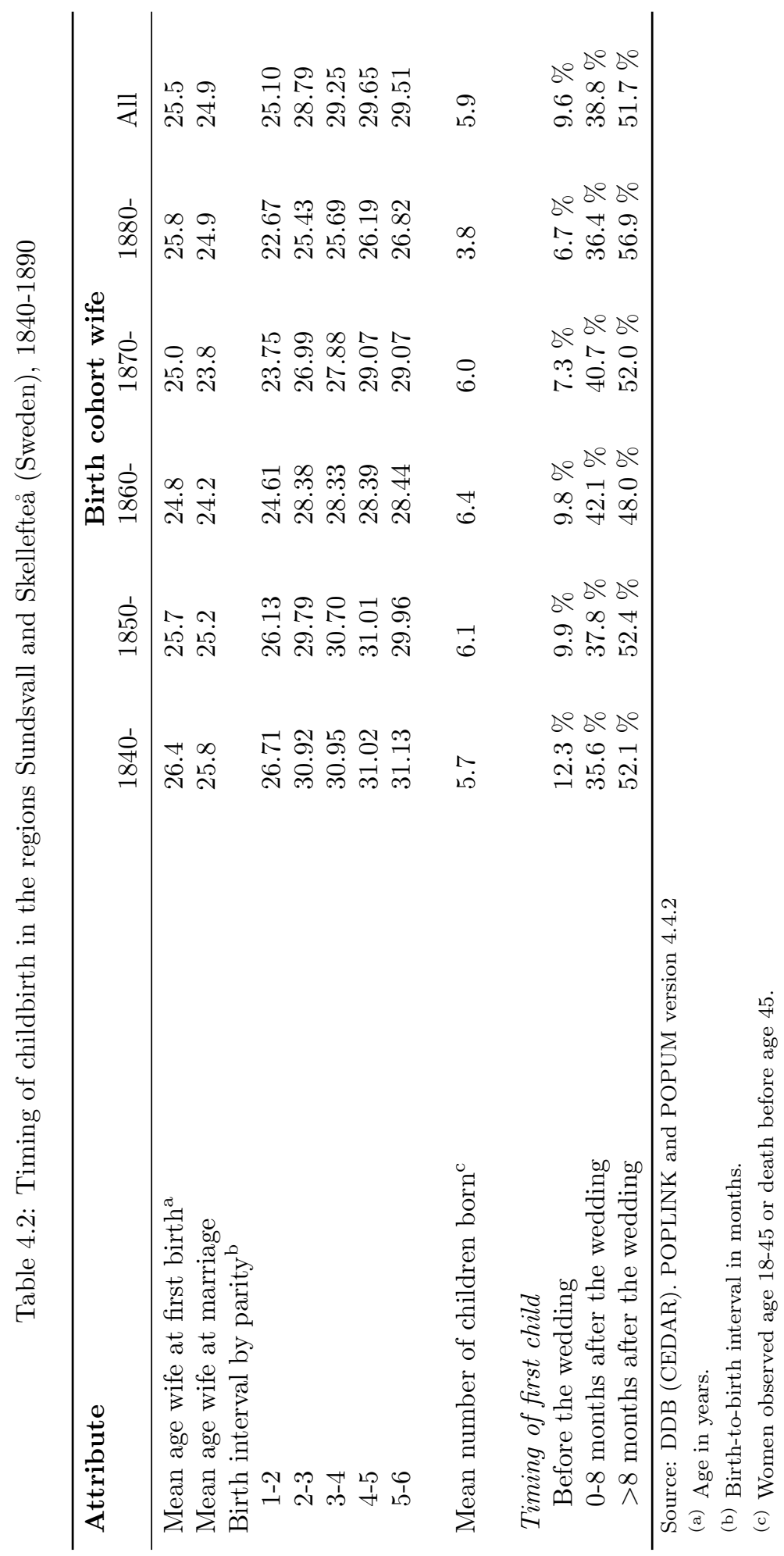


Figure 4.1: Average age at first and last birth in Sundsvall and Skellefteå (Sweden), 1840-1890, by spousal age difference

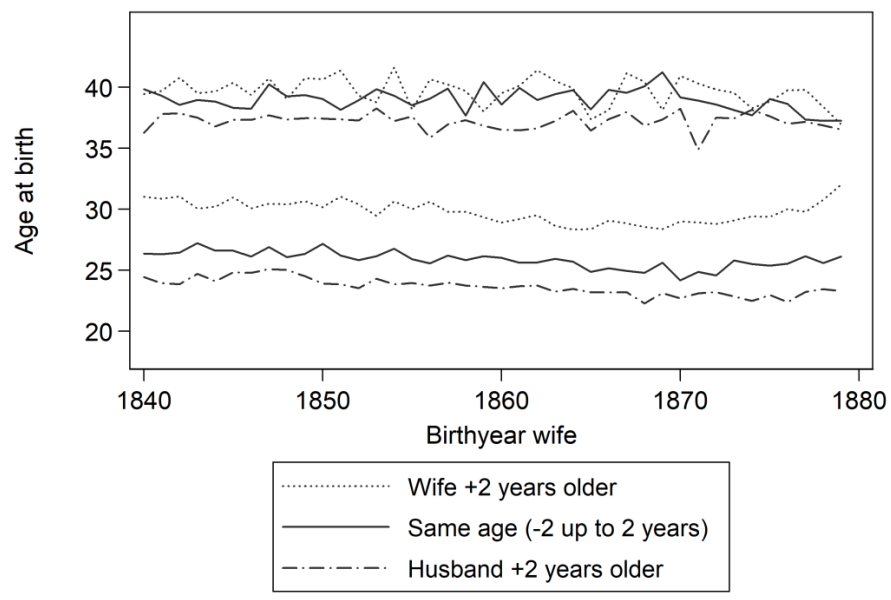

Note: The upper three lines show the average age of women at last childbirth, the bottom three lines show the average age of women at first childbirth $(\mathrm{N}=6.235)$.

Source: CEDAR. POPLINK and POPUM version 4.4.2 (see text).

Table 4.3 provides hazard ratios for the Cox proportional hazard models for each open birth interval. The first column provides the estimates for the transition to first birth. Column 2 provides the estimates for the hazard of a second birth for all women who already had one childbirth (including still births). Columns 3 indicates the hazard of a third birth for all women who had two childbirths (including multiple births and still births), and so on. The regression parameters are given in exponentiated form and represent the waiting time (in the form of hazard ratios) until next childbirth relative to the reference category (women in same-age marriages). A value greater than one represents a higher risk of having a child as time progresses, meaning a shorter interval between childbirths, while a value lower than one represents a longer interval compared to the reference category. All event history models are stratified on the wife's birth cohort, temporal variations in the duration of the birth interval are therefore controlled for but not visible in these models. 
4.6. RESULTS

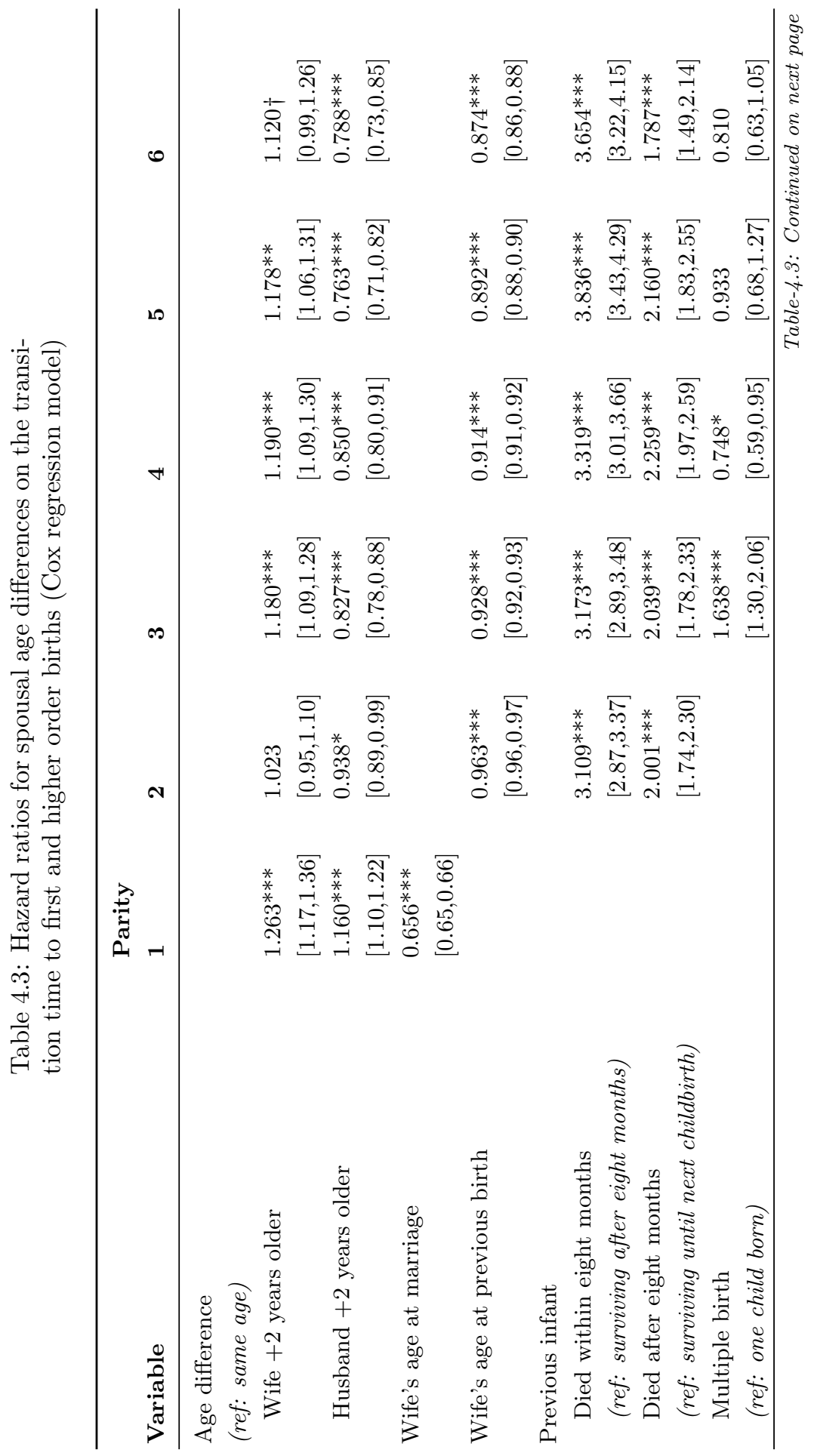


CHAPTER 4. SPOUSAL AGE DIFFERENCES

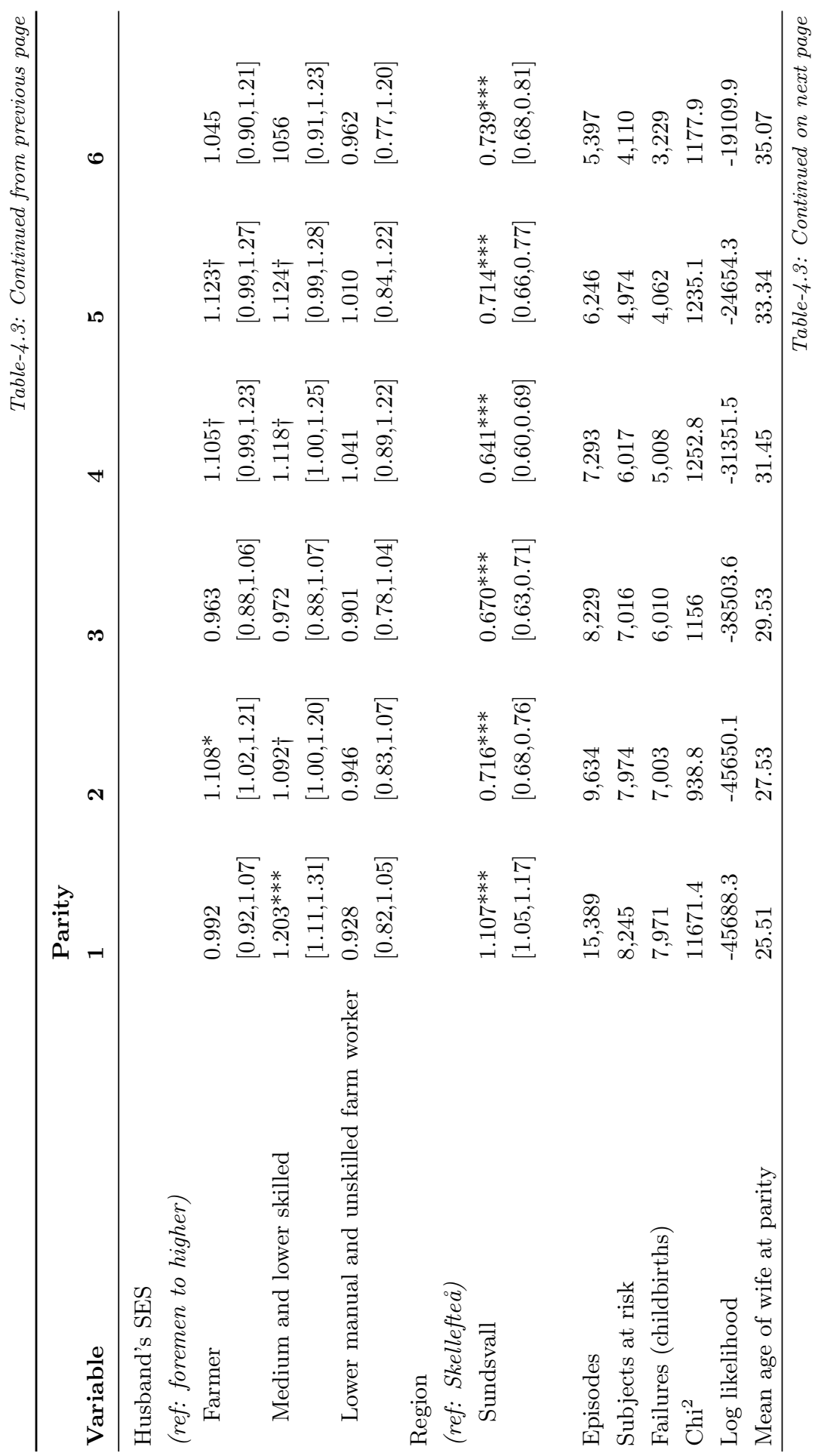


4.6. RESULTS

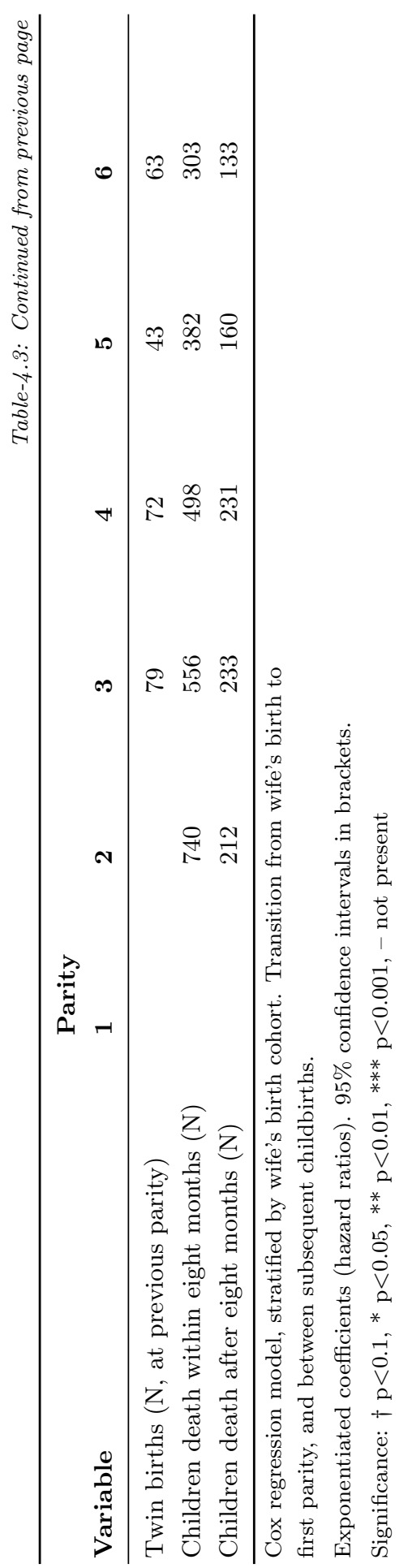




\section{CHAPTER 4. SPOUSAL AGE DIFFERENCES}

The results indicate that, controlled for the age at marriage, the hazard of a first childbirth (column 1) is higher for both wife-older and husband-older couples, compared to same-age couples. Given a particular age at marriage, women who were at least two years older or younger than their husband had their first child at a lower age compared to women in age-homogamous couples. In other words, age-homogamous couples were likely to be more able in delaying the birth of the first child. Age at marriage itself is, as expected, positively associated with age at first birth, meaning that women who married later were having their first child at a higher age. Between social classes, little differences are visible except for an increased likelihood of first childbirth for couples where the husband had a medium or lower skilled occupation compared to the reference group of foremen and higher occupations. The hazard ratio for the birth of the first child was higher in the economically and industrially more developed region of Sundsvall compared to rural Skellefteå.

Looking at the parity transition rates from first to second birth (column 2), second to third birth (column 3), etc., it can be observed that the likelihood of a subsequent birth is higher in wife-older marriages and lower in husband-older marriages compared to age-homogamous marriages. This finding is robust for other specifications of age differences (e.g. 0-5 years as reference). The results are significant for all parity transitions, except for the transition from first to second birth in the case of wife-older marriages (column 2). The age of the wife at previous birth is included as a control variable for fecundity and as expected this variable is negatively associated with the hazard of parity transition. The loss of a previous child significantly increases the likelihood of a subsequent birth, regardless of whether the previous child passed away within eight months after birth or later. Multiple births are adjusted for in the sense that these women 'skip' a parity. If the first birth is a twin birth, the next birth is registered as the third parity. Women whose first birth were twins had a significantly higher hazard of parity transition, but this result should be seen in light of the fact that they had been pregnant only once until the birth of the third child. In contrast, the occurrence of multiple births significantly reduced the likelihood of transitioning to the fourth parity, either because the care of raising multiple young children required considerable energy from the parents causing the delay of the next birth, or because the parents stopped having children altogether. For higher order parities the occurrence of multiple births has no significant effect. Similar to what is observed for the transition to first birth, there are only small differences between social groups regarding parity transition. Farmers and medium or lower skilled workers seem to have higher hazards of parity transition for some birth intervals compared to couples where the husband was a foreman or higher, but 


\subsection{RESULTS}

with no clear pattern. Between regions, the birth interval was longer for women living in Sundsvall than in Skellefteå.

Table 4.4 provides the results of two Poisson regression models for the association between spousal age differences and the total number of childbirths for all women observed from age 18 until age 45. Both model 1 and 2 include control variables for socio-economic status, regional differences and cohort effects. In the second model, the wife's age at marriage is included as an additional control variable. As in Table 4.3, a regression coefficient greater than one denotes a positive association between the number of children born and the independent variable, while a coefficient smaller than one indicates a negative association.

Without controlling for the wife's age at marriage, the first model in Table 4.4 shows that women in wife-older marriages had fewer children ever born compared to women in age-homogamous marriages, while husband-older couples had more children. These associations are in line with Table 4.1, which shows that on average women in wife-older marriages had 4.9 children compared to 6.1 children in husband-older marriages and 6.0 children in age-homogamous marriages. However, after controlling for the woman's age at marriage (model 2), age differences between spouses show another association with the number of children born. After controlling for the age of women at marriage, women who were married to a younger husband were likely to have as many children as women in age-homogamous marriages. In contrast, women who were married to an older husband, were likely to have slightly fewer children over their life course compared to age-homogamous couples. As expected, the age of the woman at marriage itself is inversely associated with complete family size.

Table 4.4: Effect of spousal age differences on children ever born (Poisson model)

\begin{tabular}{lll}
\hline Variable & $\begin{array}{l}(\mathbf{1}) \\
\text { Baseline model }\end{array}$ & $\begin{array}{l}(\mathbf{2}) \\
\text { Including age }\end{array}$ \\
\hline $\begin{array}{l}\text { Age difference } \\
\text { (ref: } \text { same age) } \\
\text { Wife older }\end{array}$ & & \\
& & \\
Husband older & $0.822^{* * *}$ & 1.000 \\
& {$[0.79,0.85]$} & {$[0.97,1.04]$} \\
Wife's age at marriage & $1.039^{* *}$ & $0.926^{* * *}$ \\
& {$[1.01,1.06]$} & {$[0.90,0.95]$} \\
& & $0.950^{* * *}$ \\
& & {$[0.95,0.95]$} \\
\hline
\end{tabular}


Table-4.4: Continued from previous page

(1) (2)

Variable

Baseline model Including age

Husband's SES

(ref: foremen to higher)

Farmer

$1.169^{* * *}$

$1.105^{* * *}$

$[1.12,1.22]$

$[1.06,1.15]$

$1.136^{* * *}$

$1.094^{* * *}$

$[1.09,1.19]$

$[1.05,1.14]$

Lower manual and

$1.149^{* * *}$

$1.068^{*}$

unskilled farm worker

[1.08,1.23]

[1.00,1.14]

Region

(ref: Skelleftea)

Sundsvall

$0.747^{* * *}$

$0.723^{* * *}$

$[0.73,0.77]$

$[0.70,0.74]$

Wife's birth cohort

(ref: 1840-1849)

1850-1859

1.006

0.980

$[0.98,1.03]$

$[0.95,1.01]$

1860-1869

0.968*

$0.935^{* * *}$

$[0.94,1.00]$

$[0.91,0.97]$

$1870-1879$

$0.946^{* *}$

$0.924^{* * *}$

$[0.91,0.98]$

$[0.89,0.96]$

1880-1889

0.920 ***

$0.905^{* * *}$

$[0.89,0.95]$

$[0.87,0.94]$
Observations
6,235
6,235
$\mathrm{Chi}^{2}$
771.6
1946.7
Log likelihood
$-15918.7$
$-15331.2$

Poisson regression of children ever born to women followed age 18-45. Exponentiated coefficients; $95 \%$ confidence intervals in brackets.

Significance: $\dagger \mathrm{p}<0.1,{ }^{*} \mathrm{p}<0.05,{ }^{*} * \mathrm{p}<0.01, * * * \mathrm{p}<0.001,-$ not present

Looking at the effects of the other independent variables, the number of children born is negatively associated with husbands belonging to the foremen or higher class. Farmers and medium or lower skilled workers were likely to have more children, suggesting a connection with the significant positive hazard of parity transition for these socio-economic groups, as observed in Table 4.3. Fur- 


\subsection{DISCUSSION}

thermore, according to Table 4.3, women in Sundsvall had a higher hazard of first birth compared to Skellefteå, but birth intervals were longer in Sundsvall. The net effect observed in Tables 4.2 and 4.4 is that women in Sundsvall were likely to have fewer children overall. Finally, although cohort effects are not central to this study, fewer children were born to women born in later cohorts.

The results from Table 4.4 show that, after controlling for the age of the wife at marriage, the effects of the spousal age gap on the total number of children born are fairly small with a coefficient of 0.926 for husband-older marriages. In order to further illustrate the limited impact of spousal age differences on the number of children ever born, the total number of childbirths is set graphically against the age of the wife at marriage (figure 4.2. It is clear from this figure that women who married at a higher age had fewer children than those who married young. However, as figure 4.2 shows, it is hard to identify stark differences in the total number of children ever born between age-heterogeneous and age-homogamous couples.

Figure 4.2: Average number of children ever born in Sundsvall and Skellefteå (Sweden), 1840-1890, by spousal age difference and age at marriage

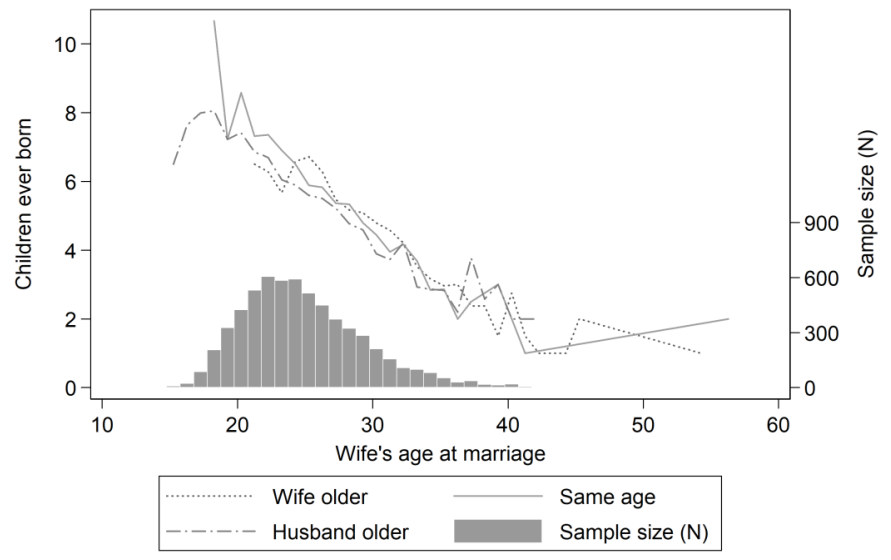

Note: Number of children ever born calculated for women followed age 18-45 $(\mathrm{N}=$ $6,235)$.

\subsection{Discussion}

What do these findings say about the relation between spousal age differences and reproductive outcomes? First it is important to recognize the difference between 


\section{CHAPTER 4. SPOUSAL AGE DIFFERENCES}

absolute effects of the age of the wife, and the relative effects of the spousal age gap. In all findings, the absolute age of the woman at marriage or previous birth is an important factor influencing the fertility outcomes of the couple, as a higher absolute age reduces the likelihood of transitioning to next childbirth. Table 4.1 shows that women in wife-older marriages on average had a higher age at first marriage compared to women in husband-older marriages. Women in wife-older marriages also had fewer children and started having children relatively late age of around 30 years on average, compared to women in husband-older marriages, who on average had their first child at the age of 24. Given that women in wife-older marriages on average started later but stopped at more or less the same age (see figure 4.1), they also had a shorter 'window' to have children until reaching menopause. Table 4.3 confirms that birth intervals were shorter for women in wife-older marriages compared to same-age or husband-older marriages after controlling for the woman's age. These findings show that a higher absolute age of women at marriage or previous childbirth reduces the hazard of first and subsequent births, and reduces the total number of children ever born.

Since all examinations include the age of the wife as a control variable, it is possible and perhaps more interesting to consider the relative effects of the spousal age difference on fertility outcomes, working not through fecundity but through differences in conjugal power. The results provide support for hypothesis $2 \mathrm{a}$, showing that after controlling for the age of the woman, women in wifeolder marriages have shorter birth intervals. This finding is similar to what is observed by Feng et al. (2010) for southern Sweden. Furthermore, in husbandolder marriages birth intervals are longer for higher parities and fewer children are born over the life course of each woman. These findings suggest that greater female autonomy, expressed by the spousal age gap, significantly affects fertility outcomes. After controlling for their age, it is shown that women in wife-older marriages are able to shorten their birth intervals compared to women of similar age in age-homogamous or husband-older marriages. Hypothesis 1 does not find support in our analysis, as age-homogamous couples do not stand out as early starters with short birth intervals and a relatively large number of children ever born.

However, some results presented above warrant further attention. The likelihood of first childbirth is higher not only for wife-older marriages, but also for husband-older marriages. This shows that within husband-older marriages there is some sort of 'catch-up effect' as the older husband is likely to encourage the birth of a first child. Furthermore, while women in husband-older marriages have slightly fewer children ever born, women in wife-older marriages do not have significantly more children compared to age-homogamous couples. The lower number 


\subsection{DISCUSSION}

of childbirths observed for women in husband-older marriages may suggest that either the fecundity of men decreases as they become older, thereby reducing their biological ability to have children, or that reduced marital satisfaction in husband-older marriages reduces fertility outcomes (Casterline et al., 1986).

In our analysis of the association between spousal age differences and fertility outcomes, four aspects are to be considered. First, it can be questioned whether age differences say anything about the nature of the relationship, female autonomy or the degree of equality between spouses. As is discussed above, the associations between female autonomy and age differences observed in the empirical literature are mixed (cf. Abadian, 1996; Barbieri et al., 2005). The results of this study show that women in wife-older marriages are indeed able to use their conjugal power to reduce the time interval between births. Second, it is not clear from the literature whether women with a younger husband would use their autonomy to demand either more or fewer children (Feng et al., 2010) or whether fertility preferences between spouses are similar. The analysis conducted here suggests that women with a younger husband did strive to increase fertility by closely spacing births while women in husband-older marriages had relatively long birth intervals. Third, although women seem to strive to increase fertility if they are older than their husband, why would men not strive to increase fertility when they are older than their wife? Given that for men the fitness benefits of reproduction are larger than the biological costs, it seems likely that men have an incentive to increase fertility if they are in a position to do so (Borgerhoff Mulder, 2000, 2007; Hamilton, 1964a,b). The findings in this study show that the transition time to first birth in husband-older marriages is indeed shorter compared to age-homogamous couples (indicating a catch-up effect for the first childbirth). However, for higher order births we find a longer parity transition time and the total number of children ever born are lower after controlling for age at marriage. Fourth and last, the absolute age of both spouses plays a crucial role in determining their fertility outcomes through its effects on fecundity (Matthijs, 2002).

It is clear that the effects of spousal age differences must be seen in relation to the age at which the spouses entered marriage. Women who were older than their husband usually entered their marriage at a relatively late age compared to their age-homogamous or husband-older counterparts. As a result, women in wife-older couples had children at a later age and had fewer years ahead before reaching menopause. These characteristics had positive effects on the hazard of first and higher order births resulting in closely spaced births. The net effect is that, when the age at marriage is taken into account, they did not significantly produce more children compared to age-homogamous couples. 


\subsection{Conclusion}

In this study, historical parish registration data from central and northern Sweden of women born between 1840 and 1889 is used to examine the associations between conjugal power and various measures of reproductive outcomes. The spousal age gap is used as an indicator of conjugal power (Skinner, 1993). The results show that, after controlling for the age at marriage, women in wife-older marriages - having greater conjugal power - display shorter birth intervals compared to women in age-homogamous marriages. For women in husband-older marriages the transition to first birth also occurs more quickly compared to women in agehomogamous marriages, indicating a catch-up effect. In contrast, the likelihood of transitioning to the second or higher order parity is lower in husband-older marriages, suggesting that the lower female bargaining power in such marriages is associated with lower fertility outcomes. The overall effect on the number of children ever born is shown to be highly dependent on the absolute age of the woman at marriage. Nevertheless, when the absolute age is controlled for, the results show that women in husband-older marriages had slightly fewer children overall.

The main contribution of this study is that it confirms suggests that when examining fertility outcomes, conjugal power can be approximated using the spousal age gap. However, this study also highlights that the effects of the absolute age of the wife have to be carefully accounted for. It is shown that having greater conjugal power, women in wife-older marriages display a preference for shorter birth intervals and a faster transition to first birth. This suggests that while women face considerable costs of reproduction, having children yields a positive inclusive fitness benefit (Conde-Agudelo et al., 2006, 2007; Hamilton, 1964a,b; Hrdy, 2009; Mace, 2014). Vice versa, although the biological costs of having children are lower for men, they do not employ their greater bargaining power within marriage in order to shorten the transition time between births - with the exception of the transition to first birth. In contrast, after the first parity the birth interval is longer in husband-older marriages and the total number of children ever born is slightly lower.

Further research is needed in order to more closely examine the association between female autonomy and reproductive outcomes. Owing to the nature of the available historical data, it is difficult to examine other operationalizations of female autonomy. Other studies show that more autonomous women are able to delay subsequent births, and thus played an important part in the fertility decline (e.g. Bras \& Schumacher, 2019). Also, there is no evidence of an increase in age homogamy for the sample used in this study (cf. Van de Putte et al., 


\subsection{CONCLUSION}

2009). Perhaps if we were able to extent the time period of our study, it would be interesting to see whether our findings remain robust after the population has completed the fertility transition. Fertility outcomes in reality were determined by the specific historical, social and economic context in which the household was situated. As discussed above, men and women in nineteenth century Sweden had relatively equal rights within marriage. Especially for the farming community, which dominates the sample in this study, the marriage pattern was likely to show conservative elements, with instrumental marriages being the norm instead of modern companionate marriages. Parents influenced the choice of a partner, for example to reduce uncertainties surrounding the continued existence of the family farm. While spousal age differences are connected to fertility outcomes, future research - lying beyond the scope of this chapter - on the interactions between age differences and regional social norms concerning marriage and kinship may further illuminate the connection between the nature of the relationship between spouses and reproductive outcomes. 



\section{Chapter 5}

\section{Family Systems and \\ Fertility, Western Europe 1870-1960}

This chapter is based on: Rotering, P. (2019). Family Systems and Fertility, Western Europe 1870-1960. Historical Social Research, 44 (3) 



\subsection{INTRODUCTION}

\subsection{Introduction}

Between 1870 and 1930, more than half of all countries in Western Europe experienced a decline in fertility by more than ten percent (Coale \& Treadway, 1986). This major change had far-reaching consequences for Western societies, as it arguably contributed to the rise of modern democracy and sustained economic development (Dyson, 2010; Galor, 2012; Greif, 2006). But how can we understand the marked regional differences in fertility levels between European regions? There has been considerable debate in the literature on the question whether fertility change is a consequence of changes in structural conditions for example economic growth or increasing secularism - or ideational change (see Casterline, 2001, for a summary of the literature). ${ }^{1}$

Previous authors have emphasized the effects of economic and structural factors such as urbanization and industrialization on reproductive outcomes in explaining the explaining the decline in fertility at the turn of the twentieth century (Davis, 1945; Thompson, 1929; Becker, 1981; Becker \& Barro, 1988; Easterlin, 1975). Others have argued that processes of ideational change, such as secularization and individualization, where at the root of the decrease in family size (Coale \& Treadway, 1986; Lesthaege, 1983). However, these explanations, alone or in tandem, have not been able to clarify the large regional differences in the timing of fertility decline between European societies. For instance, while France pioneered in family limitation already in the eighteenth century, the country was still largely agrarian. Conversely, many areas in England retained high levels of fertility until far in the nineteenth century, even though this country is considered a forerunner in industrialization. The Princeton European Fertility Project has shown that language borders provided a better explanation for variations in regional European fertility levels than socio-economic differences. In contrast, European regions which were adjacent and shared a common language but were otherwise heterogeneous in economic characteristics, showed a decline in fertility at similar moments in time. This suggests that fertility decline should not be regarded as only an adaptive response to changing social and economic conditions, but also that it could spread between regions as an innovative social behaviour among people with a common language or cultural understanding (Watkins, 1986, p. 441).

Recent studies explaining European fertility decline have highlighted the role of social interactions with both kin and non-kin in the study of reproductive behaviour (Bongaarts \& Watkins, 1996; Watkins, 1990). By providing resources

\footnotetext{
${ }^{1}$ I would like to thank Emmanuel Todd for exchanging his views on the association between family systems and fertility during a masterclass in Utrecht (2014).
} 
and support (Turke, 1989; Tymicki, 2004; Rotering \& Bras, 2015), or by passing on preferences, attitudes and information on parenthood and childbearing (Axinn et al., 1994; Bernardi, 2004; Kohler, 2001), family and kin play an important role in influencing people's reproductive behaviour. Regional clusters of such norms, values and practices surrounding kinship and family can be viewed as 'family systems' (Das Gupta, 1999; Davis, 1955; Hajnal, 1982; Mason, 2001; Skinner, 1997; Therborn, 2004; Todd, 1985, 1990, 2011; Reher, 1998; Kok, 2009). Between family systems, the extent and opportunities for the diffusion of new reproductive norms might vary in highly distinctive ways.

This chapter aims to examine whether family systems are associated with the spatial diffusion of fertility decline in Western Europe between 1870 and 1960, using regionally aggregated measures of fertility from the Princeton European Fertility Project. Family systems can be defined as "a set of beliefs and norms, common practices, and associated sanctions through which kinship and the rights and obligations of particular kin relationships are defined" (Mason, 2001), or as the "cultural mould [that is] shaping behaviour" (Kok, 2009).

A large number of studies have explored the connections between family systems and various outcomes, including fertility behaviour (Mönkediek \& Bras, 2016), extramarital fertility (Kok, 2009), disparities in social and economic indicators (Duranton et al., 2009), economic performance (Alesina \& Giuliano, 2007; Greif, 2006; Kick et al., 2000), alternative indicators of well-being (Brulé \& Veenhoven, 2014), gender systems Bertocchi \& Bozzano (2014); Mason (2001), and the origins of political divergence (Mamadouh, 1999; Todd, 1985, 1990, 2011). Several authors have developed typologies of family systems. Emmanuel Todd (1985) has organised his system using the degree of parental authority and sibling equality. David Reher (1998) distinguishes between regions with 'weak' and 'strong' ties between family members, with a particular focus on how societies take care of their elderly citizens. Göran Therborn (2004) has defined family systems that are geographically anchored to the major continents.

Although there are other typologies of family systems, this chapter makes use of Emmanuel Todd's typology of family systems because of the theoretical connections between reproductive outcomes and the organising principles of this classification. Some reflection on the merits of Todd's family systems for this study is however required. Todd's typology originates from his work on political ideologies and while the organising principles of family systems are well-defined, Todd's allocation of family systems to particular regions has left room for interpretation (Moch, 1986; Rijpma \& Carmichael, 2016). An important disadvantage for this study is that Todd's typology of family systems may not be precise or selective enough to differentiate between European regions. However, there are only 


\subsection{FAMILY SYSTEMS AND FERTILITY}

few typologies of family systems and Todd's scheme is particularly well-developed for Western Europe, displaying considerable regional variation. We will come back to this point in the discussion.

A better understanding of the role that family systems play in the diffusion of fertility decline, may help public policy makers who are concerned with the rapid growth of populations in present-day developing countries. If fertility decline is regarded as a behavioural innovation, regarded in a broad sense as the spread of information, attitudes, values and means of birth control between social groups or regions, then knowledge on whether and how family systems affect the diffusion of such innovations helps policy makers to identify key areas on where to focus their efforts. This article is organized as follows: the next section describes the classification of family systems by Emmanuel Todd. Then follows a theoretical review of the connection between family systems and fertility decline. In the third section, the data, measurements and methods are described, as well as some limitations of our approach. Finally, the results of the analysis are presented followed by a discussion of how these findings help to better understand the role of family systems in the decline of fertility in Western Europe.

\subsection{Family Systems and Fertility}

\subsubsection{Classification of Family Systems}

In his book L'invention de l'Europe, published in 1990, Emmanuel Todd examines regional variations in the development of modernity, marked by indicators such as industrialization, secularization and literacy in Western Europe since the Middle Ages. He draws connections between the different pathways of development and particular local ideologies, or unconscious, implicit values and norms about the place of the individual in his social group, which manifest themselves in what he describes as pre-modern family systems. Building upon the works of Frédéric le Play, Todd distinguishes two main organising principles for his classification of family systems in Western Europe; parental authority and sibling equality.

The first principle, parental authority, refers to the age at which children become independent and leave the household of their parents. In authoritarian family systems at least some of the children - usually only the first born son - remain living within or in close vicinity of the parental household after marriage, with parents exercising considerable control over their children. In non-authoritarian, or nuclear family systems, children are expected to become economically selfsufficient and leave the parental home to form independent families when they marry or reach adulthood. In order to identify the degree of parental authority, 
Todd studied regional censuses from the 1950-1960s to determine the proportion of adult children living with their parents. He then compared his findings with historical monographs about these regions to examine whether the pattern that was found matches that of earlier descriptions in the literature. The second principle, sibling equality, refers to the division of parental property among siblings (brothers in particular). In egalitarian family systems, all children receive an equal share of their parents' inheritance, while in non-egalitarian systems inheritance is impartible. In non-egalitarian systems, the parents favour one child often the oldest son - who inherits the parental property. In order to identify in which regions egalitarian family structures prevail, Todd examined contemporary inheritance laws and practices and also compared these findings with historical monographs. The combination of these two organising principles results in four family systems (see Table 5.1).

Table 5.1: Main Characteristics of Emmanuel Todd's Typology of Family Systems in Europe

\begin{tabular}{|c|c|}
\hline $\begin{array}{l}\text { Family system: } \\
\text { Characteristics: }\end{array}$ & $\begin{array}{l}\text { Absolute nuclear family } \\
\text { Weak authority, inegalitarian } \\
\text { Neolocal residence of children upon marriage, no clear } \\
\text { inheritance rules and frequent use of wills (Todd, 1990, p. 37, } \\
\text { Todd, 1985, p. 99). Kinship networks dispersed, liberal ties } \\
\text { between parents and children (Bras and Van Tilburg, 2007). } \\
\text { Le Pay refers to this system as 'unstable' (Todd, 1985). } \\
\text { England, North-Holland, Denmark }\end{array}$ \\
\hline $\begin{array}{l}\text { Family system: } \\
\text { Characteristics: }\end{array}$ & $\begin{array}{l}\text { Egalitarian nuclear family } \\
\text { Weak authority, egalitarian } \\
\text { Neolocal residence of children upon marriage, relatively strong } \\
\text { relationships between parents and children (Todd, } 1990 \text { p. 37). } \\
\text { Bilateral and equal inheritance. No involvement of parents in } \\
\text { choice of partners, although endogamous marriage is common } \\
\text { in order to prevent dispersal of property. In many areas, such } \\
\text { as in southern Italy, daughters receive their share of the } \\
\text { inheritance in the form of a dowry. } \\
\text { Northern France, southern Italy, central and southern Spain, } \\
\text { central Portugal }\end{array}$ \\
\hline $\begin{array}{l}\text { Family system: } \\
\text { Characteristics: }\end{array}$ & $\begin{array}{l}\text { Stem family (also known as authoritarian family) } \\
\text { Strong authority, inegalitarian }\end{array}$ \\
\hline
\end{tabular}

Table-5.1: Continued on next page 


\subsection{FAMILY SYSTEMS AND FERTILITY}

Table-5.1: Continued from previous page

\begin{tabular}{|c|c|}
\hline Principal regions: & $\begin{array}{l}\text { Impartible inheritance and co-residence of heir with parents } \\
\text { after marriage. Siblings of the heir can only remain in the } \\
\text { household as long as they remain unmarried. Non-inheriting } \\
\text { siblings often receive financial compensation, while heir } \\
\text { inherits the house and landholdings. Exogamous marriage, } \\
\text { often arranged by parents. Married women have a strong } \\
\text { position. Kin members form large part of social network, } \\
\text { community ties are strong. } \\
\text { Germany, Austria, southern Sweden, Norway, south and east of } \\
\text { the Netherlands, northern Portugal, northern Spain, southern } \\
\text { France }\end{array}$ \\
\hline $\begin{array}{l}\text { Family system: } \\
\text { Characteristics: }\end{array}$ & $\begin{array}{l}\text { Incomplete stem family } \\
\text { Strong authority, inegalitarian practices under formal } \\
\text { egalitarian laws } \\
\text { Same family system as stem family, but inheritance rules are } \\
\text { less strict. Formal rule stipulates partible inheritance, although } \\
\text { often one heir receives largest share. } \\
\text { Belgium, north-western Italy, western France (i.e. Maine and } \\
\text { Vendée) }\end{array}$ \\
\hline Characteristics: & $\begin{array}{l}\text { Exogamous community family (also known as communitarian } \\
\text { family) } \\
\text { Strong authority, egalitarian } \\
\text { Extended family form wherein several generations live under } \\
\text { one roof. Married sons bring their wives into the family home. } \\
\text { Household generally split up after death of father and } \\
\text { inheriting sons form new households, inducing a new cycle of } \\
\text { nuclear, stem and joint phases of co-residence. Women have a } \\
\text { relatively weak position. Marriages arranged by parents and } \\
\text { inheritance is patrilineal. Equal inheritance among brothers. } \\
\text { Kinship networks are cohesive and social interactions are } \\
\text { mainly kin-based. }\end{array}$ \\
\hline Principal regions: & Northern Italy, Finland \\
\hline
\end{tabular}

Source: Todd (1990)

In addition, Todd distinguishes a fifth family system observed in Western Europe where non-egalitarian inheritance practices persist under formal egalitarian laws. He calls this system the incomplete stem family system. Some regions could not be categorized along the organising principles of authority and equality, these 
regions are categorized as undetermined (Todd, 1990). The main characteristics of family systems and the European regions where they are found are summarized in Table 5.1. Todd has portrayed his family systems on a map of Western Europe, which has been digitized by Gilles Duranton et al. for a study on the associations between family systems and a series of socio-economic indicators (Duranton et al., 2009). Todd's original map and the adaptation used in this article are given in figure 5.1 .

\subsubsection{Regional differences and persistence of Family Systems}

Figure 5.1 shows Todd's classification of the predominant family systems in Western Europe. National borders do not seem to form a clear separation between family systems and nearly all countries display considerable variation in family systems. In many countries, such as Italy, the Netherlands and France for example, there are regions where cohabitation of parents and married children is observed (stem or communitarian family) and regions where neolocal family structures are predominant (nuclear family).

As mentioned above there are other classifications of family systems, which differ in their organising principles as well as geographical distribution (e.g. Therborn, 2004; Reher, 1998). Therborn's family systems cover larger geographical areas and Europe in his view contains one single family system - or geoculture. Reher's (1998) demarcation between the southern and northern European family system is not observable in Todd's classification of family systems. Although Todd's absolute nuclear family system is only found in northern Europe, a clear geographical north-south division between family systems is not visible. Furthermore, within regions, individual families or communities may display very different levels of parental authority and equality than the predominant regional family system. Todd identifies several regions, such as southern Portugal, where smaller communities can be found that have a family system which is markedly different from the regional family system (see bottom figure 5.1). Todd's family systems are not necessarily related to the composition of the household or structure of the conjugal unit, but more to the predominant local ideologies of the place of an individual within the group (Todd, 1985; Skinner, 1997). Recently, Viazzo and Zanotelli (2010) have for example shown that in Italy it has become more common in recent years for adolescents to live in close proximity of their parents instead of cohabiting with their parents. Although variations in household compositions are visible in recent times, family systems still display the same norms, values and practices surrounding the family.

An important assumption about family systems made here is that they are 
Figure 5.1: Family Systems in Western Europe

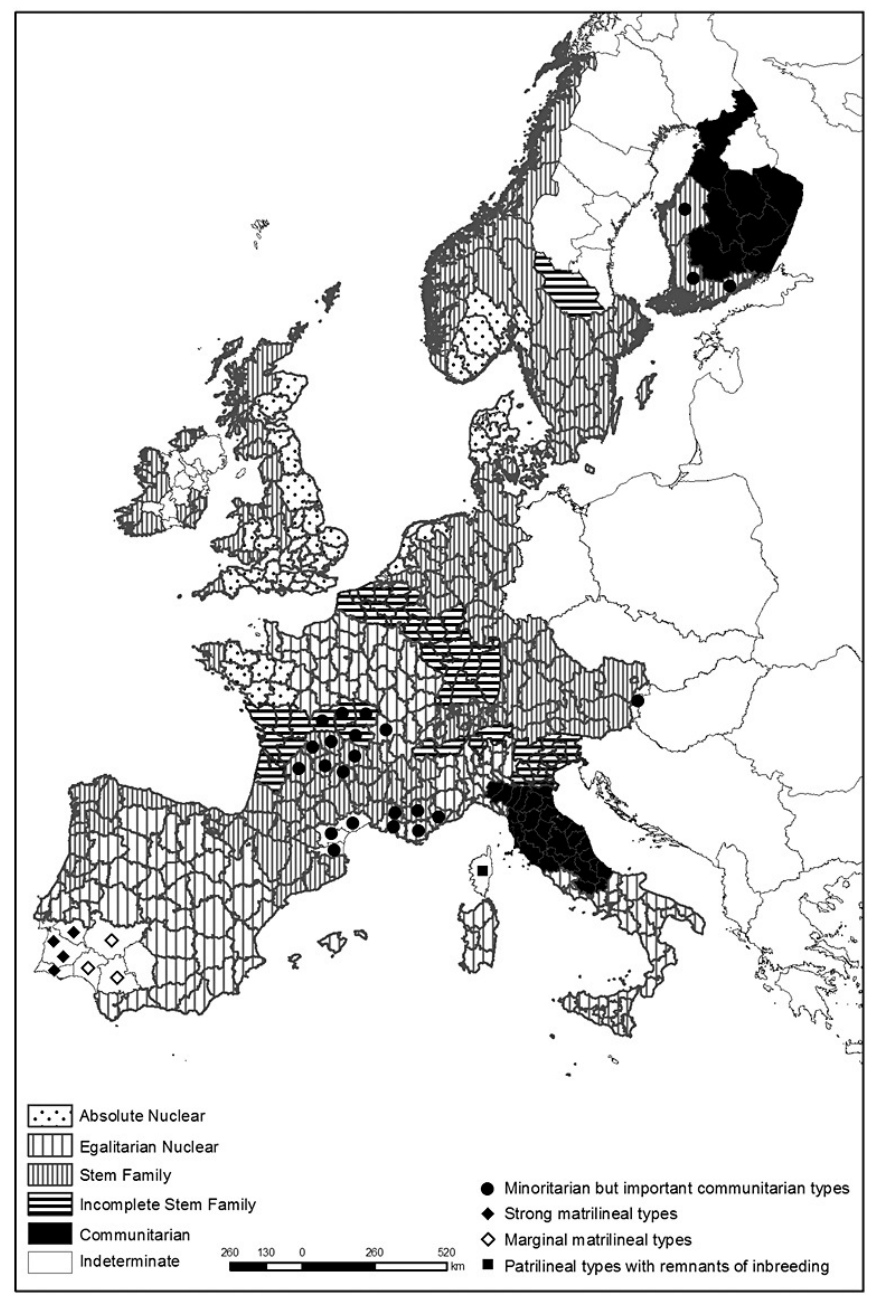

Original classification of family systems in Western Europe by Emmanuel Todd (Todd 1990, p. 7). 

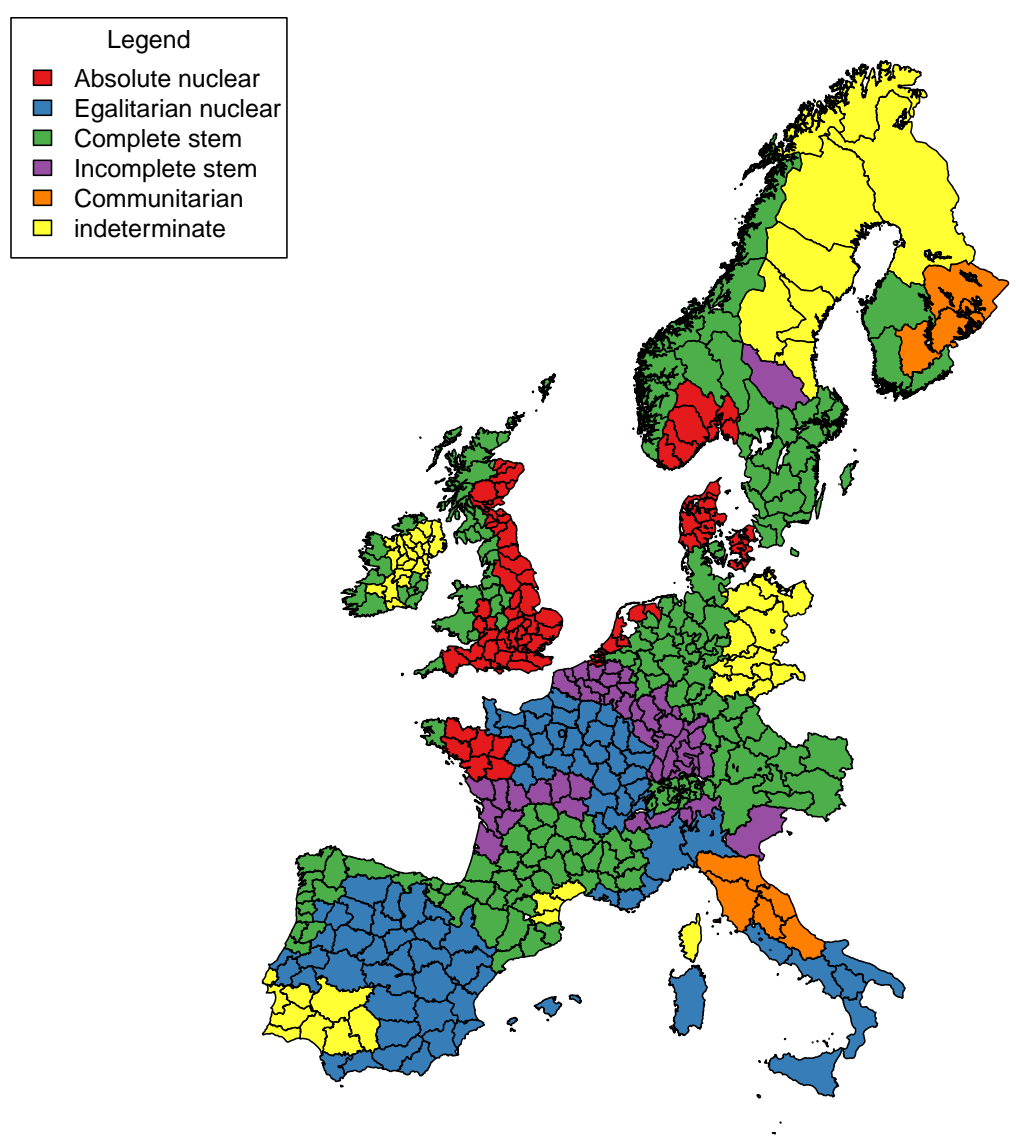

Classification of family systems used in this chapter, based on administrative division around 1900 (Duranton, 2009). 


\subsection{FAMILY SYSTEMS AND FERTILITY}

fairly persistent over time, caused by the children's unconscious imitation of their parents. Todd argues that when parents raise their children, their values are reproduced within the family. "[As] a unit of biological and social reproduction, the family needs no sense of history or of life in order to perpetuate its structures" (Todd, 1985, p. 196). In southern European societies, where parental authority is high, children today still leave the parental household at a relatively higher age, compared to northern European societies where parental authority is lower (Reher, 1998). Historical census data shows that at least since the nineteenth century joint families (households with two or more co-residing children) have not been common in Western Europe (Ruggles, 2010).

However, the persistence of family systems over a considerably longer period of time has been questioned by some scholars. For example, Greif, who studies the influence of institutions on economic performance, suggests that the rise of modern corporations has led family systems to evolve towards the nuclear family over time, although not necessarily in a monotonically or geographically uniform manner (Greif, 2006). Coleman argues that social capital rather than family systems has become a more important institution over time (Coleman, 1994). Social capital identifies the value of relationships and exchanges between family members and as it develops, relationships between family members become less defined by their family system, but more by the social capital of their exchange. Not all researchers however agree with the declining importance and diversity of family systems over time. According to Astone et al. "(...) family formation is among the most important types of investment in social capital made in all societies [and], there is little evidence that the family is withering away along the lines Coleman suggested" (Astone et al., 1999). Kertzer and Hogan (1988) also observe that demographers since the mid-1960s have regarded family systems as markedly stable elements over long periods of time. In spite of the changing social and economic functions of the family, even throughout periods of industrialization, families systems have retained largely the same structure and geographical distribution.

\subsubsection{Family Systems and regional differences in reproductive outcomes}

Family systems reflect regional norms, values and practices surrounding the family and kinship, such as marriage, birth control, parenthood, or the role of children (Todd, 1990; Mason, 2001). As such, family systems may have both direct and indirect effects on fertility outcomes, either by specifying 'normal' behaviour or by regulating the diffusion of innovations from one region to another (Bocquet-Appel \& Jakobi, 1998; Weeks et al., 2000; Rogers, 1962). 


\section{CHAPTER 5. FAMILY SYSTEMS}

Direct effects of family systems work through norms and values that are maintained within a particular community or region, such as egalitarian inheritance principles or cohabitation of parents with married children. In a way, family systems can facilitate or constrain particular reproductive behaviours by specifying what is to be considered as 'normal'. For example, Davis (1955) argues that in the joint family system found in East Asian societies, newly-wed couples are absorbed into the parental home. Since childbearing was one way for the young couple to establish themselves as adults within the joint household, reproductive outcomes in the joint family system were higher than in nuclear family system regions, explaining in part the association between joint family systems and universal, early marriage (Davis, 1955).

The utility of children however does not need to relate only to the social status of the couple, but can also be expressed in economic terms. When children are able to provide additional income to the household - i.e. the utility of each additional child is higher than the costs - fertility levels are likely to be higher in regions where it is customary for children to remain living with their parents after marriage, compared to non-authoritarian family system regions where children are more likely to leave the household at younger age (Becker \& Barro, 1988; Klep, 2004, 2010). However, these mechanisms may be too simplistic and household composition does not always reflect power relations within the household. For example, Fertig (2018) argues that within the stem family system, parental authority could be low even in multi-generational households. Since children had alternative options to make a living and their parents were dependent on them for retirement, children had considerable bargaining power over their parents. Historical property transfer contracts from western Germany show that parents for example gave up their property rights or the right to manage the family farm (Fertig, 2018).

Family systems may be indirectly be associated with fertility outcomes through the geographical diffusion of knowledge, attitudes, values and norms regarding reproduction (Cleland \& Wilson, 1987). In this way, family systems do not specify norms concerning 'normal' behaviour but instead reflect an 'openness' to new ideas or behaviours. As such, family systems may not be directly associated with the level of fertility, but with the speed by which behavioural innovations - such as changes in reproductive behaviours - may spread from one geographical area to another. By facilitating or constraining contact with others outside the closekin group, family systems for example shape opportunities for social learning (Bernardi, 2004). Bras and Van Tiburg (2007) have shown that the frequency of contact with kin is affected by the family form. In summary, family systems may have both direct and indirect effects on fertility outcomes either through regional 


\subsection{FAMILY SYSTEMS AND FERTILITY}

norms, practices and values surrounding the family and kin, or through a certain 'openness' of the kin network for new ideas or behavioural innovations.

\subsubsection{Hypotheses}

This study examines the association between family systems and fertility decline in western Europe. The literature described above suggests that family systems may be associated with fertility outcomes either directly, through norms, values and practices that favour particular reproductive outcomes, or indirectly by shaping the flow of information concerning reproduction from one regions to another. Although these mechanisms are difficult to disentangle, it is important to consider whether fertility outcomes are correlated between regions. First, we examine whether particular family systems are associated with specific fertility outcomes. Next, the notion of 'openness' to change is examined, by including diffusion effects in our analysis.

When local norms, values and practices attribute a relatively large utility to having children, it is likely that fertility outcomes within such systems are higher. The value of children - either economic, or status increasing - is assumed to be higher in authoritarian family systems than non-authoritarian family systems (Becker \& Barro, 1988; Klep, 2004, 2010). David Reher (1998) for example observes that much of the aid provided to vulnerable members of the Mediterranean societies in southern Europe, such as the elderly, comes from family members and charities instead of public funds and individual insurances. It is hypothesized that fertility levels are likely to be higher in authoritarian family systems than in nuclear family system regions (H1).

Family systems that are relatively open and show varied networks of both kin and non-kin, are more likely to facilitate the acceptance of new ideas or behaviours, such as family limitation, than family systems that foster closed kinbased networks. The two dimensions of Todd's family systems, the degree of parental authority and sibling equality, are assumed to be indicators of the openness of family systems to new ideas regarding reproduction. Family systems with low parental authority (nuclear) are relatively open to new ideas because of the relatively young age at which children leave the parental home. Neolocal household formation, customary in nuclear family systems, forms an opportunity for social learning as individuals form networks comprised of both kin and non-kin. In contrast, authoritarian families (stem and communitarian) display a stronger ethic of kinship leading to cohesive kinship networks in which social interactions are highly kin-based (Bras \& Van Tilburg, 2007). Even when children marry and move out of the household in an authoritarian family system, they still remain bound to the parental home and often live in close vicinity of their parents. 
The degree of sibling equality, represented by the distribution of parental property between siblings, also determines the openness of family systems to social innovation. Family limitation is more likely to diffuse over time in regions where children have more opportunities to seek contact with others, or when there are fewer incentives to preserve close bonds with kin-members. Family systems where impartible inheritance is custom provide little incentives for siblings to form close bonds between each other and their parents. Non-inheriting siblings have nothing to gain - or cannot risk their share of the inheritance by falling out of favour from the parents, simply because there is no share - and are therefore more likely to seek contact with others compared to children living under a system of partible inheritance. Accordingly, family limitation is more likely to diffuse within the absolute nuclear family system than in the egalitarian nuclear system, while exogamous community family systems may be the least open for social innovation since in these areas kinship networks are dense and information from non-kin members hardly enters these networks. It is hypothesized that over time, fertility outcomes will be lower in inegalitarian family systems (under impartible inheritance) than in egalitarian family systems (H2).

\subsection{Data, Measurements, and Methods}

\subsubsection{Data and measures}

The fertility indices used in this article are from the Princeton European Fertility Project (Coale \& Watkins, 1986). Initiated in 1963, the Princeton project aimed to gain insight in the causes of the decline of fertility in Europe since the midnineteenth century. The project in particular considered the question whether social and economic change set off the demographic transition in Europe, or whether modernization, as defined by urbanization and industrialization, played a more important role by undermining traditional high fertility patterns. Based on a large selection of census materials and population registers, the Princeton project developed an index, $I_{f}$, to represent total fertility in a given area at any moment in time. $I_{f}$ ranges between 0 and 1 and describes the number of births by all women between 15 and 49 years old in a region relative to the fertility schedule of married Hutterite women between 1921 and 1930. The Hutterites were an Anabaptist sect founded in Western Europe in the sixteenth century which in the nineteenth century migrated to the United States and southern Canada. The Hutterites show the largest number of births ever registered for women in each age group. The fertility schedule of the Hutterites was particularly high because contraception methods were strictly forbidden and children were only nursed for 


\subsection{DATA, MEASUREMENTS, AND METHODS}

a few months after birth. While $I_{f}$ provides a relative measure of total fertility, the Princeton project also developed indices of marital fertility, $I_{g}$, non-marital fertility, $I_{h}$ and a measure of the contribution of marital status to the overall rate of childbearing, $I_{m}$ (Coale \& Treadway, 1986). These four indices are related by the following identity:

$$
I_{f}=\left(I_{m} \cdot I_{g}\right)+\left(1-I_{m}\right) \cdot I_{h}
$$

In this chapter, $I_{f}$ is used to examine the association between family systems and total fertility. While a discussion of marital and extramarital births specifically is beyond the scope of this chapter, other researchers have found that extramarital births are connected to family systems, in particular through norms regarding partner choice and age at marriage (Kok, 2009). While for example age at marriage in the Netherlands was relatively high around 1900, strong norms objecting cohabitation prevented high extramarital fertility rates.

The fertility indices developed by the Princeton Project have been disputed in the literature. For example, Brown and Guinnane argue that the Princeton Project data underestimated the role of economic and social change (Brown \& Guinnane, 2003; Guinnane et al., 1994). Also, the high level of aggregation caused the calculated fertility indices for Germany to differ from those uncovered by other studies (Brown \& Guinnane, 2003). Furthermore, the measures developed by the Princeton Project are sensitive to the age composition of the population (Coale \& Treadway, 1986, p. 162). However, the observations provided by the European Fertility Project are at this moment the only available source which provides a European wide coverage of the historical variation in the rate of fertility decline. The extensive geographical coverage and long period of observation make the Princeton project's data a relevant source for studying the associations between persistent institutions and regional variations in fertility patterns, even in face of the issues mentioned above.

Digital maps of historical administrative boundaries in Europe and the fertility indices of the Princeton project are provided by the Max Planck Institute for Demographic Research. ${ }^{2}$ Historical maps are drawn for the years 1870, 1900, 1930 and 1960. The Princeton $I_{f}$ indices are used only if the census used to calculate the index did not deviate more than 10 years from the base year of the map. Since the earliest data for Spain is from 1887, no fertility data is available for the earliest period of observation, 1870. A machine-readable map of the distribution of Todd's family systems in Europe is provided by Gilles Duranton et al. (2009). Duranton

\footnotetext{
${ }^{2}$ Max Planck Institute for Demographic Research (MPIDR) and Chair for Geodesy and Geoinformatics (CGG), University of Rostock: MPIDR Population History GIS Collection Europe (Rostock, 2013). Administrative boundaries partly based on EuroGeographics ${ }^{\circledR}$.
} 


\section{CHAPTER 5. FAMILY SYSTEMS}

made two small corrections to Todd's original map, in accordance with the text in L'invention de l'Europe. The Languedoc region (France) and the Andalucía regions (Spain) are labelled as undetermined on Todd's original map, whereas in his text Todd describes the Languedoc region as incomplete stem family and Andalucía as egalitarian nuclear (Duranton et al., 2009). The Princeton maps are overlaid with the map of family systems to determine the dominant family system in each region. Changes in the level of fertility are determined by laying the Princeton maps on top of each other and calculating the difference in fertility levels for each region. These procedures allow for tracking fertility over time in individual regions, while changes in administrative boundaries would only lead to small errors in the sample. The spatial distribution of fertility levels is shown in Figure 5.2.

\subsubsection{Methods}

In order to examine the association between family systems and fertility levels, we first estimate a simple model where fertility levels are a function of family systems and country fixed effects. Since absolute fertility levels at any point in time are expected to be related to previous fertility levels, we include previous the fertility level for each region as a time-lagged variable. Since the Princeton fertility indices are given with around thirty years between each observation, the OLS model specified has the following form:

$$
Y_{i}(t)=\alpha+\beta_{1} F_{i}(t)+\beta_{2} D_{i}(t)+Y_{i}(t-30)+\epsilon_{i}(t)
$$

where $Y_{i}(t)$ denotes the level of fertility in region $i, F_{i}$ are dummy variables for the family system in region $i, D_{i}$ are national dummy variables used to capture country specific effects and $Y_{i}(t-30)$ is the level of fertility in region $i$ thirty years before. The absolute nuclear family and Austria are used as reference categories for family systems and country level dummies respectively. The choice for the absolute nuclear family as reference category is motivated by the hypothesis that this family system is the most open to change and influence from others outside the kin network.

As can been seen in Figure 5.2, differences in fertility levels or the rate of fertility change between neighbouring regions are often very small. This suggests that a spatial diffusion process may affect reproductive outcomes; behaviour is adjusted according to processes observed in neighbouring regions (Tolnay, 1995; Goldstein \& Klüsener, 2014). We first examine the presence of spatial autocorrelation to determine whether regions which are adjacent to each other display similar fertility outcomes. Neighbours are identified using k-nearest neighbours 
5.3. DATA, MEASUREMENTS, AND METHODS

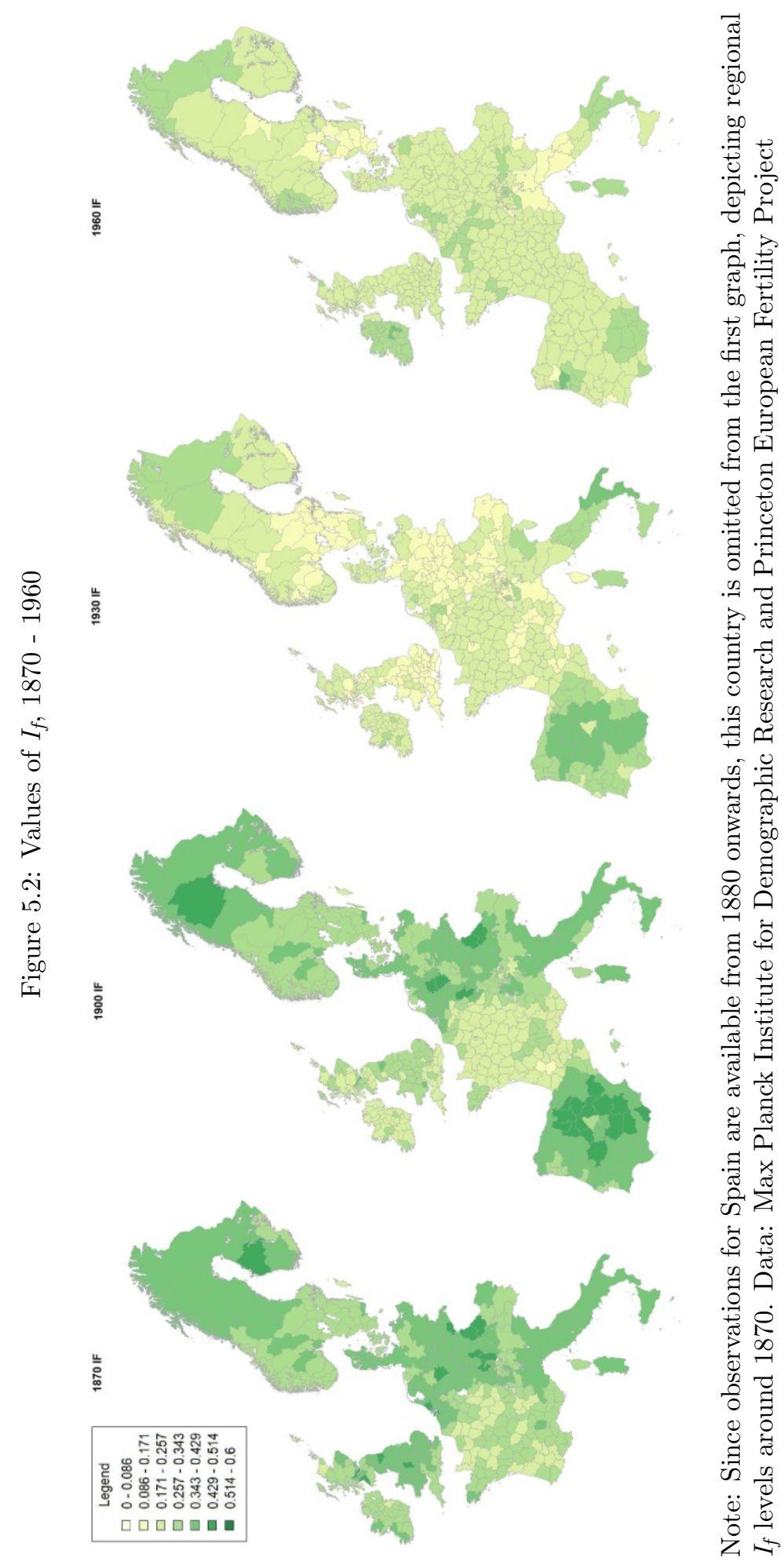


analysis, where $k$ is 5 , with islands connected to the nearest mainland. This procedure shows similar results as with neighbours-lists based on direct connections such as Queen's contiguity. We specify Moran's I as a global measure of spatial autocorrelation (Moran, 1950a,b). In addition, in order to control for the diffusion of fertility decline from one region to adjacent regions, we include spatial lag variable to the OLS model specified above. The resulting spatial lag model includes an additional control variable which captures for each region the effect of fertility levels or fertility change in surrounding regions. We specify the model both with and without a time-lagged control variable for fertility levels in each region:

$$
\begin{gathered}
Y_{i}(t)=\alpha+\beta_{1} F_{i}(t)+\beta_{2} D_{i}(t)+\beta_{3} W Y_{i}(t)+\epsilon_{i}(t) \\
Y_{i}(t)=\alpha+\beta_{1} F_{i}(t)+\beta_{2} D_{i}(t)+\beta_{3} W Y_{i}(t)+Y_{i}(t-30)+\epsilon_{i}(t)
\end{gathered}
$$

These models, used to examine whether changes in fertility levels are associated with family systems, are estimated for each thirty-year period between 1870 and 1960.

\subsection{Results}

A summary of the level of fertility, by family system is given in Table 5.2. Table 5.2 shows that total fertility rates declined most strongly between 1900 and 1930, and slightly rose thereafter. The number of observations differs markedly between family systems, there are only a few communitarian family system regions while most regions are a stem family system. Interestingly, the regions marked by Todd as having an 'indeterminate' family system do not stand out by having a particularly large standard deviation in fertility outcomes. Between family systems, Table 5.2 shows that there are little differences in fertility levels. Based on our hypotheses, fertility levels are likely to be higher in regions where parental authority is high, or where egalitarian inheritance rules are the norm. As such, the communitarian family system is likely to show the highest level of fertility, while regions where the absolute nuclear family systems is dominant are likely to show the lowest levels of fertility. However, the figures given in Table 5.2 do not confirm these expectations. While the communitarian family system has the highest fertility levels in 1870 and 1900, it shows a stark decline in 1930 and 1960 with levels lower than the absolute nuclear family system. The absolute nuclear family system shows a lower level of fertility on average than the egalitarian nuclear family system, apart from 1870. The stem family system seems to be in 


\subsection{RESULTS}

between the other family systems regarding the average level of fertility in each period.

Table 5.2 also includes Moran's I, the statistical measure designed to represent the correlation between fertility levels across neighbouring regions. The positive value indicates that in all periods there is a significant positive correlation between fertility levels of neighbouring regions.

Figure 5.3 shows box plots of the compound annual growth rates for the Princeton fertility indices for each region, by period and by family system. A positive figure indicates an increase in fertility. Although Table 5.2 shows that there are little differences in fertility levels between family systems, Figure 5.3 shows that between family systems the change in fertility over time can be considerable. The communitarian family system shows the smallest rate of change between 1900 and 1930, and between 1930 and 1960. However, the absolute nuclear family system does not stand out by showing markedly higher changes in fertility levels than the other family systems, apart from the period between 1930 and 1960 where in fact is shows the highest median increase in fertility.

The results of the OLS model are given in Table 5.3. Table 5.3 shows for each time period the association between the level of fertility ( $I_{f}$ index) and family systems. The model also includes country fixed effects dummies and a time-lagged measure of fertility in each region thirty years before. Due to the inclusion of the time-lagged measure, there are no results for 1870 since this is the earliest point of observation. The results show that family systems do not show a strong association with fertility outcomes, as most coefficients are not significant. Fertility outcomes are significantly higher in communitarian family system regions in 1900 compared to the absolute nuclear family system - which is the reference category. For 1930, egalitarian nuclear family system regions show significantly higher fertility outcomes compared to the absolute nuclear family system. However, for 1960, fertility levels are significantly lower in the communitarian family system than in the absolute nuclear family system regions.

For each time period, the time-lagged independent $I_{f}$ index shows that there is significant positive autocorrelation between fertility outcomes of the current and previous period of observation. The values of Moran's I on the residuals of the model show that there is still considerable spatial autocorrelation between the regions. The Lagrange multiplier diagnostics show that a spatial error model is preferred to properly cope with the autocorrelation observed in the residuals, but since we are interested in the effect of neighbouring regions we will follow up the OLS model by fitting a spatial lag model. The adjusted $R$-Squared measures of the OLS models shows that the models have considerable explanatory power, but this may also be indicative of overfitting the model. Given that for each region 
CHAPTER 5. FAMILY SYSTEMS

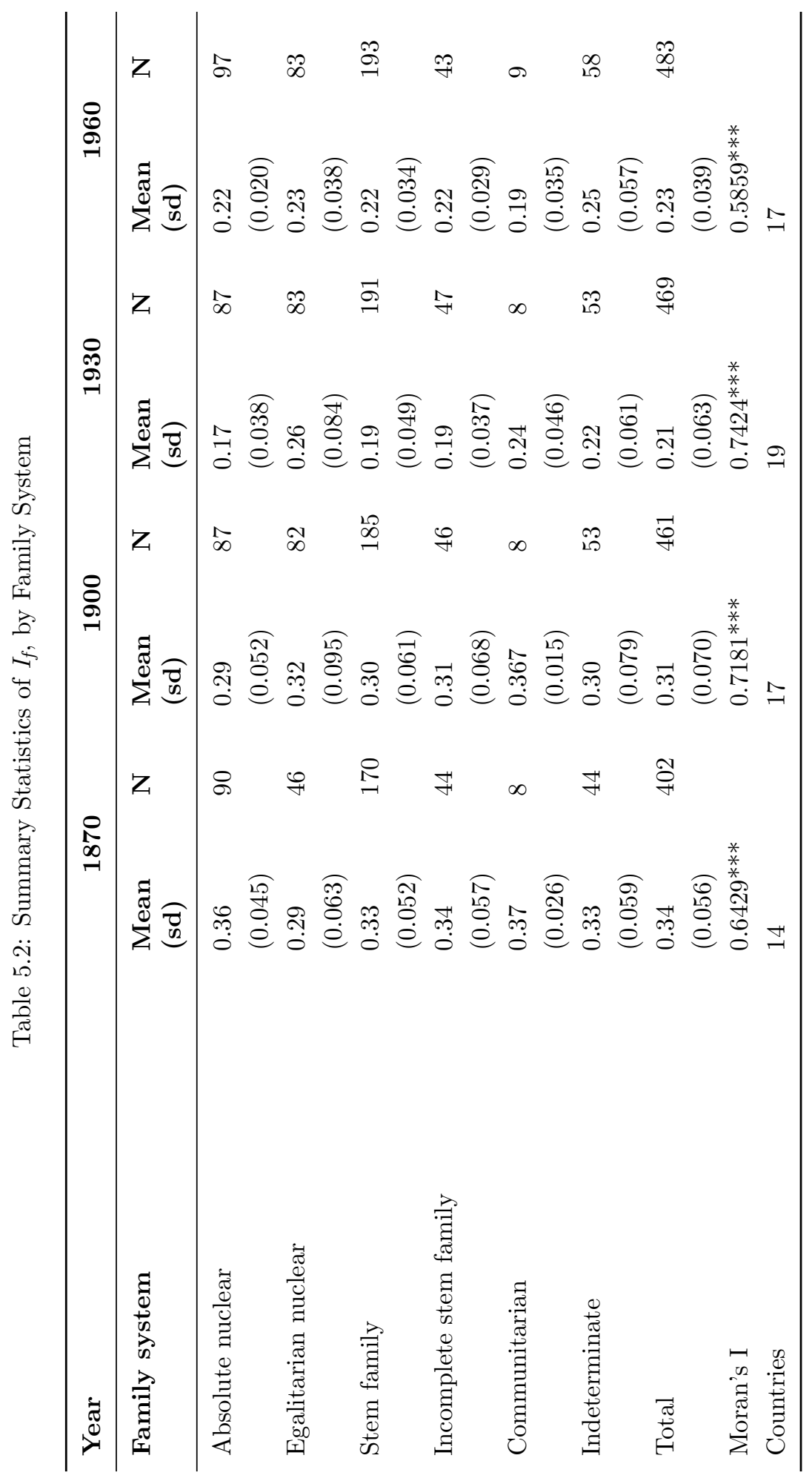




\subsection{RESULTS}

Figure 5.3: Change in $I_{f}$ by Family System (box plots)
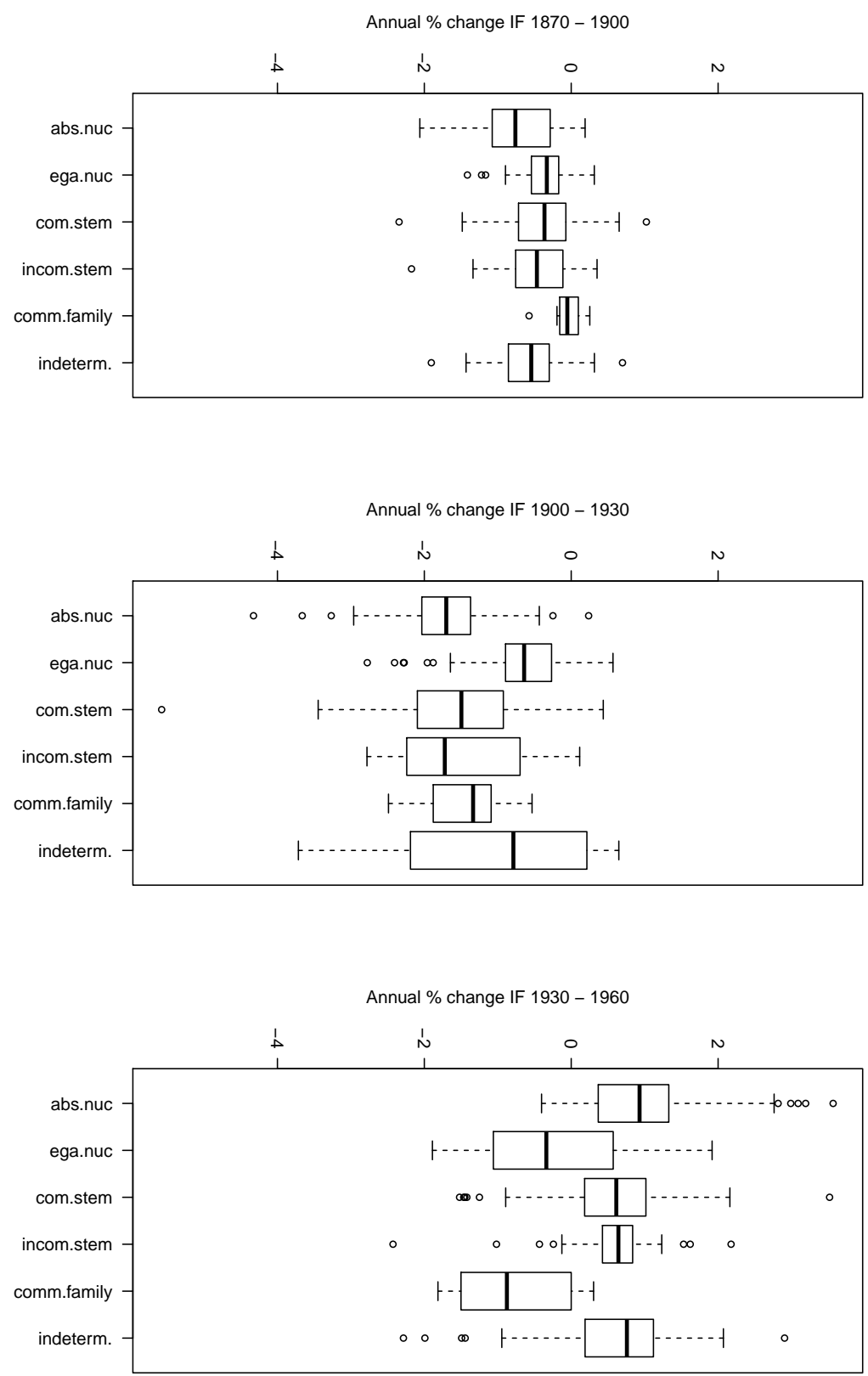


\section{CHAPTER 5. FAMILY SYSTEMS}

fixed-effect dummies for the country level and a time-lagged measure of previous fertility is taken into account, there may be too little variation left to be explained by the family systems.

Fertility levels may be correlated between regions, as indicated by the residuals in Table 5.3. Figure 5.4 shows the distribution of spatial autocorrelation for each period, based on a local measure of Moran's I on the Princeton $I_{f}$ index. Figure 5.4 shows that in all time periods there is significant spatial autocorrelations in some region, but not in all regions. When comparing Figure 5.4 to the distribution of family systems in Figure 5.1, there are no clear similarities between these maps. In other words, a clear association between family systems and a particular 'openness' to fertility diffusion is not visible.

The results of the spatial lag models are given in Tables 5.4 and 5.5. Table 5.4 shows the association between fertility levels and family systems, including control variables for the country (using a fixed effects dummy) and the spatially lagged value of $I_{f}$ (denoted by $R h o$; it represents the average $I_{f}$ values of neighbouring regions). Table 5.5 additionally includes a time-lagged observation of fertility in each region thirty years before.

The results in Table 5.4 do not seem to support the hypothesis that fertility levels are higher in authoritarian family systems. While the incomplete stem family system shows higher fertility levels in 1930 and 1960 after controlling for national effects and a spatial lag, the overall picture is less clear. Contrary to our hypotheses, communitarian family system regions for example show lower fertility levels in 1870 compared to the absolute nuclear family system. The egalitarian nuclear family system is associated with higher fertility outcomes in 1930 and 1960 as expected, but for 1870 fertility levels in egalitarian nuclear family system areas are lower compared to absolute nuclear family system. The stem family seems not to be significantly associated with fertility outcomes, as could be expected since overall no strong effects of family systems are observed.

Table 5.5 further extends the findings presented in Table 5.4, by including a time-lagged observation of fertility in each region thirty years before. Both the time-lagged and spatial-lag variable show strong positive autocorrelation, although the residuals of the model still show evidence of significant spatial autocorrelation. The findings in Table 5.5 are in line with Table 5.3 (the OLS model) and thus not supportive of our hypotheses. The expectation is that fertility outcomes will be the highest in authoritarian and egalitarian family systems. For 1900, no significant association between family systems and fertility is however observed. For 1930, egalitarian nuclear family system regions indeed show fertility outcomes higher than the absolute nuclear family system, but the communitarian family system (which is also based on egalitarian principles) does not show to 


\subsection{RESULTS}

Table 5.3: Ordinary Least Squares Regression Coefficients of the Princeton $I_{f}$ Fertility Index

\begin{tabular}{|c|c|c|c|}
\hline \multirow[t]{2}{*}{ Attribute } & \multicolumn{3}{|c|}{ Model } \\
\hline & 1900 & 1930 & 1960 \\
\hline \multirow[t]{2}{*}{ Egalitarian nuclear } & 0.012 & $0.027 * * *$ & 0.006 \\
\hline & $(0.008)$ & $(0.007)$ & $(0.005)$ \\
\hline \multirow[t]{2}{*}{ Stem family } & 0.008 & 0.008 & 0.002 \\
\hline & $(0.005)$ & $(0.005)$ & $(0.004)$ \\
\hline \multirow[t]{2}{*}{ Incomplete stem family } & 0.0003 & 0.009 & 0.008 \\
\hline & $(0.008)$ & $(0.008)$ & $(0.006)$ \\
\hline \multirow[t]{2}{*}{ Communitarian } & $0.026^{*}$ & 0.002 & $-0.026^{* *}$ \\
\hline & $(0.015)$ & $(0.014)$ & $(0.010)$ \\
\hline \multirow[t]{2}{*}{ Indeterminate } & 0.003 & 0.007 & 0.003 \\
\hline & $(0.008)$ & $(0.007)$ & $(0.005)$ \\
\hline \multirow[t]{2}{*}{$I_{f}$ (time lagged, t-30) } & $0.697^{* * *}$ & $0.548^{* * *}$ & $0.479^{* * *}$ \\
\hline & $(0.040)$ & $(0.033)$ & $(0.028)$ \\
\hline Country & Included & Included & Included \\
\hline \multirow[t]{2}{*}{ Constant } & $0.079^{* * *}$ & $-0.028^{*}$ & $0.155^{* * *}$ \\
\hline & $(0.018)$ & $(0.016)$ & $(0.009)$ \\
\hline Moran's I for spatial & $0.159 * * *$ & $0.252 * * *$ & $0.271 * * *$ \\
\hline $\begin{array}{l}\text { autocorrelation } \\
\text { in error term }\end{array}$ & & & \\
\hline \multicolumn{4}{|l|}{ Lagrange multiplier } \\
\hline \multicolumn{4}{|l|}{ diagnostics } \\
\hline LMerr & $28.691^{* * *}$ & $85.622 * * *$ & $101.874^{* * *}$ \\
\hline RLMerr & $9.26^{* * *}$ & $9.583^{* * *}$ & $41.405^{* * *}$ \\
\hline LMlag & $20.044^{* * *}$ & $90.983^{* * *}$ & $60.479 * * *$ \\
\hline RLMlag & 0.613 & $14.944^{* * *}$ & 0.01 \\
\hline Countries (N) & 17 & 19 & 17 \\
\hline Observations (N) & 392 & 465 & 479 \\
\hline $\mathrm{R}^{2}$ & 0.786 & 0.787 & 0.682 \\
\hline Adjusted $\mathrm{R}^{2}$ & 0.776 & 0.776 & 0.667 \\
\hline \multirow[t]{2}{*}{ Residual Std. Error } & 0.030 & 0.030 & 0.023 \\
\hline & $(\mathrm{df}=372)$ & $(\mathrm{df}=440)$ & $(\mathrm{df}=456)$ \\
\hline \multirow[t]{2}{*}{ F Statistic } & $72.114^{* * *}$ & $67.906^{* * *}$ & $44.430 * * *$ \\
\hline & $(\mathrm{df}=19 ; 372)$ & $(\mathrm{df}=24 ; 440)$ & $(\mathrm{df}=22 ; 456)$ \\
\hline
\end{tabular}

Significance: ${ }^{*} \mathrm{p}<0.1,{ }^{* *} \mathrm{p}<0.05,{ }^{* * *} \mathrm{p}<0.01$

Standard errors in parentheses. Reference categories are the absolute nuclear family system (for family systems) and Austria (for countries). Sources: See text. 
CHAPTER 5. FAMILY SYSTEMS

Figure 5.4: Moran's I: Spatial Autocorrelation in Fertility Levels (significant clusters)

Local moran's I, only significant clusters IF 1870

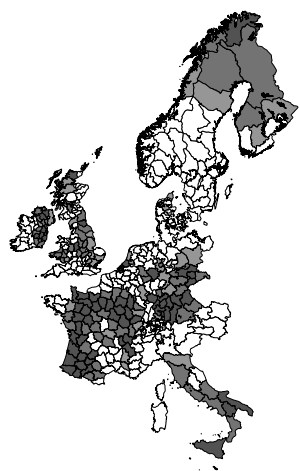

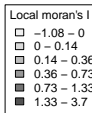

Local moran's I, only significant clusters IF 1930

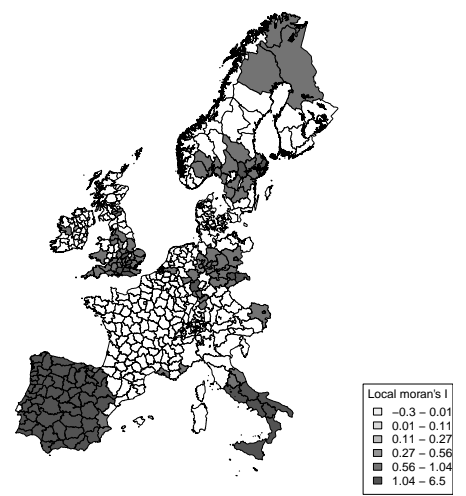

Local moran's I, only significant clusters IF 1900

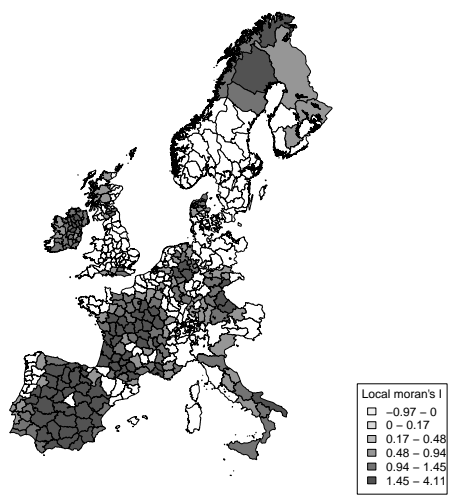

Local moran's I, only significant clusters IF 1960

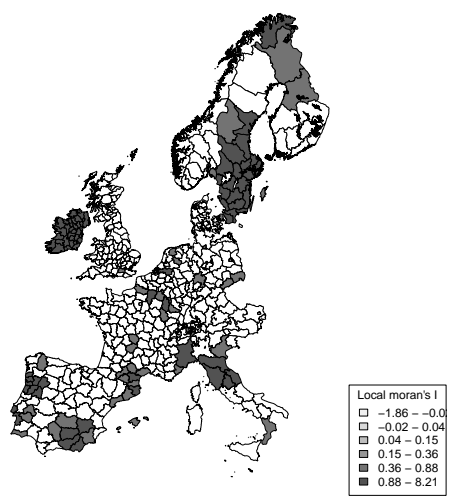


Table 5.4: Spatial Lag Model of the Princeton $I_{f}$ Index (Maximum Likelihood Estimation)

\begin{tabular}{|c|c|c|c|c|}
\hline \multirow[t]{2}{*}{ Attribute } & \multicolumn{4}{|c|}{ Model } \\
\hline & 1870 & 1900 & 1930 & 1960 \\
\hline \multirow[t]{2}{*}{ Egalitarian nuclear } & $-0.028 * * *$ & 0.005 & $0.021^{* * *}$ & $0.014^{* * *}$ \\
\hline & $(0.008)$ & $(0.009)$ & $(0.007)$ & $(0.006)$ \\
\hline \multirow[t]{2}{*}{ Stem family } & -0.006 & 0.002 & 0.008 & 0.006 \\
\hline & $(0.006)$ & $(0.007)$ & $(0.006)$ & $(0.004)$ \\
\hline \multirow[t]{2}{*}{ Incomplete stem family } & -0.002 & 0.006 & $0.015^{*}$ & $0.013^{* *}$ \\
\hline & $(0.008)$ & $(0.009)$ & $(0.008)$ & $(0.006)$ \\
\hline \multirow[t]{2}{*}{ Communitarian } & $-0.036^{* *}$ & 0.008 & 0.010 & -0.017 \\
\hline & $(0.016)$ & $(0.018)$ & $(0.015)$ & $(0.011)$ \\
\hline \multirow[t]{2}{*}{ Indeterminate } & 0.0002 & 0.003 & 0.009 & $0.011^{*}$ \\
\hline & $(0.008)$ & $(0.009)$ & $(0.008)$ & $(0.006)$ \\
\hline Rho & $0.531^{* * *}$ & $0.507^{* * *}$ & $0.559^{* * *}$ & $0.547^{* * *}$ \\
\hline Country & Included & Included & Included & Included \\
\hline \multirow[t]{2}{*}{ Constant } & $0.147 * * *$ & $0.150 * * *$ & $0.055^{* * *}$ & $0.106^{* * *}$ \\
\hline & $(0.022)$ & $(0.022)$ & $(0.015)$ & $(0.014)$ \\
\hline Observations $(\mathrm{N})$ & 402 & 461 & 469 & 483 \\
\hline Log Likelihood & 787.858 & 854.228 & 928.089 & 1079.98 \\
\hline Sigma $^{2}$ & 0.001 & 0.001 & 0.001 & 0.001 \\
\hline Wald Test $(\mathrm{df}=1)$ & $100.480^{* * *}$ & $100.902^{* * *}$ & $139.759 * * *$ & $131.058^{* * *}$ \\
\hline LR Test $(\mathrm{df}=1)$ & $71.509^{* * *}$ & $71.301^{* * *}$ & $101.984^{* * *}$ & $91.820^{* * *}$ \\
\hline $\begin{array}{l}\text { LM test for residual } \\
\text { autocorrelation }\end{array}$ & 2.917 & 0.008 & 0.507 & $14.34^{* * *}$ \\
\hline
\end{tabular}

Significance: * $\mathrm{p}<0.1, * * \mathrm{p}<0.05, * * * \mathrm{p}<0.01$

Standard errors in parentheses. Reference categories are the absolute nuclear family system (for family systems) and Austria (for countries). Sources: See text. 
Table 5.5: Spatial Lag Model of the Princeton $I_{f}$ Index, including a Time-Lagged Control Variable (Maximum Likelihood Estimation)

\begin{tabular}{|c|c|c|c|}
\hline \multirow[t]{2}{*}{ Attribute } & \multicolumn{3}{|c|}{ Model } \\
\hline & 1900 & 1930 & 1960 \\
\hline \multirow[t]{2}{*}{ Egalitarian nuclear } & 0.010 & $0.017 * * *$ & 0.003 \\
\hline & $(0.008)$ & $(0.006)$ & $(0.005)$ \\
\hline \multirow[t]{2}{*}{ Stem family } & 0.008 & 0.007 & 0.003 \\
\hline & $(0.005)$ & $(0.005)$ & $(0.003)$ \\
\hline \multirow[t]{2}{*}{ Incomplete stem family } & 0.001 & 0.007 & 0.007 \\
\hline & $(0.007)$ & $(0.007)$ & $(0.005)$ \\
\hline \multirow[t]{2}{*}{ Communitarian } & 0.022 & 0.001 & $-0.021^{* *}$ \\
\hline & $(0.014)$ & $(0.013)$ & $(0.009)$ \\
\hline \multirow[t]{2}{*}{ Indeterminate } & 0.0002 & 0.004 & 0.004 \\
\hline & $(0.007)$ & $(0.006)$ & $(0.005)$ \\
\hline Rho & $0.276 * * *$ & $0.433^{* * *}$ & $0.38^{* * *}$ \\
\hline \multirow[t]{2}{*}{ IF (time lagged, t-30) } & $0.642^{* * *}$ & $0.477^{* * *}$ & $0.417^{* * *}$ \\
\hline & $(0.041)$ & $(0.031)$ & $(0.027)$ \\
\hline Country & Included & Included & Included \\
\hline Constant & $\begin{array}{c}0.004 \\
(0.022)\end{array}$ & $\begin{array}{l}-0.077^{* * *} \\
(0.015)\end{array}$ & $\begin{array}{l}0.081^{* * *} \\
(0.013)\end{array}$ \\
\hline $\begin{array}{l}\text { LM test for residual } \\
\text { autocorrelation }\end{array}$ & $9.559 * * *$ & $2.826 *$ & $34.534 * * *$ \\
\hline Observations & 392 & 465 & 479 \\
\hline Log Likelihood & 834.441 & 1020.63 & 1172.47 \\
\hline sigma2 & 0.001 & 0.001 & 0.0004 \\
\hline Wald Test $(\mathrm{df}=1)$ & $24.700^{* * *}$ & $88.531^{* * *}$ & $62.878^{* * *}$ \\
\hline LR Test $(\mathrm{df}=1)$ & $20.235^{* * *}$ & $75.993^{* * *}$ & $52.567 * * *$ \\
\hline
\end{tabular}

Significance: ${ }^{*} \mathrm{p}<0.1,{ }^{* *} \mathrm{p}<0.05,{ }^{* * *} \mathrm{p}<0.01$

Standard errors in parentheses. Reference categories are the absolute nuclear family system (for family systems) and Austria (for countries). Sources: See text. 


\subsection{DISCUSSION}

be associated with fertility outcomes. In contrast, for 1960 the opposite effect is found; communitarian family system regions show lower fertility outcomes than the reference category, the absolute nuclear family system.

\subsection{Discussion}

Fertility levels in Western Europe declined strongly since the mid-nineteenth century, but also show marked regional variations. The aim of this chapter is to investigate whether family systems, defined as norms and practices which define relationships between kin, are associated with variations in the level of fertility. Two hypothesis are tested using data from the Princeton European Fertility Project (Coale \& Watkins, 1986). First, fertility levels are expected to be higher in authoritarian family systems (communitarian and stem) than in nonauthoritarian family systems (egalitarian and absolute nuclear). Second, fertility levels are expected to be higher in egalitarian family systems (egalitarian nuclear and communitarian) compared to inegalitarian family systems (absolute nuclear and stem). In order to test these hypotheses, models are estimated including both time- and spatial-lag variables. Since the level of fertility may be associated with past fertility levels or the level of fertility in neighbouring regions, these models aim to uncover and control for these effects.

The findings in this study show no clear association between family systems and reproductive outcomes. Overall, although some findings are in line with our hypotheses, other findings are contradictory or no significant effects are observed. Several aspects of this study may suggest why no clear association is observed. First, Todd's typology of family systems warrants further discussion. As an explanatory variable, Todd's typology may not be precise or selective enough to differentiate between geographical areas with distinctive norms, attitudes and values towards kinship and family, resulting in an underestimation of the actual effect of family systems when measured more accurately. Furthermore, in order to develop his typology, Todd has drawn upon evidence from very different time periods and different social and cultural phenomena, and his methodology for quantifying and aggregating his findings to geographical areas has been questioned (Moch, 1986; Rijpma \& Carmichael, 2016).

It is difficult to measure family systems accurately - assuming there is consensus on its dimensions and measures. Such an approach would require more detailed information about local communities, preferably including information at the level of the individual and their household, but this information is not available for the time period covered in this study. Although the concept of family systems takes into account the role of others, through local norms, values or 


\section{CHAPTER 5. FAMILY SYSTEMS}

practices, it is not specific on the role of non-kin household members, even though co-residence with non-kin was widespread in parts of Europe into the beginning of the twentieth century. Although there are other typologies of family systems, such as Therborn $(2004 ; 2006)$ or Reher (1998), they too provide only broad categorisations of local clusters of norms, practices and values surrounding kinship and fertility and share the important disadvantages of Todd's typology. Even though having important drawbacks, Todd's typology is chosen primarily because it is well-defined for Western Europe and because of its theoretical connections with fertility behaviour.

Besides the potential shortcomings of Todd's typology, there are other aspects which future studies could improve on. Some family systems - in particular the communitarian family system - are poorly represented in terms of numbers in our data. The use of aggregated measures over a long time span (1870 to 1960) is not likely to be conducive to this study. Also, the measures are aggregated by region and do not take into account the size of regions or other conditions which may affect fertility. Although national and time or spatially lagged dummy variables are included, particular regional conditions or circumstances favouring higher or lower fertility outcomes are not taken into account. The inclusion of time and spatial lagged effects may have captured too much of the variation within the models. Therefore, if family systems would only have weak effects these will not be clearly visible in our analysis.

A suggestion for a future study would be to examine the fertility behaviour of individuals within well-defined family systems. Such an approach requires information on both fertility outcomes of individuals as well as precise measures of their local family systems, but can ultimately provide a better answer to the question which reproductive outcomes are favoured within a particular family system. Furthermore, and perhaps more insightful, such an approach can show how deviations from regional norms, practices and values lead to alternative fertility outcomes (see e.g. Mönkediek \& Bras, 2016, as an example of this method). Another alternative direction for future research is to examine whether diffusion effects play a role in fertility decline and whether family systems affect the degree to which new fertility behaviours can spread from one regions to another (Bras \& Van Tilburg, 2007; Bras, 2014). If family systems indeed affect fertility outcomes through diffusion processes, e.g. some family systems are more 'open' to new ideas such as family limitation, future research could focus on the interplay between local spatial autocorrelation and fertility outcomes. However, as a quick glance at figures 5.1 and 5.4 suggests, it is unlikely that this association will be found on the basis of the aggregated Princeton $I_{f}$ measures.

Perhaps the most elementary reason why family systems are expected to be 


\subsection{DISCUSSION}

associated with fertility outcomes is that family systems entail social norms, practices or values which either prevent or facilitate making connections with others outside the kin-network. When these local norms more easily allow people other than direct kin to enter your social network - for example because you are expected to move out of your parental home when you marry or, or because the absence of an inheritance in the form of a farm forces you to establish an independent living - these other people may bring in new ideas which may not have been introduced when your social network is mainly comprised of kin. When family limitation is seen as an innovation, a learned behaviour, family systems thus facilitate the degree to which the decline of fertility can spread. The fact that fertility levels of neighbouring regions are significantly and positively correlated, provides support for this view. The opposite however may also be true; relatively open family systems may also be more likely to display increases in fertility. Closely-knit kin networks on the other hand are probably more likely to show fertility levels which are more constant over time.

The influence of family systems on regional variations in fertility decline warrants further attention. While both the data and methods used in this chapter do not allow to infer causal relationships, the results indicate that further research is warranted to examine the associations between regional changes in fertility outcomes and family systems. A better understanding of the role of family systems may be of value for understanding transitions in fertility in the developing world today. For example, fertility levels in sub-Saharan Africa have been declining since the end of the twentieth century, in tandem with other demographic and social developments. In the 1980s, age at marriage was low, child mortality was high and women had on average 6.7 children. This figure declined to about 5.4 children in 2004 , although there are large and persistent differences between countries, similar to the experience of Western Europe (Tabutin \& Schoumaker, 2004). There are however unique characteristics of African family relationships, which may affect reproductive decision-making in highly distinctive ways. Examples of such conducts are the transition of property or services from the groom's family to that of the bride at marriage, or rites surrounding the passage to adulthood, the practise of polygyny and the large variation and influence of religion. When we learn more about the various ways in which family systems, or the relationships between kin, as well as non-kin, affect demographic outcomes, this information can be valuable to policy makers who implements and judge birth control programmes. However, more research is needed to further understand the mechanisms through which practices and norms surrounding kinship interact with reproductive outcomes, in particular in relation to diffusion processes. 

Chapter 6

Conclusion and Discussion 



\subsection{CONCLUSION}

\subsection{Conclusion}

\subsubsection{The family factor in fertility}

Fertility rates showed a marked decline in Western Europe from the mid-nineteenth century until the beginning of the twentieth century. The causes of this decline have been studied extensively, but no complete explanation to the observed patterns has yet been given. Why did fertility rates begin to fall? What can explain the spatial variation in the onset and speed of the decline? Recent studies have focussed on the fertility decision-making process at the level of the individual and the role of others in shaping perceived constraints and preferences. Family members can increase or reduce offspring survival chances and fertility outcomes by providing resources and support, or through social influences as social learning, social pressure, subjective obligations and social contagion.

This study hoped to contribute to the debate on the First Demographic Transition in Western Europe, by focussing on the role of family members in particular. The first aim of this study was to examine in which ways and to what extent fertility outcomes are influenced by family members. The second aim was to understand how family influences on fertility outcomes are shaped by 'family systems', which can be defined as "a set of beliefs and norms, common practices, and associated sanctions through which kinship and the rights and obligations of particular kin relationships are defined" (Mason, 2001, p. 160). In order to answer the main research questions, this thesis has focussed on four themes: Household composition, intergenerational transmission, spousal relations, and the role of the regional family system.

This dissertation has shown that family members had a significant influence on fertility outcomes in Western Europe during the First Demographic Transition. The influences of family members however varied depending on the type of kin and on the time period. As chapter 3 for example showed, the correlation between the total offspring size for parents and their children has decreased over the course of the nineteenth century. The following section summarizes the findings of this dissertation.

\subsubsection{Summary and contributions to the literature}

Chapter 2 examined the effects of co-resident (non-)kin on the length of birth intervals of Dutch women born in the second half of the nineteenth century. The dependent variable was the length of the closed birth interval, the predictors were the presence of other people in the household (parents, siblings, servants). Data was obtained from the Historical Sample of the Netherlands. Using survival anal- 
ysis, it was found that Dutch women who lived with their widowed father, or the widowed father of their husband, experienced significantly longer birth intervals compared to women who lived without a widowed father. In contrast, when a brother of either spouse was present, the waiting time until next childbirth was shorter than when no brother was present. In contrast to other studies, we found that parity progression rates were not significantly affected by the presence of widowed mothers or both parents of either spouse; the 'grandmother-hypothesis' was not confirmed in this study. This chapter is one of few examining the role of household composition on fertility outcomes, in particular using data from a population during a fertility decline. While this study employed an evolutionary perspective in order to understand the association between kin presence and fertility outcomes, its findings also highlight the role of the family economy. The resources which male siblings brought into the household apparently had enabling effects on fertility, while the presence of widowed fathers brought increased competition over household resources.

Chapter 3 examined the occurrence of intergenerational transmission of fertility in Sweden at the end of the nineteenth century, using data from the Demographic DataBase. The dependent variables were wife's age at marriage, age at first birth, length of birth interval and completed family size. The explanatory attributes were parent's age at marriage, age at first birth and completed family size. This study found evidence of weak, but positive correlations in reproductive outcomes between parents and children during a period of fertility transition. The intergenerational correlation for children ever born decreased over time, likely as a result of declining family sizes in general. This chapter confirms the intergenerational correlation in fertility observed in other studies.

Chapter 4 also made use of the Demographic DataBase and examines the associations between female autonomy (approximated by the spousal age gap) and reproductive outcomes. It focussed on the length of birth intervals and the number of children ever born for women born in Sundsvall and Skellefteå between the end of the nineteenth century until the beginning of the twentieth century. The main predictor was the age difference between spouses. After controlling for the age at marriage, women in wife-older marriages displayed shorter birth intervals compared to women in age-homogamous marriages. For women in husband-older or wife-older marriages the transition to first birth also occurred more quickly compared to women in age-homogamous marriages, indicating a catch-up effect. ${ }^{1}$ Women in husband-older marriages had slightly fewer children overall.

Chapter 5 aimed to examine whether family systems were associated with the

\footnotetext{
${ }^{1}$ Given that the age of the wife is controlled for, a catch-up effect arises when one of the spouses is older. It should be noted that women in wife-older marriages were on average older when they had their first child than women in age-homogamous marriages.
} 


\subsection{DISCUSSION}

spatial diffusion of fertility decline in Western Europe between 1870 and 1960. This chapter used Emmanuel Todd's operationalization of family systems and aggregated fertility indices were obtained from the Princeton European Fertility Project. The outcome variable of this study was the Princeton $I_{f}$ index in European provinces. The main explanatory attributes were the family system, fertility in adjacent regions (k-nearest neighbours) and time lagged fertility in the same region. The findings in this study showed no clear association between Todd's family systems and reproductive outcomes. Instead, fertility rates were strongly correlated with neighbouring regions and time-lagged fertility rates.

In conclusion, the chapters in this dissertation have contributed to our understanding of the complex associations between family and fertility during the course of the First Demographic Transition. Unfortunately, the second research aim of this study - understanding how fertility outcomes are shaped by family systems - has not been fully achieved. Between European regions, there were variations in fertility outcomes but the connection between fertility and Todd's typology of family systems was weak. There are some reasons for why there was no connection between fertility and family systems, as observed in chapter 5. These are discussed further below, but the most important methodological concern is that the typology of family systems used may not be precise enough to actually capture the local norms and values surrounding childbearing and parenthood. Future studies can improve upon this approach by examining the fertility behaviour of individuals, rather than regions, within well-defined family systems.

\subsection{Discussion}

\subsubsection{Methodological considerations}

The theoretical framework of this study regarded fertility decisions as the product of an individual's preferences (perceived benefits) in relation to their constraints (perceived costs). Both preferences and constraints were in turn assumed to be shaped by contextual factors working at, on the one hand, the meso- and macro-level, and on the other at the individual or micro-level. It was furthermore assumed that the behaviour of individuals is driven by their biological inclination to pass on their genes to future generations. This suggests that individuals are more willing to provide (pro-natal) support to close-kin than to distant-others. It was also assumed that fertility decisions are the result of an imperfect cost-benefit analysis when deciding whether or not to have a(nother) child. This imperfect cost-benefit analysis is however complicated by the postulation that people are highly social beings and that fertility decisions are both directly and indirectly in- 


\section{CHAPTER 6. CONCLUSIONS}

fluenced by other people. The perception or anticipation of support, punishment, attitudes or obligations from others are crucial factors in the highly contextspecific fertility decision faced by the individual (Leibenstein, 1957; Becker, 1981; Caldwell, 1982; Easterlin, 1975; Pollet et al., 2007; Voland \& Beise, 2002; Hawkes et al., 1997, 1998; Tymicki, 2004; Crognier et al., 2001; Kramer, 2005; Draper \& Hames, 2000; Feng et al., 2010; Hill \& Hurtado, 2009; Sear et al., 2003; Sear \& Mace, 2008; Kana'iaupuni et al., 2005).

From this theoretical framework, this thesis has focussed in four thematic chapters on the particular influences of family members on fertility outcomes. It must immediately be recognized that the theoretical framework draws attention to a wide body of contextual factors (at both the individual and the meso/macro level) that affect the perceived constraints and preferences of the individual facing a fertility decision. However, the chapters in this thesis were much more narrow in scope, focussing on the role of particular family members rather than taking into perspective the context as a whole. An important limitation, provided by the data available for this study, is that many relevant variables could not be observed. For example, it has been impossible to look beyond the parental household or to consider family systems at the level of local communities. However, the lack of suitable data often necessitated a focus on particular pathways of kin-influence, for otherwise the study would have become too complex and it would have been impossible to draw clear conclusions. The theoretical framework was for this reason used more as a model that was guiding the approach; a highly stylized representation of the factors at play when an individual is considering whether or not to have another child. This thesis has therefore aspired to provide insights into particular family influences, extending the continuing academic debate on the wider body of contextual factors affecting fertility outcomes.

Based on the chapters in this dissertation, three main recommendations for future research can be made. First, the concept of 'family systems' - as representations of local clusters of norms, values and attitudes towards parenthood provided an interesting perspective on the social and cultural context. However, the operationalization of family systems seems to be not precise enough to capture demographic patterns at the regional level. Second, in order to thoroughly test hypotheses concerning the relevance of evolutionary biology, the methodological approach should carefully separate biological effects from other (contextual) influences (Sear, 2015; Sear et al., 2016; Borgerhoff Mulder, 1998). Third and last, when examining particular explanatory attributes in an empirical study, it is vital to recognize the narrow perspective on what is shaping the perceived preferences and constraints regarding fertility decision-making. These three points are discussed further below. 


\subsection{DISCUSSION}

\section{Family systems}

When applied as regional rather than local clusters, family systems may not be precise or selective enough to capture the social norms, values, and practices surrounding parenthood faced by individuals. Chapter 5 examined the association between family systems and fertility outcomes at the level of European provinces. Based on this chapter we can draw the conclusion that Todd's typology of family systems in particular was not really useful for the study of fertility patterns at an aggregated level. Todd's methodology for quantifying and aggregating his findings to geographical areas has been questioned before (Moch, 1986; Rijpma \& Carmichael, 2016). Furthermore, Todd originally developed his family systems as a model for understanding variations in political ideologies, not reproductive behaviours.

The proposition that the association between fertility outcomes and the role of family systems - as they are currently defined - can be empirically tested, may be inherently false. The concept of family systems is still not well-defined and there is a large variation in regional norms, attitudes, and values towards kinship and family. ${ }^{2}$ This is a matter of concern for all typologies that cover large geographical areas, such as the works of Emmanuel Todd (1985), David Reher (1998) and Göran Therborn (2004). Lacking a definition or theory, it is difficult to model and perhaps impossible to definitively test the hypotheses on the role of family systems. Endogeneity concerns arise when family systems are proven to be a function of the organization of the local economy, suggesting that it is more important to focus on elements of the local economy such as the share of agriculture in order to understand regional and temporal variations in the composition of households, living arrangements, and the strength of kin ties (Ruggles, 2009). Within regions there are many local configurations of norms, values and practices towards parenthood. Looking only at what is considered to be a 'dominant' family system may therefore conceal the actual family context that is shaping the preferences and constraints of individuals in local communities. The abundance of local variation in family forms by itself therefore perhaps discredits the notion of macro-level family systems.

Furthermore, if we are to acknowledge the role of family systems in shaping fertility outcomes, we must consider more precisely the particular elements that set family systems apart from each other in terms of how they affect fertility. Moreover we must also examine the degree to which family systems are actually the responsible factor compared to other - more universal - explanatory mechanisms such as evolutionary biology or economic responses. An important criticism

\footnotetext{
${ }^{2}$ Similar methodological challenges are faced by studies in the field of Economics focussing on the role of 'institutions' (North, 1990).
} 


\section{CHAPTER 6. CONCLUSIONS}

of the Princeton European Fertility Project was that while it highlighted the role of cultural barriers in shaping fertility outcomes, the findings did not explain how fertility was influenced by culture. The same criticism may be applicable to family systems; while we may conceptualize their presence and meaning, it is difficult to deduce from them hypotheses on their effects on fertility and to offset their role to universal mechanisms in which people behave predictably depending on what they are maximizing with which resources. ${ }^{3}$

The recommendations for future studies on the role of family systems in fertility are twofold. First, empirical testing of the role of family systems necessitates the continuous development of its theory and subsequently falsifiable hypotheses. In particular, further research is needed in order to understand the various pathways or elements through which high or low fertility outcomes are enabled or constrained by family systems. Without such refinement, it is difficult if not impossible to examine to what extent family systems differ in terms of explanatory power from other factors such as biology and economic drivers. Second, in order to properly understand regional variations in fertility outcomes, studies should focus on the behaviours of individuals - rather than regional aggregated patterns - for who we truly understand their social norms, practices, and values regarding fertility decision-making.

Together, these two suggestions call for comparative studies focussing on fertility behaviours in small communities for which the family systems are well-defined. Comparative analyses of fertility outcomes in communities of which local norms and attitudes are more clearly outlined may prove to be of greater merit (Greenhalgh, 1995; Szreter, 1996).

\section{Evolutionary approaches}

The second recommendation for future research is to further examine evolutionary approaches in understanding fertility decline. 'Fitness theory' provides a useful framework for understanding why and which people are willing to provide support to others. Generally speaking, a stronger genetic bond between individuals would encourage them to provide support to each other since this - from an evolutionary perspective - increases the chance that their genes, or more precisely alleles, will be passed over to future generations (Fisher, 1930; Hamilton, 1964a,b). It is difficult to differentiate empirically between the effects of genetics and the context of individuals; the classic 'nature versus nurture' debate in biology. It is therefore important to apply research designs that carefully reduce endogenous variation,

\footnotetext{
${ }^{3}$ Evolutionary biology and economic models suggest that people allocate their resources in such way that they are maximizing their inclusive fitness (evolutionary biology) or their personal utility (economic models.)
} 


\subsection{DISCUSSION}

in order to advance fertility studies using an evolutionary framework (see Sear, 2015; Nettle et al., 2013; Kramer, 2010). ${ }^{4}$

As discussed in chapter 2 , the presence of kin members did not necessarily yield higher fertility outcomes; only for brothers of either the husband or wife who were present in the household a positive effect on fertility was observed (higher parity transition rates). An important limitation of this study is that 'kin presence' was equated with 'kin support'. Given that childbearing bears costs, there is however a difference between 'maximum' and 'optimum' fertility; increased kin support may not necessarily augment reproduction. In addition it is not optimal for parents to strive for maximum fertility since this reduces the chance that they can provide enough support for all their offspring. Unfortunately, we did not have information on the exact role of each individual within the household, their financial status, their health, and the distribution of resources within the household. We could only assume that brothers of the husband or wife were able to provide additional resources and support, while other individuals did not or were even consumers of resources (in the case of widowed fathers). We also could not look beyond the household in chapter 2, leaving a blind-spot for assistance from kin or friends from outside the parental home. Given that the examined communities were small, the support provided from outside the household should not be underestimated. Future studies should therefore consider the many other factors to be taken into account for a fuller understanding of the association between the presence of kin and fertility.

Chapter 3 accentuated the inherent biological nature of reproduction. This study is one of only a few examining intergenerational fertility correlations for a historical population during a transition period from high to low fertility (see figure 3.2 on page 86 ). The inclination and ability to reproduce may be genetically predetermined and does not need to be randomly distributed between individuals. In line with other literature, a positive association in fertility between subsequent generations was observed in this study. While chapter 3 considered intergenerational correlations in fertility, a recommendation for future research is to also examine the correlation of fertility outcomes of siblings. Siblings share genetic traits and while their life courses and spouses may be different, it would be interesting to examine the hypothesis that siblings are more likely to share fertility patterns than random individuals with similar characteristics (such as similar community, socio-economic status, birth cohort, etc. See e.g. Axinn et al., 1994; Bras et al., 2013).

\footnotetext{
${ }^{4}$ Attributes are said to be endogenous when their value is determined by the state of other attributes - within or outside the scope of the model.
} 


\section{CHAPTER 6. CONCLUSIONS}

\section{A matter of perspective}

Encouraged by academic journals or publishers, empirical studies often accentuate their contribution to their field of interest. It is however vital to recognize that often in academic studies, most of the observed effects are only of concern within the particular context of the study. Frequently, exogenous factors are implicitly assumed to be constant or to be 'controlled for' within the specifications of the empirical model. Besides unobserved heterogeneity, the strength of the observed effect also warrants attention - even though weak effects too may be responsible for serious changes in human fertility over a longer period of time (Murphy, 1999). The focus of empirical studies in demography is therefore - and should be - inevitably narrow in order to make sense of the pluriformity of reality. Nevertheless, one should not forget the fact that while such a narrow perspective helps to examine a precise mechanism, other factors and their mutual interactions are easily overlooked.

To further illustrate this issue, in chapter 4 it was observed that after controlling for the age at marriage, women in wife-older marriages displayed shorter birth intervals compared to women in age-homogamous marriages. For women in husband-older marriages the transition to first birth also occurred more quickly compared to women in age-homogamous marriages. Women in husband-older marriages had slightly fewer children overall. However, the role of spousal age differences in fertility decision-making can be questioned. Is the age gap indeed a proxy for spousal power relations? The associations between female autonomy and age differences observed in the empirical literature are mixed (cf. Abadian, 1996; Barbieri et al., 2005). If women seemed to strive to increase fertility when they were older than their spouse, why would men not also strive to increase fertility when they were older? Given that the fitness benefits of reproduction are for men larger than the biological costs, it seems likely that men have an incentive to increase fertility if they are in a position to do so (Borgerhoff Mulder, 2000, 2007; Hamilton, 1964a,b). Chapter 4 sharpened our understanding of the implications of age differences regarding fertility. However, it considered only one aspect of spousal power relations (i.e. age differences) in matters concerning reproduction. The final picture remains incomplete and further research is necessary in order to better understand the ways in which the nature of the relationship shapes perceived constraints and preferences regarding fertility decisions.

Human fertility is undoubtedly a very complex trait. It is highly variable, both over time and between regions. At the same time it is 'sticky', as reproductive patterns are transmitted over generations, and regional, cultural boundaries can be clearly discerned. Moreover, fertility decisions are highly personal, affected by the perceived constraints and preferences shaped by individual physiology, 


\subsection{DISCUSSION}

culture and behaviours originating from both a micro- and a macro context. The conception of each (subsequent) child or the act of stopping having children, is each time a decision which is not made lightly. Academic research in fertility currently employs many different theoretical perspectives in an effort to increase our understanding of this complex reality. As is described in chapter 1 , the scientific debate has advanced from a focus on descriptive macro-approaches, such as Demographic Transition Theory and the role of 'culture' in the Princeton Project, towards decision-making at the level of the individual using concepts such as evolutionary biology, social influences, and the (family) context in which decision-making takes place (Sear et al., 2016). It is perhaps no surprise that when different perspectives are employed, it is difficult to unify them into one coherent body.

Following Sear (2015) demographers should not be afraid to expand their toolkit, building upon insights from other disciplines in their effort to understand how demographic processes are shaped. This dissertation has tried to provide a modest contribution to the demographic debate by examining the association between the role of the family and fertility outcomes from different perspectives. The evolutionary approach was employed as a means to understand the motivation behind support from kin, family systems were regarded as a cultural mould - however imperfect - enabling particular fertility outcomes by shaping interactions between kin, and finally diffusion theory provided a perspective on the geographical distribution of fertility patterns. Each separate study in this dissertation has focussed on a distinctive subject, but taken together they show that the family context can influence fertility outcomes in very specific but also unexpected ways. In light of the way the academic debate has progressed in recent decades, this study underlines the need for a focus on fertility decision-making at the level of the individual, with a clear focus on the (family) context in which this decision-making takes place.

\subsubsection{Policy and societal implications}

This study has sought to improve our understanding of the way reproductive outcomes in West-European countries were shaped by family relationships, during a historical period of fertility decline. The implications of this study for society and policy makers today are clear; reproduction is not only of great importance for (young) parents who see their lives changing with the birth of a child, it also relates to matters such as population ageing, child-care arrangements and women's labour force participation. The explanatory attributes in this study - the presence, roles, attitudes and fertility outcomes of family members - are by themselves not something policy makers are likely to directly intervene in. However, when faced 


\section{CHAPTER 6. CONCLUSIONS}

with challenges regarding changes in the (future) demographic composition of a nation, policy makers should be aware that people's childbearing decisions are linked to the (fertility) behaviour of their family.

This dissertation finds that family members actively influence fertility outcomes of kin by shaping perceived constraints and preferences regarding childbearing, through kin priming and through the provision of resources and support. What does this mean for future fertility outcomes in countries currently confronted with high or low birth rates, facing issues regarding population growth or ageing? When examining the effect of kin presence within the household on the waiting time until the next birth (chapter 2), we observed an important role for family members who could provide support to the couple, perhaps financially. Households in which brothers of either spouse co-reside show higher hazard ratios for the transition to next birth. Does this imply that financial incentives are likely to encourage childbirth? This question cannot be answered based on this chapter, but it is interesting in light of the recent increase in 'baby-bonuses' provided by governments in Europe. ${ }^{5}$

Financial incentives or received support from kin are however not the only element affecting fertility. Chapter 3 illustrates the persistence of intergenerational fertility outcomes; the number of children born to an individual is positively correlated with their number of siblings. An important limitation of the data used in this study was that it only observed families who were residing within particular geographic areas over a longer period of time. Cross-country migrants were thus not included in this study. However, the observation that fertility is 'sticky' over time, due to the transmission of parental fertility, may explain why policy interventions may seem ineffective in the short run. Similarly, chapter 5 showed that regionally aggregated fertility rates were correlated with fertility in adjacent areas. This effect may also provide an explanation for ineffective policy measures in the short run, although it should be noted that diffusion effects are stronger for countries with similar culture (Lesthaege, 1983; Coale \& Watkins, 1986).

Each childbirth is a true wonder; it is the beginning of new life full of possibilities and it marks an irreversible, but rewarding change in the life of the parents. Today, around 385.000 children are born around the world each day. ${ }^{6}$ Although each childbirth is special, from a wider perspective it is clear that there are regional differences in the timing and quantum of childbirth. These regional

\footnotetext{
${ }^{5}$ Financial incentives provided by governments aimed at increasing fertility are not a new phenomenon, but recently the topic has been reported on by several media. See for example: https://www.bbc.com/worklife/article/20191017-does-it-make-sense-to-paypeople-to-have-kids and https://www.reuters.com/article/us-hungary-orban-benefits/ orban-offers-financial-incentives-to-boost-hungarys-birth-rate-idUSKCN1PZOI0

${ }^{6}$ UN Population Division, Department of Economic and Social Affairs. World Population Prospects (2019). ID: POP/DB/WPP/Rev. 2019/FERT/F01.
} 


\subsection{DISCUSSION}

differences, this thesis argues, are persistent over time and linked to the family context which is shaping individual fertility decision-making. The main aim of this thesis was to examine in which ways and to what extent fertility outcomes are influenced by family members. Using data from 19th century West-European countries, this thesis has confirmed findings by other academic studies on the persistence of regional fertility patterns (chapter 5) and the presence of intergenerational fertility correlations (chapter 3). It also highlighted the role of spousal age differences (chapter 4) and the effects of co-resident kin on the timing of childbirth (chapter 2). Nevertheless, based on the chapters in this dissertation, it is also clear that further research is needed to better understand the precise mechanisms through which fertility decisions are shaped by the behaviours and influences of family members. We also do not yet fully understand the impact of the socio-economic and regional family system context on fertility outcomes. In this concluding chapter, some hopefully promising directions of further study are discussed. If we understand better how fertility decisions are shaped by the (family) context today and in the past, policy makers are better equipped to develop intervention schemes, and to predict their countries' demographic future. 


\section{Bibliography}

Aagren, M. (2009). Domestic Secrets: Women 6 Property in Sweden, 1600-1857. Chapel Hill: University of North Carolina Press.

Abadian, S. (1996). Women's autonomy and its impact on fertility. World Development, $24(12), 1793-1809$.

Aksoy, O., \& Billari, F. (2018). Political Islam, Marriage and Fertility: Evidence from a Natural Experiment. American Journal of Sociology, 123(5).

Alesina, A., \& Giuliano, P. (2007). The Power of the Family. National Bureau of Economic Research Working Paper Series, No. 13051.

Alm-Stenflo, G. (1994). Demographic description of the Skelleftea and Sundsvall regions during the 19th century. Umeå: Demographic Database.

Alter, G. (1988). Family and the female life course: the women of Verviers, Belgium, 1849-1880. Univ of Wisconsin Press.

Alter, G. (1992). Theories of Fertility Decline: A Nonspecialist's Guide to the Current Debate. In J. R. Gillis, L. A. Tilly, \& D. Levine (Eds.) The European experience of declining fertility: a quiet revolution, 1850-1970, (pp. 13-30). Cambridge, Massachusetts: Blackwell Publishers.

Alter, G., \& Mandemakers, K. (2014). The Intermediate Data Structure (IDS) for Longitudinal Historical Microdata, version 4. Historical Life Course Studies, $1,1-26$.

Anderton, D. L., \& Bean, L. L. (1985). Birth Spacing and Fertility Limitation: A Behavioral Analysis of a Nineteenth Century Frontier Population. Demography, 22(2), 169-183.

Anderton, D. L., Tsuya, N. O., Bean, L. L., \& Mineau, G. P. (1987). Intergenerational Transmission of Relative Fertility and Life Course Patterns. Demography, $24(4), 467-480$. 


\section{BIBLIOGRAPHY}

Aries, P. (1980). Two Successive Motivations for the Declining Birth Rate in the West. Population and Development Review, 6(4), 645-650.

Ashraf, N., Field, E., \& Lee, J. (2014). Household Bargaining and Excess Fertility: An Experimental Study in Zambia. American Economic Review, 104 (7), 221037.

Astone, N. M., Nathanson, C. A., Schoen, R., \& Kim, Y. J. (1999). Family Demography, Social Theory, and Investment in Social Capital. Population and Development Review, 25(1), 1-31.

Axinn, W., Clarkberg, M., \& Thornton, A. (1994). Family influences on family size preferences. Demography, 31(1), 65-79.

Axinn, W., \& Thornton, A. (1996). The Influence of Parents' Marital Dissolutions on Children's Attitudes Toward Family Formation. Demography, 33(1), 66-81.

Bairoch, P., \& Goertz, G. (1986). Factors of Urbanisation in the Nineteenth Century Developed Countries: A Descriptive and Econometric Analysis. Urban Studies, 23(4), 285-305.

Balbo, N., Billari, F. C., \& Mills, M. (2013). Fertility in Advanced Societies: A Review of Research. European Journal of Population / Revue europièenne de Démographie, 29(1), 1-38.

Barber, J. S. (2001). The Intergenerational Transmission of Age at First Birth among Married and Unmarried Men and Women. Social Science Research, 30(2), 219-247.

Barbieri, M., Hertrich, V., \& Madeleine, G. (2005). Age Difference between Spouses and Contraceptive Practice in Sub-Saharan Africa. Population (English Edition), 60(5/6), 617-654.

Becker, G. (1960). An economic analysis of fertility. In National Bureau Committee for Economic Research (Ed.) Demographic and Economic Change in Developed Countries. Princeton: Princeton University Press.

Becker, G. S. (1981). A Treatise on the Family. Cambridge, MA: Harvard University Press.

Becker, G. S., \& Barro, R. J. (1988). A Reformulation of the Economic Theory of Fertility. The Quarterly Journal of Economics, 103(1), 1-25.

Bengtson, V. L. (1975). Generation and Family Effects in Value Socialization. American Sociological Review, 40(3), 358-371. 


\section{BIBLIOGRAPHY}

Bengtsson, T., \& Dribe, M. (2006). Deliberate Control in a Natural Fertility Population: Southern Sweden, 1766-1864. Demography, 43(4), 727-746.

Bereczkei, T. (1998). Kinship Network, Direct Childcare, and Fertility Among Hungarians and Gypsies. Evolution and Human Behavior, 19 (5), 283-298.

Bereczkei, T., \& Csanaky, A. (1996). Mate choice, marital success, and reproduction in a modern society. Ethology and Sociobiology, 17(1), 17-35.

Bernardi, L. (2004). Channels of social influence on reproduction. Population Research and Policy Review, 22, 527-555.

Bernardi, L. (2013). From mothers to daughters: intergenerational transmission of fertility norms. In A. Ellingsaeter, A. Jensen, \& M. Lie (Eds.) The social meaning of children and fertility change in Europe, (pp. 153-169). New York: Routledge.

Bernardi, L., Keim, S., \& von der Lippe, H. (2007). Social Influences on Fertility: A Comparative Mixed Methods Study in Eastern and Western Germany. Journal of Mixed Methods Research, 1(1), 23-47.

Bernardi, L., \& Klärner, A. (2014). Social networks and fertility. Demographic Research, S16(22), 641-670.

Bernardi, L., Mynarska, M., \& Rossier, C. (2015). Uncertain, Changing and Situated Fertility Intentions. In D. Philipov, A. C. Liefbroer, \& J. E. Klobas (Eds.) Reproductive Decision-Making in a Macro-Micro Perspective, (pp. 113139). Dordrecht: Springer Netherlands.

Bernardi, L., \& White, R. (2010). Close kin influences on fertility behaviour. In P. Heady, \& M. Kohli (Eds.) Kinship and State in Contemporary Europe. Perspectives on Theory And Policy Vol. 3. Frankfurt: Campus Verlag.

Bertocchi, G., \& Bozzano, M. (2014). Family Structure and the Education Gender Gap: Evidence from Italian Provinces. CESifo Economic Studies (working paper).

Bittles, A., Murphy, M., \& Reher, D. (2008). Inherited Dimensions of Human Populations in the Past. Human Nature, 19(1), 1-6.

Bloom, D. E., Canning, D., Fink, G., \& Finlay, J. E. (2010). The cost of low fertility in Europe. European Journal of Population/Revue Européenne de Démographie, 26(2), 141-158. 


\section{BIBLIOGRAPHY}

Bocquet-Appel, J.-P., \& Jakobi, L. (1998). Evidence for a Spatial Diffusion of Contraception at the Onset of the Fertility Transition in Victorian Britain. Population: An English Selection, 10(1), 181-204.

Bongaarts, J., \& Potter, R. (1983). Fertility, Biology, and Behavior: An Analysis of the Proximate Determinants. New York, London: Academic Press.

Bongaarts, J., \& Watkins, S. C. (1996). Social Interactions and Contemporary Fertility Transitions. Population and Development Review, 22(4), 639-682.

Boonstra, O. (2007). NLGis shapefiles. URL https://easy.dans.knaw.nl/ui/datasets/id/easy-dataset : 44426

Booth, A. L., \& Kee, H. J. (2009). Intergenerational Transmission of Fertility Patterns. Oxford Bulletin of Economics and Statistics, 71(2), 183-208.

Borgerhoff Mulder, M. (1998). The demographic transition: are we any closer to an evolutionary explanation? Trends in ecology \& evolution, 13, 266-70.

Borgerhoff Mulder, M. (2000). Optimizing offspring: the quantity-quality tradeoff in agropastoral Kipsigis. Evolution and Human Behavior, 21 (6), 391-410.

Borgerhoff Mulder, M. (2007). Hamilton's rule and kin competition: the Kipsigis case. Evolution and Human Behavior, 28(5), 299-312.

Boyd, R., \& Richerson (1985). Culture and the Evolutionary Process. Chicago: University of Chicago Press.

Bras, H. (2014). Structural and diffusion effects in the Dutch fertility transition, 1870-1940. Demographic Research, 30 (5), 151-186.

Bras, H., Kok, J., \& Mandemakers, K. (2010a). Sibship size and status attainment across contexts: Evidence from the Netherlands, 1840-1925. Demographic Research, S10(4), 73-104.

Bras, H., Liefbroer, A., \& Elzinga, C. (2010b). Standardization of pathways to adulthood? An analysis of Dutch cohorts born between 1850 and 1900 . Demography, 47(4), 1013-1034.

Bras, H., \& Schumacher, R. (2019). Changing gender relations, declining fertility? An analysis of childbearing trajectories in 19th-century Netherlands. Demographic Research, 41(30), 873-912.

Bras, H., Van Bavel, J., \& Mandemakers, K. (2013). Unraveling the intergenerational transmission of fertility: genetic and shared-environment effects during the demographic transition in the Netherlands, 1810-1910. The History of the Family, 18(2), 116-134. 


\section{BIBLIOGRAPHY}

Bras, H., \& Van Tilburg, T. (2007). Kinship and Social Networks: A Regional Analysis of Sibling Relations in Twentieth-Century Netherlands. Journal of Family History, 32(3), 296-322.

Breschi, M., Esposito, M., Mazzoni, S., \& Pozzi, L. (2014). Fertility transition and social stratification in the town of Alghero, Sardinia (1866-1935). Demographic Research, 30(28), 823-852.

Brändström, A., \& Sundin, J. (1981). Infant mortality in a changing society. The effects of child care in a Swedish parish 1820-1894. In A. Brändström, \& J. Sundin (Eds.) Tradition and Transition. Studies in microdemography and social change, (pp. 67-104). Umeå: University of Umeå.

Brown, J. C., \& Guinnane, T. W. (2003). Two statistical problems in the Princeton project on the European fertility transition. Yale University Economic Growth Center Discussion paper No. 869.

Brown, L. (1981). Innovation Diffusion: A New Perspective. New York: Methuen.

Brulé, G., \& Veenhoven, R. (2014). Average happiness and dominant family type in Western Europe around 2000. Advances in Applied Sociology, 4, 271-288.

Burch, T. (1996). Icons, straw men, and precision: Reflections on demographic theories of fertility decline. Sociological Quarterly, 37(1), 59-81.

Cain, M. (1993). Patriarchal structure and demographic change. In N. Frederici, K. Mason, \& S. e. Sogner (Eds.) Women's position and demographic change, (pp. 43-60). Oxford: Clarendon Press.

Caldwell, J. (1982). Theory of fertility decline. London: Academic Press.

Caldwell, J. C. (1976). Toward A Restatement of Demographic Transition Theory. Population and Development Review, 2(3/4), 321-366.

Caldwell, J. C. (1978). A Theory of Fertility: From High Plateau to Destabilization. Population and Development Review, 4(4), 553-577.

Casterline, J. B. (2001). Diffusion Processes and Fertility Transition. Washington D.C.: National Academy Press.

Casterline, J. B. (2017). Prospects for Fertility Decline in Africa. Population and Development Review, 43(S1), 3-18.

Casterline, J. B., Williams, L., \& McDonald, P. (1986). The Age Difference Between Spouses: Variations among Developing Countries. Population Studies, $40(3), 353-374$. 


\section{BIBLIOGRAPHY}

Chesnais, J., Kreager, P., \& Kreager, E. (1992). The Demographic Transition: Stages, Patterns, and Economic Implications : a Longitudinal Study of Sixtyseven Countries Covering the Period 1720-1984. Clarendon Press.

Cleland, J., \& Wilson, C. (1987). Demand Theories of the Fertility Transition: an Iconoclastic View. Population Studies, 41(1), 5-30.

Cleves, M., Gutierrez, R., Gould, W., \& Marchenko, Y. (2010). An introduction to survival analysis using Stata. Stata Press.

Coale, A., \& Treadway, R. (1986). A Summary of the Changing Distribution of Overall Fertility, Marital Fertility, and the Proportion Married in the Provinces of Europe. In A. Coale, \& S. C. Watkins (Eds.) The Decline of Fertility in Europe: The Revised Proceedings of a Conference on the Princeton European Fertility Project, (pp. 31-181). Princeton: Princeton University Press.

Coale, A., \& Watkins, S. C. (1986). The Decline of Fertility in Europe: the Revised Proceedings of a Conference on the Princeton European Fertility Project. Princeton University Press.

Coall, D. A., \& Hertwig, R. (2010). Grandparental investment: Past, present, and future. Behavioral and Brain Sciences, 33(1), 1-19.

Coleman, J. (1994). Foundations of Social Theory. Cambridge: Belknap Press.

Conde-Agudelo, A., Rosas-Bermúdez, A., \& Kafury-Goeta, A. (2006). Birth spacing and risk of adverse perinatal outcomes: A meta-analysis. JAMA, 295(15), 1809-1823.

Conde-Agudelo, A., Rosas-Bermúdez, A., \& Kafury-Goeta, A. (2007). Effects of birth spacing on maternal health: a systematic review. American Journal of Obstetrics and Gynecology, 196(4), 297-308.

Cools, S., \& Kaldager Hart, R. (2016). The Effect of Childhood Family Size on Fertility in Adulthood: New Evidence From IV Estimation. Demography, (pp. $1-22)$.

Cox, D. R., \& Snell, E. J. (1968). A General Definition of Residuals. Journal of the Royal Statistical Society. Series B (Methodological), 30(2), 248-275.

Crognier, E., Baali, A., \& Hilali, M. (2001). Do 'Helpers at the Nest' Increase their Parents' Reproductive Success? American Journal of Human Biology, 13, 365-373. 


\section{BIBLIOGRAPHY}

Dahlberg, J. (2013). Family influence in fertility: A longitudinal analysis of sibling correlations in first birth risk and completed fertility among Swedish men and women. Demographic Research, 29(9), 233-246.

Das Gupta, M. (1999). Lifeboat versus Corporate Ethic: Social and Demographic Implications of Stem and Joint Families. Social Science $\&$ Medicinee, 49, 173 184.

Davis, K. (1945). The World Demographic Transition. The Annals of the American Academy of Political and Social Science, 237(1), 1-11.

Davis, K. (1955). Institutional Patterns Favoring High Fertility in Underdeveloped Areas. Eugenics Quarterly, 2, 33-39.

Demeny, P. (1968). Early Fertility Decline in Austria-Hungary: A Lesson in Demographic Transition. Daedalus, 97(2), 502-522.

Derosas, R. (2006). Between identity and assimilation: Jewish fertility in nineteenth-century Venice. In R. Derosas, \& F. Van Poppel (Eds.) Religion and the Decline of Fertility in the Western World, (pp. 177-206). Springer.

Desjardins, B., Bideau, A., Heyer, E., \& Brunet, G. (1991). Intervals between marriage and first birth in mothers and daughters. Journal of Biosocial Science, $23(01), 49-54$.

Draper, P., \& Hames, R. (2000). Birth order, sibling investment, and fertility among Ju/'Hoansi (!Kung). Human Nature, 11(2), 117-156.

Dribe, M. (2003). Dealing with economic stress through migration: Lessons from nineteenth century rural Sweden. European Review of Economic History, 7(3), 271-299.

Dribe, M., \& Lundh, C. (2005). Gender aspects of inheritance strategies and land transmission in rural Scania, Sweden, 1720-1840. The History of the Family, $10(3), 293-308$.

Dribe, M., \& Lundh, C. (2014). Social Norms and Human Agency: Marriage in Nineteenth-Century Sweden. In C. Lundh, \& S. Kurosu (Eds.) Similarity in Difference. Marriage in Europe and Asia 1700-1900, (pp. 211-260). Cambridge: MIT Press.

Duncan, O. D., Freedman, R., Coble, J. M., \& Slesinger, D. P. C. (1965). Marital Fertility and Size of Family of Orientation. Demography, 2, 508-515. 


\section{BIBLIOGRAPHY}

Duranton, G., Rodriguez-Pose, A., \& Sandall, R. (2009). Family Types and the Persistence of Regional Disparities in Europe. Economic Geography, 85(1), 23-47.

Dyson, T. (2010). Population and Development, the Demographic Transition. London and New York: Zed Books.

Easterlin, R. (1975). An economic framework for fertility analysis. Studies in Family Planning, 6(3), 54-63.

Easterlin, R., Pollak, R., \& Wachter, M. (1980). Toward a More General Economic Model of Fertility Determination: Endogenous Preferences and Natural Fertility. In R. Easterlin (Ed.) Population and Economic Change in Developing Countries, (pp. 81-150). University of Chicago Press.

Edvinsson, S., \& Nilsson, H. (2000). Urban mortality in Sweden during the 19th century. In A. Brändstrøm, \& L.-G. Tedebrand (Eds.) Population dynamics during industrialization. Umeå: Umeå University.

Egerbladh, I. (1989). From Complex to Simple Family Households: Peasant Households in Northern Coastal Sweden 1700-1900. Journal of Family History, $14(3), 241-264$.

Euler, H., \& Weitzel, B. (1996). Discriminative grandparental solicitude as reproductive strategy. Human Nature, 7(1), 39-59.

Fasang, A. E., \& Raab, M. (2014). Beyond Transmission: Intergenerational Patterns of Family Formation Among Middle-Class American Families. Demography, 51(5), 1703-1728.

Feldman, B. S., Zaslavsky, A. M., Ezzati, M., Peterson, K. E., \& Mitchell, M. (2009). Contraceptive Use, Birth Spacing, and Autonomy: An Analysis of the Oportunidades Program in Rural Mexico. Studies in Family Planning, 40(1), 51-62.

Feng, W., Lee, J. Z., Tsuya, N. O., \& Kurosu, S. (2010). Household Organization, Co-resident Kin, and Reproduction. In N. O. Tsuya, W. Feng, G. Alter, \& J. Z. Lee (Eds.) Prudence and Pressure, Reproduction and Human Agency in Europe and Asia, 1700-1900, (pp. 67-96). Cambridge: MIT Press.

Fertig, C. (2018). Stem families in rural northwestern Germany? Family systems, intergenerational relations and family contracts. The History of the Family, 23(2), 196-217. 


\section{BIBLIOGRAPHY}

Fisher, R. (1930). The genetical theory of natural selection. Oxford: Clarendon Press.

Fricke, T., \& Teachman, J. D. (1993). Writing the Names: Marriage Style, Living Arrangements, and First Birth Interval in a Nepali Society. Demography, 30 (2), 175-188.

Gagnon, A., \& Heyer, E. (2001). Intergenerational correlation of effective family size in early Québec (Canada). American Journal of Human Biology, 13(5), 645-659.

Galor, O. (2012). The demographic transition: causes and consequences. Cliometrica, 6(1), 1-28.

Gaunt, D. (1983). The property and kin relationships of retired farmers in northern and central Eurepe. In J. Wall, R. Robin, \& P. Laslett (Eds.) Family forms in historic Europe, (pp. 249-280). Cambridge: Cambridge University Press.

Gaunt, D. (1987). Rural Household Organization and Inheritance in Northern Europe. Journal of Family History, 12(1), 121-141.

Geroski, P. (2000). Models of technology diffusion. Research Policy, 29(4), 603625 .

Giddens, A. (1984). The constitution of society. Outline of the theory of structuration. Berkeley and Los Angeles: University of California Press.

Goldstein, J. R., \& Klüsener, S. (2014). Spatial Analysis of the Causes of Fertility Decline in Prussia. Population and Development Review, 40(3), 497-525.

Grafen, A. (1984). Natural selection, kin selection and group selection. In J. Krebs, \& N. Davies (Eds.) Behavioural ecology, (pp. 62-84). Oxford: Blackwell.

Grandits, H. (Ed.) (2010). Family, Kinship and State in Contemporary Europe. Vol. 1 The Century of Welfare: Eight Countries.. Frankfurt/New York: Campus Verlag.

Granovetter, M. S. (1973). The strength of weak ties. American Journal of Sociology, $78(6), 1360-1380$.

Gray, R. H., Campbell, O. M., Apelo, R., Eslami, S. S., Zacur, H., Ramos, R. M., Gehret, J. C., \& Labbok, M. H. (1990). Risk of ovulation during lactation. The Lancet, 335 (8680), 25-29.

Green, L. (2009). Diffusion theory and knowledge dissemination, utilization, and integration in public health. Annual review of public health, 30 . 


\section{BIBLIOGRAPHY}

Greenhalgh, S. (Ed.) (1995). Situating Fertility: Anthropology and Demographic Inquiry. Cambridge: Cambridge University Press.

Greif, A. (2006). Family Structure, Institutions, and Growth: The Origins and Implications of Western Corporations. The American Economic Review, $96(2)$, 308-312.

Guinnane, T., Okun, B., \& Trussell, J. (1994). What do we know about the timing of fertility transitions in europe? Demography, 31(1), 1-20.

Gurven, M., Allen-Arave, W., Hill, K., \& Hurtado, A. M. (2001). Reservation food sharing among the Ache of Paraguay. Human Nature, 12(4), 273-297.

Hajnal, J. (1982). Two Kinds of Preindustrial Household Formation Systems. Population and Development Review, 8(3), 449-494.

Hames, R., \& Draper, P. (2004). Women's work, child care, and helpers-at-thenest in a hunter-gatherer society. Human Nature, 15(4), 319-341.

Hamilton, W. D. (1964a). The genetical evolution of social behaviour. I. Journal of Theoretical Biology, 7(1), 1-16.

Hamilton, W. D. (1964b). The genetical evolution of social behaviour. II. Journal of Theoretical Biology, 7(1), 17-52.

Hank, K., \& Kreyenfeld, M. (2003). A Multilevel Analysis of Child Care and Women's Fertility Decisions in Western Germany. Journal of Marriage and Family, 65(3), 584-596.

Hawkes, K. (2003). Grandmothers and the evolution of human longevity. American Journal of Human Biology, 15(3), 380-400.

Hawkes, K., O'Connell, J. F., \& Blurton Jones, N. G. (1997). Hadza Women's Time Allocation, Offspring Provisioning, and the Evolution of Long Postmenopausal Life Spans. Current Anthropology, 38(4), 551-577.

Hawkes, K., O'Connell, J. F., Jones, N. G. B., Alvarez, H., \& Charnov, E. L. (1998). Grandmothering, menopause, and the evolution of human life?histories. Proceedings of the National Academy of Sciences, 95(3), 1336-1339.

Heckman, J. J., \& Walker, J. R. (1990). The Relationship Between Wages and Income and the Timing and Spacing of Births: Evidence from Swedish Longitudinal Data. Econometrica, 58(6), 1411-1441.

Heckscher, E. (1954). An Economic History of Sweden. Harvard economic studies. Harvard University Press. 


\section{BIBLIOGRAPHY}

Hendershot, G. (1969). Familial satisfaction, birth order, and fertility values. Journal of Marriage and the Family, 31(1), 27-33.

Hilevych, Y. (2016). Strong families and declineing fertility; a comparative study of family relations and reproductive careers in Soviet Ukraine. Ph.D. thesis, Wageningen University.

Hilevych, Y., \& Rotering, P. (2013). Moederschap en sociale netwerken in Oekraïne, 1955-1965. In K. Matthijs, P. Puschmann, \& H. Bras (Eds.) Gender in/en demografie, Jaarboek Demografie 2013, (pp. 209 - 231). Leuven/Den Haag: Acco.

Hill, K., \& Hurtado, A. M. (2009). Cooperative breeding in South American hunter-gatherers. Proceedings of the Royal Society B: Biological Sciences, 276(1674), 3863-3870.

Hofsten, E., \& Lundström, H. (1976). Swedish Population History. Main trends from 1750-1970. Stockholm: National Central Bureau of Statistics.

Hotz, V. J., Klerman, J. A., \& Willis, R. J. (1997). The economics of fertility in developed countries. In M. R. Rosenzweig, \& O. Stark (Eds.) Handbook of Population and Family Economics, vol. Volume 1, Part A, (pp. 275-347). Elsevier.

Hrdy, S. (1999). Mother Nature, A History of Mothers, Infants, and Natural Selection. New York: Pantheon Books.

Hrdy, S. (2007). Evolutionary Context of Human Development: The Cooperative Breeding Model. In C. Salmon, \& T. Shackelford (Eds.) Family Relationships: An Evolutionary Perspective, (pp. 39-68). Oxford: Oxford University Press.

Hrdy, S. (2009). Mothers and others: The evolutionary origins of mutual understanding. Cambridge: Harvard University Press.

HSN (Release 2007). Historical Sample of the Netherlands. URL https://iisg.amsterdam/en/data/datasets

Janssens, A. (1993). Family and social change: The household as a process in an industrializing community. Cambridge: Cambridge University Press.

Janssens, A. (2007). "Were women present at the demographic transition?" A question revisited. The History of the Family, 12(1), 43-49.

Jayakody, R., Thornton, A., \& Axinn, W. G. (Eds.) (2008). International family change: ideational perspectives. New York: Lawrence Erlbaum Associates. 


\section{BIBLIOGRAPHY}

Jennings, J. A., \& Leslie, P. W. (2013). Differences in intergenerational fertility associations by sex and race in Saba, Dutch Caribbean, 1876-2004. The History of the Family, 18(2), 135-153.

Jennings, J. A., Sullivan, A. R., \& Hacker, J. D. (2012). Intergenerational Transmission of Reproductive Behavior during the Demographic Transition. The Journal of Interdisciplinary History, 42(4), 543-569.

Jeub, U. N. (1993). Parish Records. 19th Century Ecclesiastical Registers. Information from the Demographic Data Base. Umeå: Umeå Universitet.

Johnson, N., \& Stokes, C. (1976). Family size in successive generations: the effects of birth order, international change in lifestyle, and familial satisfaction. Demography, 13(2), 175-187.

Johow, J., \& Voland, E. (2012). Conditional Grandmother Effects on Age at Marriage, Age at First Birth, and Completed Fertility of Daughters and Daughtersin-law in Historical Krummhörn. Human Nature, 23(3), 341-359.

Junkka, J., \& Edvinsson, S. (2015). Gender and fertility within the free churches in the Sundsvall region, Sweden, 1860-1921. The History of the Family, (pp. $1-24)$.

Kana'iaupuni, S. M., Donato, K. M., Thompson-Colón, T., \& Stainback, M. (2005). Counting on Kin: Social Networks, Social Support, and Child Health Status. Social Forces, 83(3), 1137-1164.

Kaplan, H. (1996). A theory of fertility and parental investment in traditional and modern human societies. American Journal of Physical Anthropology, 101 (S23), 91-135.

Kaplan, H., \& Lancaster, J. (2003). An Evolutionary and Ecological Analysis of Human Fertility, Mating Patterns and Parental Investment. In K. Wachter, \& R. Bulatao (Eds.) Offspring: Human Fertility Behavior in Biodemographic Perspective, (pp. 170-223). National Academies Press, Washington DC.

Kaptijn, R., Thomese, F., Van Tilburg, T., \& Liefbroer, A. (2010). How Grandparents Matter. Human Nature, 21 (4), 393-405.

Keim, S., Klärner, A., \& Bernardi, L. (2009). Qualifying Social Influence on Fertility Intentions: Composition, Structure and Meaning of Fertility-relevant Social Networks in Western Germany. Current Sociology, 57(6), 888-907. 


\section{BIBLIOGRAPHY}

Kemkes-Grottenthaler, A. (2005). Of grandmothers, grandfathers and wicked step-grandparents. Differential impact of paternal grandparents on grandoffspring survival. Historical Social Research/Historische Sozialforschung, (pp. 219-239).

Kertzer, D., Kertzer, P., Hogan, D., Freckmann, R., \& Clark, L. (1989). Family, Political Economy, and Demographic Change: The Transformation of Life in Casalecchio, Italy, 1861-1921. Life course studies. University of Wisconsin Press.

Kertzer, D. I., \& Hogan, D. P. (1988). Family structure, individual lives and societal change. In M. W. Riley (Ed.) Social Structures and Human Lives, Social change and the life course. California: SAGE Publications.

Kick, E., Davis, B., Lehtinen, M., \& Wang, L. (2000). Family and Economic Growth: A World-System Approach and a Cross-National Analysis. International Journal of Comparative Sociology, 41(2), 225-244.

Kim, K. (2014). Intergenerational Transmission of Age at First Birth in the United States: Evidence from Multiple Surveys. Population Research and Policy Review, 33(5), 649-671.

Klep, P. M. M. (2004). The relationship between parents and adult children in the economic culture of rural Netherlands, 1880-1910. The History of the Family, $9(4), 385-399$.

Klep, P. M. M. (2010). Kleine boeren en grote gezinnen in crisistijd (1920-1970) een nieuwe these. In J. Kok, \& J. Van Bavel (Eds.) De levenskracht der bevolking. Sociale en demografische kwesties in de lage landen tijdens het interbellum, (pp. 141-196). Leuven: Leuven University Press.

Kling, S. (2010). Reproductive health, birth control, and fertility change in Sweden, circa 1900-1940. The History of the Family, 15(2), 161-173.

Kälvemark, A. (1980). Illegitimacy and marriage in three Swedish parishes in the nineteenth century. In R. M. S. P. Laslett, K. Oosterveen (Ed.) Bastardy and its comparative history, (pp. 327-335). London: Edward Arnold.

Knodel, J. (1977). Family Limitation and the Fertility Transition: Evidence from the Age Patterns of Fertility in Europe and Asia. Population Studies, 31(2), 219-249.

Knodel, J. (1982). Child Mortality and Reproductive Behaviour in German Village Populations in the Past: A Micro-Level Analysis of the Replacement Effect. Population Studies, 36(2), 177-200. 


\section{BIBLIOGRAPHY}

Knodel, J. (1988). Demographic behavior in the past: A study of fourteen German village populations in the eighteenth and nineteenth centuries. Cambridge: Cambridge University Press.

Knodel, J., \& Van de Walle, E. (1986). Lessons from the past: Policy Implications of Historical Fertility Studies. In A. Coale, \& S. C. Watkins (Eds.) The Decline of Fertility in Europe, The Revised Proceeding of a Conference on the Princeton European Fertility Project, (pp. 390-419). Princeton, New Jersey: Princeton University Press.

Knotter, A., \& Meijer, A. (1995). De gemeentelijke bevolkingsregisters, 1850-1920. Den Haag: Instituut voor Nederlandse Geschiedenis.

Kodzi, I., Johnson, D., \& Casterline, J. (2010). Examining the predictive value of fertilty preferences among Ghanaian Wwomen. Demographic Research, 22(30), 965-984.

Kohler, H. (2001). Fertility and Social Interaction. New York: Oxford University Press.

Kohler, H.-P., Rodgers, J. L., \& Christensen, K. (1999). Is Fertility Behavior in Our Genes? Findings from a Danish Twin Study. Population and Development Review, 25(2), 253-288.

Kok, J. (2009). Family Systems as Frameworks for Understanding Variation in Extra-Marital Births, Europe 1900-2000. Romenian Journal of Population Studies, (pp. 13-38).

Kok, J. (2010). The family factor in migration decisions. In J. Lucassen, L. Leo, \& P. Manning (Eds.) Migration history in world history. Multidisciplinary approaches. Leiden: Brill.

Kok, J. (2017). Women's agency in historical family systems. In J. L. Van Zanden, A. Rijpma, \& J. Kok (Eds.) Agency, gender and economic development in the world economy 1850-2000. Testing the Sen hypothesis, (pp. 10-50). London and New York: Routledge.

Kok, J., Bras, H., \& Rotering, P. (2016). Courtship and Bridal Pregnancy in The Netherlands, 1870-1950. Annales de démographie historique, 2(132), 165-191.

Kok, J., \& Mandemakers, K. (2009). Je zoudt maar last van mij hebben. Verwanten in het Nederlands huishouden, 1860-1940. Tijdschrift voor Sociale en Economische Geschiedenis, 6(4), 139-165. 


\section{BIBLIOGRAPHY}

Kok, J., \& Mandemakers, K. (2010). A life-course approach to co-residence in the Netherlands, 1850-1940. Continuity and Change, 25(02), 285-312.

Kok, J., \& Van Bavel, J. (2006). Stemming the tide. Denomination and religiousness in the Dutch fertility transition, 1845-1945. In R. Derosas, \& F. Van Poppel (Eds.) Religion and the Decline of Fertility in the Western World, (pp. 83-105). Dordrecht: Springer Netherlands.

Kok, J., Vandezande, M., \& Mandemakers, K. (2011). Household structure, resource allocation and child well-being. A comparison across family systems. Tijdschrift voor Sociale en Economische Geschiedenis, 4.

Kolk, M. (2011). Deliberate Birth Spacing in Nineteenth Century Northern Sweden. European Journal of Population / Revue européenne de Démographie, 27(3), 337-359.

Kolk, M. (2014a). Multigenerational transmission of family size in contemporary Sweden. Population Studies, 68(1), 111-129.

Kolk, M. (2014b). Understanding transmission of fertility across multiple generations - Socialization or socioeconomics? Research in Social Stratification and Mobility, 35, 89-103.

Kolk, M. (2015). The causal effect of an additional sibling on completed fertility: An estimation of intergenerational fertility correlations by looking at siblings of twins. Demographic Research, 32(51), 1409-1420.

Kotte, M., \& Ludwig, V. (2012). Intergenerational transmission of fertility intentions and behaviour in Germany: the role of contagion. Vienna Yearbook of Population Research, 9, 207-226.

Kramer, K. L. (2005). Children's Help and the Pace of Reproduction: Cooperative Breeding in Humans. Evolutionary Anthropology: Issues, News, and Reviews, $14(6), 224-237$.

Kramer, K. L. (2010). Cooperative Breeding and its Significance to the Demographic Success of Humans. Annual Review of Anthropology, 39(1), 417-436.

Kurosu, S., \& Lundh, C. (2014). Nuptiality: Local Populations, Sources, Models. In C. Lundh, \& S. Kurosu (Eds.) Similarity in Difference. Marriage in Europe and Asia 1700-1900, (pp. 47-88). Cambridge: MIT Press.

Landry, A. (1934). La révolution démographicque selon. Paris: Sirey. 


\section{BIBLIOGRAPHY}

Langford, C. M., \& Wilson, C. (1985). Is there a Connection between a Woman's fecundity and that of her mother? Journal of Biosocial Science, 17(04), 437443.

Laslett, P., \& Wall, R. (1972). Household and Family in Past Times. Cambridge University Press.

Leasure, J. W. (1963). Factors involved in the Decline of Fertility in Spain 19001950. Population Studies, 16(3), 271-285.

Leibenstein, H. (1957). Economic backwardness and economic growth. John Wiley. New York.

Lerch, M. (2019). Fertility Decline in Urban and Rural Areas of Developing Countries. Population and Development Review, 45(2), 301-320.

Lesthaege, R. (1983). A Century of Demographic and Cultural Change in Western Europe: An Exploration of Underlying Dimensions. Population and Development Review, 9(3), 411-435.

Lesthaege, R., \& Wilson, C. (1986). Modes of Production, Secularization, and the Pace of the Fertility Decline in Western Europe, 1870-1930. In A. Coale, \& S. C. Watkins (Eds.) The Decline of Fertility in Europe: The Revised Proceedings of a Conference on the Princeton European Fertility Project, (pp. 261-292). Princeton: Princeton University Press.

Lesthaeghe, R. (1977). The Decline of Belgian Fertility, 1800-1970. Cambridge: Princeton University Press.

Lesthaeghe, R. (1998). On Theory Development: Applications to the Study of Family Formation. Population and Development Review, 24(1), 1-14.

Liefbroer, A., \& Jong Gierveld, J. (1995). Standardization and Individualization: The transition from youth to adulthood among cohorts born between 1903 and 1965. In H. Brekel, \& F. Deven (Eds.) Population and Family in the Low Countries 1994, vol. 2 of European Studies of Population, (pp. 57-79). Springer Netherlands.

Lin, D. Y., \& Wei, L. J. (1989). The Robust Inference for the Cox Proportional Hazards Model. Journal of the American Statistical Association, 84(408), 1074-1078.

Low, B. (2015). Why Sex Matters: A Darwinian Look at Human Behavior Revised Edition. Princeton University Press. 


\section{BIBLIOGRAPHY}

Low, B. S. (1991). Reproductive life in nineteenth century Sweden: An evolutionary perspective on demographic phenomena. Ethology and Sociobiology, 12(6), 411-448.

Low, B. S., \& Clarke, A. L. (1991). Family Patterns in Nineteenth-Century Sweden: Impact Of Occupational Status and Landownership. Journal of Family History, 16(2), 117-138.

Lundh, C. (2003). Swedish marriages. Customs, Legislation and Demography in the Eighteenth and Nineteenth Centuries. Lund Papers in Economic History, (88), 63 .

Lyngstad, T., \& Prskawetz, A. (2010). Do siblings' fertility decisions influence each other? Demography, 47(4), 923-934.

Mace, R. (2014). When not to have another baby: An evolutionary approach to low fertility. Demographic Research, 30(37), 1074-1096.

Mace, R., \& Colleran, H. (2008). Kin influence on the decision to start using modern contraception: a longitudinal study from rural Gambia. American Journal of Human Biology, 21, 472-277.

Mace, R., \& Sear, R. (2005). Are humans cooperative breeders? In E. Voland, A. Chasiotis, \& W. Schiefenhoevel (Eds.) Grandmotherhood: The evolutionary significance of the second half of female life, (pp. 143-159). New Brunswick: Rutgers University Press.

Madhavan, S., Adams, A., \& Simon, D. (2003). Women's Networks and the Social World of Fertility Behavior. International Family Planning Perspectives, 29(2), $58-68$.

Madsen, J. B., Solmaz, M., \& Cong, W. (2018). What Has Driven the Great Fertility Decline in Developing Countries since 1960? The Journal of Development Studies, 54(4), 738-757.

Mamadouh, V. (1999). A political-cultural map of Europe. Family structures and the origins of differences between national political cultures in the European Union. GeoJournal, 47, 477-486.

Mandemakers, K. (2002). Building Life Course Datasets From Population Registers by the Historical Sample of the Netherlands (HSN). History and Computing, 14(1-2), 87-107.

Mandemakers, K. (2004). De Historische Steekproef Nederlandse bevolking (HSN) en het project Life Courses in Context. Bevolking en gezin, 33, 91-114. 


\section{BIBLIOGRAPHY}

Mason, K. (1992). Culture and the fertility transition: Thoughts on theories of fertility decline. Genus, 48(3), 1-14.

Mason, K. (1993). The impact of women's position on demographic change during the course of development. In N. Federici, K. O. Mason, \& S. Sogner (Eds.) Women's position and demographic change, (pp. 19-42). Oxford: Clarendon Press.

Mason, K. (2001). Gender and Family Systems in the Fertility Transition. Population and Development Review, 27, 160-176.

Mathews, P., \& Sear, R. (2013a). Does the kin orientation of a British woman's social network influence her entry into motherhood? Demographic Research, 28, 313-340.

Mathews, P., \& Sear, R. (2013b). Family and Fertility: Kin Influence on the Progression to a Second Birth in the British Household Panel Study. PLoS ONE, 8(3).

Matthijs, K. (2002). Mimetic Appetite for Marriage in Nineteenth-Century Flanders: Gender Disadvantage As an Incentive for Social Change. Journal of Family History, 27(2), 101-127.

McDonald, P. (2000). Gender Equity in Theories of Fertility Transition. Population and Development Review, 26 (3), 427-439.

Miller, J. E., Trussell, J., Pebley, A. R., \& Vaughan, B. (1992). Birth Spacing and Child Mortality in Bangladesh and the Philippines. Demography, 29(2), 305-318.

Mineau, G. P., \& Trussell, J. (1982). A specification of marital fertility by parents' age, age atmarriage and marital duration. Demography, 19(3), 335-349.

Mönkediek, B. (2016). Family Systems and Fertility; Fertility Behaviour in Europe from a Network Perspective. Ph.D. thesis, Wageningen University.

Mönkediek, B., \& Bras, H. (2016). The Interplay of Family Systems, Social Networks and Fertility in Europe Cohorts Born Between 1920 and 1960. Economic History of Developing Regions, 31, 136-166.

Mönkediek, B., Rotering, P., \& Bras, H. (2017). Regional Differences in the Intergenerational Transmission of Family Size in Europe. Population, Space and Place, 23(2), e2003.

Moch, L. P. (1986). Book Review. Todd, Emmanuel. 'The Explanation of Ideology' (1985). The American Historical Review, 91 (5), 1162-1163. 


\section{BIBLIOGRAPHY}

Montgomery, M. R., \& Casterline, J. B. (1993). The Diffusion of Fertility Control in Taiwan: Evidence from Pooled Cross-Section Time-Series Models. Population Studies, 47(3), 457-479.

Montgomery, M. R., \& Casterline, J. B. (1996). Social Learning, Social Influence, and New Models of Fertility. Population and Development Review, 22, 151-175.

Moran, P. (1950a). Notes on continuous stochastic phenomena. Biometrika, 37, 17-23.

Moran, P. (1950b). A test for serial independence of residuals. Biometrika, 37, 178-181.

Morgan, S. P., \& King, R. (2001). Why Have Children in the 21st Century? Biological Predisposition, Social Coercion, Rational Choice. European Journal of Population / Revue européenne de Démographie, 17(1), 3-20.

Morgan, S. P., \& Rindfuss, R. R. (1984). Household Structure and the Tempo of Family Formation in Comparative Perspective. Population Studies, 38(1), $129-139$.

Murphy, M. (1999). Is the relationship between fertility of parents and children really weak? Biodemography and Social Biology, 46(1-2), 122-145.

Murphy, M. (2012). Intergenerational fertility correlations in contemporary developing counties. American Journal of Human Biology, 24(5), 696-704.

Murphy, M. (2013a). Cross-National Patterns of Intergenerational Continuities in Childbearing in Developed Countries. Biodemography and Social Biology, $59(2), 101-126$.

Murphy, M. (2013b). The intergenerational transmission of reproductive behaviour: comparative perspectives. The History of the Family, 18(2), 107-115.

Murphy, M., \& Knudsen, L. B. (2002). The Intergenerational Transmission of Fertility in Contemporary Denmark: The Effects of Number of Siblings (Full and Half), Birth Order, and Whether Male or Female. Population Studies, $56(3), 235-248$.

Murphy, M., \& Wang, D. (2001). Family-Level Continuities in Childbearing in Low-Fertility Societies. European Journal of Population, 17(1), 75-96.

Murphy, M., \& Wang, D. (2003). The Impact of Intergenerationally-Transmitted Fertility and Nuptiality on Population Dynamics in Contemporary Populations. In J. Rodgers, H.-P. Kohler, M. Murphy, \& D. Wang (Eds.) The Biodemography 


\section{BIBLIOGRAPHY}

of Human Reproduction and Fertility, book section 11, (pp. 209-228). Springer US.

Myrskalä, M., Kohler, H., \& Billari, F. (2009). Advances in development reverse fertility decline. Nature, 460(6), 741-743.

Nath, D. C., Leonetti, D. L., \& Steele, M. S. (2000). Analysis of birth intervals in a non-contracepting Indian population: An evolutionary ecological approach. Journal of Biosocial Science, 32(03), 343-354.

Nettle, D., Gibson, M. A., Lawson, D. W., \& Sear, R. (2013). Human behavioral ecology: current research and future prospects. Behavioral Ecology, 24(5), 1031-1040.

Newson, L., Postmes, T., Lea, S., \& Webley, P. (2005). Why are modern families small? Toward and evolutionary and cultural explantion for the demographic transition. Personality and social psychology review, 9(4), 360-375.

Newson, L., Postmes, T., Lea, S. E. G., Webley, P., Richerson, P. J., \& McElreath, R. (2007). Influences on communication about reproduction: the cultural evolution of low fertility. Evolution and Human Behavior, 28(3), 199-210.

North, D. C. (1990). Institutions, institutional change and economic performance. Cambridge: Cambridge university press.

Notestein, F. (1945). Population: the long view. In T. Schultz (Ed.) Food for the World, (pp. 36-57). Chicago: Chicago University Press.

Notestein, F. (1953). Economic problems of population change. In Proceedings of the eight international conference on agricultural economics, (pp. 13-31). London: Oxford University Press.

Opp, K.-D. (2001). How do norms emerge? An outline of a theory. Mind $\mathscr{G}$ Society, 2(1), 101-128.

O'Rourke, K. H., \& Williamson, J. G. (1995). Open economy forces and late nineteenth century Swedish catch-up. A quantitative accounting. Scandinavian Economic History Review, 43(2), 171-203.

Osiewalska, B. (2018). Partners' empowerment and fertility in ten European countries. Demographic Research, 38(49), 1495-1534.

Palloni, A., \& Millman, S. (1986). Effects of Inter-Birth Intervals and Breastfeeding on Infant and Early Childhood Mortality. Population Studies, 40(2), $215-236$. 


\section{BIBLIOGRAPHY}

Pashos, A., \& McBurney, D. (2008). Kin Relationships and the Caregiving Biases of Grandparents, Aunts, and Uncles. Human Nature, 19(3), 311-330.

Pearson, K., Lee, A., \& Bramley-Moore, L. (1899). Mathematical Contributions to the Theory of Evolution. VI. Genetic (Reproductive) Selection: Inheritance of Fertility in Man, and of Fecundity in Thoroughbred Racehorses, vol. 192. Unknown publisher.

Pebley, A. R., \& Stupp, P. W. (1987). Reproductive Patterns and Child Mortality in Guatemala. Demography, $24(1), 43-60$.

Pluzhnikov, A., Nolan, D. K., Tan, Z., McPeek, M. S., \& Ober, C. (2007). Correlation of Intergenerational Family Sizes Suggests a Genetic Component of Reproductive Fitness. The American Journal of Human Genetics, 81(1), 165169.

Pollak, R. A., \& Watkins, S. C. (1993). Cultural and Economic Approaches to Fertility: Proper Marriage or Mesalliance? Population and Development Review, 19(3), 467-496.

Pollet, T., Nettle, D., \& Nelissen, M. (2007). Maternal grandmother do go the extra mile: Factoring distance and lineage into differential contact with grandchildren. Evolutionary Psychology, 5(4), 832-843.

Preston, S. H. (1986). Changing values and falling birth rates. In K. Davis, M. Bernstam, \& R. Ricardo-Campbell (Eds.) Below-Replacement Fertility in Industrial Societies: Causes, Consequences, Policies, vol. Supplement to Population and Development Review, vol 12, (pp. 176-195). New York: The Population Council.

Pyke, K., \& Adams, M. (2010). What's Age Got to Do With It? A Case Study Analysis of Power and Gender in Husband-Older Marriages. Journal of Family Issues, 31(6), 748-777.

Raab, M., Fasang, A., Karhula, A., \& Erola, J. (2014). Sibling Similarity in Family Formation. Demography, 51(6), 2127-2154.

Reher, D. (1998). Family Ties in Western Europe: Persistent Contrasts. Population and Development Review, 24 (2), 203-234.

Reher, D. (2007). Towards long-term population decline: a discussion of relevant issues. European Journal of Population, 23(2), 189-207. 


\section{BIBLIOGRAPHY}

Reher, D., Ortega, J. A., \& Sanz-Gimeno, A. (2008). Intergenerational Transmission of Reproductive Traits in Spain during the Demographic Transition. Human Nature, 19(1), 23-43.

Rijken, A. J., \& Liefbroer, A. C. (2009). Influences of the family of origin on the timing and quantum of fertility in the Netherlands. Population Studies, 63(1), 71-85.

Rijpma, A., \& Carmichael, S. G. (2016). Testing Todd and Matching Murdock: Global Data on Historical Family Characteristics. Economic History of Developing Regions, 31(1), 10-46.

Robinson, W. C. (1997). The Economic Theory of Fertility Over Three Decades. Population Studies, 51(1), 63-74.

Rodgers, J., Kohler, H.-P., Kyvik, K., \& Christensen, K. (2001). Behavior genetic modeling of human fertility: findings from a contemporary danish twin study. Demography, 38(1), 29-42.

Rogers, E. (1962). The Diffusion of Innovations. New York: Free Press.

Rosero-Bixby, L., \& Casterline, J. B. (1993). Modelling diffusion effects in fertility transition. Poplation Studies, 47(1), 147-167.

Rotering, P. (2015). Book review: Philipov, Dimiter; Liefbroer, Aart C.; Klobas, Jane (Eds.): 'Reproductive Decision-Making in a Macro-Micro Perspective'. European Journal of Population, 31(5), 587-589.

Rotering, P. (2016). Intergenerationele overdracht van leeftijd bij eerste geboorte in Zweden. Sundsvall en Skellefteå, ca 1850-1889. In P. Puschmann, K. Matthijs, \& R. Paping (Eds.) Familie en levenskansen in het verleden, (pp. 111-130). Leuven: Acco.

Rotering, P. (2017). Intergenerational Transmission of Reproductive Behavior in Sweden, 1850-1889. Historical Life Course Studies, 4, 181-202.

Rotering, P. (2019). Family Systems and Fertility, Western Europe 1870-1960. Historical Social Research, $44(3)$.

Rotering, P., \& Bras, H. (2015). With the help of kin? Household composition and reproduction in the Netherlands, 1842 - 1920. Human Nature, 26(1).

Rotering, P., \& Bras, H. (2019). The age difference between spouses and reproduction in 19th century Sweden. Demographic Research, 41(37), 1059-1090. 


\section{BIBLIOGRAPHY}

Rotkirch, A. (2007). All that she wants is a(nother) baby? Longing for children as a fertility incentive of growing importance. Journal of Evolutionary Psychology, 5(1), 89-104.

Ruggles, S. (1994). The Transformation of American Family Structure. The American Historical Review, $99(1), 103-128$.

Ruggles, S. (2009). Reconsidering the Northwest European Family System: Living Arrangements of the Aged in Comparative Historical Perspective. Population and Development Review, 35(2), 249-273.

Ruggles, S. (2010). Stem Families and Joint Families in Comparative Historical Perspective. Population and Development Review, 36(3), 563-577.

Ryan, R., \& Gross, N. (1943). The diffusion of hybrid seed corn in two Iowa communities. Rural Sociology, 8(1), 15-24.

Salmon, C., \& Hehman, J. (2015). Evolutionary Perspectives on the Nature of Sibling Conflict: the Impact of Sex, Relatedness, and Co-residence. Evolutionary Psychological Science, 1(2), 123-129.

Salmon, C., \& Shackelford, T. (2008). Family Relationships, An Evolutionary Perspective. Oxford: Oxford University Press.

Santow, G. (1987). Reassessing the Contraceptive Effect of Breastfeeding. Population Studies, 41(1), 147-160.

Santow, G. (1995). Coitus interruptus and the Control of Natural Fertility. Population Studies, 49(1), 19-43.

Schaffnit, S. B., \& Sear, R. (2014). Wealth modifies relationships between kin and women's fertility in high-income countries. Behavioral Ecology.

Schaffnit, S. B., \& Sear, R. (2017). Support for new mothers and fertility in the United Kingdom: Not all support is equal in the decision to have a second child. Population Studies, 71(3), 345-361.

Schön, L. (1997). Internal and external factors in Swedish industrialization. Scandinavian Economic History Review, 45(3), 209-223.

Sear, R. (2015). Evolutionary contributions to the study of human fertility. Population studies, 69 Sup, S39-55.

Sear, R., \& Coall, D. (2011). How Much Does Family Matter? Cooperative Breeding and the Demographic Transition. Population and Development Review, 37, $81-112$. 


\section{BIBLIOGRAPHY}

Sear, R., Lawson, D. W., Kaplan, H., \& Shenk, M. K. (2016). Understanding variation in human fertility: what can we learn from evolutionary demography? Philosophical transactions of the Royal Society of London. Series B, Biological sciences, 371(27022071), 20150144-20150144.

Sear, R., \& Mace, R. (2008). Who keeps children alive? A review of the effects of kin on child survival. Evolution and Human Behavior, 29(1), 1-18.

Sear, R., Mace, R., \& McGregor, I. A. (2003). The effects of kin on female fertility in rural Gambia. Evolution and Human Behavior, 24 (1), 25-42.

Skinner, G. (1997). Family Systems and Demographic Processes. In D. Kertzer, \& T. Fricke (Eds.) Anthropological Demography, (pp. 53-95). Chicago and London: The University of Chicago Press.

Skinner, G. W. (1993). Conjugal power in Tokugawa Japanese families: a matter of life or death. In B. D. Miller (Ed.) Sex and Gender Hierarchies, (pp. 236266). Cambridge: Cambridge University Press.

Smith, T. E. (1988). Parental Control Techniques: Relative Frequencies and Relationships with Situational Factors. Journal of Family Issues, 9(2), 155176.

Snopkowski, K., \& Sear, R. (2013). Kin influences on fertility in Thailand: Effects and mechanisms. Evolution and Human Behavior, 34 (2), 130-138.

Stanfors, M., \& Scott, K. (2013). Intergenerational transmission of young motherhood. Evidence from Sweden, 1986-2009. The History of the Family, 18(2), 187-208.

Steenhof, L., \& Liefbroer, A. C. (2008). Intergenerational transmission of age at first birth in the Netherlands for birth cohorts born between 1935 and 1984: Evidence from municipal registers. Population Studies, 62(1), 69-84.

Strassmann, B., \& Garrard, W. (2011). Alternatives to the Grandmother Hypothesis. Human Nature, 22(1-2), 201-222.

Szreter, S. (1996). Fertility, Class and Gender in Britain, 1860-1940. Cambridge: Cambridge University Press.

Szreter, S., \& Garrett, E. (2000). Reproduction, Compositional Demography, and Economic Growth: Family Planning in England Long Before the Fertility Decline. Population and Development Review, 26 (1), 45-80.

Tabutin, D., \& Schoumaker, B. (2004). The Demography of Sub-Saharan Africa from the 1950 s to the 2000s. Population, 59(3), 455-555. 


\section{BIBLIOGRAPHY}

Tanskanen, A. O., \& Rotkirch, A. (2014). The impact of grandparental investment on mothers' fertility intentions in four European countries. Demographic Research, 31, 1-26.

Therborn, G. (2004). Between Sex and Power. Family in the World, 1900-2000. London: Routledge.

Therborn, G. (2006). African Families in a Global Context. In G. Therborn (Ed.) African families in a global context, (pp. 17-48). Uppsala: Nordic Africa Institute.

Thompson, W. (1929). Population. American Journal of Sociology, 34, 959-975.

Thomson, E., \& Hoem, J. M. (1998). Couple childbearing plans and births in Sweden. Demography, 35(3), 315-322.

Thornton, A. (1980). The influence of first generation fertility and economic status on second generation fertility. Population and Environment, 3(1), 51-72.

Todd, E. (1985). The Explanation of an Ideology. Oxford: Blackwell.

Todd, E. (1990). L'Invention de L'Europe. Paris: Éditions du Seuil.

Todd, E. (2011). L'origine des systémes familiaux. Paris: Gallimard.

Tolnay, S. (1995). The spatial diffusion of fertility: A cross-sectional analysis of countries in the American South, 1940. American Sociological Review, 60(2), 299-308.

Tropf, F. C., Barban, N., Mills, M. C., Snieder, H., \& Mandemakers, J. J. (2015). Genetic influence on age at first birth of female twins born in the UK, 1919-68. Population Studies, 69(2), 129-145.

Tsay, W.-J., \& Chu, C. Y. C. (2005). The pattern of birth spacing during Taiwan's demographic transition. Journal of Population Economics, 18(2), 323-336.

Turke, P. W. (1989). Evolution and the Demand for Children. Population and Development Review, 15(1), 61-90.

Tymicki, K. (2004). Kin Influence on Female Reproductive Behaviour: The evidence from Reconstitution of the Bejsce Parish Registers, 18th to 20th centuries, Poland. American Journal of Human Biology, 16, 508-522.

Udry, J. R. (1996). Biosocial Models of Low-Fertility Societies. Population and Development Review, 22, 325-336.

UN Population Division (2017a). The end of high fertility is near. 


\section{BIBLIOGRAPHY}

UN Population Division (2017b). World Fertility Report 2015.

Upadhyay, U. D., Gipson, J. D., Withers, M., Lewis, S., Ciaraldi, E. J., Fraser, A., Huchko, M. J., \& Prata, N. (2014). Women's empowerment and fertility: A review of the literature. Social Science \& Medicine, 115, 111-120.

Upadhyay, U. D., \& Hindin, M. J. (2005). Do higher status and more autonomous women have longer birth intervals?: Results from Cebu, Philippines. Social Science \& Medicine, 60(11), 2641-2655.

Van Bavel, J. (2004). Diffusion Effects in the European Fertility Transition: Historical Evidence from Within a Belgian Town (1846-1910). European Journal of Population/Revue européenne de Démographie, 20(1), 63-85.

Van Bavel, J., \& Kok, J. (2004). Birth Spacing in the Netherlands. The Effects of Family Composition, Occupation and Religion on Birth Intervals, 1820-1885. European Journal of Population/Revue européenne de Démographie, 20(2), 119-140.

Van Bavel, J., \& Kok, J. (2005). The role of religion in the Dutch fertility transition: starting, spacing and stopping in the heart of the Netherlands, 1845-1945. Continuity and Change, 20(2), 247-263.

Van Bavel, J., \& Kok, J. (2009). Social Control and the Intergenerational Transmission of Age at Marriage in Rural Holland 1850-1940. Population and Development Review, 64(2), 343-360.

Van Bavel, J., \& Kok, J. (2010). A mixed effects model of birth spacing for pretransition populations: Evidence of deliberate fertility control from nineteenth century Netherlands. The History of the Family, 15(2), 125-138.

Van de Putte, B., Van Poppel, F., Vanassche, S., Sanchez, M., Jidkova, S., Eeckhaut, M., Oris, M., \& Matthijs, K. (2009). The Rise of Age Homogamy in 19th Century Western Europe. Journal of Marriage and Family, 71(5), 1234-1253.

Van der Woude, A. (1977). De omvang en samenstelling van de huishouding in Nederland in het verleden. In P. Geurts, \& F. Messing (Eds.) Economische ontwikkeling en sociale emancipatie, (pp. 200-239). Den Haag: Martinus Nijhoff. M. Nijhoff, Den Haag.

Van Leeuwen, M. H., \& Maas, I. (2011). HISCLASS: A historical international social class scheme. Universitaire Pers Leuven.

Van Leeuwen, M. H., Maas, I., \& Miles, A. (2004). Creating a Historical International Standard Classification of Occupations An Exercise in Multinational 


\section{BIBLIOGRAPHY}

Interdisciplinary Cooperation. Historical Methods: A Journal of Quantitative and Interdisciplinary History, 37(4), 186-197.

Van Poppel, F. (1974). De differentiële vruchtbaarheid in Nederland in historisch perspectief: de invloed van religie. Bevolking en Gezin, (pp. 329-348).

Van Poppel, F. (1985). Late Fertility Decline in the Netherlands. The Influence of Religious Denomination, Socio-Economic Group and Region. European Journal of Population, I, 347-373.

Van Poppel, F., Monden, C., \& Mandemakers, K. (2008). Marriage Timing over the Generations. Human Nature, 19(1), 7-22.

Van Poppel, F., Reher, D., Sanz-Gimeno, A., Sanchez-Dominguez, M., \& Beekink, E. (2012). Mortality decline and reproductive change during the Dutch demographic transition: Revisiting a traditional debate with new data. Demographic Research, 27(11), 299-338.

Van Zanden, J. (2009). The Long Road to the Industrial Revolution: The European Economy in a Global Perspective, 1000-1800. Global Economic History Series. Brill.

Viazzo, P. P., \& Zanotelli, F. (2010). Welfare as moral obligation: changing patterns of family support in Italy and the Mediterranean. In H. Grandits (Ed.) Family, kinship and state in contemporary Europe, (pp. 47-92). Frankfurt: Campus.

Vogl, T. (2016). Intergenerational Dynamics and the Fertility Transition. Working paper, Princeton University, BREAD and NBER.

Voland, E., \& Beise, J. (2002). Opposite effects of maternal and paternal grandmothers on infant survival in historical Krummhörn. Behavioral Ecology and Sociobiology, 52(6), 435-443.

Voland, E., \& Engel, C. (1990). Female Choice in Humans: A Conditional Mate Selection Strategy of the Krummhörn Women (Germany, 1720-1874). Ethology, $84(2), 144-154$.

Vulsma, R. (1988). Burgerlijke stand en bevolkingsregister. Den Haag: Centraal Bureau voor Genealogie.

Watkins, S. C. (1986). Conclusions. In A. Coale, \& S. C. Watkins (Eds.) The Decline of Fertility in Europe: The Revised Proceedings of a Conference on the Princeton European Fertility Project, (pp. 420-450). Princeton: Princeton University Press. 


\section{BIBLIOGRAPHY}

Watkins, S. C. (1990). From local to national communities: The transformation of demographic regimes in Western Europe. Population and Development Review, $16(2), 241-272$.

Watkins, S. C. (1993). If all we knew about women was what we read in Demography, what would we know? Demography, 30(4), 551-577.

Weeks, J. (2011). Population: An introduction to concepts and issues. Nelson Education.

Weeks, J., Gadalla, M. S., Rashed, T., Stanforth, J., \& Hill, A. G. (2000). Spatial variability in fertility in Menoufia, Egypt, assessed through the application of remote-sensing and GIS technologies. Environment and Planning A, 32, 695714 .

Westberg, A., Engberg, E., \& S., E. (2015). A unique source for innovative longitudinal research: The poplink database. Historical Life Course Studies, 3, 20-31.

Wilson, C., Oeppen, J., \& Pardoe, M. C. (1988). What Is Natural Fertility? The Modelling of a Concept. Population Index, 54(1), 4-20.

Wintle, M. (2000). An Economic and Social History of the Netherlands, 18001920. Cambridge University Press.

Zimmer, B. G., \& Fulton, J. (1980). Size of Family, Life Chances, and Reproductive Behavior. Journal of Marriage and Family, 42(3), 657-670. 
Paul Pieter Philippus Rotering

Wageningen School of Social Sciences (WASS)

Completed Training and Supervision Plan

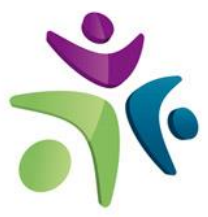

Wageningen School

of Social Sciences

\section{Name of learning activity \\ A. Project related competences}

Event history and sequence analysis in $\mathrm{R}$

Spatial Demography

Analysis of large-scale data on social connections

Agent based modelling

Longitudinal Analysis of Historical

Demographic Data

'Can family systems explain regional

disparities in European fertility levels around 1900 ?'

'Intergenerational Transmission of

Reproductive Behaviour in Sweden and The Netherlands, ca 1850-1920'

'Intergenerational transmission of entry into parenthood? Sweden, 1850-1880'

'Parental age difference and reproduction in Northern Sweden, 1820-1879'

Guest researcher: Centre for Population Studies

\section{B. General research related competences}

Basic Training Programme

Seminar I

Seminar II

Research Design Course

Individual Assessment

Advanced Training Programme

Masterclass: Pier Paolo Viazzo

Masterclass: Emmanuel Todd

NW Posthumus Conference (three years)

Review: article for History of the Family

Review: book for European Journal of

Population (published)
WOG Workshop

2011

0.3

Max Planck Institute for

Demographic Research

WOG Workshop

2012

2.4

2012

0.3

WOG Workshop

2012

0.3

ICPSR Summer Programme, Ann

Arbor

SSHA Conference, Vancouver

2013

5.7

2012

1

$10^{\text {th }}$ ESSH Conference, Vienna,

2014

2

presenter and organiser

Day of Historical Demography

2014

2

Conference, Wageningen University

$\&$ Research, presenter and organiser

Workshop Power of the Family,

Wageningen University \& Research, presenter and organiser

Umeå University, Umeå

2012
N.W. Posthumus Institute

N.W. Posthumus Institute

N.W. Posthumus Institute

N.W. Posthumus Institute

N.W. Posthumus Institute

N.W. Posthumus Institute

N.W. Posthumus Institute
2011

2012

2012

2013

2013

2014

2015

2013

2015
1

6

8

1.5

2

2

2

0.1

0.1 


\section{Career related competences / personal development}

\begin{tabular}{|c|c|c|}
\hline Academic Writing & Radboud University & 2012 \\
\hline Management voor Promovendi & Radboud University & 2013 \\
\hline Presentation Skills & Radboud University & 2013 \\
\hline Career orientation & Wageningen Graduate School & 2015 \\
\hline
\end{tabular}

Total

*One credit according to ECTS is on average equivalent to 28 hours of study load 


\section{About the author}

Paul Rotering (Hilversum, 1984) received a Bachelor's and Master's degree in Economics, and a Bachelor's degree in History from Radboud University, the Netherlands. His Master thesis was concerned with the role of institutions and economic performance. As a student, he was an active volunteer in the student community, as board member of the Economische Studenten Vereniging, board member of faculty organization 'Boekanin', member of several programme committees, as student assistant for Dr Albert de Vaal and Prof. Dr Esther-Mirjam Sent, and as buddy for students with autism.

In September 2011, Paul began his PhD within the VIDI project 'The Power of the Family' under supervision of Prof. Dr Hilde Bras and Prof. Dr Jan Kok at the Department of Economic, Social and Demographic History, at Radboud University Nijmegen, together with Bastian Mönkediek and Yuliya Hilevych. In January 2014, the VIDI project moved to the chair group Sociology and Consumption of Households, at Wageningen University. Both in Nijmegen and Wageningen, Paul has given lectures in demography and modern history. He has joined the graduate schools Wageningen School of Social Sciences and the N.W. Posthumus Institute.

Paul's research interests are late-modern demographic, social and economic history. During his $\mathrm{PhD}$ research he has spent time abroad as student and guest researcher, to study event history analysis, spatial regression techniques, and to acquaint himself with the databases used in this dissertation. He has presented and organised sessions at international conferences, such as the European Social Science History Conference, the Social Science History Association conference, the Dutch Day of Demography, the Posthumus Conference and the VIDI project's closing conference.

Currently, Paul works at the Dutch Tax and Customs Administration as business analyst at the corporate department for Data and Analytics. He lives in Harderwijk, the Netherlands, with his wife Anneleen and their three daughters Anneloes, Willemijn and Babette. 


\section{List of publications}

Hilevych, Y., \& Rotering, P. (2013). Moederschap en sociale netwerken in Oekraïne, 1955-1965. In K. Matthijs, P. Puschmann, \& H. Bras (Eds.) Gender in/en demografie, Jaarboek Demografie 2013, (pp. 209 - 231). Leuven/Den Haag: Acco

Rotering, P., \& Bras, H. (2015). With the help of kin? Household composition and reproduction in the Netherlands, 1842 - 1920. Human Nature, 26(1)

Rotering, P. (2015). Book review: Philipov, Dimiter; Liefbroer, Aart C.; Klobas, Jane (Eds.): 'Reproductive Decision-Making in a Macro-Micro Perspective'. European Journal of Population, 31(5), 587-589

Kok, J., Bras, H., \& Rotering, P. (2016). Courtship and Bridal Pregnancy in The Netherlands, 1870-1950. Annales de démographie historique, 2(132), 165-191

Rotering, P. (2016). Intergenerationele overdracht van leeftijd bij eerste geboorte in Zweden. Sundsvall en Skellefteå, ca 1850-1889. In P. Puschmann, K. Matthijs, \& R. Paping (Eds.) Familie en levenskansen in het verleden, (pp. 111-130). Leuven: Acco

Rotering, P. (2017). Intergenerational Transmission of Reproductive Behavior in Sweden, 1850-1889. Historical Life Course Studies, 4, 181-202

Mönkediek, B., Rotering, P., \& Bras, H. (2017). Regional Differences in the Intergenerational Transmission of Family Size in Europe. Population, Space and Place, 23(2), e2003

Rotering, P., \& Bras, H. (2019). The age difference between spouses and reproduction in 19th century Sweden. Demographic Research, 41(37), 1059-1090

Rotering, P. (2019). Family Systems and Fertility, Western Europe 1870-1960. Historical Social Research, 44(3) 


\section{Summary}

Fertility rates showed a marked decline in Western Europe from the mid-nineteenth century until the beginning of the twentieth century. The causes of this decline have been studied extensively, but no complete explanation to the observed patterns during this 'First Demographic Transition' has yet been given. Recent studies have focussed on the fertility decision-making process at the level of the individual, and on the role of others in shaping perceived constraints and preferences regarding parenthood. Family members can increase or reduce offspring survival chances and fertility outcomes by providing resources and support, or through social influences as social learning, social pressure, subjective obligations and social contagion.

This study contributes to the academic debate on the First Demographic Transition in Western Europe, by focussing on the role of family members in particular. The first aim of this study is to examine in which ways and to what extent fertility outcomes are influenced by family members. The second aim is to understand how family influences on fertility outcomes are shaped by 'family systems', which can be defined as "a set of beliefs and norms, common practices, and associated sanctions through which kinship and the rights and obligations of particular kin relationships are defined" (Mason, 2001, p. 160).

This dissertation includes four thematic chapters, taking a multidisciplinary approach based on evolutionary biology, family systems and diffusion theory. The chapters in this thesis focus on household composition, intergenerational transmissions, spousal relations and the role of the regional family system. Based on these chapters, the conclusion of this thesis is that family members have had a significant influence on fertility outcomes in Western Europe during the first demographic transition. The influences of family members however varied depending on the type of kin and over time. The question whether and how family systems are associated with fertility outcomes remains unanswered. An alternative research design and the use of a more well-defined typology of family systems may prove to shed more light on these questions. 
Chapter 2 examines the effect of co-resident (non-)kin on the length of birth intervals of Dutch women born in the second half of the nineteenth century. Dutch women who lived with their widowed father, or the widowed father of their husband, experienced significantly longer birth intervals compared to couples who did not live together with relatives. In contrast, when the brother of either spouse was present in the household, the waiting time until next childbirth was shorter than when the brother was not present. In contrast to other studies, we find that parity progression rates were not significantly affected by the presence of widowed mothers or both parents of either spouse; the 'grandmother-hypothesis' is not confirmed in this study. This chapter is one of few examining the role of household composition on fertility outcomes, in particular using data from a population during a fertility decline.

Chapter 3 examines the occurrence of intergenerational transmission of fertility in Sweden at the end of the nineteenth century. This study finds evidence of weak, but positive correlations in reproductive outcomes between parents and children during a period of fertility transition, in line with other literature. The intergenerational correlation for children ever born decreased over time, likely as a result of declining family sizes in general. This chapter confirms the intergenerational correlation in fertility observed in other studies.

Chapter 4 also makes use of the Demographic DataBase and examines the associations between female autonomy (approximated by the spousal age gap) and reproductive outcomes. After controlling for the age at marriage, women in wife-older marriages displayed shorter birth intervals compared to women in agehomogamous marriages. For women in husband-older marriages, the transition to first birth also occurred more quickly compared to women in age-homogamous marriages, indicating a catch-up effect. The number of children ever born was lower for husband-older marriages.

Finally, chapter 5 aims to examine whether family systems, based on the typology of Emmanuel Todd, are associated with the spatial diffusion of fertility decline in Western Europe between 1870 and 1960. The findings in this study show no clear association between Todd's family systems and reproductive outcomes. Fertility rates were strongly correlated with neighbouring regions and time-lagged fertility rates of the same region.

The results of this dissertation provide several suggestions for future research. First, the concept of family systems in current literature is not well-defined. The typologies of Emmanuel Todd, David Reher or Görhan Therborn all cover large geographical areas. These typologies are not likely to be precise or selective enough to capture local variations in fertility outcomes. There is a need for a refinement of the concept of family systems at a lower level of aggregation, in 
order to study and understand their association with fertility.

Second, the question why family members are likely to provide support or resources warrants more attention. Pro-natal support may originate out of economic self-interest; parents may want to secure (financial or social) support from their children at a later stage in life. However, self-interest may also be guided by biology; individuals may be motivated to provide resources and support to genetically-close family members since this increases the chance that their genes (more precisely alleles) are passed on to future generations. The merits of evolutionary approaches in demography deserve more attention and require careful research designs.

Third and last, when interpreting the results of an empirical study it is important to recognize the limited choice of explanatory attributes and control variables. One must be constantly aware of the relative strength of the observed effects and the possible presence of unobserved variables.

The societal and policy implications are clear; reproduction is not only of great importance for (young) parents who see their lives changing with the birth of a child, it also relates to matters such as population ageing, child-care arrangements and women's labour force participation. The explanatory attributes in this study - the presence, roles, attitudes and fertility outcomes of family members - are by themselves not something policy makers are likely to intervene in. However, when faced with challenges regarding changes in the (future) demographic composition of a nation, policy makers should be aware that people's childbearing decisions depend on much more than financial incentives or issues related to work and childcare. 


\section{Samenvatting}

Het geboortecijfer in West Europa vertoont een opvallende daling tussen het midden van de negentiende eeuw en het begin van de twintigste eeuw. De oorzaken en het verloop van deze daling zijn intensief bestudeerd, maar een sluitende verklaring voor de timing en ruimtelijke distributie van deze 'Eerste Demografische Transitie' is door wetenschappers nog niet gevonden. Recente onderzoeken richten zich op de vraag hoe individuen worden beïnvloed in hun besluitvorming rond de kinderwens. Hierbij wordt vooral gekeken naar de invloeden van andere personen in de directe omgeving van het koppel op hun kinderwens, zoals vrienden, collega's en familieleden. Familieleden in het bijzonder konden in de negentiende eeuw de kinderwens beïnvloeden, bijvoorbeeld door het echtpaar te voorzien van materiële en immateriële steun.

Dit proefschrift draagt bij aan het academisch debat over de Eerste Demografische Transitie in West Europa, met in het bijzonder de rol van de familiale context. Het eerste doel van deze studie is te onderzoeken op welke wijze en in hoeverre vruchtbaarheid werd beïnvloed door familieleden. De term vruchtbaarheid wordt hierbij gebruikt als verzamelterm om de volgende variabelen te beschrijven: de timing van de eerste en laatste geboorten, het tijdsinterval tussen geboorten en het totaal aantal kinderen dat is geboren. Het tweede doel van deze dissertatie is om vervolgens te onderzoeken hoe de invloeden van de familiale context op vruchtbaarheid aan het einde van de negentiende eeuw samenhingen met zogenaamde 'familie systemen'. Familie systemen kunnen worden gedefinieerd als "een set overtuigingen, normen, gemeenschappelijke gebruiken en daarbij behorende sancties, door welke verwantschappen en de rechten en plichten van verschillende typen familieleden zijn gedefinieerd" (Mason, 2001, p. 160).

Dit boek bevat vier thematische hoofdstukken, gebaseerd op inzichten vanuit evolutionaire biologie, familie systemen en diffusie-theorie. De hoofdstukken in dit proefschrift richten zich achtereenvolgens op de samenhang tussen het geboorteinterval en de samenstelling van het huishouden, de mate van gelijkheid tussen man en vrouw, intergenerationele transmissie en tot slot regionale familie syste- 
men. Op basis van deze hoofdstukken kan worden geconcludeerd dat familieleden een significante invloed hebben gehad op het geboortecijfer in West Europa in de onderzochte periode. De precieze invloed van familieleden op vruchtbaarheid hing echter sterk samen met het type familielid en de onderzochte periode; bepaalde correlaties namen na verloop van tijd af. De tweede hoofdvraag - of familie systemen van invloed zijn op het geboortecijfer - kan echter niet goed worden beantwoord op basis van dit proefschrift. Een alternatieve onderzoeksopzet en de keuze voor een scherper gedefinieerde typologie van familie systemen zal wellicht een beter antwoord op deze vraag kunnen geven.

In hoofdstuk 2 is onderzocht of de lengte van het tijdsinterval tussen geboorten werd beïnvloed door bij het echtpaar inwonende familieleden en andere personen. Hiervoor zijn gegevens gebruikt van Nederlandse vrouwen die geboren zijn in de tweede helft van de negentiende eeuw. Voor echtparen waar een alleenstaande grootvader bij hen inwoonde werd een significant langer tijdsinterval tussen opeenvolgende geboorten geobserveerd, in vergelijking met echtparen zonder inwonende familieleden. Wanneer daarentegen een broer van de man of de vrouw inwonend was, dan was het tijdsinterval tussen geboorten relatief korter. De in de literatuur vaak besproken 'grootmoeder hypothese' is echter niet bevestigd in deze studie; er is geen samenhang geconstateerd tussen de aanwezigheid van (geweduwde) grootmoeders en een korter geboorte interval voor de onderzochte Nederlandse echtparen. Deze studie is één van de weinige waarin de invloed van de samenstelling van huishoudens op het geboorte interval is onderzocht gedurende een periode waarin het geboortecijfer daalde.

In hoofdstuk 3 is onderzocht in hoeverre opeenvolgende generaties gelijkenis vertoonden met betrekking tot de timing van geboorten en het totaal aantal geboren kinderen. Hiervoor is data gebruikt over Zweedse personen die zijn geboren in de tweede helft van de negentiende eeuw. In deze studie is een zwak, maar positief verband gevonden tussen het geboortepatroon van ouders en dat van hun kinderen. Deze uitkomsten komen overeen met andere studies. De correlatie tussen het aantal geboorten van de onderzochte koppels en het kindertal van hun ouders nam echter af aan het einde van de negentiende eeuw, wat kan worden verklaard door de algemene daling van het geboortecijfer in Zweden.

Hoofdstuk 4 maakt ook gebruik van de Zweedse Demografische Databse. In dit hoofstuk is onderzoek of de gelijkheid tussen man en vrouw (gemeten aan de hand van het onderlinge leeftijdsverschil) van invloed was op de timing van de geboorten van het echtpaar. Nadat is gecontroleerd voor de huwelijksleeftijd van de vrouw, blijkt dat echtparen een korter tijdsinterval tussen geboorten hadden wanneer de vrouw ouder was dan de man, in vergelijking met echtparen waarbij beide partners dezelfde leeftijd hadden. Wanneer de man ouder was dan de vrouw, 
werd ook het eerste kind eerder geboren in vergelijking met echtparen van dezelfde leeftijd. Het totaal aantal kinderen dat werd geboren lag echter lager bij echtparen waar de man ouder was dan de vrouw.

Tot slot is in hoofdstuk 5 onderzocht of familie systemen, geclassificeerd aan de hand van de typologie van Emmanuel Todd, gecorreleerd zijn met de ruimtelijke spreiding van de daling van het geboortecijfer in West Europa, tussen 1870 en 1960. De uitkomsten van dit onderzoek wijzen echter niet op een duidelijk verband tussen Todd's familie systemen en (veranderingen in) het geboortecijfer. Het geboortecijfer was daarentegen wel sterk gecorreleerd met het geboortecijfer in omliggende regio's en met het geboortecijfer van dezelfde regio in het verleden.

De uitkomsten van dit proefschrift bieden enkele suggesties voor vervolgonderzoek. Ten eerste zijn familie systemen als concept onvoldoende scherp gedefinieerd om bruikbaar te zijn in empirisch, kwantitatief onderzoek. In de typologieën van Emmanuel Todd, David Reher en Görhan Therborn worden grote geografische regio's beschreven. Hierdoor zijn zij onvoldoende geschikt om lokale variaties in vruchtbaarheid te beschrijven; een verdere verfijning van het concept 'familie systeem' op een lager geografisch aggregatieniveau is noodzakelijk.

Ten tweede is meer aandacht nodig voor de vraag waarom familieleden meer geneigd zijn om hulp te bieden aan elkaar dan aan onbekenden. Waarom zou de aanwezigheid van familieleden bepalend kunnen zijn voor het kindertal? Het is mogelijk dat pro-natale ondersteuning door familieleden voortkomt uit economisch eigenbelang; ouders willen mogelijk hun financiële en sociale toekomst veilig stellen en rekenen daarvoor op de steun van hun kinderen op een later moment in hun leven. Echter, het handelen uit eigenbelang kan ook voortkomen uit een biologische impuls. Recente studies wijzen op de hypothese dat individuen meer geneigd zijn om hulp te verlenen aan andere individuen wanneer de onderlinge genetische gelijkenis groter is. Zij zijn welwillend om deze hulp te verlenen omdat dit de kans vergroot dat hun eigen genen (allelen) worden overgedragen naar volgende generaties (de Engelstalige term hiervoor is inclusive fitness). De potentie van deze evolutionaire benadering in demografisch onderzoek verdient meer aandacht, evenals een zorgvuldig opgezette onderzoeksopzet.

De derde en laatste aanbeveling tot slot is de oproep om nauwkeurig de resultaten van empirisch onderzoek te interpreteren. De keuze van de afhankelijke, verklarende en controlevariabelen is vaak beperkt, zeker waar het historisch onderzoek betreft. De verklaringskracht van het model kan beperkt zijn wanneer onvoldoende wordt stil gestaan bij andere (contextuele) factoren die niet meegenomen zijn in de analyse.

De implicaties van dit proefschrift voor onze samenleving en beleidsmakers zijn duidelijk; iedere geboorte is niet alleen van grote invloed op het leven van de 
kersverse ouders, op grotere schaal heeft de ontwikkeling van het geboortecijfer ook invloed op de groei van de bevolking, vergrijzing, de wijze waarop de samenleving kinderopvang inricht, de arbeidsparticipatie van vrouwen, enzovoort. Het is niet waarschijnlijk dat beleidsmakers directe invloed zullen willen uitoefenen op de verklarende attributen in dit onderzoek - de aanwezigheid van familieleden en het aantal kinderen dat familieleden kregen. Echter, wanneer wordt stilgestaan bij de uitdagingen die de toekomstige demografische samenstelling van een bevolking met zich meebrengt, dan zullen beleidsmakers zeker rekening moeten houden met de rol van de sociale omgeving. Het besluit om de kinderwens te vervullen - of juist uit te stellen - hangt niet alleen af van financiële prikkels of de wijze waarop arbeid en kinderopvang in de bredere samenleving zijn ingericht, maar zeker ook met de familiale context. 
The research in this thesis was supported by a VIDI Innovational Research Grant from the Netherlands Organisation for Scientific Research (NWO) to Prof. Dr Hilde Bras for the research project 'The Power of the Family: Family Influences on Long-Term Fertility Decline in Europe, 1850-2010' (contract grant number 452-10-013).

Cover illustration:

DigitalHandArt Studio, based on a photograph by Aernout Jacobs 